Department of Energy, Idaho Operations Office psdrept@id.doe.gov

Re: Final Report, DE-FC07-06ID14738

Dear Sir,

Attached is our final report for the project, "Enhancements to High Temperature In-Pile Thermocouple Performance,” award number DE-FC07-06ID14738, awardee name, University of Idaho.

We feel that the project has been successful, and many useful results have been obtained. Thank you for funding this project.

Please contact me if you have any questions.

Best Regards,

John Crepeau, Ph.D., P.E.

Professor of Mechanical Engineering

University of Idaho

1776 Science Center Drive

Idaho Falls, ID 83402

Phone: (208)282-7955

Fax: (208)282-7950

Email: crepeau@uidaho.edu 


\section{Enhancements to High Temperature In- Pile Thermocouple Performance}

J.C. Crepeau, J. L. Rempe, J. E. Daw, D. L. Knudson, K. G. Condie, and S. C. Wilkins

March 2008

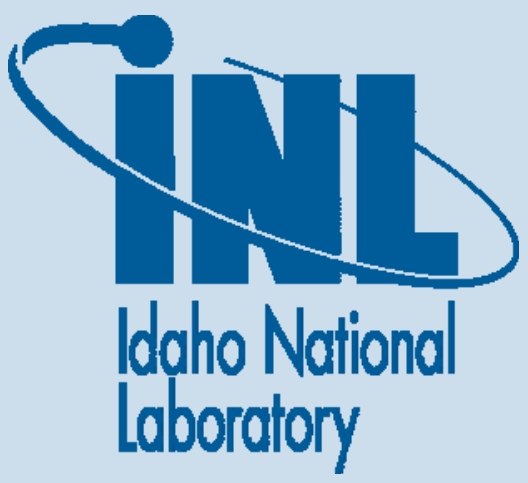

The INL is a U.S. Department of Energy National Laboratory operated by Battelle Energy Alliance 
The INL is a U.S. Department of Energy National Laboratory operated by Battelle Energy Alliance 
INL/EXT-08-14042

\title{
Enhancements to High Temperature In-Pile Thermocouple Performance
}

J.C. Crepeau, J. L. Rempe, J. E. Daw, D. L. Knudson, K. G. Condie, and S. C. Wilkins

\author{
March 2008 \\ Idaho National Laboratory \\ Idaho Falls, Idaho 83415
}

Prepared for the

U.S. Department of Energy

Office of Nuclear Energy, Science, and Technology

Under DOE Idaho Operations Office

Contract DE-AC07-05ID14517 
INL/EXT-08-14042 


\section{CONTENTS}

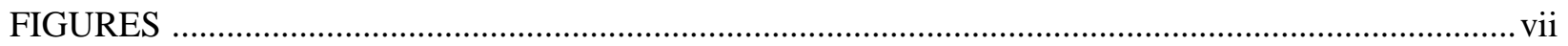

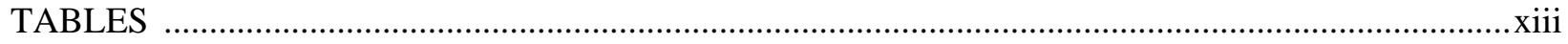

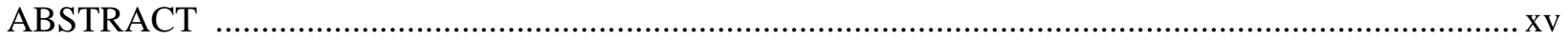

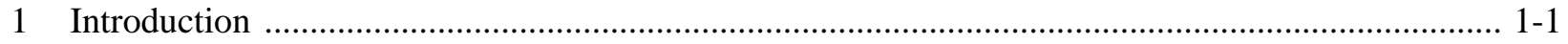

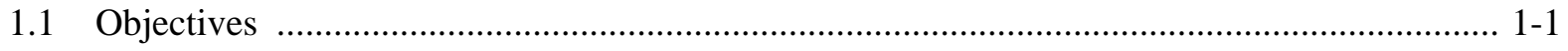

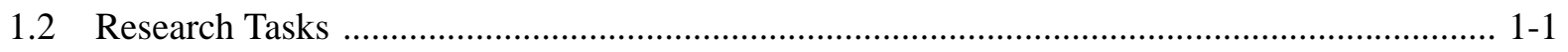

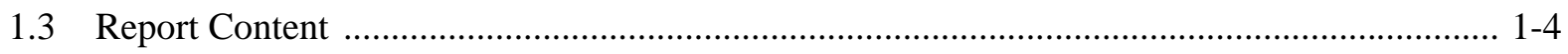

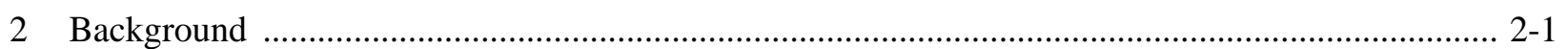

2.1 Recent INL HTIR-TC Development Efforts ..................................................................... 2-1

2.2 Prior $\mathrm{Mo} / \mathrm{Nb}$ Thermocouple Evaluations .............................................................................. 2-4

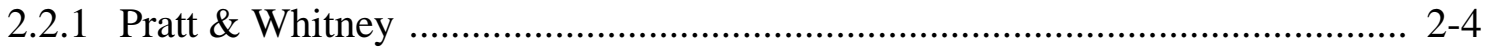

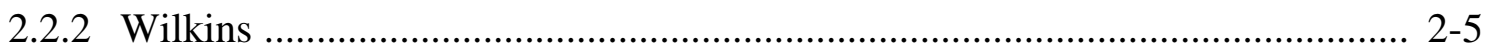

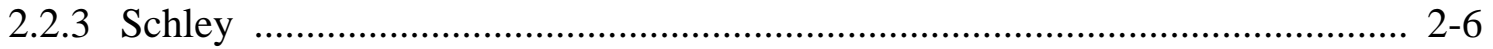

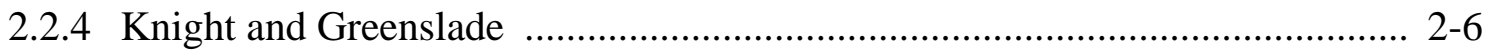

2.2 .5 Villard ......................................................................................... 2-7

2.3 Effect of Wire Diameter and Heat Treatment …..................................................................... 2-7

2.4 Enhanced Performance of Niobium and Molybdenum Alloys ............................................... 2-8

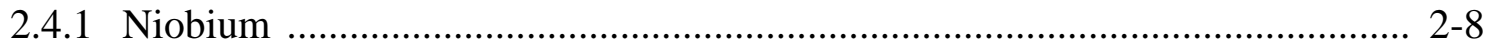

2.4.2 Molybdenum ........................................................................................... 2-10

2.4.3 Schley and Metauer ........................................................................... 2-11

3 Alternate Alloy Ductility Evaluations (Task 1.1) ...................................................................... 3-1

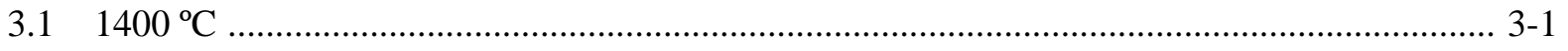

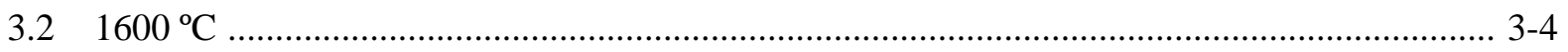

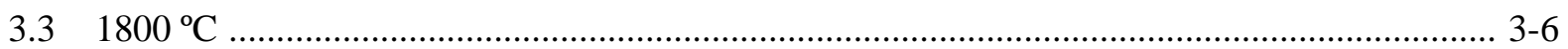

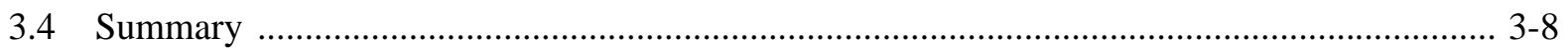

4 Calibration Curve Development (Task 1.2) .................................................................................. 4-1

4.1 As Received Bare Wire (ARBW) ........................................................................................ 4-1

4.2 As Received Swaged (ARS) ........................................................................................... 4-27

4.3 Swaged Then Heat Treated (SHT) …….............................................................................. 4-33

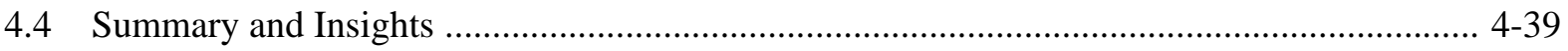


5 Long Duration and Transient Evaluations (Task 1.3) ................................................................. 5-1

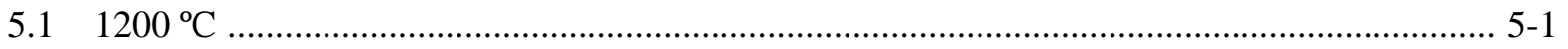

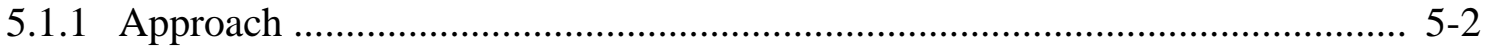

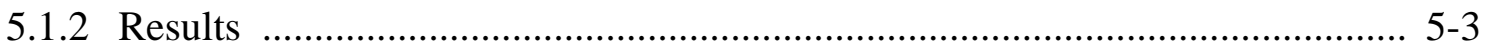

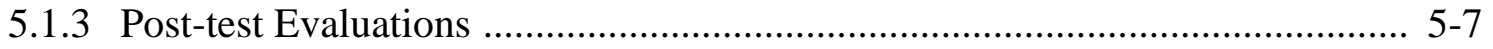

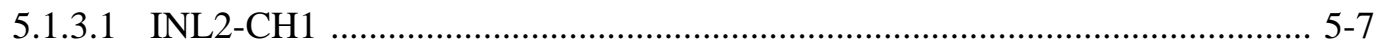

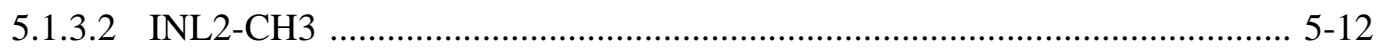

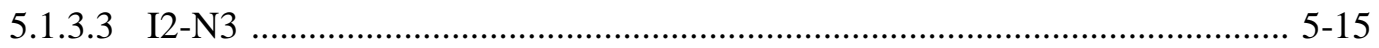

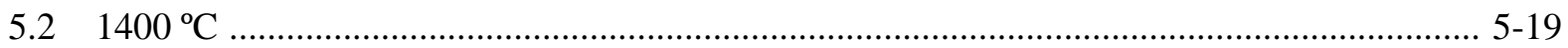

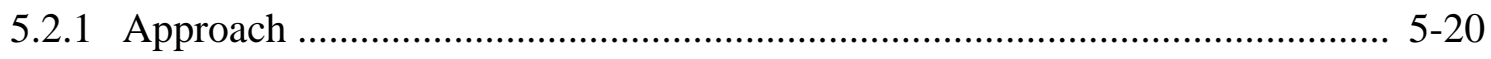

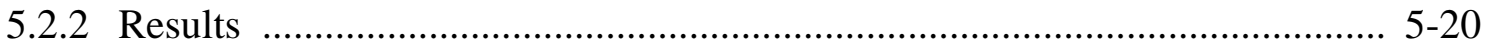

5.2.3 Post Test Evaluations ................................................................................ 5-21

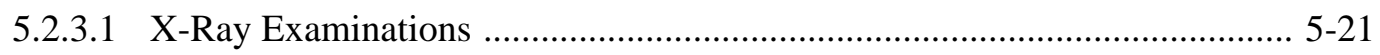

5.2.3.2 SEM Examinations ................................................................................. 5-22

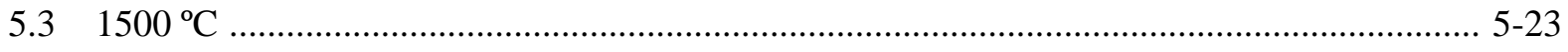

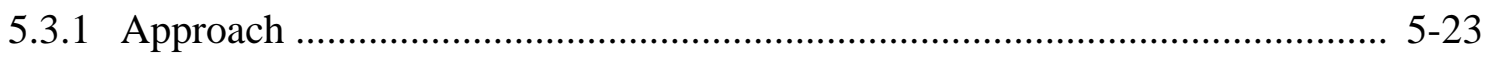

5.3.2 $1500{ }^{\circ} \mathrm{C}$ Test Results and Post-test Evaluations ......................................... 5-24

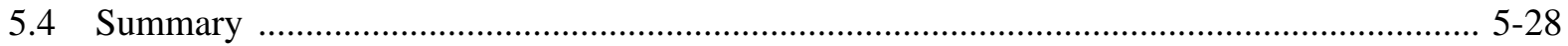

6 Alternate Geometry Evaluations (Task 2) .................................................................................... 6-1

6.1 Ductility Evaluations ...................................................................................................... 6-1

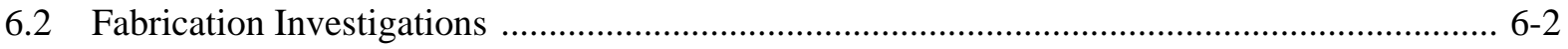

6.3 Heat Treatment Investigations …................................................................................. 6-3

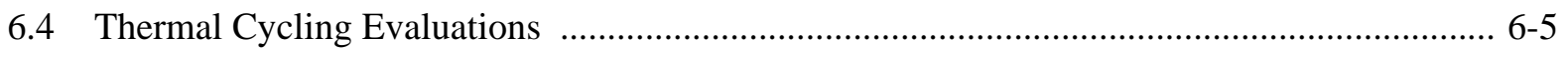

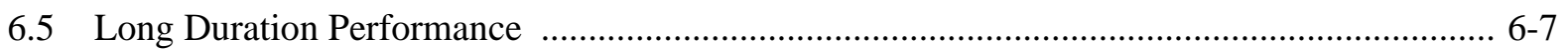

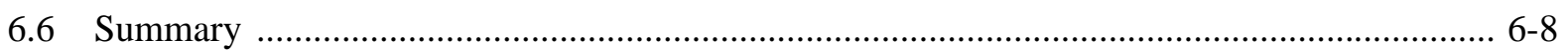

7 Alternate Fabrication Techniques - Heat Treatment (Task 3.2) .................................................. 7-1

7.1 Heat Treatments for $1200{ }^{\circ} \mathrm{C}$ Operation ............................................................................. 7-1

7.2 Heat Treatments for $1500{ }^{\circ} \mathrm{C}$ Operation …........................................................................... 7-3

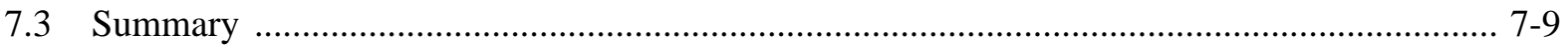

8 Alternate Fabrication Techniques - Loose Assembly Construction (Task 3.2) ............................... 8-1

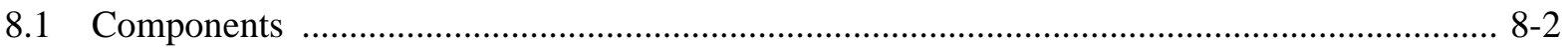

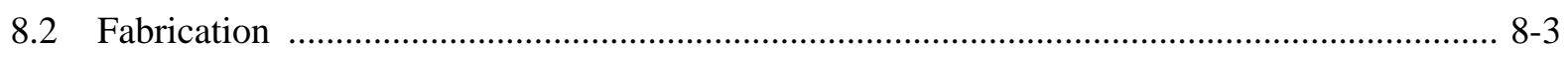

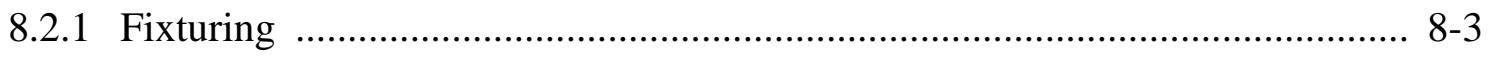

8.2.2 Lessons Learned ........................................................................................... 8-4 
8.3 Long Term High Temperature Evaluations

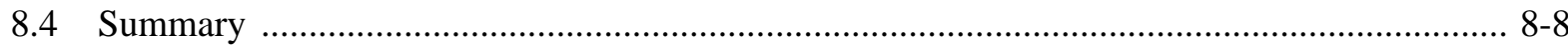

9 Summary and Recommendations ............................................................................................. 9-1

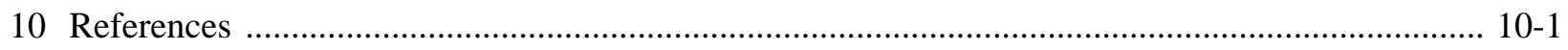




\section{FIGURES}

Figure 1-1. Comparison of "swaged” versus "loose assembly" thermocouple configurations.

Figure 2-1. Materials interaction test results (wire-insulator-sheath) using representative thermocouple samples.

Figure 2-2. Selected Mo wire mandrel wrap test results

Figure 2-3. Comparison of calibration curves for tested thermoelement combinations.

Figure 2-4. Molybdenum/niobium thermocouple output obtained by Wilkins during the first two temperature cycles $(0.25 \mathrm{~mm}$ wires).....

Figure 2-5. Exploded view of THERMEX experiment device: stainless steel capsule (1), graphite barrel (3) filled with pure Copper (2), additional electric heating elements (4),thermocouples (5). ........... 2-8

Figure 2-6. Recrystallization diagram for niobium (holding time, 1 hour) ............................................ 2-9

Figure 2-7. Effects of alloying elements on the recrystallization temperature of niobium and its alloys.

Figure 2-8. Comparison of temperature-emf curves for pure Mo versus pure $\mathrm{Nb}$, pure Mo versus $\mathrm{Nb}-1 \% \mathrm{Zr}, \mathrm{Mo}-\mathrm{Nb}$ alloy, and $\mathrm{W}-\mathrm{Re}$ alloy thermocouples,

Figure 3-1. Candidate molybdenum-based wire after heating for 2 hours at $1400{ }^{\circ} \mathrm{C} \ldots \ldots \ldots \ldots \ldots \ldots \ldots \ldots . . . . . . . . . . . .3-1$

Figure 3-2. Candidate molybdenum-based wire after heating for 5 hours at $1400{ }^{\circ} \mathrm{C}$............................ 3-2

Figure 3-3. Candidate molybdenum-based wire after heating for 12 hours at $1400{ }^{\circ} \mathrm{C} \ldots \ldots \ldots \ldots \ldots \ldots \ldots \ldots . . . . . . . . . . . .2$

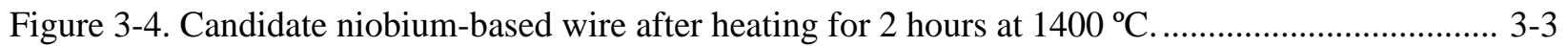

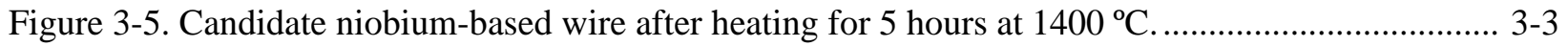

Figure 3-6. Candidate niobium-based wire after heating for 12 hours at $1400{ }^{\circ} \mathrm{C}$................................. 3-3

Figure 3-7. Candidate molybdenum-based wire after heating for 2 hours at $1600{ }^{\circ} \mathrm{C}$............................ 3-4

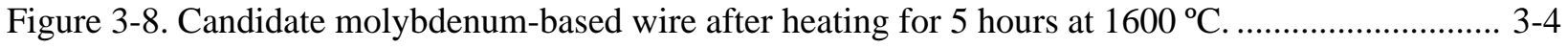

Figure 3-9. Candidate molybdenum-based wire after heating for12 hours at $1600{ }^{\circ} \mathrm{C}$........................... 3-5

Figure 3-10. Candidate niobium-based wire after heating for 2 hours at $1600{ }^{\circ} \mathrm{C}$................................ 3-5

Figure 3-11. Candidate niobium-based wire after heating for 5 hours at $1600{ }^{\circ} \mathrm{C}$................................. 3-6

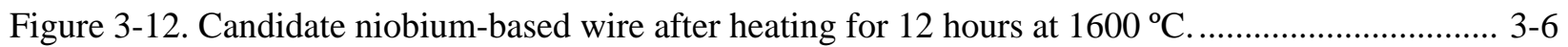

Figure 3-13. Candidate molybdenum-based wire after heating for 2 hours at $1800{ }^{\circ} \mathrm{C} \ldots \ldots \ldots \ldots \ldots \ldots \ldots \ldots \ldots . . . . . . . . . . . .3-7$

Figure 3-14. Candidate molybdenum-based wire after heating for 5 hours at $1800^{\circ} \mathrm{C} \ldots \ldots \ldots \ldots \ldots \ldots \ldots \ldots . . . . . . . . . . . .3-7$

Figure 3-16. Tantalum carrier after heating at $1800{ }^{\circ} \mathrm{C}$ for 5 hours. .................................................... 3-8

Figure 3-15. Candidate molybdenum-based wire after heating for 12 hours* at $1800^{\circ} \mathrm{C}$...................... 3-8

Figure 4-1. Initial emf versus temperature for ARBW ODS-Mo/Nb-1\%Zr thermocouple ..................... 4-2

Figure 4-2. Comparison of measured emf during first heating and cooling cycle for ARBW

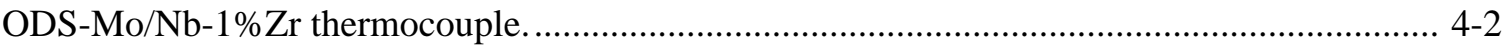

Figure 4-3. Measured emf for two heating and cooling cycles for ARBW ODS-Mo/Nb-1\%Zr

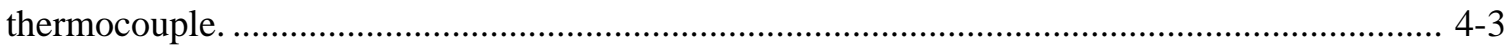

Figure 4-4. Initial emf versus temperature for ARBW KW-Mo/Nb-1\%Zr thermocouple....................... 4-4 
Figure 4-5. Comparison of measured emf during first heating and cooling cycle for ARBW KW-Mo/Nb1\%Zr thermocouple

Figure 4-6. Measured emf for two heating and cooling cycles for ARBW KW-Mo/Nb-1\%Zr thermocouple.

Figure 4-7. Initial emf versus temperature for ARBW Mo-3\%Nb/Nb-1\%Zr thermocouple 4-6

Figure 4-8. Comparison of measured emf during first heating and cooling cycle for ARBW Mo-3\%Nb/Nb-1\%Zr thermocouple..

Figure 4-9. Measured emf for two heating and cooling cycles for ARBW Mo-3\%Nb/Nb-1\%Zr thermocouple.

Figure 4-10. Initial emf versus temperature for ARBW Mo-1.6\% Nb/Nb-1\%Zr thermocouple

Figure 4-11. Comparison of measured emf during first heating and cooling cycle for ARBW Mo-1.6\% Nb/Nb-1\%Zr thermocouple.

Figure 4-12. Measured emf for two heating and cooling cycles for ARBW Mo-1.6\%Nb/Nb-1\%Zr thermocouple.

Figure 4-13. Initial emf versus temperature for ARBW KW-Mo/Nb-4\%Mo thermocouple

Figure 4-14. Comparison of measured emf during first heating and cooling cycle for ARBW $\mathrm{KW}-\mathrm{Mo} / \mathrm{Nb} 4 \% \mathrm{Mo}$ thermocouple

Figure 4-15. Measured emf for two heating and cooling cycles for ARBW KW-Mo/Nb-4\%Mo thermocouple.

Figure 4-16. Initial emf versus temperature for ARBW Mo-3\%Nb/Nb-4\%Mo thermocouple 4-12

Figure 4-17. Comparison of measured emf during first heating and cooling cycle for ARBW Mo-3\%Nb/Nb-4\%Mo thermocouple

Figure 4-18. Measured emf for two heating and cooling cycles for ARBW Mo-3\%Nb/Nb-4\%Mo thermocouple.

Figure 4-19. Initial emf versus temperature for ARBW Mo-1.6\%Nb/Nb-4\%Mo thermocouple $4-14$

Figure 4-20. Comparison of measured emf during first heating and cooling cycle for ARBW Mo-1.6\% Nb/Nb-4\%Mo thermocouple.

Figure 4-21. Measured emf for two heating and cooling cycles for ARBW Mo1.6\%Nb/Nb4\%Mo thermocouple.

Figure 4-22. Initial emf versus temperature for ARBW KW-Mo/Nb6\%Mo thermocouple

Figure 4-23. Comparison of measured emf during first heating and cooling cycle for ARBW $\mathrm{KW}-\mathrm{Mo} / \mathrm{Nb}-6 \% \mathrm{Mo}$ thermocouple

Figure 4-24. Measured emf for two heating and cooling cycles for ARBW KW-Mo/Nb-6\%Mo thermocouple.

Figure 4-25. Initial emf versus temperature for ARBW Mo-3\%Nb/Nb-6\%Mo thermocouple ....

Figure 4-26. Comparison of measured emf during first heating and cooling cycle for ARBW Mo-3\%Nb/Nb-6\%Mo thermocouple

Figure 4-27. Measured emf for two heating and cooling cycles for ARBW Mo-3\%Nb/Nb-6\%Mo thermocouple.

Figure 4-28. Initial emf versus temperature for ARBW Mo-1.6\%Nb/Nb-6\%Mo thermocouple 
Figure 4-29. Comparison of measured emf during first heating and cooling cycle for ARBW Mo-1.6\%Nb/Nb-6\%Mo thermocouple.

Figure 4-30. Measured emf for two heating and cooling cycles for ARBW Mo-1.6\%Nb/Nb-6\%Mo thermocouple.

Figure 4-31. Initial emf versus temperature for ARBW KW-Mo/Nb-8\%Mo thermocouple $4-22$

Figure 4-32. Comparison of measured emf during first heating and cooling cycle for ARBW $\mathrm{KW}-\mathrm{Mo} / \mathrm{Nb}-8 \% \mathrm{Mo}$ thermocouple

Figure 4-33. Measured emf for two heating and cooling cycles for ARBW KW-Mo/Nb-8\%Mo thermocouple.

Figure 4-34. Initial emf versus temperature for ARBW Mo-3\%Nb/Nb-8\%Mo thermocouple $4-24$

Figure 4-35. Comparison of measured emf during first heating and cooling cycle for ARBW Mo-3\%Nb/Nb-8\%Mo thermocouple

Figure 4-36. Measured emf for two heating and cooling cycles for ARBW Mo-3\%Nb/Nb-8\%Mo thermocouple.

Figure 4-37. Initial emf versus temperature for ARBW Mo-1.6\%Nb/Nb-8\%Mo thermocouple $4-26$

Figure 4-38. Comparison of measured emf during first heating and cooling cycle for ARBW Mo-1.6\%Nb/Nb-8\%Mo thermocouple

Figure 4-39. Measured emf for two heating and cooling cycles for ARBW Mo-1.6\%Nb/Nb-8\%Mo thermocouple.

Figure 4-40. Initial emf versus temperature for ARS KW-Mo/Nb-1\% Zr thermocouple $4-28$

Figure 4-41. Comparison of measured emf during first heating and cooling cycle for ARS $\mathrm{KW}-\mathrm{Mo} / \mathrm{Nb}-1 \% \mathrm{Zr}$ thermocouple.

Figure 4-42. Measured emf for two heating and cooling cycles for ARS KW-Mo/Nb-1\%Zr thermocouple.

Figure 4-43. Initial emf versus temperature for ARS Mo-3\%Nb/Nb-1\%Zr thermocouple 4-30

Figure 4-44. First heating and cooling cycle for ARS Mo-3\%Nb/Nb-1\%Zr thermocouple. 4-30

Figure 4-45. Two heating and cooling cycles for ARS Mo-3\%Nb/Nb-1\%Zr thermocouple 4-31

Figure 4-46. initial emf versus temperature for ARS Mo-1.6\%Nb/Nb-1\%Zr thermocouple. 4-32

Figure 4-47. First heating and cooling cycle for ARS Mo-1.6\%Nb/Nb-1\%Zr thermocouple. 4-32

Figure 4-48. Two heating and cooling cycles for ARS Mo-1.6\%Nb/Nb-1\%Zr thermocouple. 4-33

Figure 4-49. Initial emf versus temperature for SHT KW-Mo/Nb-1\%Zr thermocouple 4-34

Figure 4-50. First heating and cooling cycle for SHT KW-Mo/Nb-1\%Zr thermocouple. 4-34

Figure 4-51. Two heating and cooling cycles for SHT KW-Mo/Nb-1\%Zr thermocouple. 4-35

Figure 4-52. Initial emf versus temperature for SHT Mo3\%Nb/Nb1\%Zr thermocouple 4-36

Figure 4-53. First heating and cooling cycle for SHT Mo-3\%Nb/Nb-1\%Zr thermocouple. 4-36

Figure 4-54. Two heating and cooling cycles for SHT Mo-3\%Nb/Nb-1\%Zr thermocouple. 4-37

Figure 4-55. Initial emf versus temperature for SHT Mo-1.6\%Nb/Nb-1\%Zr thermocouple. 4-38

Figure 4-56. First heating and cooling cycle for SHT Mo-1.6\%Nb/Nb-1\%Zr thermocouple. 4-38

Figure 4-57. Two heating and cooling cycles for SHT Mo-1.6\%Nb/Nb-1\%Zr thermocouple. 4-39 
Figure 4-58. Comparison of first heating cycle for ARS, SHT, and ARBW KW-Mo Nb1\%Zr thermocouples

Figure 4-59. Comparison of ARS, SHT, and ARBW KW-Mo Nb1\%Zr thermocouples at high temperatures for two heating and cooling cycles. 4-40

Figure 4-60. Comparison of first heating cycle for ARS, SHT, and ARBW Mo3\%Nb/ Nb1\%Zr thermocouples

Figure 4-61. Comparison of ARS, SHT, and ARBW Mo3\%Nb Nb1\%Zr thermocouples at high temperatures for two heating and cooling cycles

Figure 4-62. Comparison of first heating cycle for ARS, SHT, and ARBW Mo1.6\%Nb Nb1\%Zr thermocouples

Figure 4-63. Comparison of ARS, SHT, and ARBW Mo1.6\%Nb Nb1\%Zr thermocouples at high temperatures for two heating and cooling cycles.

Figure 4-64. Comparison of ARBW thermocouples constructed with Nb1\%Zr negative thermoelements.

Figure 4-65. Comparison of ARBW thermocouples constructed with KW-Mo positive thermoelements.

Figure 4-66. Comparison of ARBW thermocouples constructed with Mo3\%Nb positive thermoelements.

Figure 4-67. Comparison of ARBW thermocouples constructed with Mo1.6\%Nb positive thermoelements

Figure 4-68. High temperature comparison of all ARBW thermocouples tested.

Figure 4-69. Comparison of sensitivity between SHT thermocouples

Figure 5-1. Typical setup for long duration tests.................................................................................. 5-1

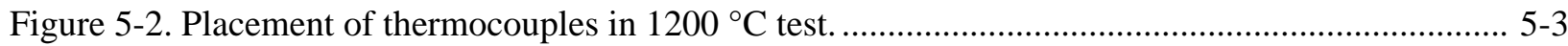

Figure 5-3. Measured emf of Type N and “coaxial” NN versus Inconel 600 thermocouples included in $1200{ }^{\circ} \mathrm{C}$ test.

Figure 5-4. Measured emf of Type K thermocouples included in $1200^{\circ} \mathrm{C}$ test.................................... 5-5

Figure 5-5. Measured emf of INL-developed Mo/Nb alloy thermocouples included in $1200{ }^{\circ} \mathrm{C}$ test...... 5-5

Figure 5-6. Comparison of representative thermocouples included in $1200{ }^{\circ} \mathrm{C}$ test................................ 5-6

Figure 5-7. Corresponding temperatures of representative thermocouples included in $1200{ }^{\circ} \mathrm{C}$ test ....... 5-6

Figure 5-8. BSE (left) and SE (right) images of INL2 CH1 thermocouple............................................ 5-8

Figure 5-9. Higher magnification images of the sheath cross section for sample INL2 CH1................. 5-8

Figure 5-10. X-ray maps of the individual elements in the sheath.......................................................... 5-9

Figure 5-11. X-ray maps of the individual elements in the insulator and wires.................................... 5-10

Figure 5-12. BSE image and elemental profiles across Nb-1\%Zr wire in sample INL2 CH1 ............... 5-11

Figure 5-13. BSE Image and elemental profiles across Mo wire........................................................ 5-11

Figure 5-14. BSE (left) and SE (right) images of INL2 CH3 thermocouple...................................... 5-12

Figure 5-15. X-ray maps of the individual elements in the sheath..................................................... 5-12

Figure 5-16. SE image and carbon X-ray map of reaction layer on outer perimeter of sheath.............. 5-13 
Figure 5-17. Elemental x-ray maps of three major phases present in sheath, matrix, oxygen enriched phase and carbon enriched phase. Note: Zr-rich precipitates also observed. 5-13

Figure 5-18. Elemental profiles across Nb1\%Zr wire in sample INL2 CH3. ..................................... 5-14

Figure 5-19. Point composition profiles across Nb1\%Zr wire in sample INL2 CH3. .......................... 5-15

Figure 5-20. Point composition profiles across Mo wire in sample INL2 CH3................................... 5-15

Figure 5-21. BSE (left) and SE (right) images of I2 N3 thermocouple............................................... 5-16

Figure 5-22. X-ray maps of the individual elements in the sheath....................................................... 5-17

Figure 5-23. Elemental profiles across sheath in sample I2 N3....................................................... 5-18

Figure 5-24. Elemental profiles across second wire in sample I2 N3............................................. 5-19

Figure 5-25. Elemental profiles across first wire in sample I2 N3 .................................................. 5-19

Figure 5-26. Measured emf of INL-developed Mo/Nb alloy thermocouples included in $1400{ }^{\circ} \mathrm{C}$ test.. 5-21

Figure 5-27. X-ray of KW Mo-1 after 4000 hour test at $1400{ }^{\circ} \mathrm{C}$ (near junction). ................................ 5-22

Figure 5-28. SE (left) and BSE (right) images of KWMo-2 thermocouple after heating at $1400{ }^{\circ} \mathrm{C}$ for over 4000 hours... $5-23$

Figure 5-29. Measured emf of INL-developed Mo/Nb alloy thermocouples included in $1500{ }^{\circ} \mathrm{C}$ test .. 5-25 Figure 5-30. Measured emf of INL-developed thermocouples for first 1000 hours in $1500{ }^{\circ} \mathrm{C}$ test ...... 5-26 Figure 5-31. Diameter impact on measured emf of INL-developed Mo/Nb alloy thermocouples. ........ 5-26

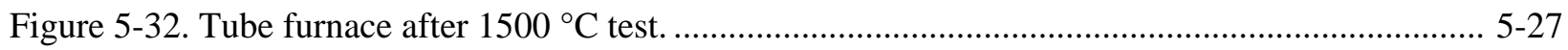

Figure 5-33. INL thermocouples (I15-11 and I15-12) after 3000 hours at $1500{ }^{\circ} \mathrm{C}$........................... 5-27

Figure 6-1. Effect of wire diameter on samples heated at $1400{ }^{\circ} \mathrm{C}$ for 5 hours .................................... 6-1

Figure 6-2. Effect of wire diameter on samples heated at $1400^{\circ} \mathrm{Cfor} 12$ hours ..................................... 6-2

Figure 6-3. Effect of wire diameter on samples heated at $1600{ }^{\circ} \mathrm{C}$ for 5 hours .................................... 6-2

Figure 6-4. Response of representative thermocouples during $1700{ }^{\circ} \mathrm{C}$ heat treatment......................... 6-4

Figure 6-5. Measured emf for larger diameter thermocouple during thermal cycling tests..................... 6-5

Figure 6-6. Measured emf for standard diameter thermocouple during thermal cycling tests................. 6-6

Figure 6-7. Measured emf for various HTIR-TC geometries in $1500^{\circ} \mathrm{C}$ test. ....................................... 6-7

Figure 7-1. Calibration data obtained from thermocouples heat treated for 20 hours at $1300{ }^{\circ} \mathrm{C}$

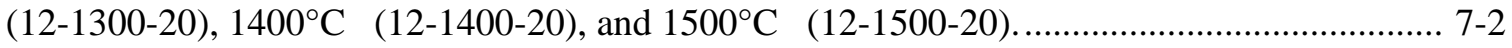

Figure 7-2. Comparison of calibration data obtained from thermocouples heat treated at $1300{ }^{\circ} \mathrm{C}$ for 5

(12-1300-5), 10 (12-1300-10), and 20 (12-1300-20) hours......................................................... 7-2

Figure 7-3. Measured drift of thermocouples heat treated at $1300{ }^{\circ} \mathrm{C}$ at 0 (12-1300-0), 5 (12-1300-5),

10 (12-1300-10), and 20 (12-1300-20) hours in $1200{ }^{\circ} \mathrm{C}$ constant temperature test. .................. 7-3

Figure 7-4. Calibration data obtained from thermocouples heat treated at $1600{ }^{\circ} \mathrm{C}$ for 4 (15-1600-4),

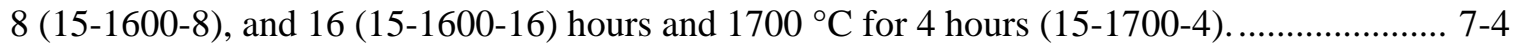

Figure 7-5. Drift exhibited in swaged thermocouples heat treated for service at $1500^{\circ} \mathrm{C}$..................... 7-5

Figure 7-6. X-ray image of thermocouple $15-1600-4$ after 100 hour $1500{ }^{\circ} \mathrm{C}$ drift test ......................... 7-5

Figure 7-7. Cross-section of thermocouple 15-1600-4 (50X)............................................................ 7-6

Figure 7-8. Cross-section of thermocouple 15-1600-4 (100X)........................................................ 7-6 
Figure 7-9. Cross-section of thermocouple 15-1600-4 sheath (200X).................................................. 7-7

Figure 7-10. Thermocouple 15-1600-4 KW-Mo thermoelement (500X). .............................................. 7-7

Figure 7-11. Thermocouple 15-1600-4 Nb1\%Zr thermoelement (500X) .............................................. 7-7

Figure 7-12. Cross-section of thermocouple 15-1600-16 (100X) …...................................................... 7-8

Figure 7-13. Thermocouple 15-1600-16 Nb1\%Zr thermoelement (500X)........................................... 7-8

Figure 7-14. Thermocouple 15-1600-16 molybdenum thermoelement (500X) ..................................... 7-9

Figure 7-15. Calibration evaluations on HTIR-TCs heat treated at different temperatures and

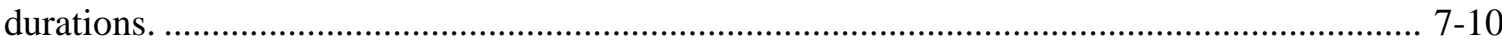

Figure 7-16. Measured drift of thermocouples heat treated at $1300{ }^{\circ} \mathrm{C}$ at 0 (12-1300-0), 5 (12-1300-5), 10

(12-1300-10), and 20 (12-1300-20) hours in $1200^{\circ} \mathrm{C}$ constant temperature test. ..................... 7-11

Figure 8-1. Comparison of "swaged” versus "loose assembly" thermocouple configurations................. 8-1

Figure 8-2. Specialized components for HTIR-TC loose assembly design........................................... 8-3

Figure 8-3. Vacuum chamber for loose assembly fabrication............................................................... 8-4

Figure 8-4. Thermoelement wire degradation following initial testing of loose assembly

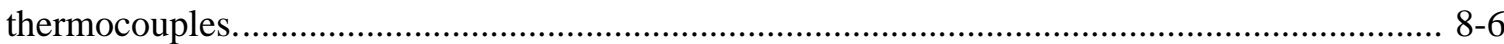

Figure 8-5. Initial results from long duration $1500{ }^{\circ} \mathrm{C}$ test with loose assembly and swaged HTIR-TCs. 8-9

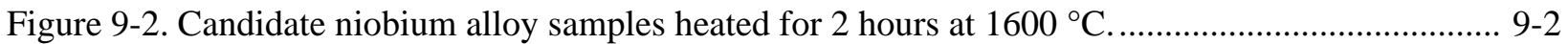

Figure 9-1. Candidate molybdenum doped and alloy samples heated for 12 hours at $1800{ }^{\circ} \mathrm{C}$............... 9-2

Figure 9-3. High temperature comparison of thermocouples containing candidate

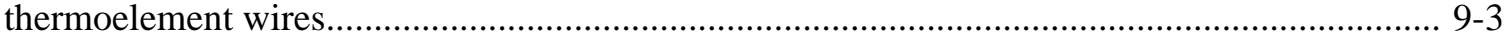

Figure 9-4. Effect of wire diameter on samples heated at $1400^{\circ} \mathrm{C}$ for 5 hours .................................... 9-4

Figure 9-5. Measured emf for various HTIR-TC geometries in $1500{ }^{\circ} \mathrm{C}$ test. ....................................... 9-5

Figure 9-6. Calibration evaluations on HTIR-TCs heat treated at different temperatures and durations. 9-6

Figure 9-7. Measured drift of thermocouples heat treated at $1300{ }^{\circ} \mathrm{C}$ at 0 (12-1300-0), 5 (12-1300-5), 10 (12-1300-10), and 20 (12-1300-20) hours in $1200^{\circ} \mathrm{C}$ constant temperature test. .................. 9-7

Figure 9-8. Drift exhibited in swaged thermocouples heat treated for service at $1500{ }^{\circ} \mathrm{C}$...................... 9-8

Figure 9-9. Cross-section of thermocouple 15-1600-16 (100X) .......................................................... 9-8

Figure 9-10. Specialized components for HTIR-TC loose assembly design.......................................... 9-9

Figure 9-11. Initial results from $1500^{\circ} \mathrm{C}$ long duration test containing loose assembly HTIR-TCs....... 9-9 


\section{TABLES}

Table 1-1. Alloys Investigated in this UNERI.......................................................................... $1-2$

Table 2-1. Candidate thermocouple component materials considered in INL evaluations...............2-1

Table 2-2. Typical chemical analysis of doped and doped molybdenum wire (ppm by weight)... 2-11

Table 5-1. Characteristics of thermocouples tested at $1200{ }^{\circ} \mathrm{C}$ for 4000 hours. ..............................5-2

Table 5-2. $\quad 1200^{\circ} \mathrm{C}$ thermocouples evaluated with SEM...............................................................5-7

Table 5-3. Characteristics of thermocouples tested at $1400{ }^{\circ} \mathrm{C}$ for 4000 hours. ............................5-20

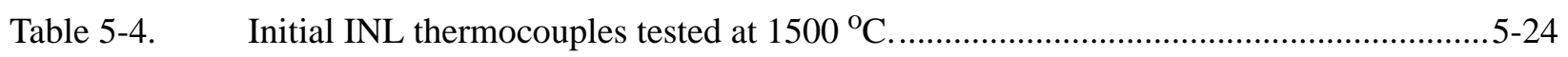

Table 6-1. $\quad$ Alternate Wire diameters Tested ................................................................................6-3

Table 6-2. Steps completed to optimize alternate geometry thermocouples ..................................6-3

Table 6-3. Measured drift during transient testing.........................................................................6-7

Table 7-1. Heat treatment temperatures and durations explored for $1200{ }^{\circ} \mathrm{C}$ operation ...................7-1

Table 7-2. Heat treatment temperatures and durations explored for $1500{ }^{\circ} \mathrm{C}$ operation ...................7-3

Table 8-1. Loose assembly thermocouple sizes and materials investigated....................................8-2

Table 8-2. Loose assembly thermocouple welds. .................................................................... $8-5$

Table 8-3. Sensitivities to investigate wire degradation. ............................................................... 8-7

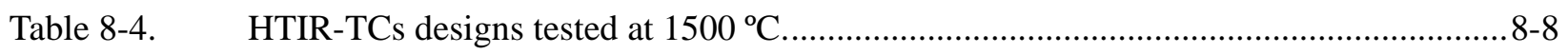

Table 9-1. Alloys investigated in this UNERI ...................................................................... $9-1$

Table 9-2. Heat treatment options explored for $1200{ }^{\circ} \mathrm{C}$ and $1500{ }^{\circ} \mathrm{C}$ operation...........................9-6

Table 9-3. Peer-reviewed publications summarizing research results ..........................................9-10 
INL/EXT-08-14042 


\begin{abstract}
A joint University of Idaho (UI) and Idaho National Laboratory (INL) University Nuclear Research Initiative (UNERI) was to initiated to extend initial INL efforts to develop doped molybdenum/niobium alloy High Temperature Irradiation Resistant Thermocouples (HTIR-TCs). The overall objective of this UNERI was to develop recommendations for an optimized thermocouple design for high temperature, long duration, in-pile testing by expanding upon results from initial INL efforts. Tasks to quantify the impact of candidate enhancements, such as alternate alloys, alternate geometries, and alternate thermocouple fabrication techniques, on thermocouple performance were completed at INL's High Temperature Test Laboratory (HTTL), a state of the art facility equipped with specialized equipment and trained staff in the area of high temperature instrumentation development and evaluation.

Key results of these evaluations, which are documented in this report, are as follows. The doped molybdenum and Nb-1\%Zr, which were proposed in the initial INL HTIR-TC design, were found to retain ductility better than the developmental molybdenum-low niobium alloys and the niobium-low molybdenum alloys evaluated. Hence, the performance and lower cost of the commercially available KW-Mo makes a thermocouple containing KW-Mo and Nb-1\%Zr the best option at this time. HTIR-TCs containing larger diameter wires offer the potential to increase HTIR-TC stability and reliability at higher temperatures. HTIR-TC heat treatment temperatures and times should be limited to not more than $100{ }^{\circ} \mathrm{C}$ above the proposed operating temperatures and to durations of at least 4 to 5 hours. Preliminary investigations suggest that the performance of swaged and loose assembly HTIR-TC designs is similar. However, the swaged designs are less expensive and easier to construct.

In addition to optimizing HTIR-TC performance, This UNERI project provided unique opportunities to several University of Idaho students, allowing them to become familiar with the techniques and equipment used for specialized high temperature instrumentation fabrication and evaluation and to author/coauthor several key conference papers and journal articles.
\end{abstract}


INL/EXT-08-14042 


\section{Introduction}

To resolve principal technical and scientific obstacles to the long-term future use of nuclear energy, new reactor designs must offer enhanced safety and overcome issues involving resistance to proliferation, economics, and nuclear waste disposition. To meet these goals, new materials are being considered for fuel, cladding, and structures in advanced and existing nuclear reactors. However, there are insufficient data to characterize the performance of these new materials in high temperature, radiation conditions. To evaluate candidate material performance, robust instrumentation is needed that can survive these conditions, but traditional methods for measuring temperature in-pile degrade at temperatures above $1100^{\circ} \mathrm{C}$. To address this need, the Idaho National Laboratory (INL) launched an effort to develop temperature measurement methods suitable for long duration, high temperature in-pile testing. Initial results indicated that specialized molybdenum/niobium-1\% zirconium alloy High Temperature Irradiation Resistant Thermocouples (HTIR-TCs) developed by INL have the potential to provide the desired accuracy for longer duration tests. Although the performance of these thermocouples appears promising, the literature suggests several options that have the potential to enhance their lifetime and reliability. Hence, a joint University of Idaho (UI) and INL University Nuclear Research Initiative (UNERI) was initiated to extend INL efforts by evaluating key enhancements associated with HTIR-TC fabrication techniques, geometry, and alloys in INL's High Temperature Test Laboratory (HTTL).

\subsection{Objectives}

The overall objective of this research was to develop recommendations for an optimized thermocouple design for high temperature, long duration, in-pile testing by expanding upon

results from initial INL efforts to develop doped molybdenum/niobium alloy HTIR-TCs. ${ }^{1-4}$ Specifically, tasks were performed to quantify the impact of candidate enhancements on thermocouple performance. Based on results from these evaluations, recommendations for an optimized design have been developed.

\subsection{Research Tasks}

This UI/INL project evaluated the impact of three options having the potential to enhance the performance of INL-developed HTIR-TCs: alternate alloys, alternate wire diameters, and alternate fabrication techniques.

\section{- Alternate Alloy Evaluations (Task 1)}

In Task 1, developmental alloys of Molybdenum and Niobium were evaluated with respect to ductility, resolution, and performance when subjected to high temperatures and transients. As noted in Section 2, prior investigations indicated that alloying Mo with small amounts of Nb or $\mathrm{Nb}$ with small amounts of Mo may enhance the thermoelectric output of Mo/Nb thermocouples 
and increase the ductility of these thermoelement by delaying the temperature at which recrystalization occurs. However, prior attempts to produce small diameter wire of Mo-low Nb/Nb-low Mo alloys were unsuccessful.

For this project, the alloys listed in Table1-1 were available for evaluations. In addition to the KW-Mo and Nb-1\%Zr initially selected by INL for HTIR-TCs, several Mo-low Nb/Nb-low Mo alloys were available for testing from two commercial vendors that specialize in fabricating Mo and $\mathrm{Nb}$ wire. Wah Chang successfully produced $0.254 \mathrm{~mm} / 0.010$ " diameter wire composed of niobium alloyed with small amounts of molybdenum (4 to 8\%). Likewise, OSRAM/Sylvania was able to produce $0.254 \mathrm{~mm} / 0.010$ inch diameter wire from two Mo-low Nb alloys (with additions of 1.6 and $3 \mathrm{wt} \%$ niobium). In addition, molybdenum doped with lanthanum oxide (ODS-Mo) was evaluated in this project.

Table 1-1. Alloys Investigated in this UNERI

\begin{tabular}{|l|l|}
\hline \multicolumn{1}{|c|}{ Designator } & \multicolumn{1}{c|}{ Description } \\
\hline+ WIre & Molybdenum doped with Potassium, Silicon, and Tungsten \\
\hline KW-Mo & Molybdenum doped with Lanthanum Oxide \\
\hline ODS-Mo & Molybdenum 1.6\% Niobium alloy \\
\hline Mo 1.6Nb & Molybdenum 3\% Niobium alloy \\
\hline Mo 3 Nb & \\
\hline - Wire & Niobium 1\% Zirconium alloy \\
\hline Nb1\%Zr & Niobium 4\% Zirconium alloy \\
\hline Nb 4\% Mo & Niobium 6\% Zirconium alloy \\
\hline Nb 6\% Mo & Niobium 8\% Zirconium alloy \\
\hline Nb 8\% Mo &
\end{tabular}

This UI/INL project conducted evaluations to assess the ductility, thermoelectric response, and reliability of thermocouples fabricated from these alloys. Specific tasks completed include:

Task 1.1 Mandrel wrap tests on wires after heating at high temperatures (from $1400{ }^{\circ} \mathrm{C}$ to $1800^{\circ} \mathrm{C}$ ) for two, five, and twelve hour intervals.

Task 1.2 Prototype thermocouple fabrication for calibration curve development. This calibration curve development effort included assessing the effects of selected heat treatments on thermoelectric response and drift.

Task 1.3 Longer duration higher temperature tests to assess the impact of alternate alloys on thermocouple reliability. 
Based on the results of these evaluations, recommendations were formulated with respect to materials and heat treatments for optimizing thermocouple performance.

\section{- Alternate Geometry Evaluations (Task 2)}

Initial INL efforts focused on swaged thermocouples fabricated from $0.254 \mathrm{~mm} / 0.010$ ” diameter thermoelement wires. Previous evaluations demonstrate that the reliability of commercial thermocouples increases with wire diameter, especially at higher temperatures. However, the performance observed in commercial thermocouples may differ from the performance of HTIR-TCs. In this project, evaluations were completed to quantify the effect of diameter on HTIR-TC performance. Three types of evaluations were completed in this task.

Task 2.1 Prototype thermocouples were fabricated for thermocouples with thermoelement wires ranging from 0.005" to 0.020" in diameter. Commercially available materials (doped KWMo and Nb-1\%Zr) were used for this task because it is difficult to obtain alternate sizes of the Task 1 non-commercial alloys. For each size of thermocouple, thermocouple sheath tubing and insulator materials were obtained and an appropriate process was developed for swaging reductions.

Task 2.2 Prototype thermocouple fabrication for calibration curve development. This calibration curve development effort included assessing the effects of selected heat treatments on thermoelectric response and drift.

Task 2.3 Longer duration, higher temperature tests with and without thermal cycling were completed for each prototype size to assess the impact of size on thermocouple reliability.

\section{- Alternate Fabrication Techniques (Task 3)}

Task 3 considered two variations in HTIR-TC fabrication that could enhance the performance of these thermocouples.

Task 3.1 Prototype thermocouples were fabricated using loose assembly techniques. Note that the task required developing appropriate parameters for this process, such as acceptable wire, insulator, and sheath size combinations.

Task 3.2 Prototype HTIR-TCs (swaged design) were fabricated to assess the impact of alternate heat treatments on thermocouple performance.

For the geometries and temperatures of initial interest, a "swaged" HTIR-TC design was selected. However, higher temperature applications or smaller geometries may require alternate fabrication techniques, such as a "loose assembly" geometry. In a loose assembly configuration (see Figure 1-1), insulator beads are loaded onto the thermoelement wires and placed within the sheath. However, the sheath tubes are not swaged. Instead, the assembly is typically placed within an enclosure in which a vacuum is achieved. The thermocouple assembly is then backfilled at room temperature with high purity inert gas and seal-welded. 


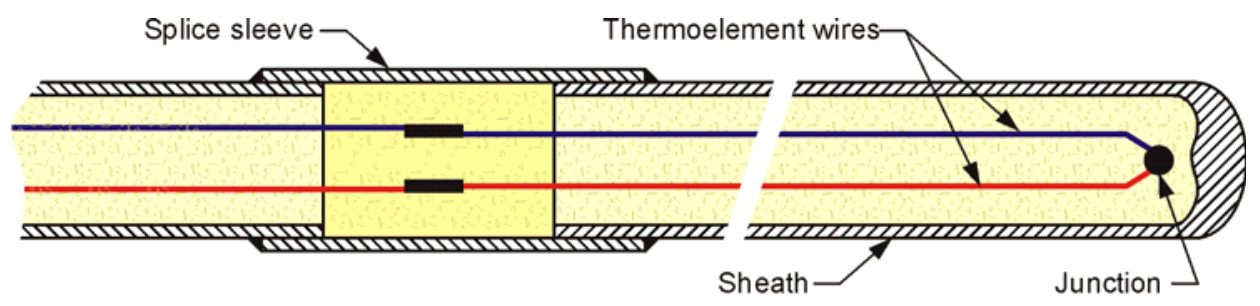

A. Swaged

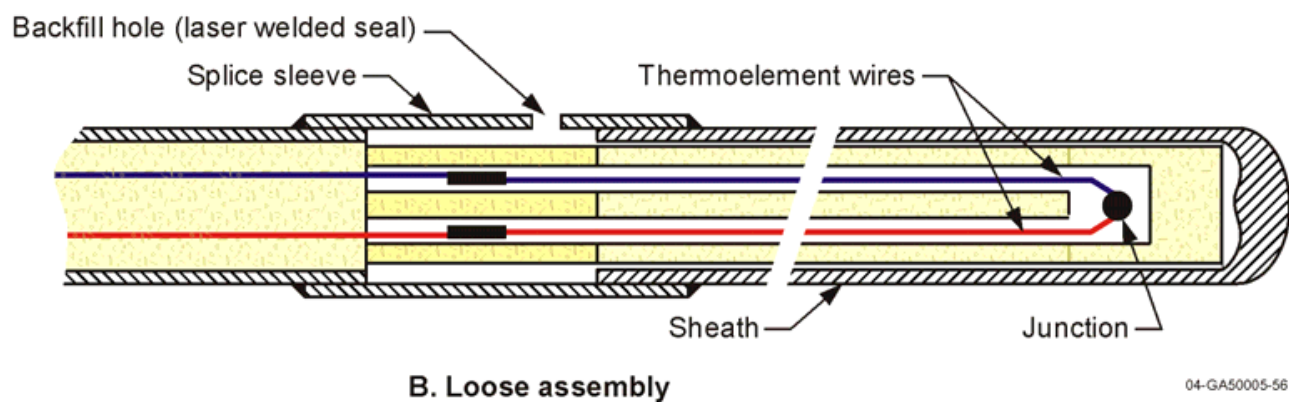

Figure 1-1. Comparison of "swaged” versus “loose assembly” thermocouple configurations.

Another aspect associated with HTIR-TC fabrication pertains to the heat treatment required for grain growth stabilization. Although initial INL studies selected heat treatment temperatures and times sufficient for grain growth stabilization for the applications of interest, no detailed evaluation of the times and temperatures required for various applications has been completed. This research project also investigated the impact of heat treatment temperature and duration.

\subsection{Report Content}

This report documents results from tasks completed as part of this UNERI. Section 2 provides additional background information related to these investigations. Section 3 presents results from ductility evaluations of alternate alloys tested as part of Task 1 for this research project. Tests completed to evaluate the resolution of various alloy combinations are presented in Section 4. Results from tests completed to evaluate the long duration performance of Mo-Nb alloy thermocouples are presented in Section 5. Section 6 presents results from tasks completed to evaluate alternate geometries of these thermocouples. Section 7 presents results from tasks completed to determine appropriate heat treatment times and temperatures required for various applications, and Section 8 presents results from tasks completed to construct a loose-assembly $\mathrm{Mo} / \mathrm{Nb}$ alloy thermocouple. Section 9 summarizes insights gained from tasks completed in this project and recommendations for an enhanced HTIR-TC design. References cited in this document are listed in Section 10. 


\section{Background}

This project builds upon recent INL efforts to develop an in-pile thermocouple for high temperature (up to $1800{ }^{\circ} \mathrm{C}$ ), long duration (up to 2 years) tests in INL's Advanced Test Reactor (ATR). INL efforts to develop a high temperature sensor for in-pile testing started with an internally-funded project, a Laboratory Directed Research Directive (LDRD), that subsequently led to several direct funded tasks to provide instrumentation for tests planned at INL Advanced Test Reactor (ATR). Several references are available that document initial INL efforts. ${ }^{1-4}$

When INL initiated this effort, a review of instrumentation that might be employed for inpile, high temperature applications was conducted. ${ }^{5-30}$ For temperatures above $1100{ }^{\circ} \mathrm{C}$, INL's review indicate that previously investigated in-pile instrumentation methods are limited to thermocouples (with thermoelements consisting of molybdenum, niobium, or zirconium, or their alloys), Johnson Noise Power Thermometers (JNPT), and ultrasonic thermometers (UTs). UT and JNPT techniques weren't considered because of the cost and complexity associated with their probe and signal processing equipment. Despite advances in signal processing equipment, recent efforts ${ }^{19-21}$ indicate that several obstacles must still be overcome. Optical pyrometer techniques were eliminated because viewing ports aren't available. Likewise, considerably more development is needed before optical fiber methods overcome difficulties associated with signal degradation in radiation fields. ${ }^{25-27}$ Hence, specialized thermocouples were deemed to be the simplest and most economic approach for in-pile high temperature measurements. Because techniques for fabricating and evaluating such thermocouples ${ }^{9-13}$ were last explored over 10 years ago, recent INL efforts have focused on developing improved versions of these thermocouples.

\subsection{Recent INL HTIR-TC Development Efforts}

Table 2-1 lists thermocouple component materials initially evaluated by INL. As documented in Reference 1, these materials were selected from a much larger list of candidate materials because of their suitability for high temperature irradiation conditions, material compatibility, and cost. Prototype thermocouples from candidate materials were fabricated and evaluated at INL's High Temperature Test Laboratory (HTTL), which has key equipment and trained staff required for these activities. Selected INL results are highlighted below.

Table 2-1. Candidate thermocouple component materials considered in INL evaluations.

\begin{tabular}{|c|c|}
\hline Component & Candidate Materials \\
\hline Thermoelement & Molybdenum, ${ }^{\mathrm{a}}$ Zircaloy-4, Titanium-45\% Niobium, Niobium-1\%Zirconium \\
\hline Insulator & Aluminum Oxide, Hafnium Oxide \\
\hline Sheaths & Tantalum, Titanium, Zircaloy-4, Niobium-1\%Zirconium \\
\hline
\end{tabular}

a. Evaluations considered several types of Molybdenum: undoped Mo, Mo-1.6\% Nb, KW-Mo (doped with Tungsten, Silicon and Potassium), and ODS-Mo (containing Lanthanum Oxide). 
Materials interaction tests were completed by heating representative thermocouple samples in gettered argon at $1300^{\circ} \mathrm{C}$ and $1600{ }^{\circ} \mathrm{C}$. As shown in Figure $2-1(\mathrm{a}), 1300{ }^{\circ} \mathrm{C}$ tests showed that significant materials interactions occurred with samples containing $\mathrm{Zr}-4$ thermoelement wires, $\mathrm{Al}_{2} \mathrm{O}_{3}$ insulators, and $\mathrm{Zr}-4$ sheaths. However, $1600{ }^{\circ} \mathrm{C}$ results for $\mathrm{Nb}-1 \% \mathrm{Zr}$ and Mo thermoelement wires and $\mathrm{Nb}-1 \% \mathrm{Zr}$ sheaths indicate that no discernible materials interactions occurred between these materials and $\mathrm{HfO}_{2}$ insulators (see Figure 2-1(b)).

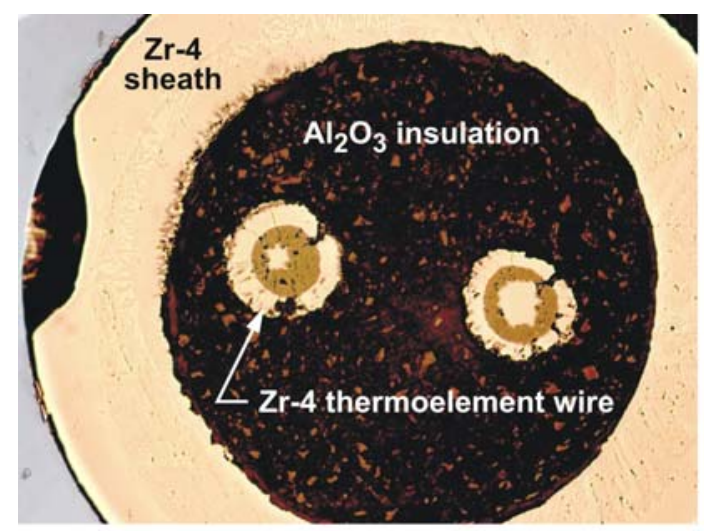

(a) $\mathrm{Zr}-4-\mathrm{Al}_{2} \mathrm{O}_{3}-\mathrm{Zr}-4$ after heating at $1300{ }^{\circ} \mathrm{C}$

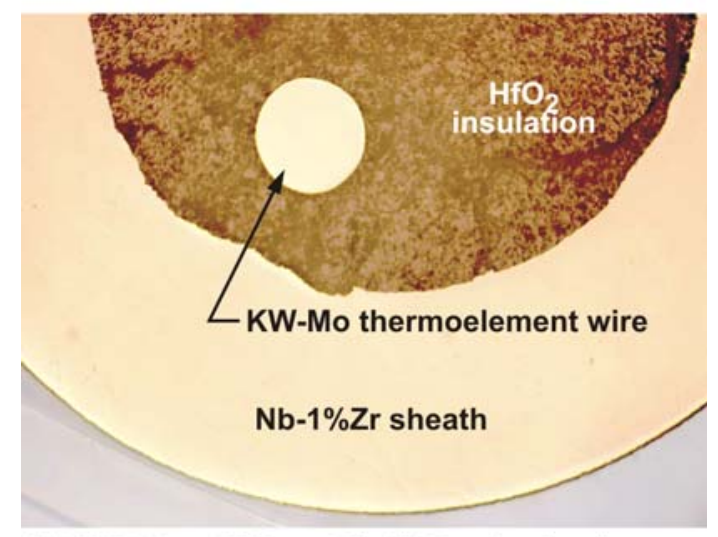

(b) $\mathrm{KW}-\mathrm{Mo}-\mathrm{HfO}_{2}-\mathrm{Nb}-1 \% \mathrm{Zr}$ after heating at

Figure 2-1. Materials interaction test results (wire-insulator-sheath) using representative thermocouple samples.

Mandrel-wrap tests on wires exposed to temperatures up to $1600{ }^{\circ} \mathrm{C}$ provided insights about thermoelement embrittlement. Samples were wrapped on mandrels of two, five, ten, and twenty times the wire diameter. Those metals that wrap without damage on a small-diameter mandrel after high-temperature exposure are better candidates from the standpoint of embrittlement. Most candidate thermocouple wires exhibited suitable ductility. The one exception, undoped Mo wire, which recrystallizes at $1200^{\circ} \mathrm{C}$, was brittle after heating at $1300{ }^{\circ} \mathrm{C}$ (see Figure 2-2a). Other tested wires, such as KW-Mo (see Figure 2-2b) remained ductile, even after heating at $1600^{\circ} \mathrm{C}$. 


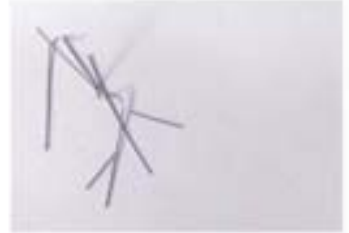

Mandrel diameter: $0.51 \mathrm{~mm}$

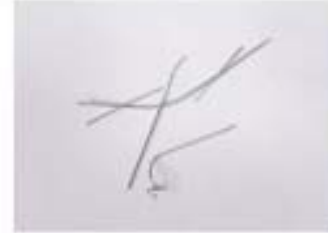

$1.27 \mathrm{~mm}$

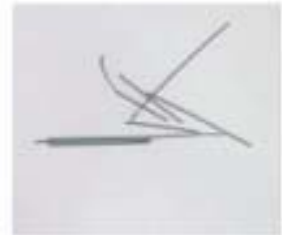

$2.54 \mathrm{~mm}$

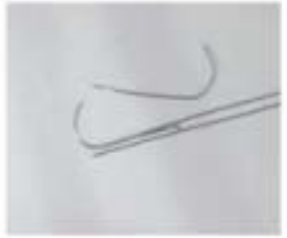

$5.08 \mathrm{~mm}$

(a) Undoped Mo $(0.254 \mathrm{~mm}$ diameter $)$ after heating at $1300^{\circ} \mathrm{C}$.

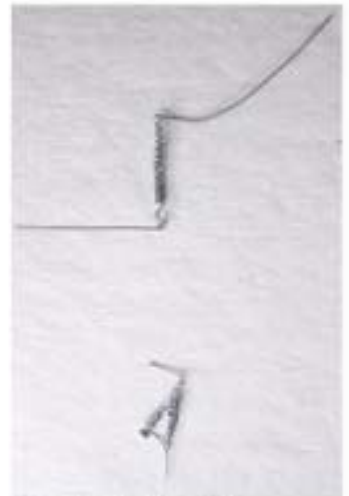

Mandrel diameter: $0.51 \mathrm{~mm}$

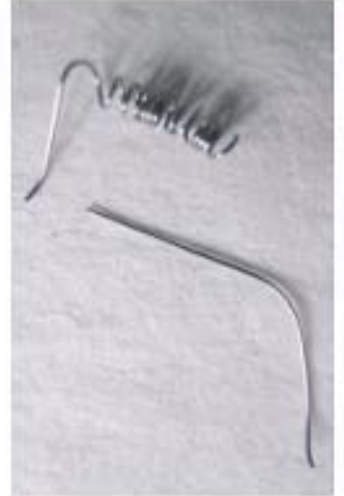

$1.27 \mathrm{~mm}$

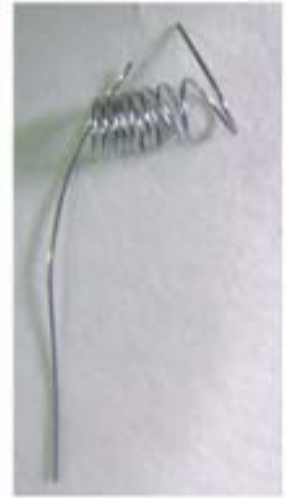

$2.54 \mathrm{~mm}$

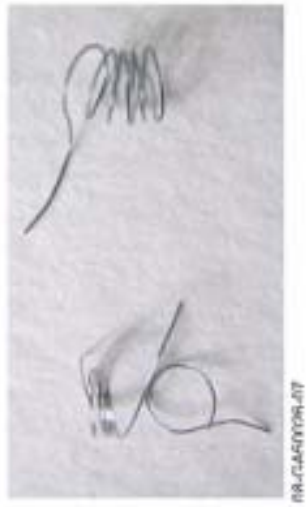

$5.08 \mathrm{~mm}$

(b) $\mathrm{KW}$-Mo wire ( $0.254 \mathrm{~mm}$ diameter) after heating in argon at $1600^{\circ} \mathrm{C}$.

Figure 2-2. Selected Mo wire mandrel wrap test results

Calibration tests were completed for candidate thermocouple combinations. Results (see Figure 2-3) indicate that the thermoelectric response is single-valued and repeatable for candidate thermoelements. In addition, results indicate that the high temperature resolution is acceptable for all thermocouples considered (although some combinations are limited due to materials interactions at temperatures below $1600{ }^{\circ} \mathrm{C}$ ). The selection of the thermoelement wire combination will depend on the desired peak temperature and accuracy requirements. If thermocouples are needed that measure temperatures at $1600{ }^{\circ} \mathrm{C}$ or higher, the doped Mo / Nb-1\% $\mathrm{Zr}$ or Mo-1.6\% Nb / Nb-1\% Zr combination is recommended.

In summary, recent INL research efforts have resulted in a thermocouple design that is capable of operation in high temperature, long duration irradiation tests. This recommended design is the result of materials testing, ductility evaluations, and thermoelectric response evaluations. In addition, INL efforts have considered extension cable requirements needed for installation in the ATR. Although initial results for this thermocouple design appear promising, additional evaluations are needed to demonstrate the reliability of this design when subjected to thermal transients, higher temperature long duration testing, and irradiations. Tasks completed as part of this UNERI and other INL programs are designed to complete these needed evaluations. 


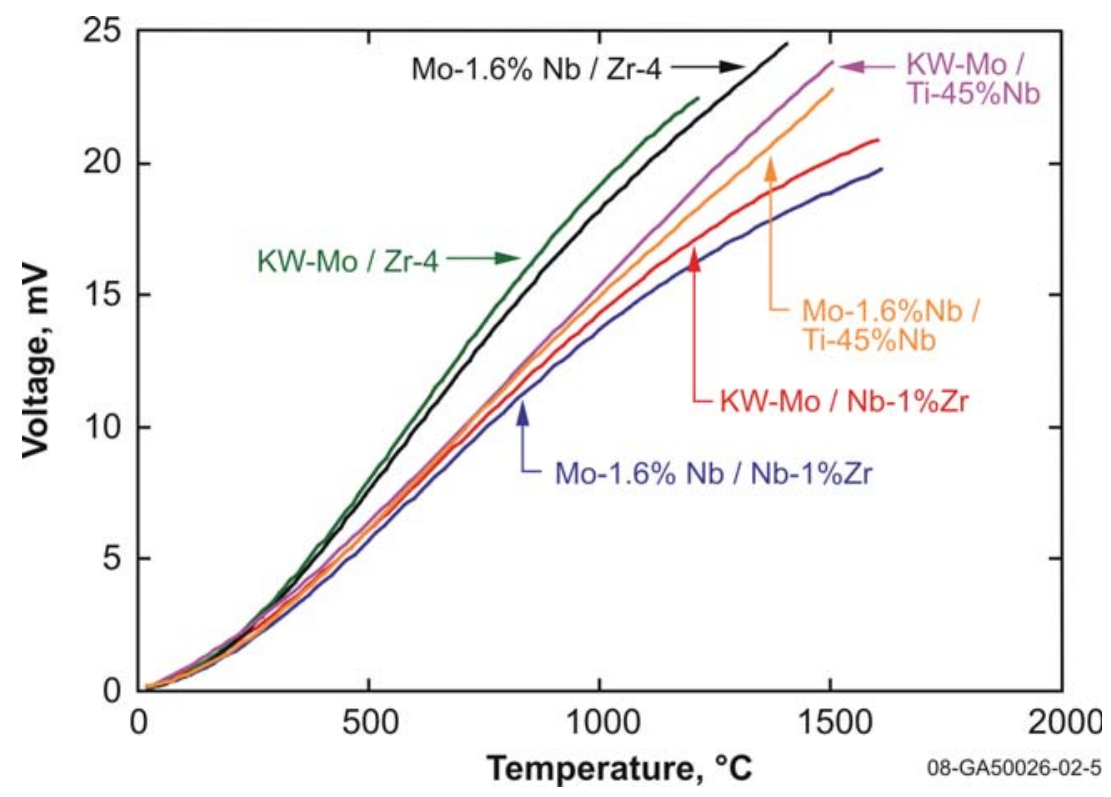

Figure 2-3. Comparison of calibration curves for tested thermoelement combinations.

\subsection{Prior Mo/Nb Thermocouple Evaluations}

As discussed in Section 2.1, several properties were considered in selecting candidate materials for the wires, insulator, and sheath of the specialized thermocouples being pursued by INL for in-pile applications. Materials selected for evaluation had high melting temperatures, low thermal cross sections, high resistance to oxidation, and similar coefficients of expansion. A review of other efforts to develop molybdenum - niobium thermocouples and other thermocouple development efforts yields several concerns related to recrystallization behavior, decalibration, and drift that can affect the performance of these thermocouples. This review also identifies several insights that may ultimately lead to a design that can overcome these difficulties with improved endurance and resolution at high temperatures. These insights are described in this section with the approach being adopted in this program to address potential difficulties.

\subsubsection{Pratt \& Whitney}

References 5 through 8 document various activities performed at Pratt \& Whitney Aircraft to investigate various candidate thermoelement and insulation combinations.

Reference 5 describes tests completed to evaluate the ductility, calibration, and long duration (up to 1000 hours) of candidate high temperature thermocouples, including pure molybdenum versus niobium-1\% zirconium combinations. Ductility evaluations indicate that the pure molybdenum wire remained ductile after heating in argon at $1430{ }^{\circ} \mathrm{C}$ for 1 hour. As discussed in Section 2.1, this differs from tests performed by INL in gettered argon on pure molybdenum wire. INL tests found pure molybdenum wires became brittle after heating for only 
30 minutes at $1300{ }^{\circ} \mathrm{C}$. Long duration (up to 725 hours) tests were run at $1065^{\circ} \mathrm{C}$. The drift observed in the Mo-Nb1\%Zr thermocouples exceeded $6 \%$ (or $67^{\circ} \mathrm{C}$ ). It was speculated that the observed drift was due to grain growth during annealing or due to oxidation or volatilization of the zirconium in the $\mathrm{Nb}-1 \% \mathrm{Zr}$ thermoelements. Subsequent long duration (1030 hours) high temperature $\left(1180{ }^{\circ} \mathrm{C}\right)$ tests were conducted on wires that had been "heat treated" at $50{ }^{\circ} \mathrm{C}$ to $135^{\circ} \mathrm{C}$ higher than the test temperature for 1 and 2 hours. The thermocouples in these tests were also observed to drift by up to $50^{\circ} \mathrm{C}$. No systematic differences in the drift were observed for the various heat treatment temperatures and durations investigated, and it was concluded that the observed drift was due to vaporization or oxidation of the zircaloy.

In Reference 7, the compatibility of various insulations $\left(\mathrm{ThO}_{2} \mathrm{Y}_{2} \mathrm{O}_{3}, \mathrm{BeO}, \mathrm{Al}_{2} \mathrm{O}_{3}\right.$, and $\mathrm{MgO}$ ) with niobium, tantalum, Nb-1\%Zr, W-5\%Re and W-26\%Re was investigated in tests at temperatures up to $1540{ }^{\circ} \mathrm{C}$ for durations as long as 1000 hours. Results indicate that commercial grades of $\mathrm{Y}_{2} \mathrm{O}_{3}, \mathrm{BeO}, \mathrm{Al}_{2} \mathrm{O}_{3}$, and $\mathrm{MgO}$ and spectrographically pure $\mathrm{Al}_{2} \mathrm{O}_{3}$ were incompatible with $\mathrm{Nb}-1 \% \mathrm{Zr}$ at $1540^{\circ} \mathrm{C}$. This incompatibility was attributed to the levels of silicon impurity in the ceramic insulation and to the zirconium in the alloy which acted as a sink for oxygen to form $\mathrm{ZrO}_{2}$ and the intermetallic compounds of $\mathrm{Nb}_{5} \mathrm{Si}_{3}, \mathrm{Nb}_{3} \mathrm{Al}$, and $\mathrm{Nb}_{2} \mathrm{Al}$.

\subsubsection{Wilkins}

References 9 and 11 document efforts by Wilkins to develop a pure molybdenum versus niobium thermocouple. Wilkins completed a series of tests to develop thermocouple calibration curves, evaluate thermocouple drift, and evaluate thermoelement wire compatibilities with candidate insulator materials $\left(\mathrm{BeO}, \mathrm{Al}_{2} \mathrm{O}_{3}\right.$, and $\left.\mathrm{HfO}_{2}\right)$. Recommendations for thermal cycling, heat treating or preconditioning, and insulator materials $\left(\mathrm{HfO}_{2}\right)$ were provided based on test results.

As indicated in Figure 2-4, the output of this thermocouple stabilized after the second thermal cycle. In addition, Wilkins' results indicate that embrittlement due to grain growth at high temperatures of the niobium thermoelement wire limits the use of this design to $1500{ }^{\circ} \mathrm{C}$.

However, Wilkins recommended that the alloys proposed by Schley and Metauer be explored to delay the effects of grain growth.

Three pure molybdenum/niobium thermocouples $0.127 \mathrm{~mm} / 0.005$ ” OD wires, hafnia insulated, $1 \mathrm{~mm} / 0.0394$ " OD Inconel sheathed) were later used in an ATR irradiation. ${ }^{15}$ In addition, the tests included three W-Re Type $\mathrm{C}$ thermocouples and three Nisil-Nicrosil (N)-type thermocouples. Originally, the tests were designed to run at $1150{ }^{\circ} \mathrm{C}$. However, it was later decided to limit test peak test temperatures to $920^{\circ} \mathrm{C}$ and run the tests for 64 days. Two of the three $\mathrm{Mo} / \mathrm{Nb}$ thermocouples did not experience any failures. In fact, as the test progressed, these two thermocouples and one of the Type $\mathrm{N}$ thermocouples provided the closest agreement. Because of their superior performance, one of the $\mathrm{Mo} / \mathrm{Nb}$ thermocouples was selected for control of the tests. 


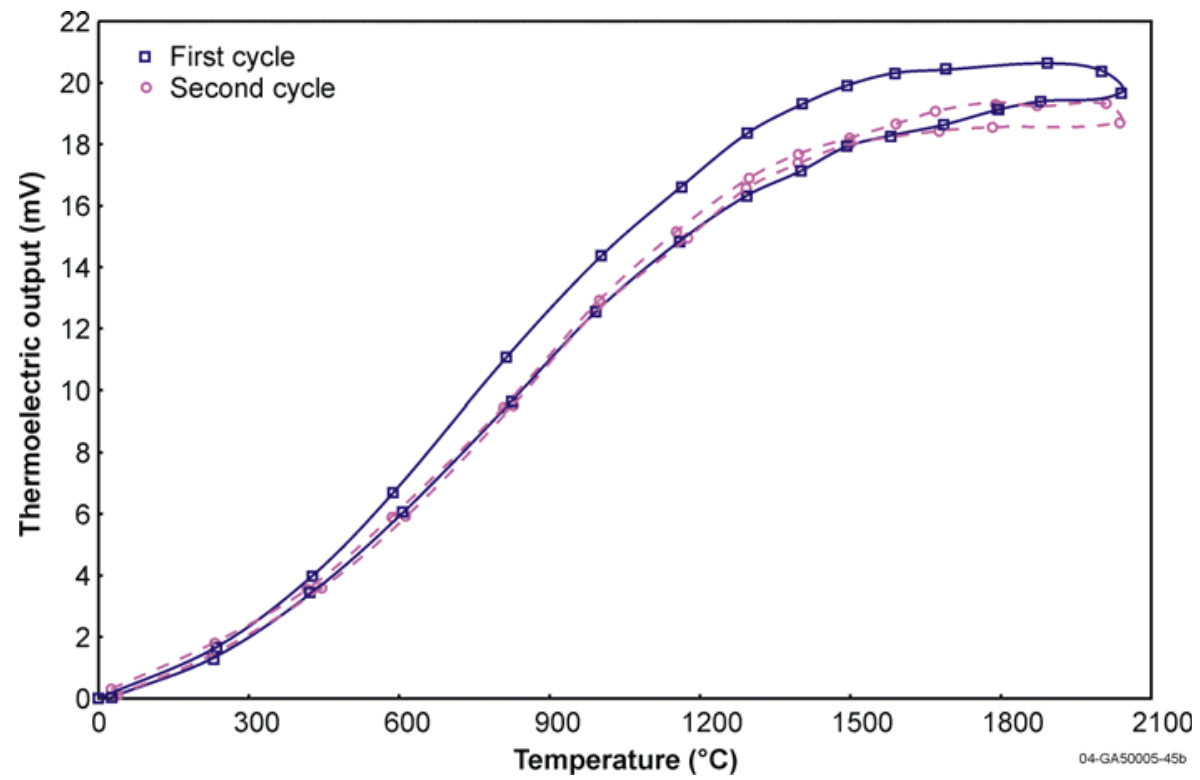

Figure 2-4. Molybdenum/niobium thermocouple output obtained by Wilkins during the first two temperature cycles (0.25 mm wires)

\subsubsection{Schley}

Reference 13 reports results from in-pile and out-of-pile tests. In-pile tests were completed at temperatures ranging from $1100{ }^{\circ} \mathrm{C}$ to $1400{ }^{\circ} \mathrm{C}$. Results indicate that the $\mathrm{Mo} / \mathrm{Nb}$ thermocouples lasted between 1840 to 2000 hours, which was longer than the Type $\mathrm{K}, \mathrm{Pt} / \mathrm{Rh}$, and W/Re thermocouples tested (1125 hours). Four hour out-of-pile tests were conducted at $1200{ }^{\circ} \mathrm{C}$ on alumina insulated thermocouples of $0.5,0.2$, and $0.12 \mathrm{~mm}$ (0.127”, 0.0079”, and 0.0047”) diameter wires. Drift was minimal. Decalibrations of $0.07,0.13$ and $0.2 \%$, respectively, were observed.

\subsubsection{Knight and Greenslade}

Reference 10 reports results from tests completed in the Fast Flux Test Facility (FFTF) at PNNL in which a pure molybdenum / niobium-1\%zirconium thermocouple was irradiated for 7200 hours at a temperature of $1070 \mathrm{~K}$ without any significant decalibration. The thermocouples were fabricated from 0.25-mm (0.0098”) diameter thermoelement wires (pure Mo and Nb-1\%Zr) with high purity (99.8\%) alumina insulators in unalloyed Mo sheath tubing (1.8-mm/0.071" OD x $1.2 \mathrm{~mm} / 0.047$ ” ID). The Nb-1\%Zr alloy was pursued because tests with a $0.25-\mathrm{mm}(0.0098$ ”) diameter pure niobium thermoelement wire heated to at $1675 \mathrm{~K}$ failed due to excessive grain growth. At the time that Reference 10 was published, a second series of irradiations were underway with a similar thermocouple that would be tested for 7200 hour at $1375 \mathrm{~K}$. In this second series, a tungsten-22\%rhenium sheath(1.6 mm/0.063” OD x $1.2 \mathrm{~mm} / 0.047$ ” ID) was 
selected. Results after 60 days of operation indicate that the Mo/Nb-1\%Zr thermocouple did not experience any significant decalibration.

An emf versus temperature curve for this $\mathrm{Mo} / \mathrm{Nb}-1 \% \mathrm{Zr}$ thermocouple that was generated in Reference 10 is compared to the calibration curves obtained by Schley and by Wilkins for various proposed thermocouples. The emf curve for a W-Re alloy thermocouple is also compared in this plot. The addition of one percent zirconium to the niobium did not significantly affect the emf of the thermocouple. However, the alloys proposed by Schley and Metauer have the potential to significantly increase the resolution of this thermocouple at high temperatures.

\subsubsection{Villard}

CEA, in collaboration with the THERMOCOAX Company, has also been conducting research on high-temperature in-pile thermocouples. ${ }^{29}$ This CEA/THERMOCOAX effort first investigated high-temperature compatibilities of candidate materials for sheath, insulators and wires, including tests of different diameter wires. The tests were conducted in a high temperature furnace, in the range from $1000^{\circ} \mathrm{C}$ to $1600{ }^{\circ} \mathrm{C}$, in pure helium atmosphere and in contact with graphite. Test results indicated that materials less susceptible to interactions were Mo and $\mathrm{Nb}$ wires with $\mathrm{HfO}_{2}$ insulation and $\mathrm{Nb}$ or Ta sheath. Then, investigations were performed to quantify the thermoelectric response of this Mo-Nb thermocouple. Results indicated that the electromotive force of the Mo-Nb couple in the intended temperature range is about $14 \mu \mathrm{V} /{ }^{\circ} \mathrm{C}$, which is of the same order as the e.m.f. of commercially-available high-temperature Type $\mathrm{C}$ or $\mathrm{S}$ thermocouples. Then, tests were performed to evaluate the thermal stability of these thermocouples. The objective was to determine the appropriate thermal treatment to be operated during the sensor fabrication, in order to minimize the thermal drift for high temperature use. The efficiency of the selected treatment is then studied during on-going long-duration high-temperature out-of-pile tests. Reference 29 reports that initial results indicate that these thermocouples were drifting at a rate somewhat lower than $0.02{ }^{\circ} \mathrm{C} / \mathrm{h}$ at $1100{ }^{\circ} \mathrm{C}$. Note that after 5000 hours, this would result in $100{ }^{\circ} \mathrm{C}$ or $10 \%$ drift, which is higher than observed in the INL long duration evaluations at $1200^{\circ} \mathrm{C}$.

Reference 29 indicates that the next phase of development for these thermocouples will be in-pile high-temperature qualifications in the OSIRIS reactor. The proposed irradiation will include both standard high-temperature and new Mo-Nb thermocouples during the irradiation. A long-term neutron irradiation experiment called "THERMEX" is under preparation in CEA (see Figure 2-5) for these tests.

\subsection{Effect of Wire Diameter and Heat Treatment}

Initial INL efforts focused on swaged thermocouples fabricated from $0.254 \mathrm{~mm} / 0.010$ ” diameter thermoelement wires. Previous evaluations ${ }^{30}$ demonstrated that the reliability of Type $\mathrm{K}$ and Type $\mathrm{N}$ thermocouples increases with wire diameter, especially at higher temperatures. 


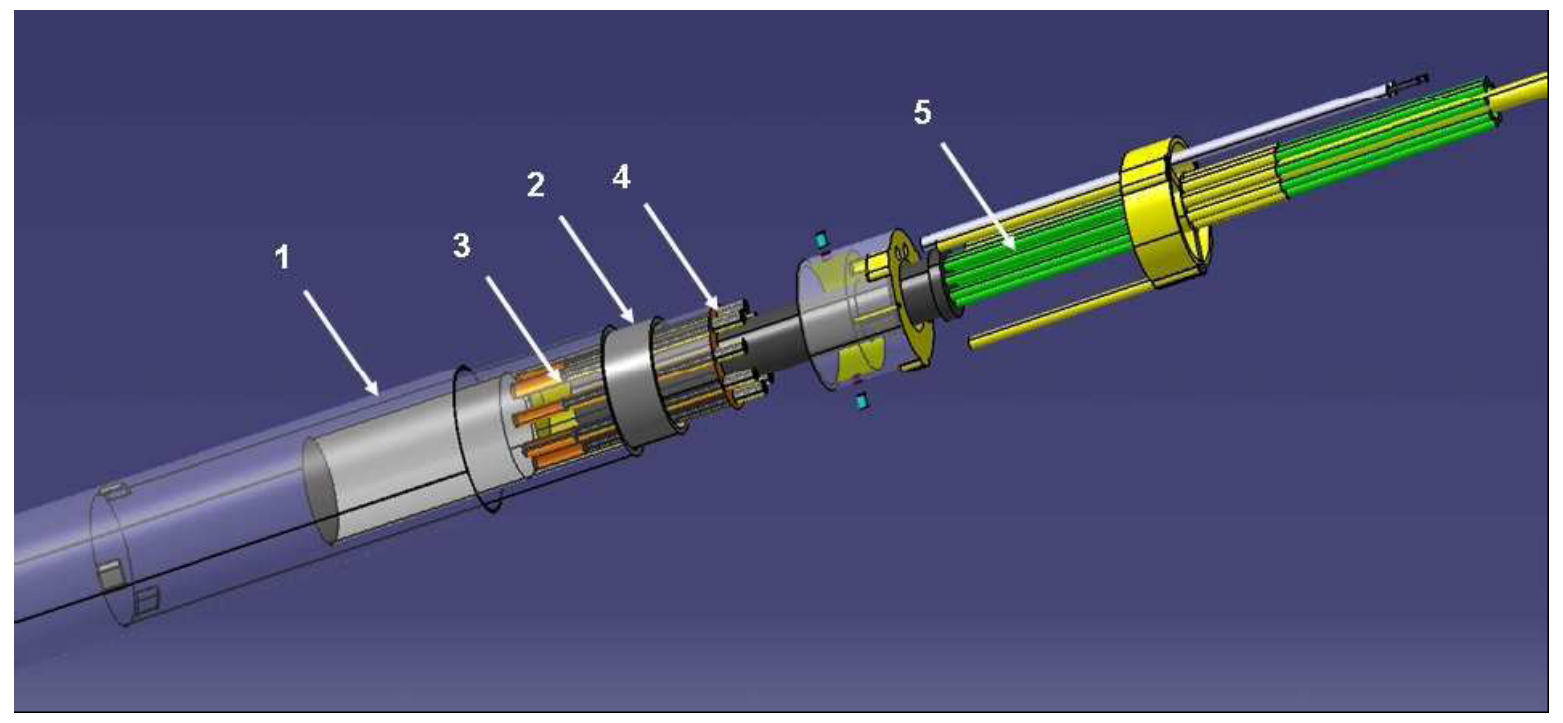

Figure 2-5. Exploded view of THERMEX experiment device: stainless steel capsule (1), graphite barrel (3) filled with pure Copper (2), additional electric heating elements (4),thermocouples (5).

However, the performance observed in these thermocouples may differ from the performance of a doped $\mathrm{Mo} / \mathrm{Nb}$ alloy thermocouple. Reference 13 reports results from bare wire, alumina insulated $\mathrm{Mo} / \mathrm{Nb}$ thermocouple tests with wires of $0.5,0.2$, and $0.12 \mathrm{~mm}$ OD that were maintained at $1700{ }^{\circ} \mathrm{C}$ for two hours. Results indicate that the smaller the wire diameter, the greater the drift of the emf. Evaluations suggest that this drift was due to grain growth when the thermoelements were annealed and recrystallized. Hence, it was postulated that the thermoelectric drift was related to the degree of cold work in the thermoelectric wires and to the wire diameter. Tests were repeated after a recrystallization treatment at $1900{ }^{\circ} \mathrm{C}$ for 1 hour. Results indicated that the emf drift was negligible for all wire diameters. Hence, it was concluded that heat treating thermocouple wires at higher temperature than expected in service stabilizes the structure of the thermoelectric wires. However, more detailed evaluations are needed to quantify the effect of diameter on the reference INL thermocouple performance and the influence of various heat treatments on the observed variations with diameter.

\subsection{Enhanced Performance of Niobium and Molybdenum Alloys}

Historically, industry developed high temperature thermocouple alloys (e.g, W/Re alloys and Pt/Rh alloys) to improve performance with respect to ductility and reliability. Prior experience with $\mathrm{Mo} / \mathrm{Nb}$ thermocouples suggests that similar efforts are warranted.

\subsubsection{Niobium}

Niobium possesses a number of properties that makes it attractive for high-temperature applications and for use in nuclear power systems. These properties include a melting temperature 
of $2470{ }^{\circ} \mathrm{C}$, a low thermal-neutron-capture cross section of 1.15 barns/atom, favorable resistance to liquid-metal corrosion at moderate temperatures, good ductility, and an abundant supply. However, there are several considerations associated with this element that can improve its performance as a thermocouple element wire or sheath.

Recrystallization Behavior. The recrystallization temperature and grain size is of interest in assessing the ductility of thermocouple wires subjected to high temperatures. Clearly, a material will remain more ductile if recrystallization is delayed (and small grain size is retained). The recrystallization temperature is time-dependent; in addition, it is sensitive to purity, amount and temperature of working, and concurrent straining during annealing treatments. The recrystallization temperature of niobium is $940{ }^{\circ} \mathrm{C}$ with $70 \%$ deformation. Figure $2-6$ shows results from an investigation of the recrystallization of niobium using specimens of twice-sintered 98.9\% niobium. In this investigation, samples with various deformations were held for one hour at temperatures between $500{ }^{\circ} \mathrm{C}$ and $1500{ }^{\circ} \mathrm{C}$. As shown in Figure 2-6, higher recrystallization temperatures were observed in samples with increased amounts of deformation. ${ }^{31}$ Grain size was reduced (which increases ductility of the niobium) if cold working is present in the material.

This is of particular interest because thermocouple wires and sheaths experience significant ( 30\%) elongation due to swaging during fabrication (see Section 3 ). Thus, the thermocouple fabrication process may tend to reduce grain size and increase ductility of the thermocouple.

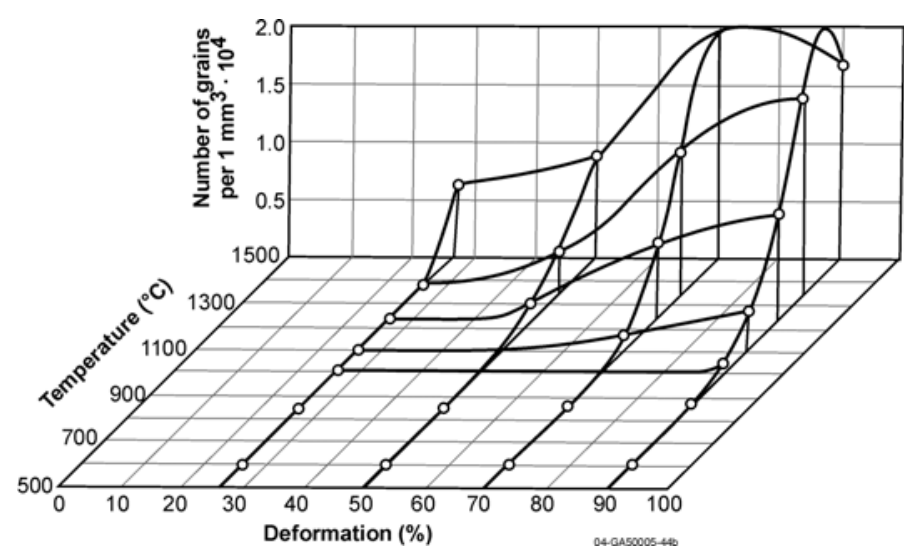

Figure 2-6. Recrystallization diagram for niobium (holding time, 1 hour).

Effects of Alloying. Alloy development programs for niobium have improved its high-temperature strength and oxidation resistance. In addition, alloying of niobium with other metals has been found to delay the temperatures at which recrystallization occurs. As shown in Figure $2-7,{ }^{31}$ the addition of small amounts (less than 1\%) of zirconium to niobium has been found to raise the recrystallization temperature by $25^{\circ} \mathrm{C}$. The addition of molybdenum (up to 4\%) may delay recrystallization by $75^{\circ} \mathrm{C}$ (up to $1200{ }^{\circ} \mathrm{C}$ ). ${ }^{31}$ 


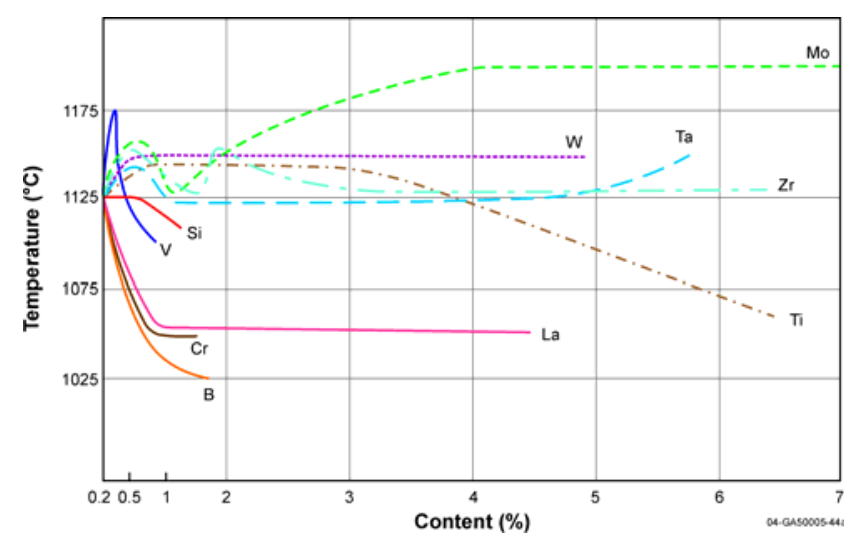

Figure 2-7. Effects of alloying elements on the recrystallization temperature of niobium and its alloys.

Reference 31 also reports results indicating that the addition of Mo to Nb increases its resistance to oxidation. In one study, the addition of $5 \%$ Mo to niobium reduce its oxidation rate at $1020{ }^{\circ} \mathrm{C}$ from 38 to $4.3 \mathrm{mg} / \mathrm{cm}^{2}$-hr. As noted in Section 2.4.3, investigations by Schley and Metauer suggest that the addition of small amounts of molybdenum (less than 10\%) to niobium will improve its thermoelectric response. However, References 9 and 11 acknowledge that it is difficult to fabricate small diameter wire $(0.025 \mathrm{~mm} / 0.010$ ”) from this alloy. Initial attempts could only produce wires with diameters of $2 \mathrm{~mm}$.

\subsubsection{Molybdenum}

Molybdenum also possesses a number of properties that makes it attractive for hightemperature applications and for use in nuclear power systems. These properties include a melting temperature of $2470{ }^{\circ} \mathrm{C}$, a low thermal-neutron-capture cross section of 2.65 barns/atom, and an abundant supply. ${ }^{32}$

The oxidation behavior of molybdenum is a disadvantage. Above $500{ }^{\circ} \mathrm{C}, \mathrm{MoO}_{3}$ begins to sublime; and at $600{ }^{\circ} \mathrm{C}$, its volatilization is significant. Cladding and coating research has been able to partially overcome molybdenum's oxidation behavior. Another disadvantage of molybdenum is its poor low-temperature ductility. However, improved consolidation, alloying, doping with interstitials, and fabrication techniques have been able to enhance molybdenum's low temperature ductility. Several considerations associated with this element that can improve its performance as a thermocouple element wire are discussed below.

Recrystallization Behavior. Reference 32 reports results from several studies directed toward raising the recrystallization temperatures and thus increasing the stability and strength of the work-hardened molybdenum at high temperatures. As in the case of niobium, the recrystallization temperature of molybdenum is time-dependent and sensitive to purity, amount and temperature of working, and concurrent straining during annealing treatments. It was concluded that the recrystallization temperatures for unalloyed molybdenum ranged from $815^{\circ} \mathrm{C}$ to $1700{ }^{\circ} \mathrm{C}$, depending upon the materials’ purity, the amount and temperature of prior deformation, and the 
length of time for recrystallization treatment. Reference 32 also reports results from several tests conducted on unalloyed Mo (with $0.01 \%$ C) to results from molybdenum alloyed with titanium and zirconium. Data indicate that one hour after hot-cold work with 75 to $97 \%$ reductions, the recrystallization temperature ranged between $1177^{\circ} \mathrm{C}$ (for unalloyed Mo with $1 \% \mathrm{C}$ ) to $1343^{\circ} \mathrm{C}$ (for Mo alloyed with 5\% Zr). Reference 31 reports that alloying molybdenum with niobium "causes a considerable increase in the recrystallization temperature of niobium." This reference also indicates that alloys containing more than $85 \% \mathrm{Mo}, 0.25$ to $10 \% \mathrm{Nb}$, up to $0.4 \% \mathrm{Al}$, and up to $0.02 \% \mathrm{C}$ can be mechanically worked at high temperatures and retain work hardening after one hour of heating at $1200^{\circ} \mathrm{C}$.

Effects of Doping and Alloying. To control crystal structure during recrystallization, suitable “dopants" are added to molybdenum. The doping procedure used for molybdenum is similar to that used for doping tungsten. However, the dope in the case of molybdenum is potassium silicate with or without the addition of aluminum nitrate. In more recent years, lanthanum oxide has been used as a dopant for molybdenum. It is added as a solution to the oxide prior to its reduction to metal powder.

The effect of the dopant and subsequent work hardening is to increase the recrystallization temperature, at the same time promoting the formation of elongated grains with boundaries axially aligned to the wire axis. In contrast, an equiaxed structure may be seen in recrystallized undoped molybdenum.

Table 2-2 compares a typical chemical analysis of an undoped and doped $0.5 \mathrm{~mm}$ diameter wire. As indicated below, the doping primarily affects the potassium and silicon content.

Table 2-2. Typical chemical analysis of doped and doped molybdenum wire (ppm by weight).

\begin{tabular}{c|c|c|c|c|c|c|c|c|c|c|c|c|c}
\hline & K & Al & Si & Fe & Cs & Ni & Cr & Cu & Mg & Mn & Pb & Sn & W \\
\hline $\begin{array}{c}\text { Updoped wire (0.5 } \\
\text { mm/0.02" dia) }\end{array}$ & 15 & 40 & 30 & 60 & 20 & $<5$ & $<10$ & 5 & $<5$ & $<5$ & $<5$ & $<5$ & \\
\hline $\begin{array}{c}\text { Doped wire } \\
\text { (0.5 mm/0.02" dia) }\end{array}$ & 130 & 30 & 200 & 60 & 20 & $<5$ & $<5$ & $<10$ & 5 & $<5$ & $<5$ & $<5$ & \\
\hline
\end{tabular}

As noted in Section 2.4.3, investigations by Schley and Metauer suggest that the addition of small amounts of niobium (less than 5\% to molybdenum) will improve its thermoelectric properties. However, References 9 and 11 acknowledge that it is difficult to fabricate small diameter wire ( $0.25 \mathrm{~mm} / 0.010$ ”) from this alloy. Initial attempts could only produce wires with diameters of $2 \mathrm{~mm}$.

\subsubsection{Schley and Metauer}

In order to optimize the thermoelectric output of a Mo/Nb thermocouple, Schley and Metauer tested the absolute thermoelectric power of binary $\mathrm{Mo} / \mathrm{Nb}$ alloys with varying amounts of $\mathrm{Nb}$. Tests were conducted on parallel-piped ingots ( $6 \times 6 \times 8 \mathrm{~mm})$. Their tests led them to propose a thermocouple with a Mo-5\%Nb / Nb-10\% Mo composition. As indicated in Figure 2-8, 
the thermoelectric response of such a sensor is similar to that of a W/Re sensor. However, the feasibility of making such alloys into small diameter wires was not investigated.

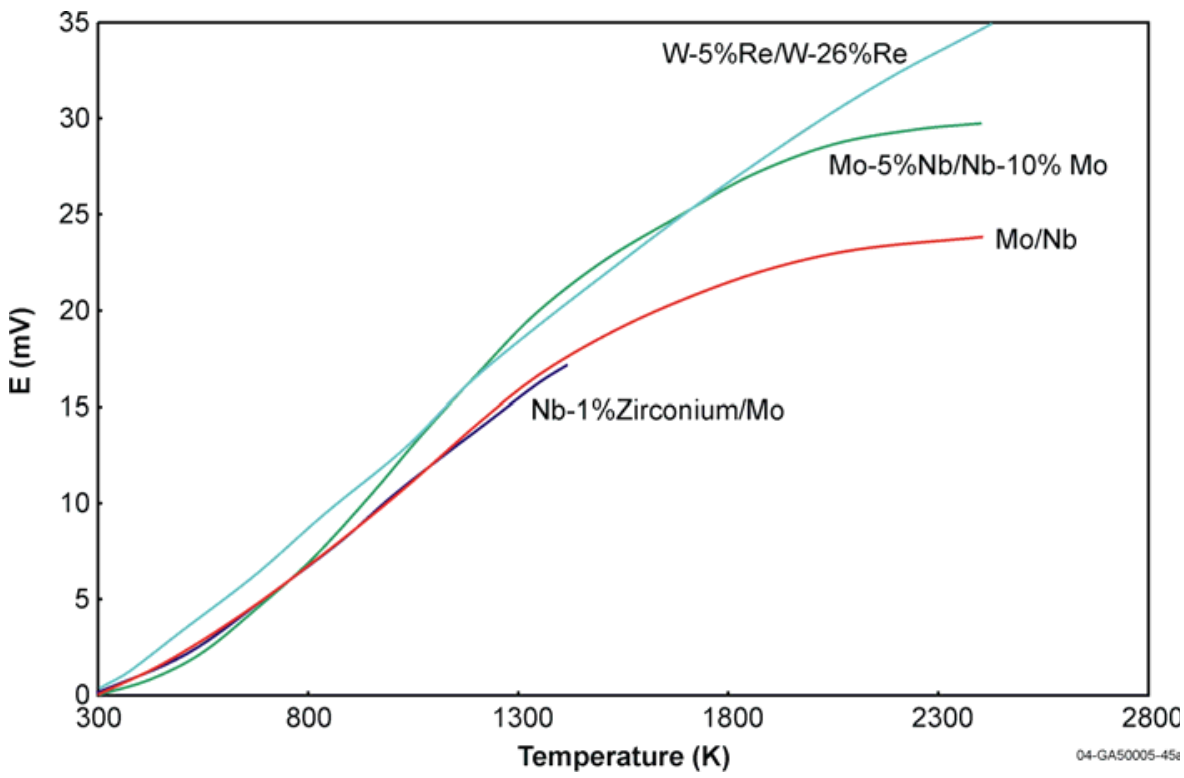

Figure 2-8. Comparison of temperature-emf curves for pure Mo versus pure Nb, pure Mo versus Nb$1 \% \mathrm{Zr}, \mathrm{Mo}-\mathrm{Nb}$ alloy, and $\mathrm{W}-\mathrm{Re}$ alloy thermocouples, 


\section{Alternate Alloy Ductility Evaluations (Task 1.1)}

As noted in Section 1, developmental alloys of Mo and Nb were evaluated with respect to ductility, resolution, and performance when subjected to high temperatures and transients. Ductility tests were completed by heating $0.254 \mathrm{~mm}\left(0.010^{\prime \prime}\right)$ diameter wires of candidate materials for 2, 5, and 12 hour intervals in gettered argon at temperatures of $1400{ }^{\circ} \mathrm{C}, 1600{ }^{\circ} \mathrm{C}$, and $1800{ }^{\circ} \mathrm{C}$ (although alloys containing primarily $\mathrm{Nb}$ were truncated at $1600{ }^{\circ} \mathrm{C}$ due to lack of ductility). Heating tests were conducted by placing wires in a tantalum carrier. Mandrel wrap tests were performed using mandrels that were two, five, ten, and twenty times the diameter of the wires (e.g., $0.51 \mathrm{~mm}$ (0.02”), $1.27 \mathrm{~mm}$ (0.05”), $2.54 \mathrm{~mm}$ (0.10”), and $5.08 \mathrm{~mm}$ (0.2”) in diameter). This section presents results from these ductility evaluations.

\section{1. $1400{ }^{\circ} \mathrm{C}$}

Figures 3-1 through 3-3 show molybdenum alloy wires wrapped around mandrels after various heating periods at $1400{ }^{\circ} \mathrm{C}$. As shown in these figures, all of the wire exhibited suitable ductility. Candidate material wires could be wrapped on mandrels of 0.020”, 0.050”, 0.100”, and 0.200 ” for several turns without breaking.
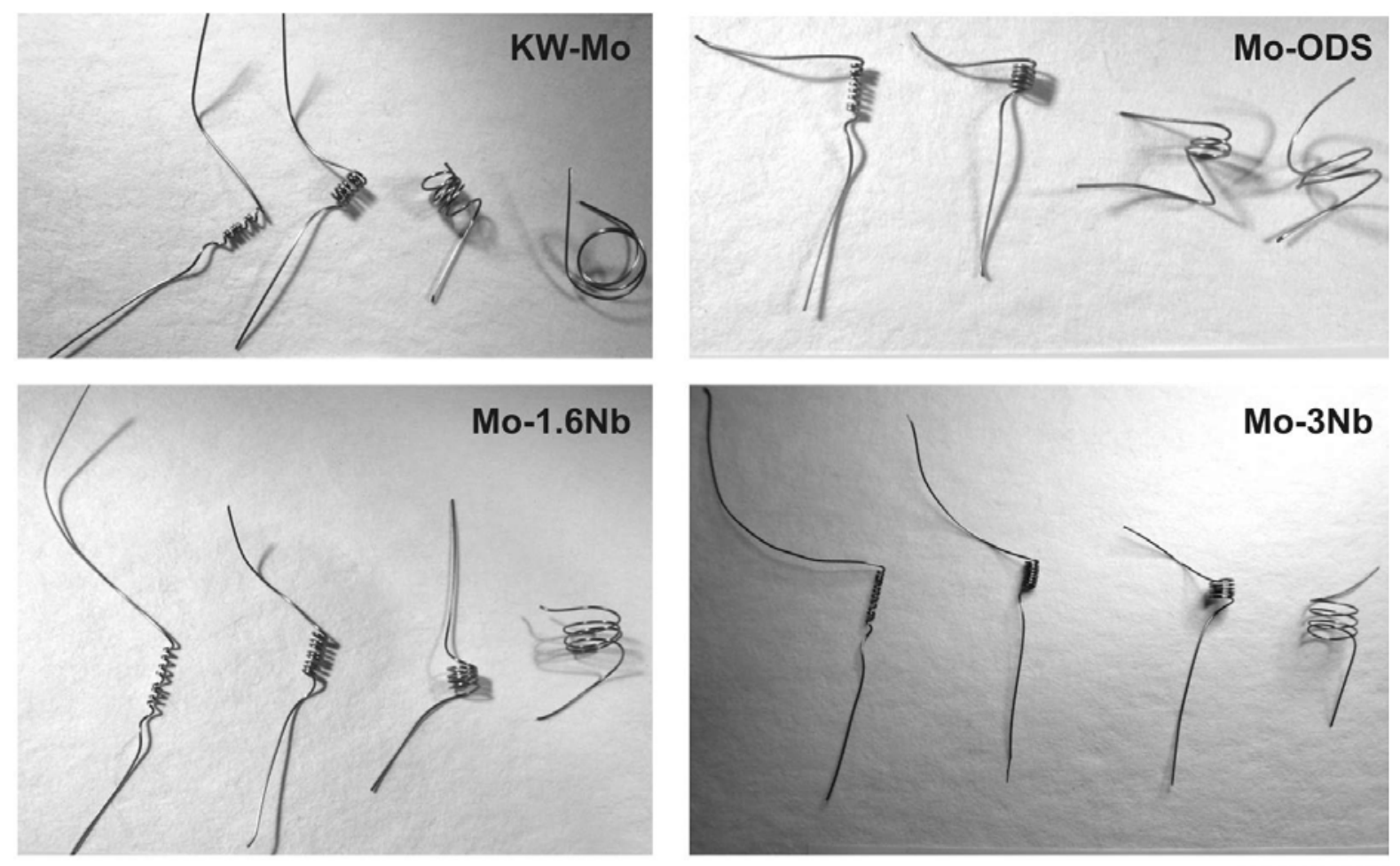

06-GA50001-23-2

Figure 3-1. Candidate molybdenum-based wire after heating for 2 hours at $1400{ }^{\circ} \mathrm{C}$. 

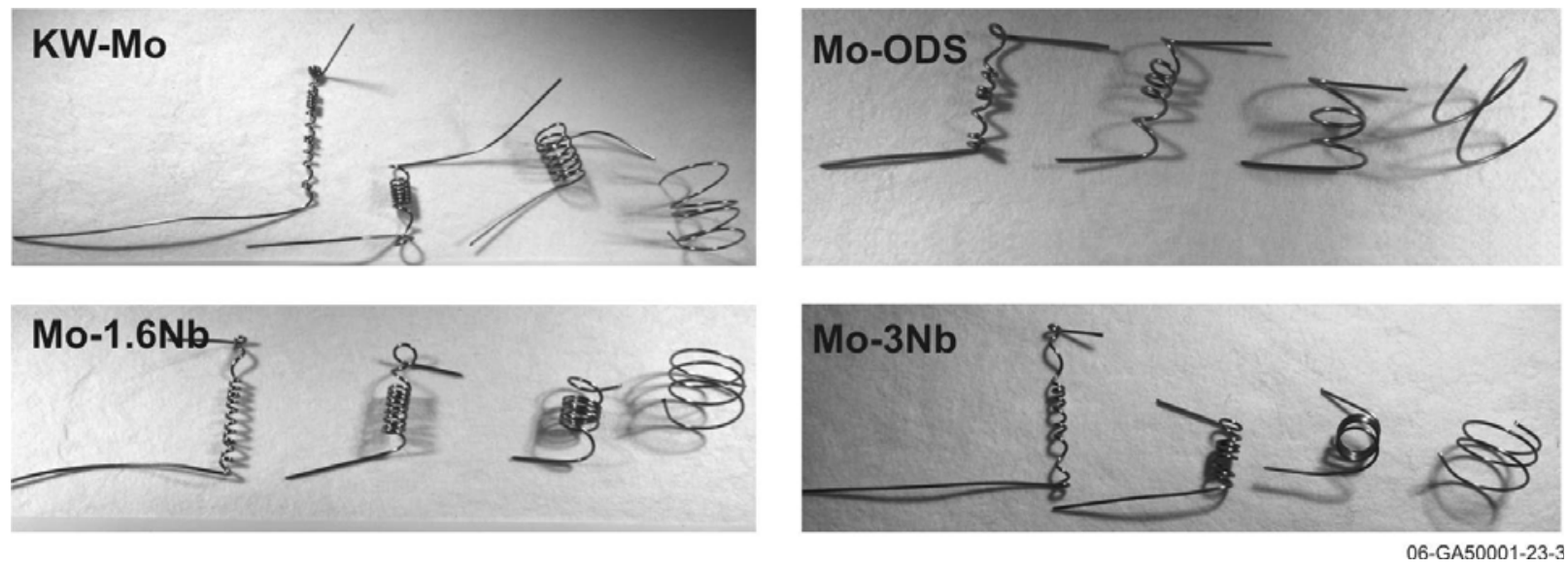

Figure 3-2. Candidate molybdenum-based wire after heating for 5 hours at $1400{ }^{\circ} \mathrm{C}$.
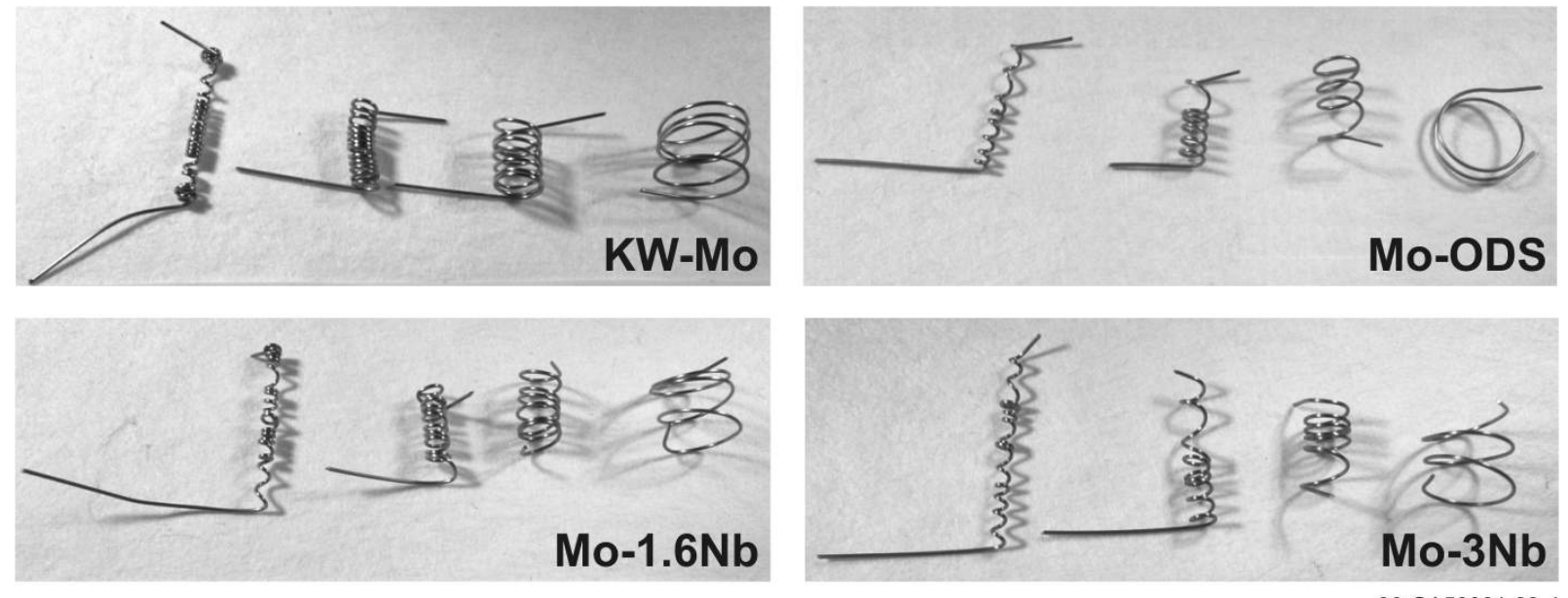

Figure 3-3. Candidate molybdenum-based wire after heating for 12 hours at $1400^{\circ} \mathrm{C}$.

Figures 3-4 through 3-6 show candidate niobium alloy wires wrapped around mandrels after various heating periods at $1400^{\circ} \mathrm{C}$. It should be noted that the Nb-8\%Mo wires have a diameter of $0.381 \mathrm{~mm}\left(0.015^{\prime}\right)$ due to manufacturing difficulties. Because of this, these samples were wrapped on mandrels of $0.762 \mathrm{~mm}(0.03$ ”), $1.905 \mathrm{~mm}(0.075$ ”), $3.81 \mathrm{~mm}(0.15$ ”), and 6.35 $\mathrm{mm}(0.25$ ”). The $6.35 \mathrm{~mm}$ mandrel is less than twenty times the wire diameter, but is the largest available mandrel. Results shown in Figure 3-4 illustrate that the Nb-4\%Mo, Nb-6\%Mo, and Nb$8 \%$ Mo wires were somewhat brittle even after the shortest (e.g., the 2 hour heating period), and results shown in Figure 3-5 show that all of the candidate wires (including the Nb-1\%Zr) were brittle after the 5 hour heating period. 

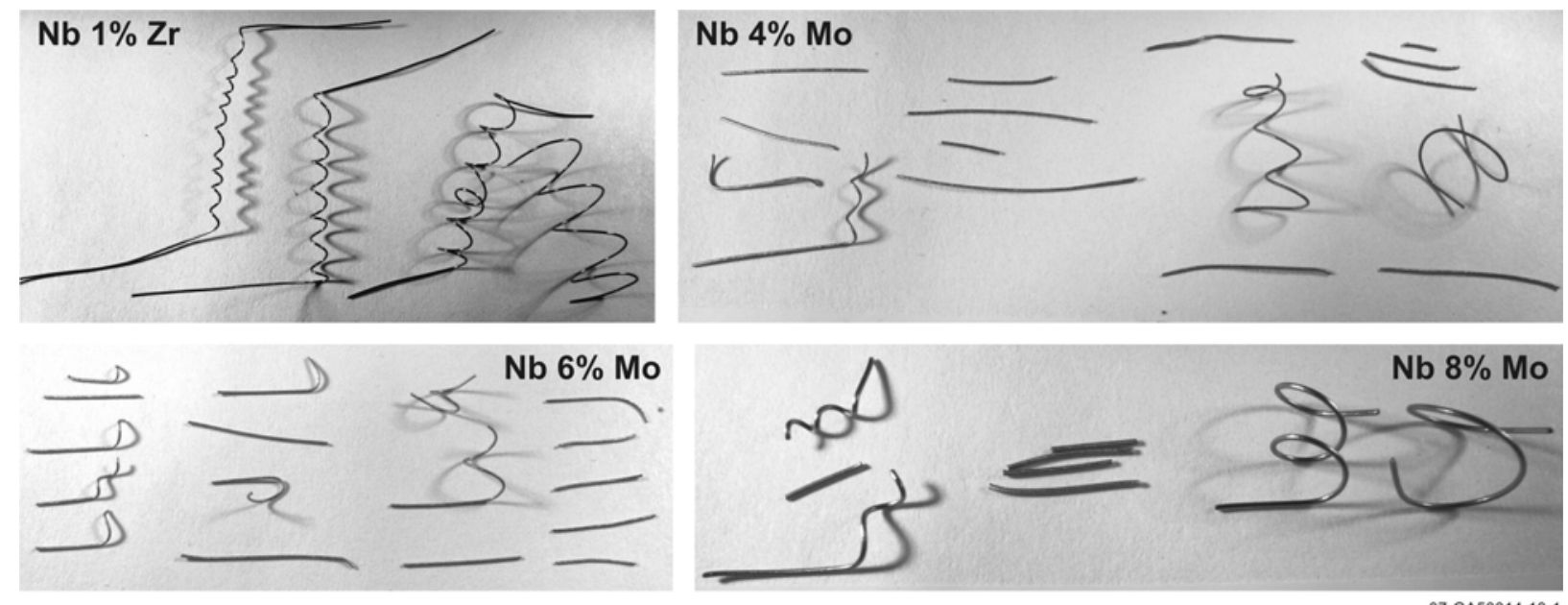

Figure 3-4. Candidate niobium-based wire after heating for 2 hours at $1400{ }^{\circ} \mathrm{C}$.
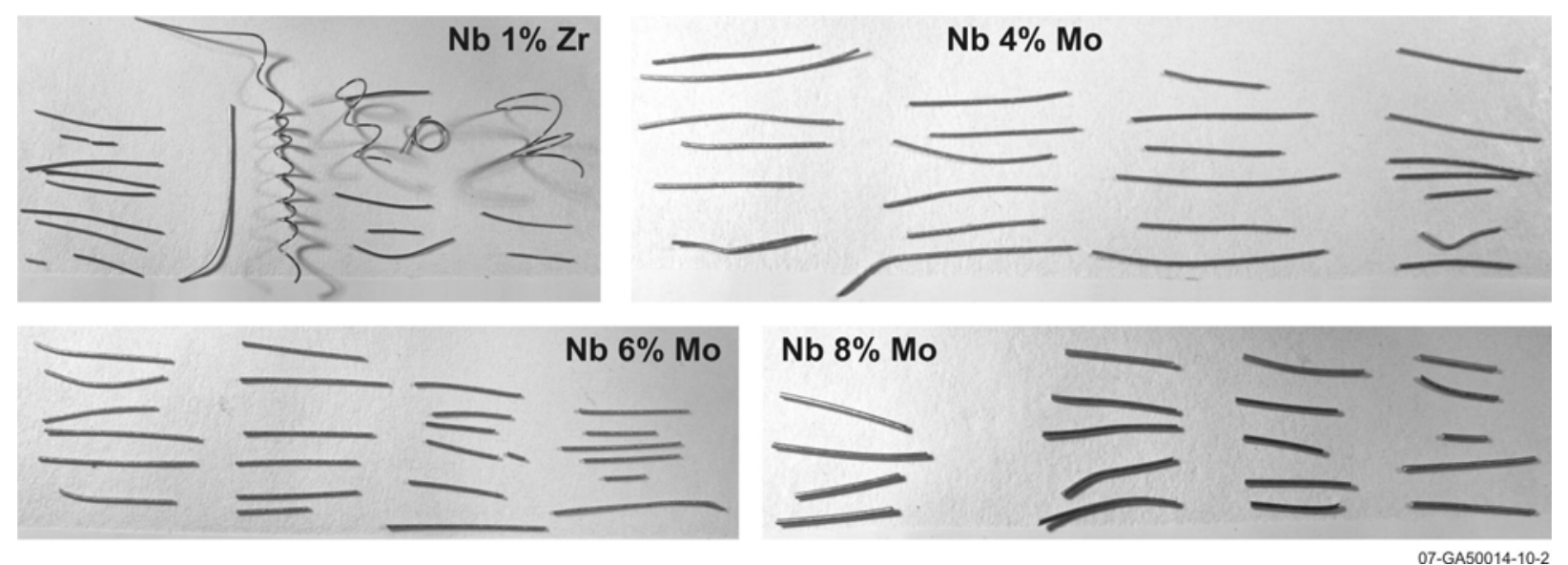

Figure 3-5. Candidate niobium-based wire after heating for 5 hours at $1400{ }^{\circ} \mathrm{C}$.
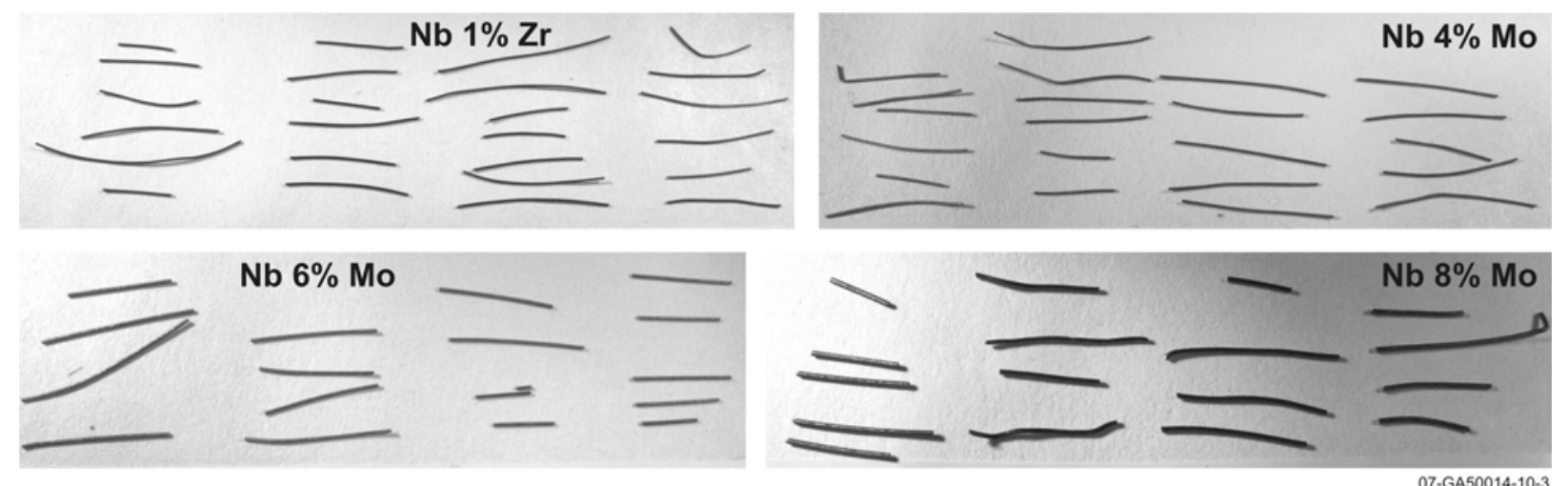

Figure 3-6. Candidate niobium-based wire after heating for 12 hours at $1400^{\circ} \mathrm{C}$. 


\section{2. $1600^{\circ} \mathrm{C}$}

Figures 3-7 through 3-9 show molybdenum alloy wires wrapped around mandrels after various heating periods at $1600{ }^{\circ} \mathrm{C}$. Candidate material wires could be wrapped on mandrels of 0.020”, 0.050”, 0.100”, and 0.200” for several turns without breaking. Note that some breaks occurred in the Mo-1.6\%Nb and Mo-3\%Nb after heating for longer durations (5 hours and 12 hours). However, the wire was still sufficiently ductile that this material can be considered as a viable thermoelement candidate at temperatures up to $1600{ }^{\circ} \mathrm{C}$.
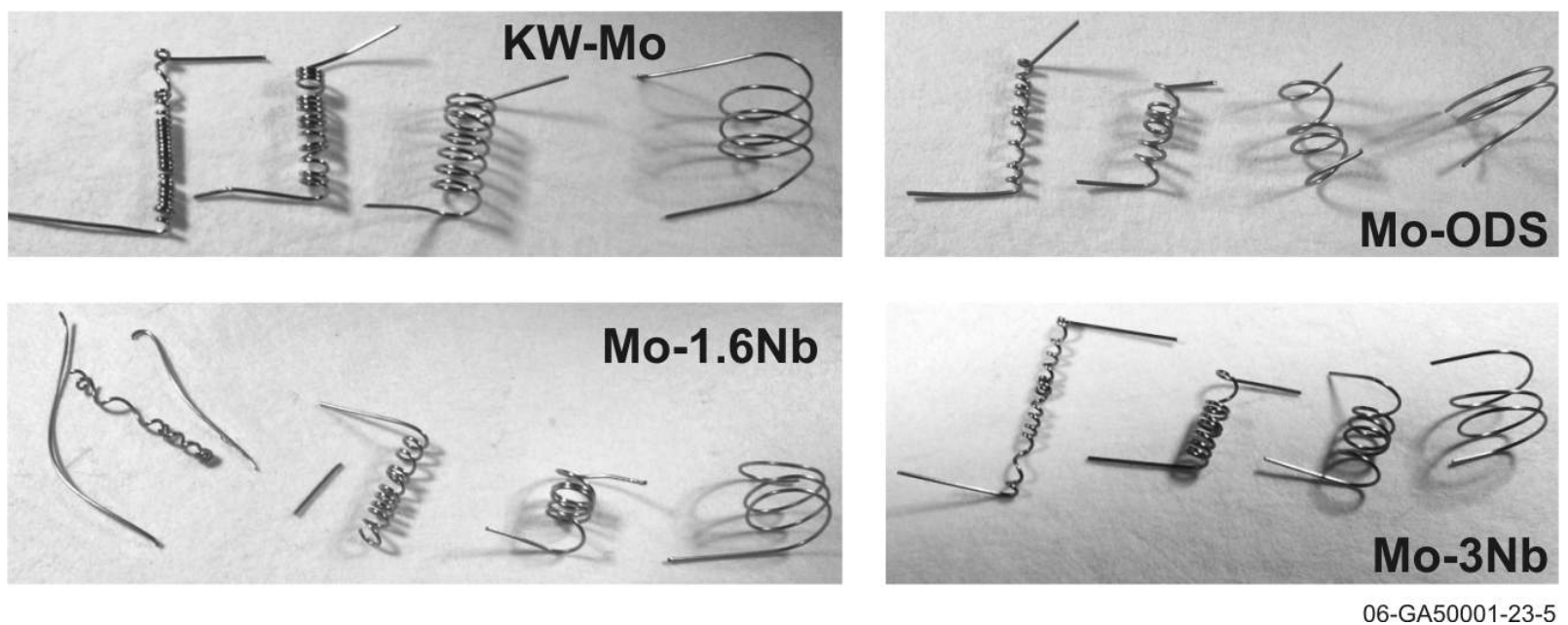

Figure 3-7. Candidate molybdenum-based wire after heating for 2 hours at $1600{ }^{\circ} \mathrm{C}$.
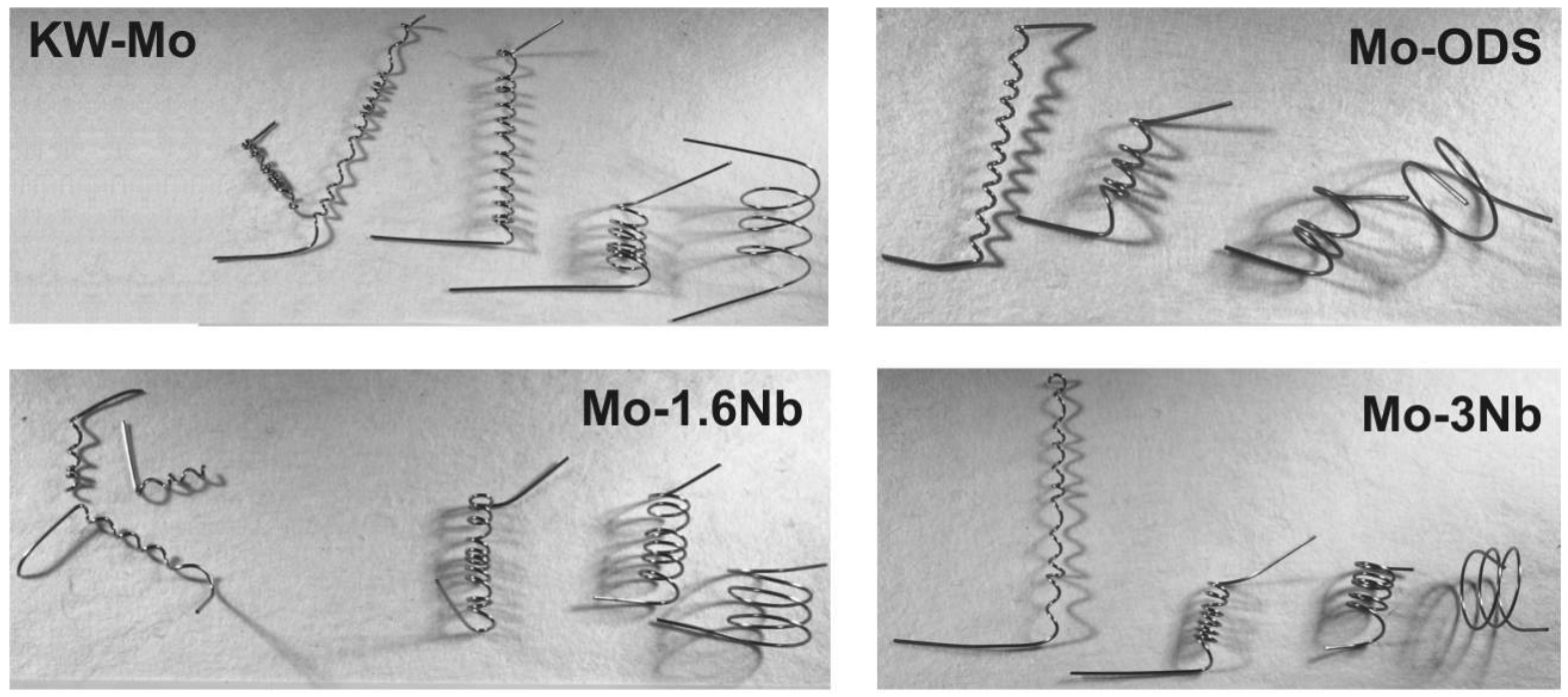

06-GA50001-23-7

Figure 3-8. Candidate molybdenum-based wire after heating for 5 hours at $1600{ }^{\circ} \mathrm{C}$. 

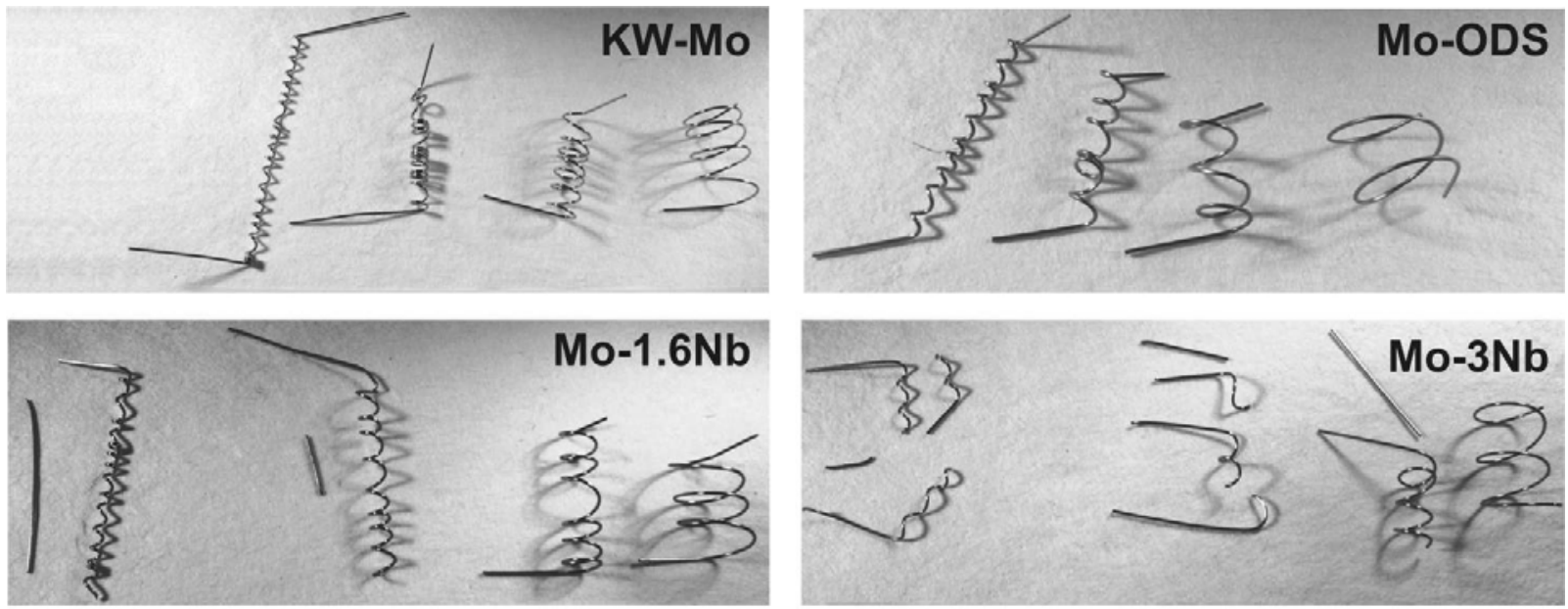

06-GA50001-23-8

Figure 3-9. Candidate molybdenum-based wire after heating for 12 hours at $1600{ }^{\circ} \mathrm{C}$.

Figures 3-10 through 3-12 show candidate niobium alloy wires wrapped around mandrels after various heating periods at $1600^{\circ} \mathrm{C}$. Results shown in Figure 3-10 illustrate that the Nb4\%Mo, Nb-6\%Mo, and Nb-8\%Mo wires were brittle even after the shortest (e.g., the 2 hour heating period), and results shown in Figure 3-11 show that all of the candidate wires (including the $\mathrm{Nb}-1 \% \mathrm{Zr}$ ) were brittle after the 5 hour heating period.
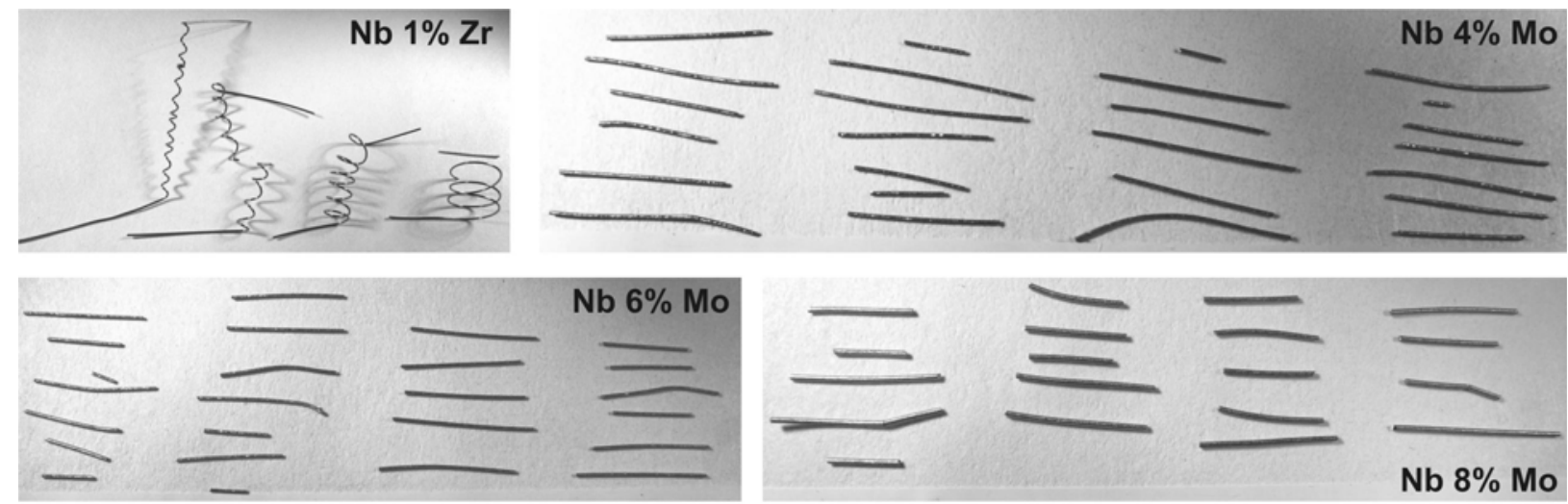

Figure 3-10. Candidate niobium-based wire after heating for 2 hours at $1600{ }^{\circ} \mathrm{C}$. 

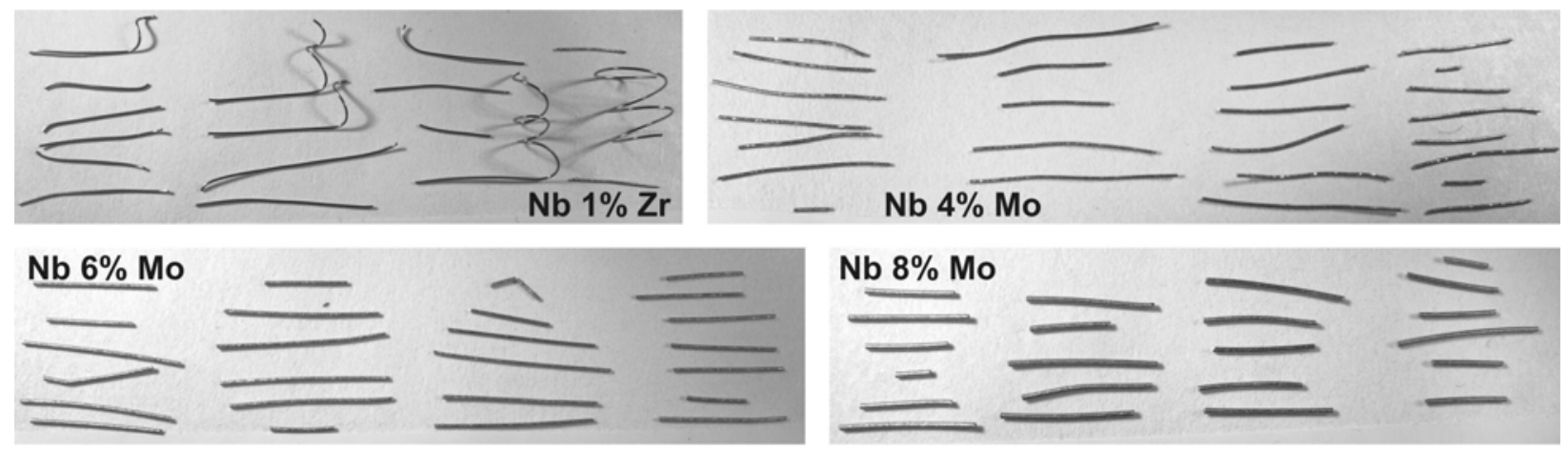

Figure 3-11. Candidate niobium-based wire after heating for 5 hours at $1600{ }^{\circ} \mathrm{C}$.
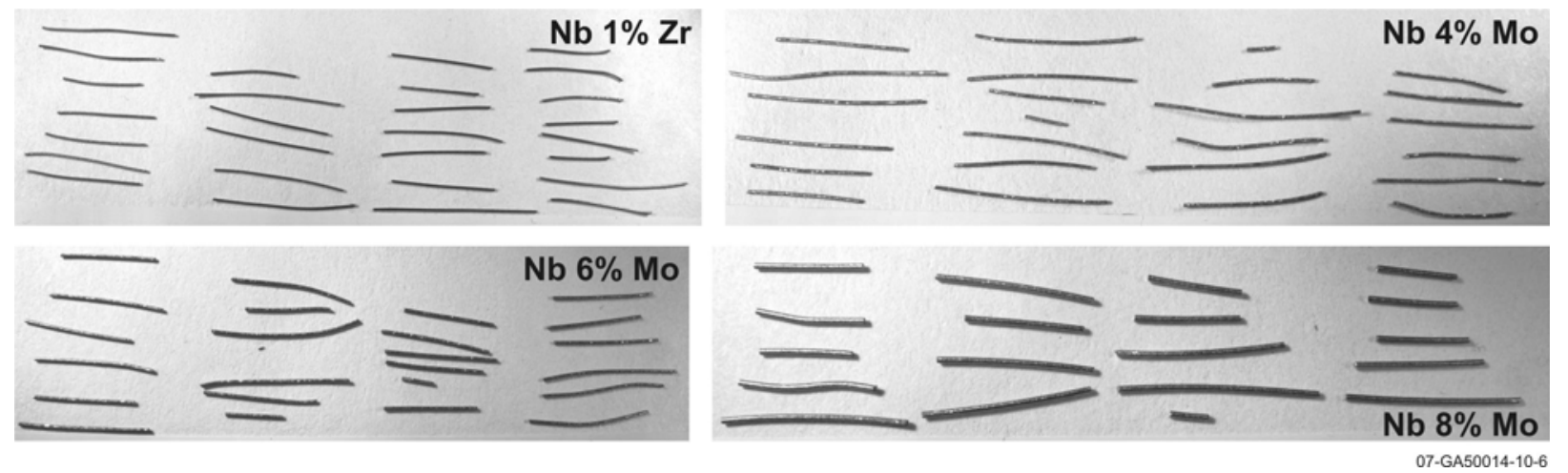

Figure 3-12. Candidate niobium-based wire after heating for 12 hours at $1600{ }^{\circ} \mathrm{C}$.

\section{3. $1800^{\circ} \mathrm{C}$}

Figures 3-13 through 3-15 show mandrel wrap test results for molybdenum alloy wires after various $1800{ }^{\circ} \mathrm{C}$ heating periods. During the 2 and 12 hour tests, furnace heater element failures occurred, which could have reduced the heating duration and/or heating temperatures during these tests. Nevertheless, results shown in Figure 3-13 illustrate that the Mo-3\%Nb wire was too brittle even after the shortest (e.g., the 2 hour heating period), and the Mo- $1.6 \% \mathrm{Nb}$ wire was too brittle after the 5 hour heating period. However, both the doped molybdenum wires (the KW-Mo and the Mo-ODS) could be wrapped on mandrels of 0.020”, 0.050”, 0.100”, and 0.200” for several turns without breaking for all the $1800{ }^{\circ} \mathrm{C}$ heating durations evaluated. 

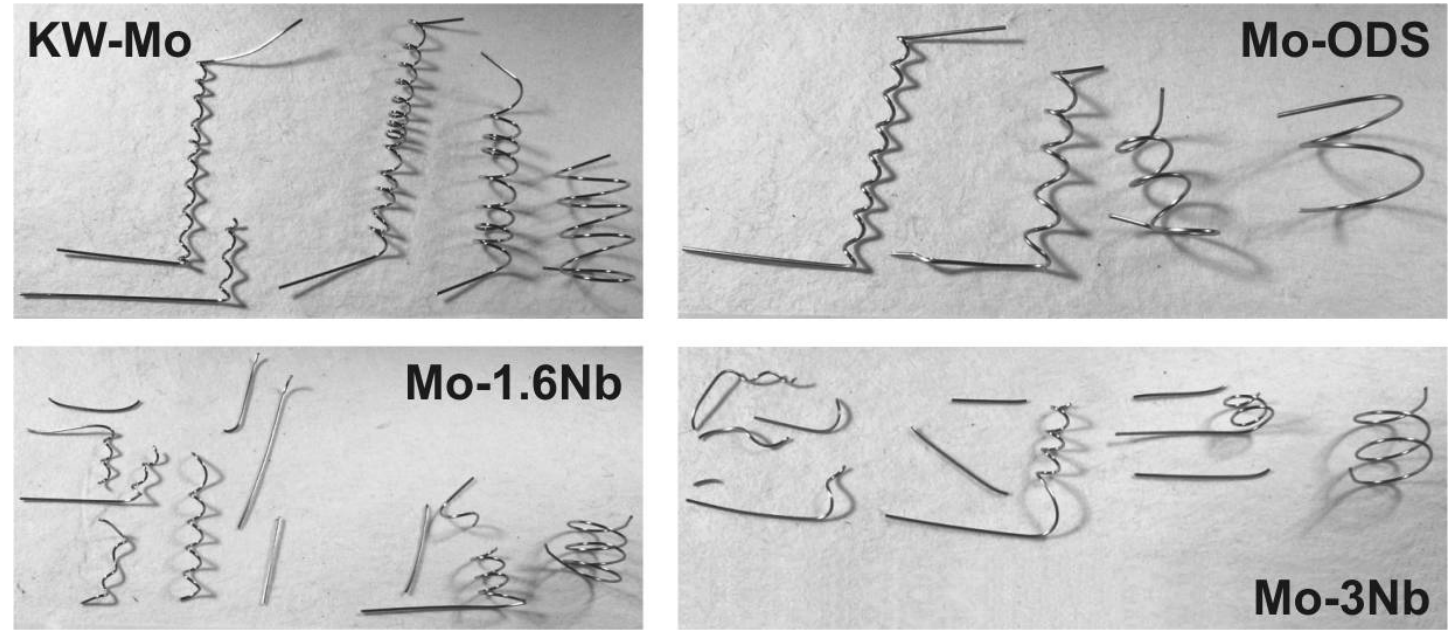

*Furnace heater failure may have shortened heating time.

06-GA50001-23-9

Figure 3-13. Candidate molybdenum-based wire after heating for 2 hours at $1800{ }^{\circ} \mathrm{C}$.
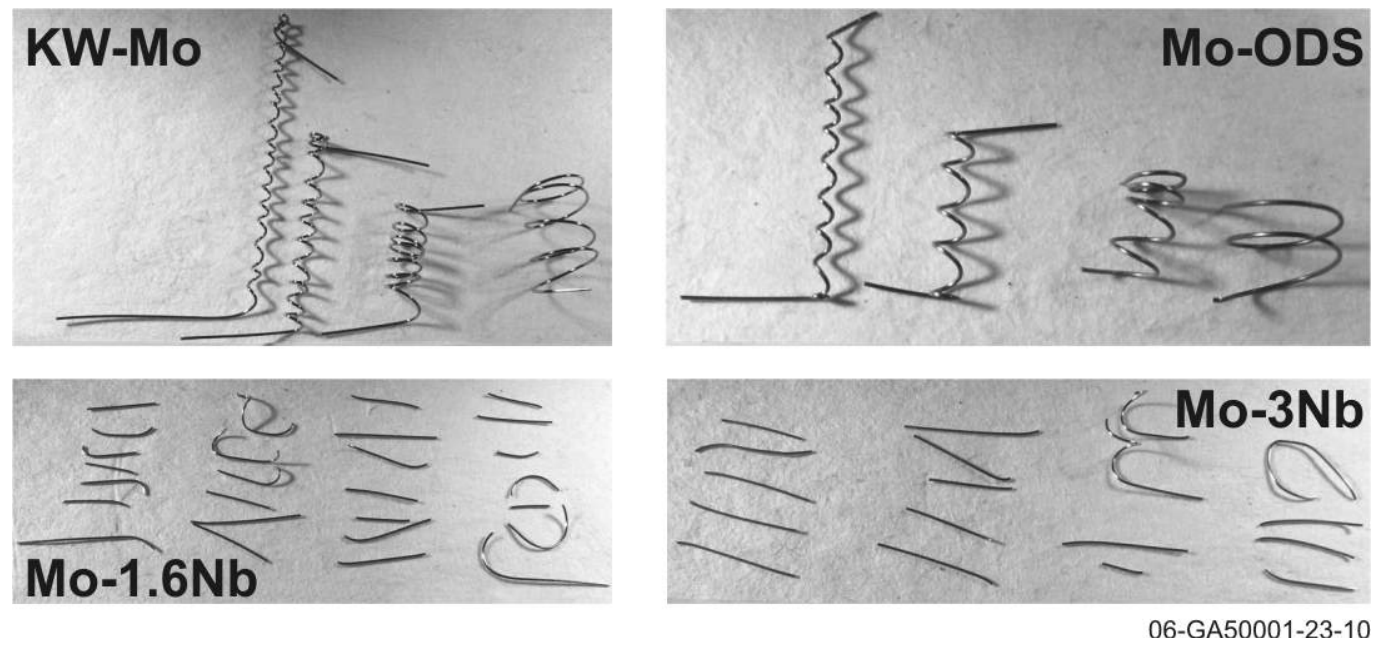

Figure 3-14. Candidate molybdenum-based wire after heating for 5 hours at $1800^{\circ} \mathrm{C}$. 

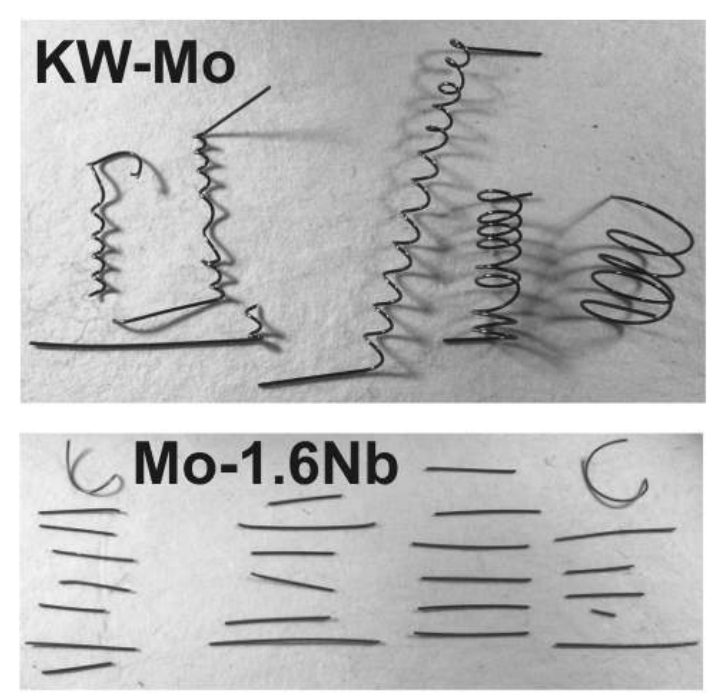

*Furnace heater failure may have shortened heating time.
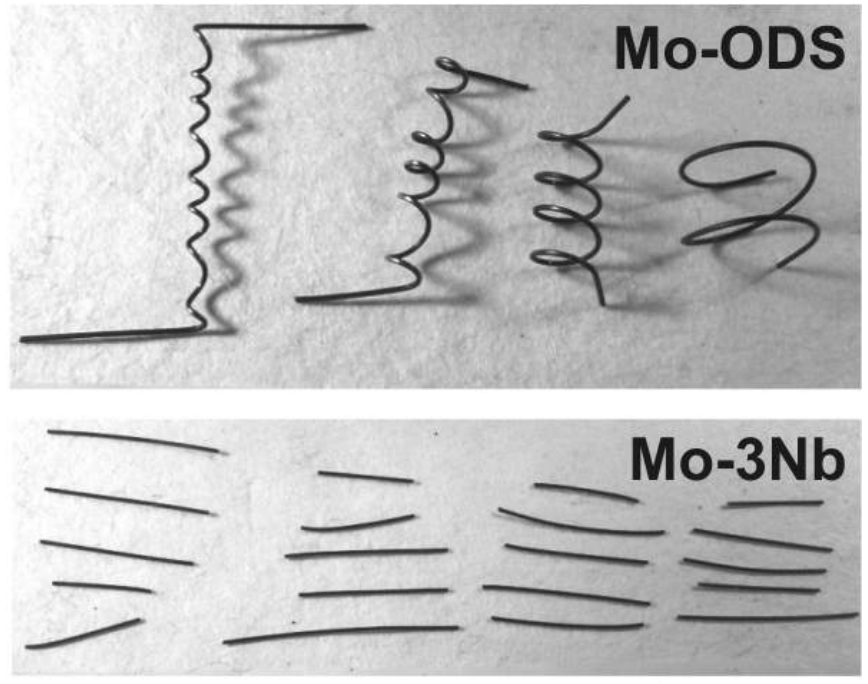

06-GA50001-23-11

Figure 3-15. Candidate molybdenum-based wire after heating for 12 hours* at $1800{ }^{\circ} \mathrm{C}$.

It is interesting to note that the tantalum carrier experienced significant grain growth after the 5 hour $1800{ }^{\circ} \mathrm{C}$ heating test. Despite the crystallization shown in Figure 3-16, the wires could be removed and subjected to mandrel wrap tests in both the 5 and 12 hour tests.

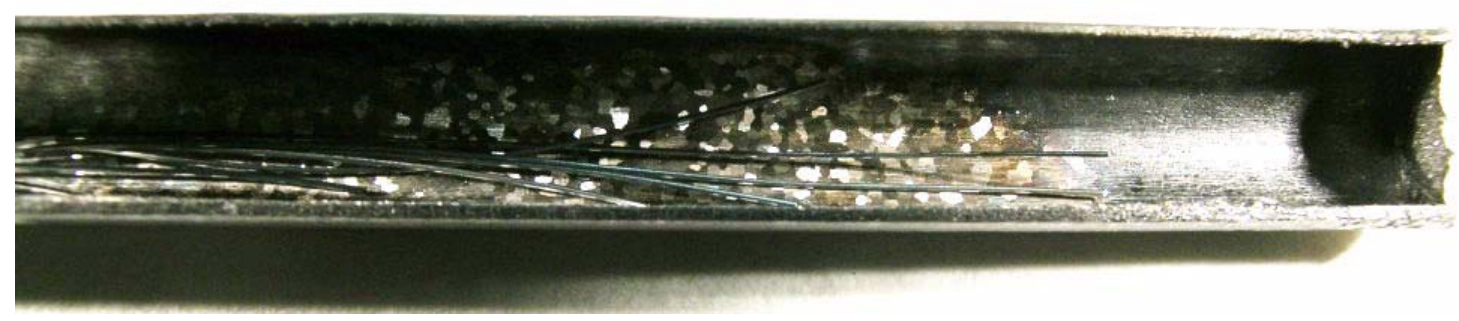

Figure 3-16. Tantalum carrier after heating at $1800{ }^{\circ} \mathrm{C}$ for 5 hours.

\subsection{Summary}

The ductility of candidate thermoelement materials was tested by wrapping samples of wire around mandrels of two, five, ten, and twenty times the wire diameter after heating. Samples were heated at $1400{ }^{\circ} \mathrm{C}, 1600{ }^{\circ} \mathrm{C}$, and $1800{ }^{\circ} \mathrm{C}$ for two, five, and twelve hours. Results for positive thermoelement candidate samples (ODS-Mo, KW-Mo, Mo-1.6\%Nb, and Mo-3\%Nb) indicate that the doped Molybdenum wires (ODS-Mo and KW-Mo) do not become brittle after heating at any of the test temperatures or times. The non-commercial alloys (Mo-1.6\%Nb and $\mathrm{Mo}-3 \% \mathrm{Nb}$ ) do become brittle after heating $1800{ }^{\circ} \mathrm{C}$ for 5 and 2 hours respectively. The negative thermoelement candidates (Nb-1\%Zr, Nb-4\%Mo, Nb-6\%Mo, and Nb-8\%Mo) were shown to become brittle at lower heating temperatures and after shorter heating times than any of the positive wire samples. The Nb-1\%Zr wire became brittle after 12 hours at $1400^{\circ} \mathrm{C}$ and 5 hours at $1600{ }^{\circ} \mathrm{C}$. The 
developmental alloys became brittle after 5 hours at $1400{ }^{\circ} \mathrm{C}$. Test results seem to indicate that a combination of either ODS-Mo or KW-Mo with $\mathrm{Nb}-1 \% \mathrm{Zr}$ will produce a thermocouple that is best able to maintain ductility at elevated temperatures. 
INL/EXT-08-14042 


\section{Calibration Curve Development (Task 1.2)}

As noted in Section 2, non-commercial alloys of Mo and Nb were evaluated with respect to ductility, resolution, and performance when subjected to high temperatures and transients. To provide insights about the resolution of these alloys, calibration curves were generated by connecting prototype thermocouples to a data acquisition system (DAS) that includes LabView software installed on a personal computer and incrementally cycling them, twice, to $1600{ }^{\circ} \mathrm{C}$ in a tube furnace purged with gettered argon. The temperature at which calibration data were obtained was measured using a NIST-traceable Type S thermocouple. Test thermocouples were fabricated from 0.01 " (0.254 mm) diameter wire for each of the alloys listed in Table 1-1. Each positive thermoelement/negative thermoelement combination was used to create one "as received bare wire” (ARBW) thermocouple for all of the alloys available. Due to material limitations, additional tests were performed on selected alloys. Specifically, when materials were available, one "as received swaged" (ARS) thermocouple and one "swaged then heat treated" (SHT) thermocouple, which had been exposed to a heat treatment of 20 hours at $1700{ }^{\circ} \mathrm{C}$ after swaging, were fabricated. This section presents results from these resolution evaluations.

\subsection{As Received Bare Wire (ARBW)}

Figures 4-1 through 4-3 show the output voltage generated by the "as received bare wire" ODS-Mo/Nb-1\%Zr test thermocouple plotted against the applied temperature for the first heating cycle up to $1600{ }^{\circ} \mathrm{C}$. Figure 4-1 is the calibration curve for the heating cycle, with the calibration equation displayed. Figure 4-2 compares the calibration curve obtained during the initial heating cycle with data obtained as the thermocouple was cooled down to $1000^{\circ} \mathrm{C}$. The emf produced by the thermocouple during the cooling cycle is slightly less than that shown for the initial heating cycle. This is likely due to grain growth that occurs during heating in the first cycle. Figure 4-3 compares the initial heating cycle calibration curve along with data obtained from the first cooling cycle to $1000{ }^{\circ} \mathrm{C}$, and the second heating and cooling cycles, to $1600{ }^{\circ} \mathrm{C}$ and $1000{ }^{\circ} \mathrm{C}$, respectively. The emf produced during the second heating and cooling cycles is stable, when compared to that of the first cooling cycle. 


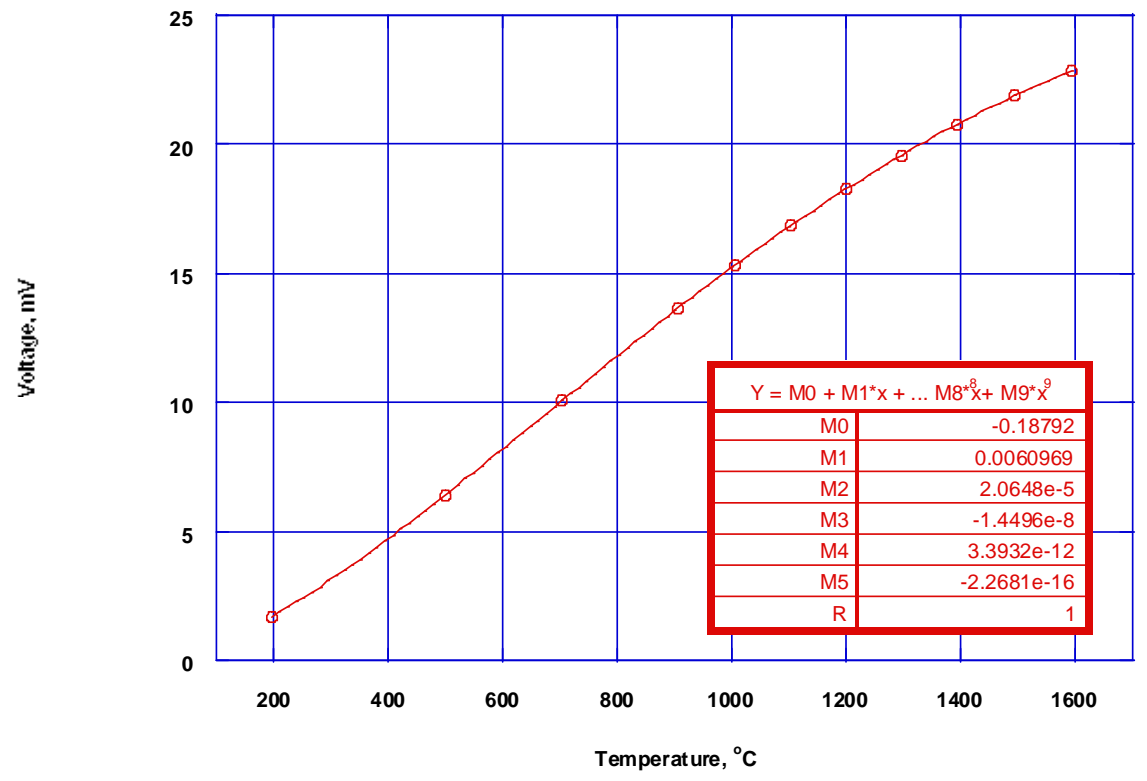

Figure 4-1. Initial emf versus temperature for ARBW ODS-Mo/Nb-1\%Zr thermocouple

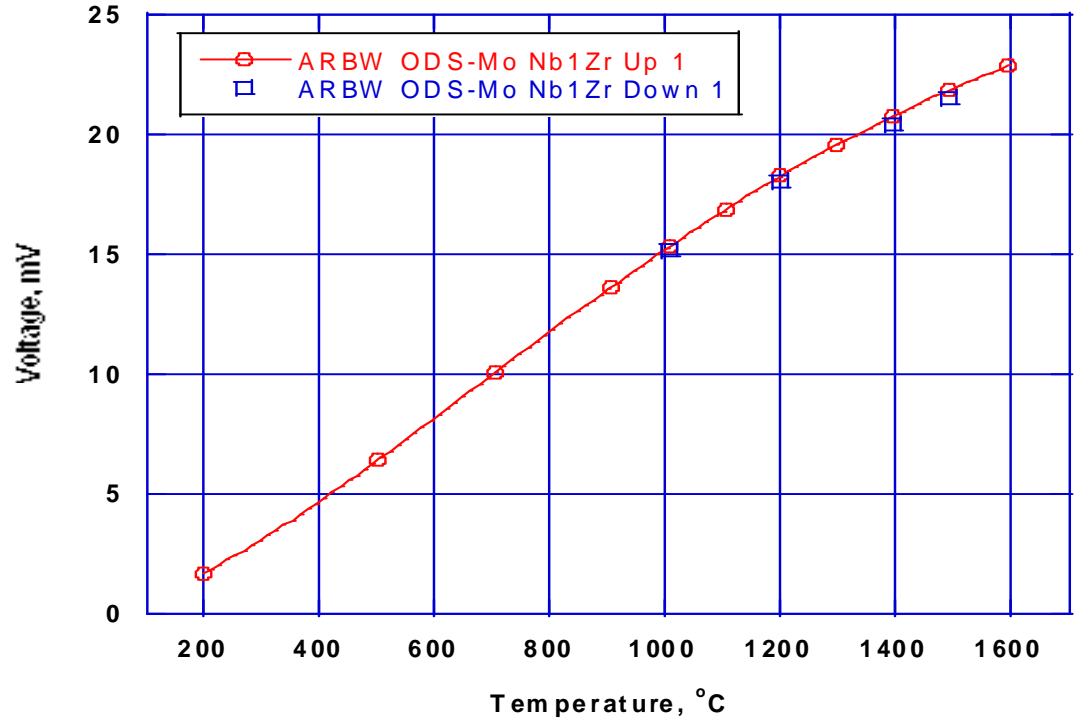

Figure 4-2. Comparison of measured emf during first heating and cooling cycle for ARBW ODS$\mathrm{Mo} / \mathrm{Nb}-1 \% \mathrm{Zr}$ thermocouple. 


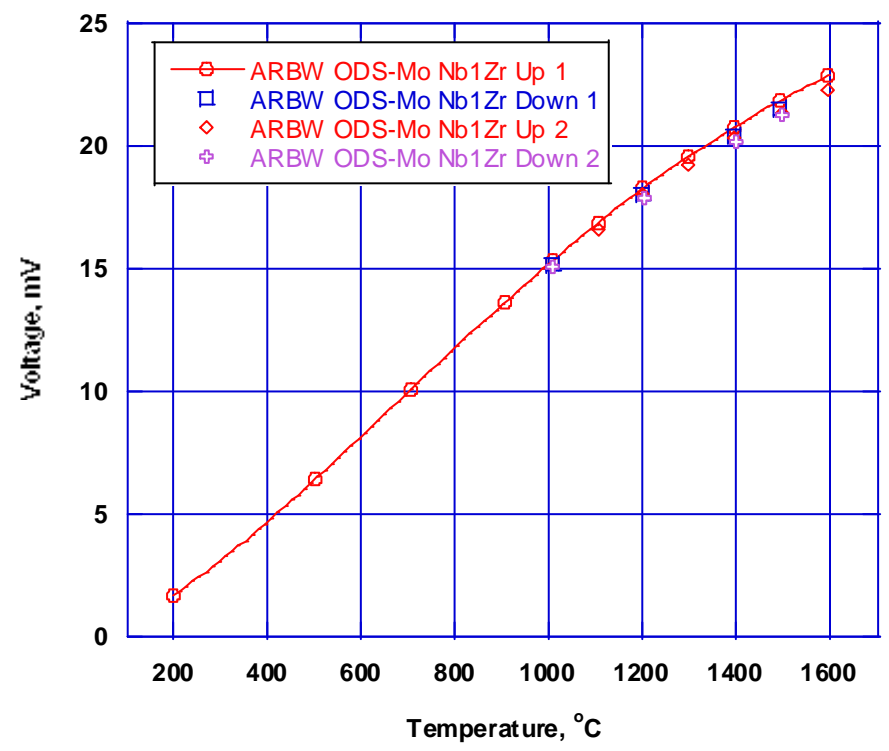

Figure 4-3. Measured emf for two heating and cooling cycles for ARBW ODS-Mo/Nb-1\%Zr thermocouple.

Figures 4-4 through 4-6 show the output voltage generated by the "as received bare wire" $\mathrm{KW}-\mathrm{Mo} / \mathrm{Nb}-1 \% \mathrm{Zr}$ test thermocouple plotted against the applied temperature for the first heating cycle up to $1600{ }^{\circ} \mathrm{C}$. Figure 4-4 is the calibration curve for the heating cycle, with the calibration equation displayed. Figure 4-5 compares the initial heating calibration curve with data obtained from the first cooling cycle to $100{ }^{\circ} \mathrm{C}$. As with the ODS-Mo thermocouple, the emf produced by the thermocouple during the cooling cycle is slightly less than that shown for the initial heating cycle. This is also likely due to grain growth that occurred during the first heating cycle. Figure 46 shows the heating cycle calibration curve along with data from the first cooling cycle to $1000{ }^{\circ} \mathrm{C}$, and the second heating and cooling cycles, to $1600{ }^{\circ} \mathrm{C}$ and $1000{ }^{\circ} \mathrm{C}$, respectively. The emf produced during the second heating and cooling cycles is stable, when compared to that of the first cooling cycle. 


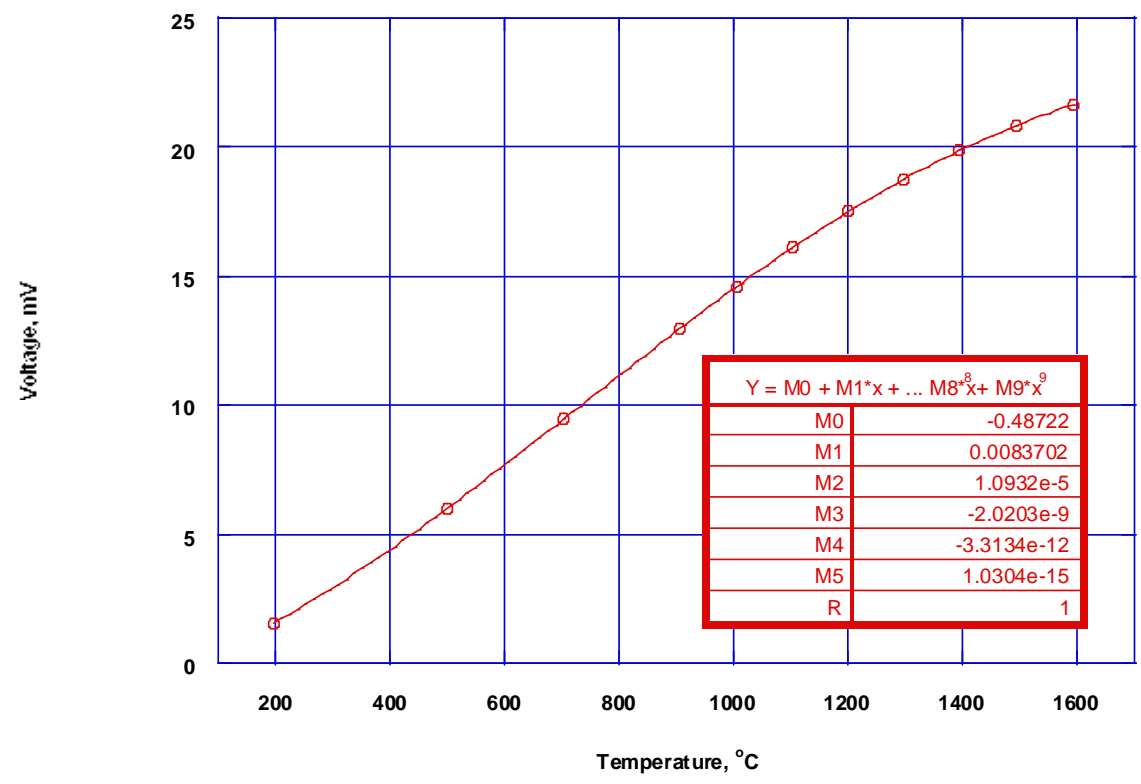

Figure 4-4. Initial emf versus temperature for ARBW KW-Mo/Nb-1\%Zr thermocouple

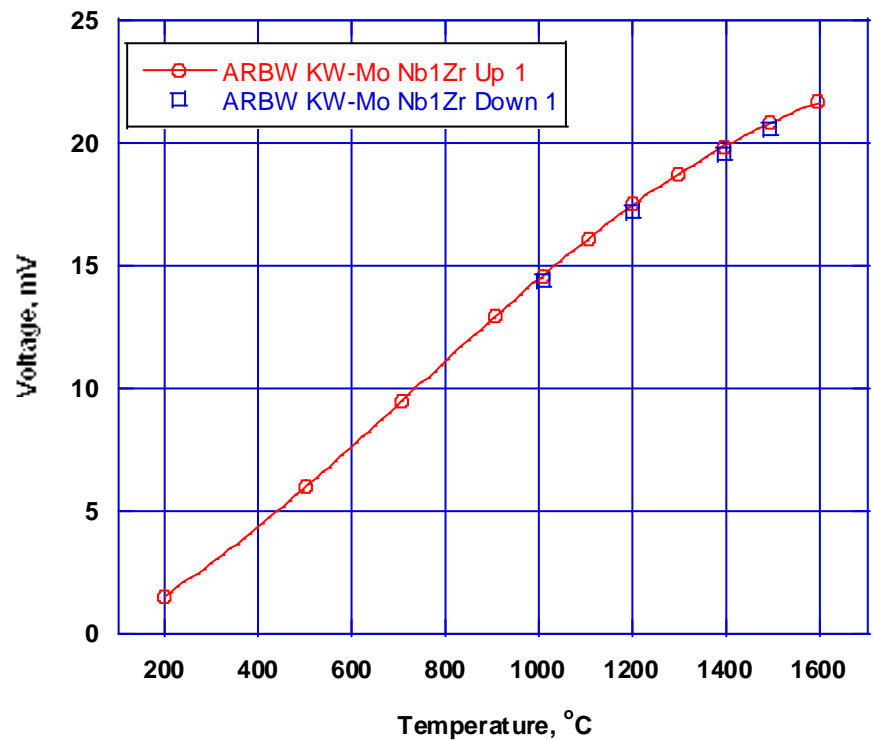

Figure 4-5. Comparison of measured emf during first heating and cooling cycle for ARBW KW$\mathrm{Mo} / \mathrm{Nb} 1 \% \mathrm{Zr}$ thermocouple. 


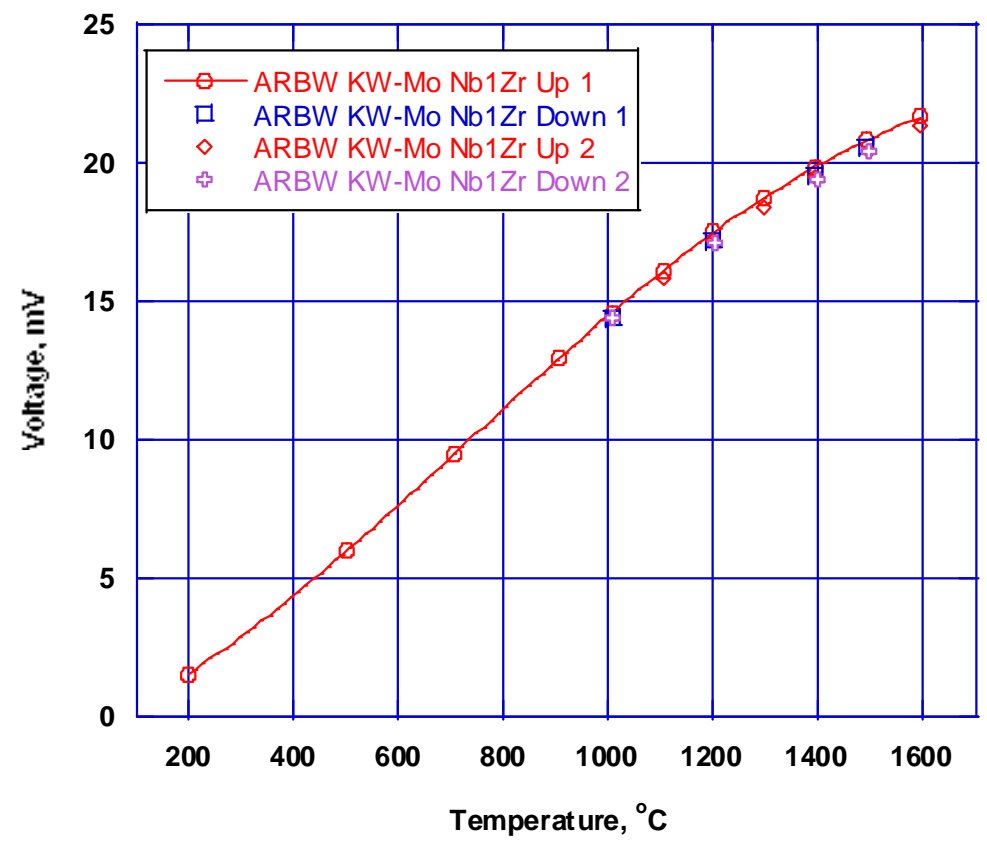

Figure 4-6. Measured emf for two heating and cooling cycles for ARBW KW-Mo/Nb-1\%Zr thermocouple.

Figures 4-7 through 4-9 show the output voltage generated by the "as received bare wire" $\mathrm{Mo}-3 \% \mathrm{Nb} / \mathrm{Nb}-1 \% \mathrm{Zr}$ test thermocouple plotted against the applied temperature for the first heating cycle up to $1600{ }^{\circ} \mathrm{C}$. Figure $4-7$ is the calibration curve for the heating cycle, with the calibration equation displayed. Figure 4-8 shows the heating calibration curve along with data from the first cooling cycle to $1000{ }^{\circ} \mathrm{C}$. As with the previous thermocouples, the emf produced by the thermocouple during the cooling cycle is slightly less than that shown for the initial heating cycle (and is likely due to grain growth that occurred during the first heating cycle). Figure 4-9 shows the heating cycle calibration curve along with data from the first cooling cycle to $1000^{\circ} \mathrm{C}$, and the second heating and cooling cycles, to $1600{ }^{\circ} \mathrm{C}$ and $1000{ }^{\circ} \mathrm{C}$, respectively. There is a very slight drop in emf, even after two heating cycles, present during the second cooling cycle. This may indicate that the thermocouple has not completely stabilized. 


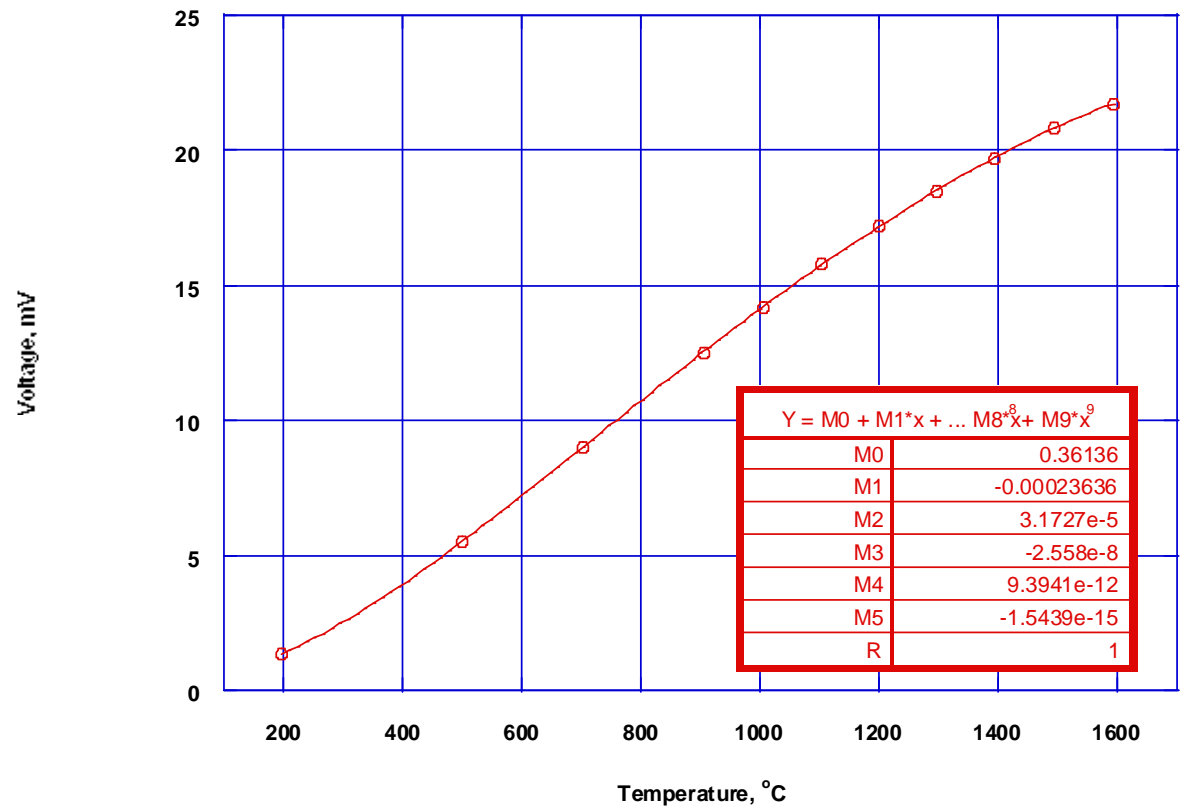

Figure 4-7. Initial emf versus temperature for ARBW Mo-3\%Nb/Nb-1\%Zr thermocouple

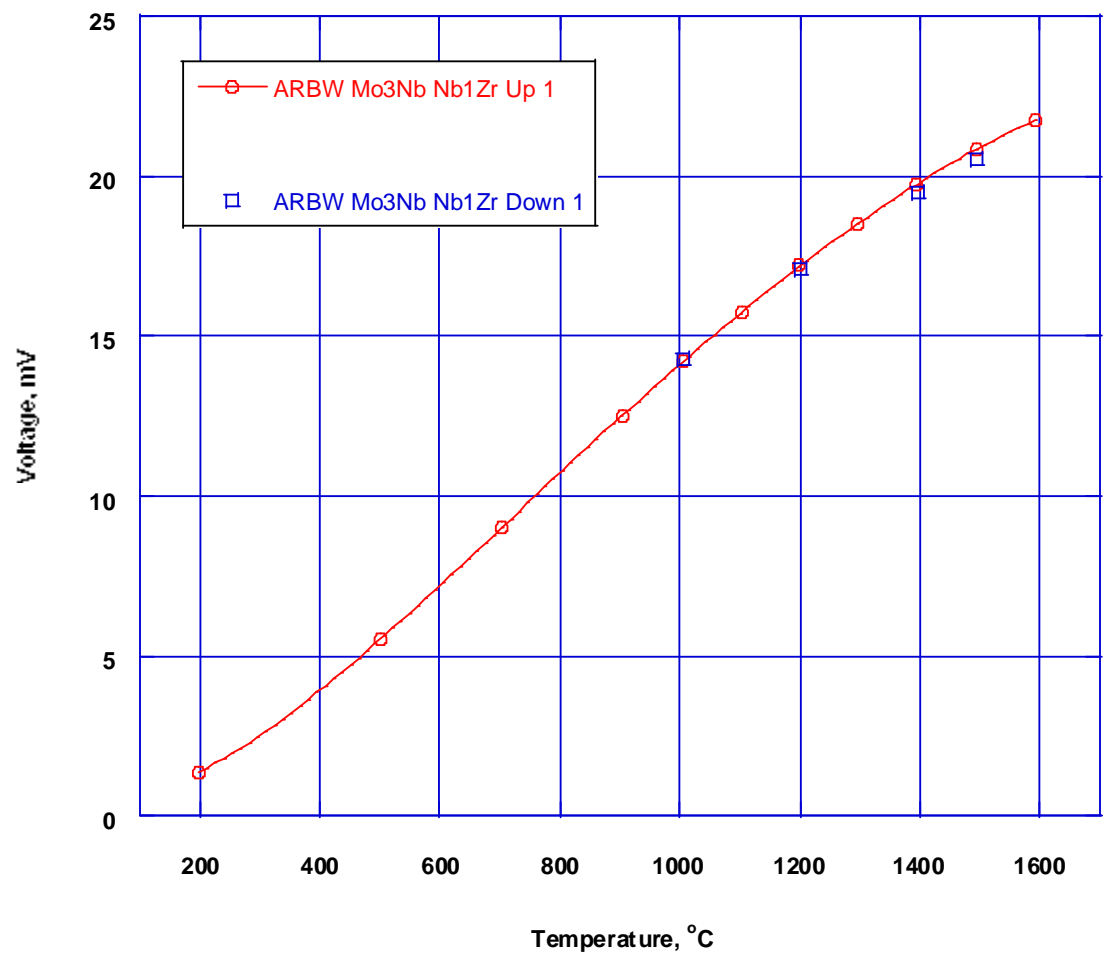

Figure 4-8. Comparison of measured emf during first heating and cooling cycle for ARBW Mo$3 \% \mathrm{Nb} / \mathrm{Nb}-1 \% \mathrm{Zr}$ thermocouple. 


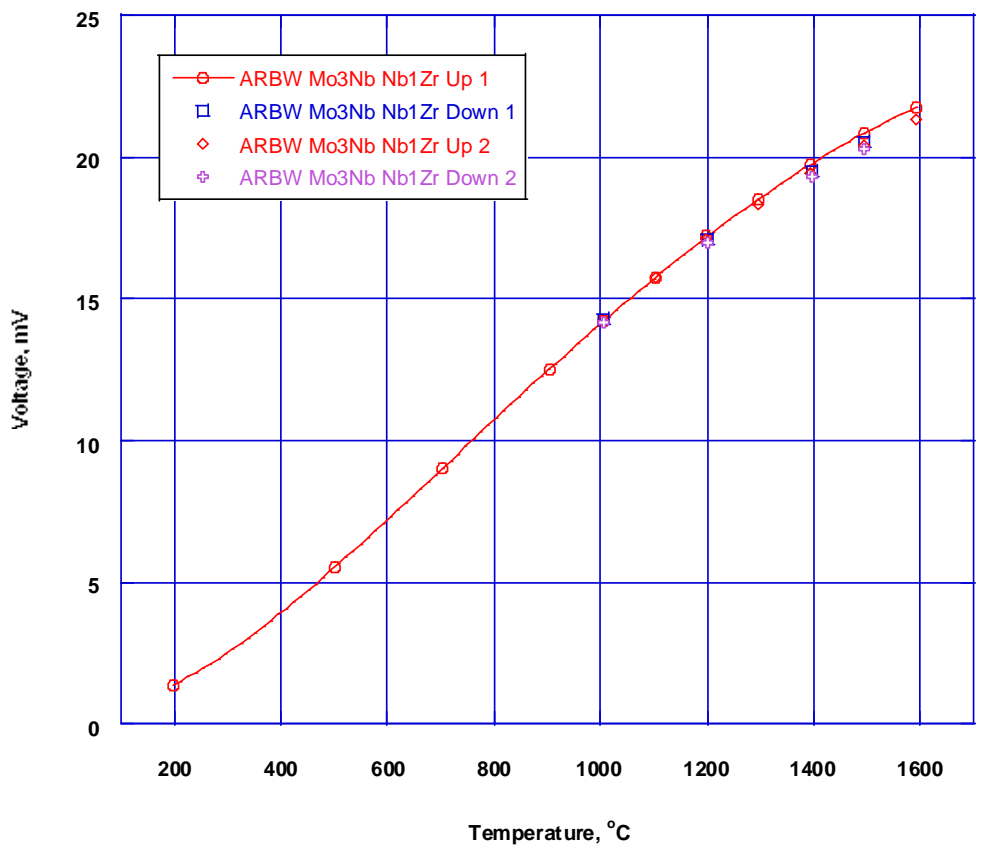

Figure 4-9. Measured emf for two heating and cooling cycles for ARBW Mo-3\%Nb/Nb-1\%Zr thermocouple.

Figures 4-10 through 4-12 show the output voltage generated by the "as received bare wire" Mo- $1.6 \% \mathrm{Nb} / \mathrm{Nb}-1 \% \mathrm{Zr}$ test thermocouple plotted against the applied temperature for heating up to $1600{ }^{\circ} \mathrm{C}$. Figure $4-10$ is the calibration curve for the first heating cycle to $1600{ }^{\circ} \mathrm{C}$, with the calibration equation displayed. Figure 4-11 shows the heating calibration curve along with data from the first cooling cycle to $1000^{\circ} \mathrm{C}$. As with the previous thermocouples, the emf produced by the thermocouple during the cooling cycle is slightly less than that shown for the initial heating cycle (and is probably due to grain growth that occurred during the first heating cycle). Figure 4-12 shows the heating cycle calibration curve along with data from the first cooling cycle to $1000{ }^{\circ} \mathrm{C}$, and the second heating and cooling cycles, to $1600{ }^{\circ} \mathrm{C}$ and $1000{ }^{\circ} \mathrm{C}$, respectively. There is a very slight drop in emf, even after two heating cycles, present during the second cooling cycle. This may indicate that the thermocouple has not completely stabilized. 


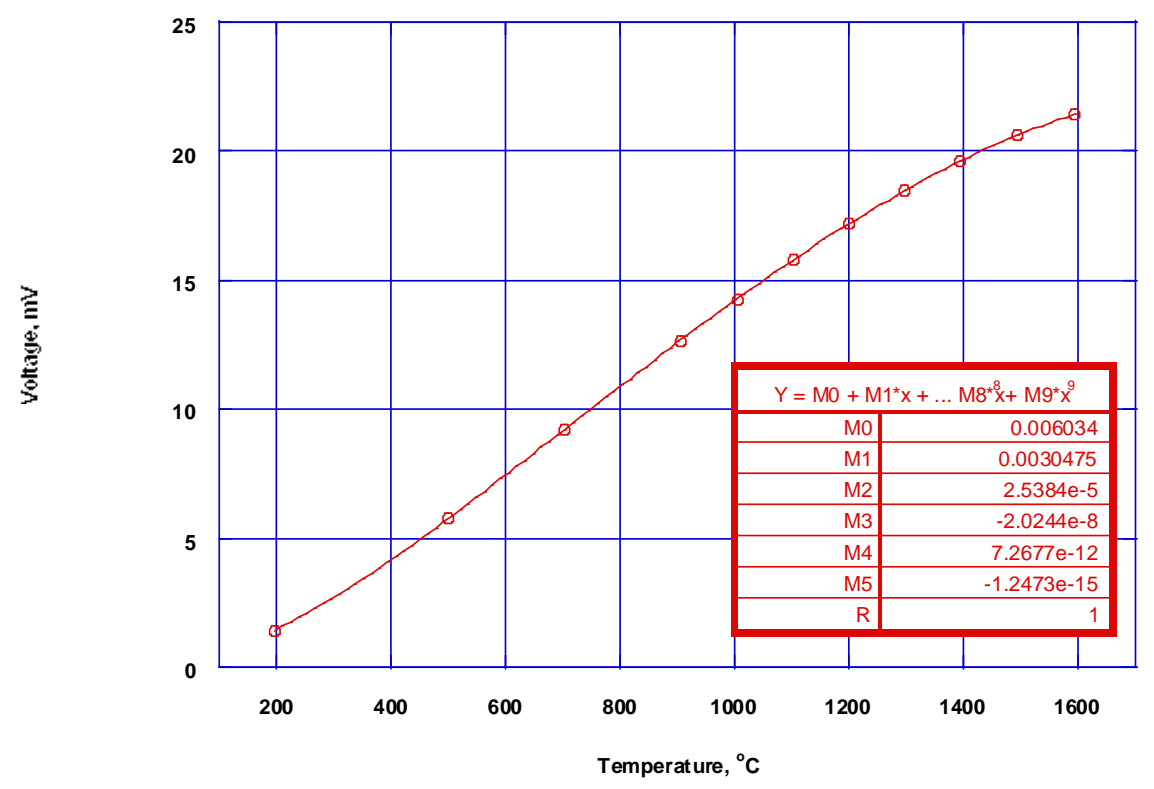

Figure 4-10. Initial emf versus temperature for ARBW Mo- $1.6 \% \mathrm{Nb} / \mathrm{Nb}-1 \% \mathrm{Zr}$ thermocouple

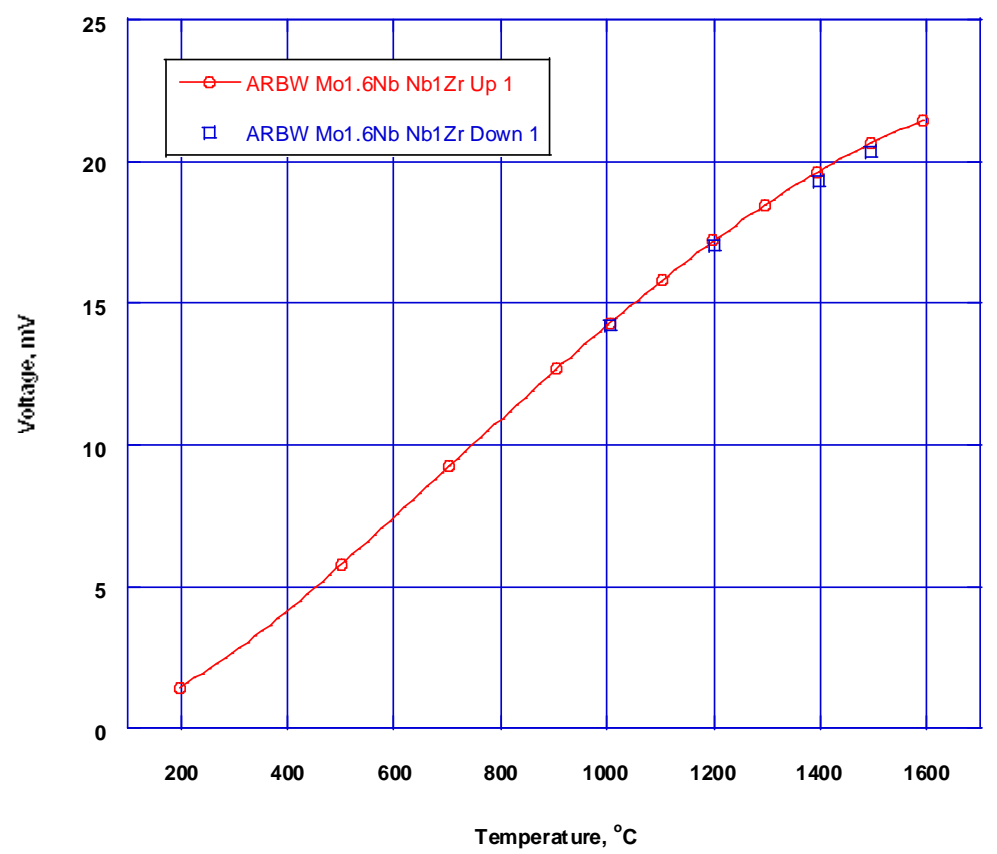

Figure 4-11. Comparison of measured emf during first heating and cooling cycle for ARBW Mo$1.6 \% \mathrm{Nb} / \mathrm{Nb}-1 \% \mathrm{Zr}$ thermocouple. 


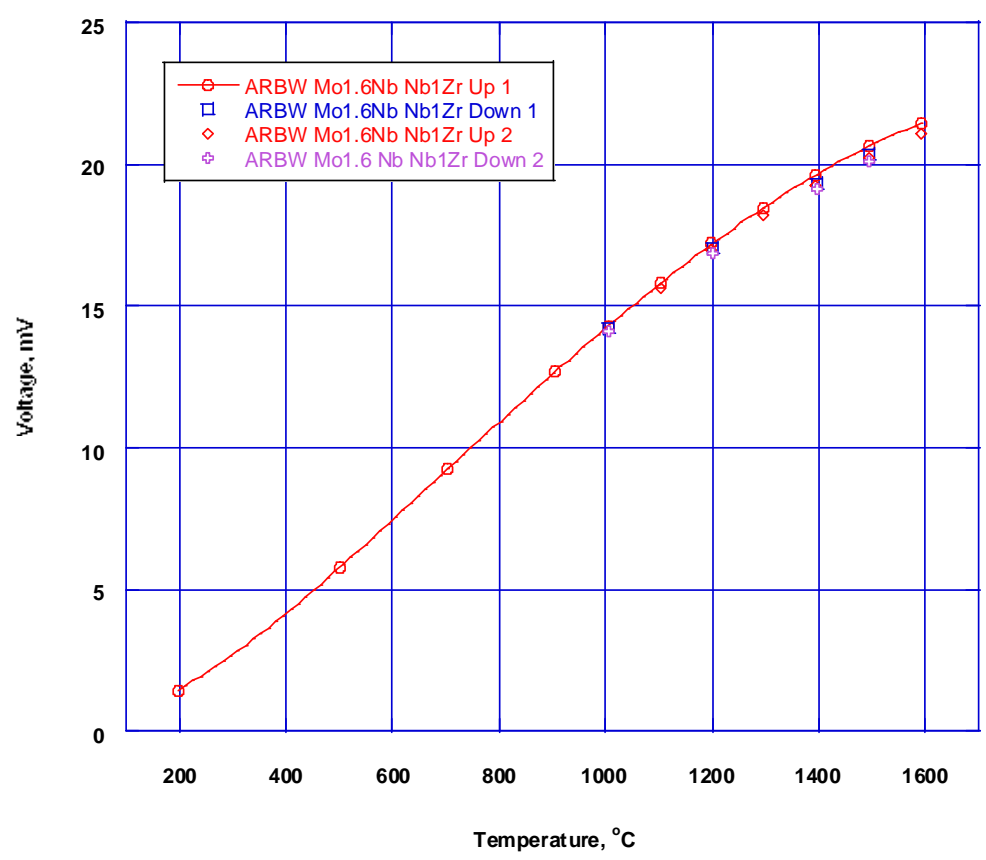

Figure 4-12. Measured emf for two heating and cooling cycles for ARBW Mo-1.6\%Nb/Nb-1\%Zr thermocouple.

Figures 4-13 through 4-15 show the output voltage generated by the "as received bare wire” KW-Mo/Nb-4\%Mo test thermocouple plotted against the applied temperature for calibration to $1600{ }^{\circ} \mathrm{C}$. Figure $4-13$ is the calibration curve for the first heating cycle to $1600{ }^{\circ} \mathrm{C}$, with the calibration equation displayed. Figure 4-14 shows the heating calibration curve along with data from the first cooling cycle to $1000{ }^{\circ} \mathrm{C}$. As with the previous thermocouples, the emf produced by the thermocouple during the cooling cycle is slightly less than that shown for the initial heating cycle. Figure 4-15 shows the heating cycle calibration curve along with data from the first cooling cycle to $1000^{\circ} \mathrm{C}$, and the second heating and cooling cycles, to $1600{ }^{\circ} \mathrm{C}$ and $1000{ }^{\circ} \mathrm{C}$, respectively. There is a very slight drop in emf, even after two heating cycles, present during the second cooling cycle. The emf, after two heating cycles, seems to have stabilized. 


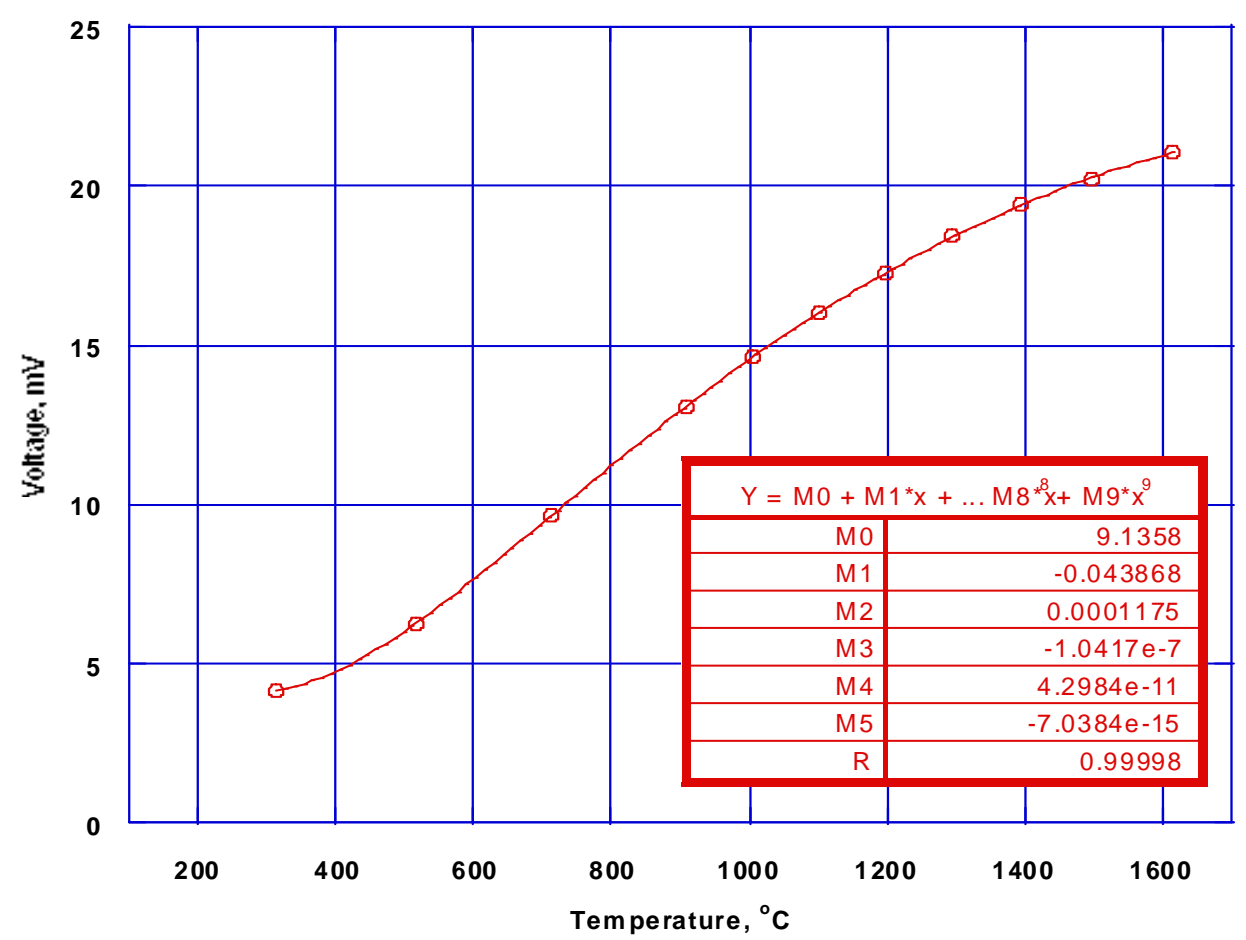

Figure 4-13. Initial emf versus temperature for ARBW KW-Mo/Nb-4\%Mo thermocouple

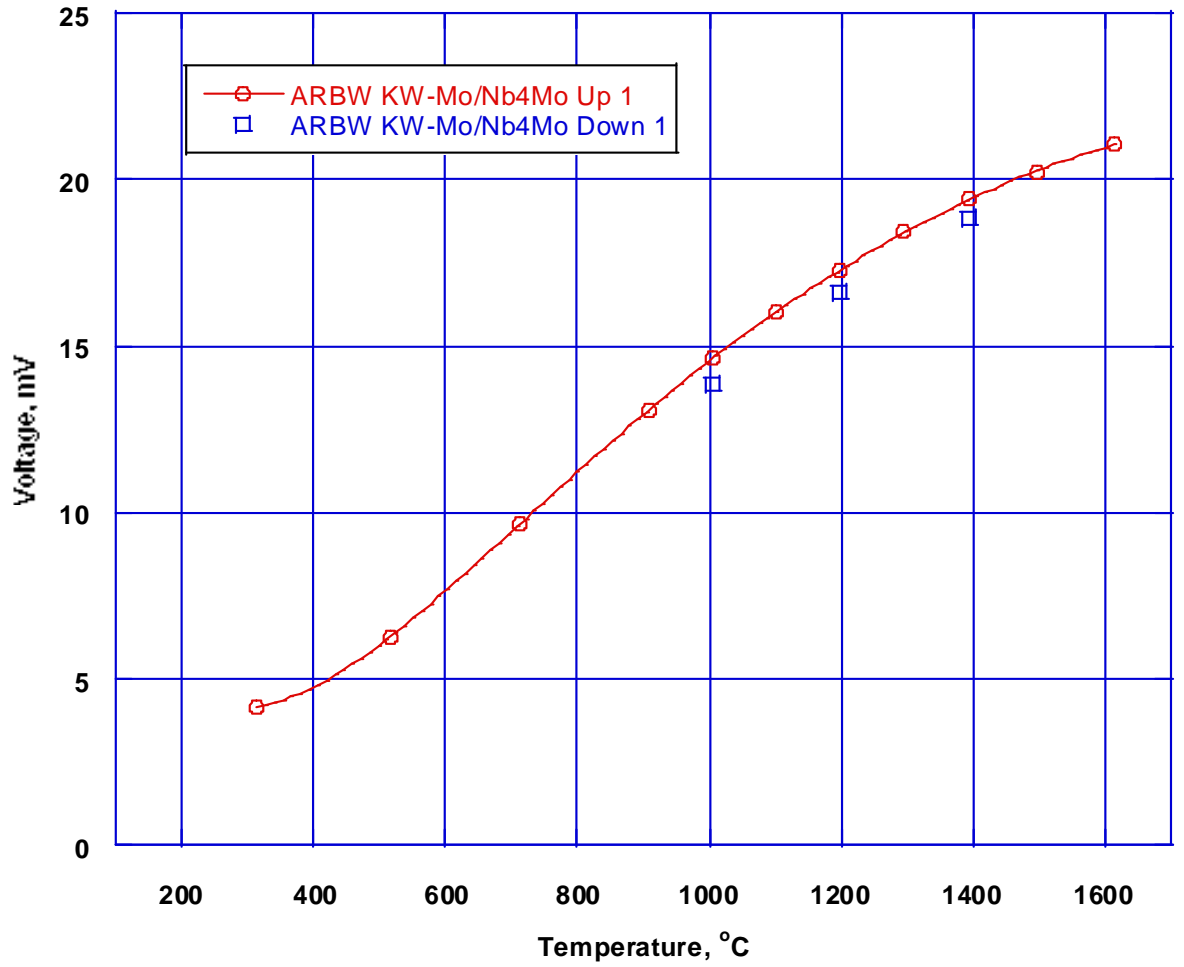

Figure 4-14. Comparison of measured emf during first heating and cooling cycle for ARBW KWMo/Nb4\%Mo thermocouple 


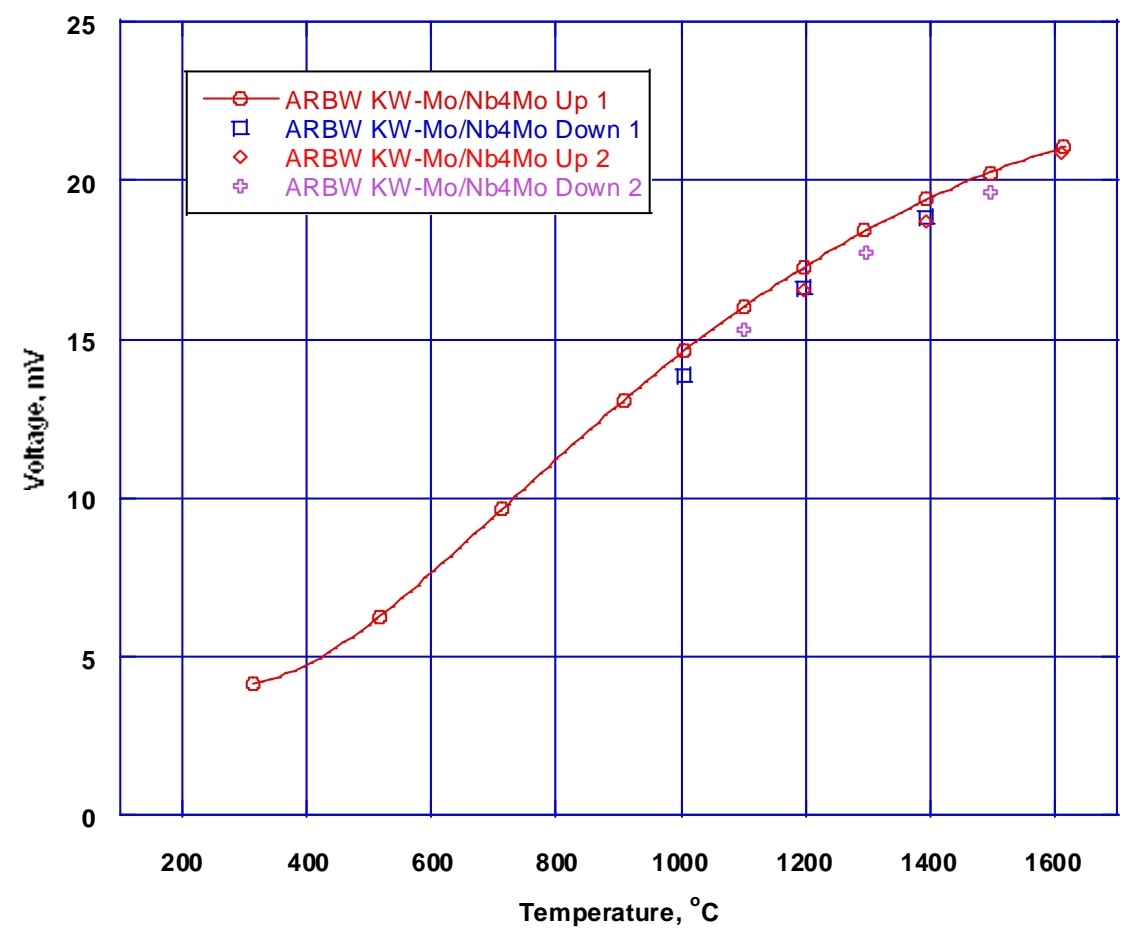

Figure 4-15. Measured emf for two heating and cooling cycles for ARBW KW-Mo/Nb-4\%Mo thermocouple.

Figures 4-16 through 4-18 show the output voltage generated by the "as received bare wire" Mo-3\%Nb/Nb-4\%Mo test thermocouple plotted against the applied temperature for calibration to $1600{ }^{\circ} \mathrm{C}$. Figure $4-16$ is the calibration curve for the first heating cycle to $1600{ }^{\circ} \mathrm{C}$, with the calibration equation displayed. Figure 4-17 shows the heating calibration curve along with data from the first cooling cycle to $1000{ }^{\circ} \mathrm{C}$. As with the previous thermocouples, the emf produced by the thermocouple during the cooling cycle is slightly less than that shown for the initial heating cycle. Figure 4-18 shows the heating cycle calibration curve along with data from the first cooling cycle to $1000{ }^{\circ} \mathrm{C}$, and the second heating and cooling cycles, to $1600{ }^{\circ} \mathrm{C}$ and $100{ }^{\circ} \mathrm{C}$, respectively. The emf, after two heating cycles, seems to have stabilized. 


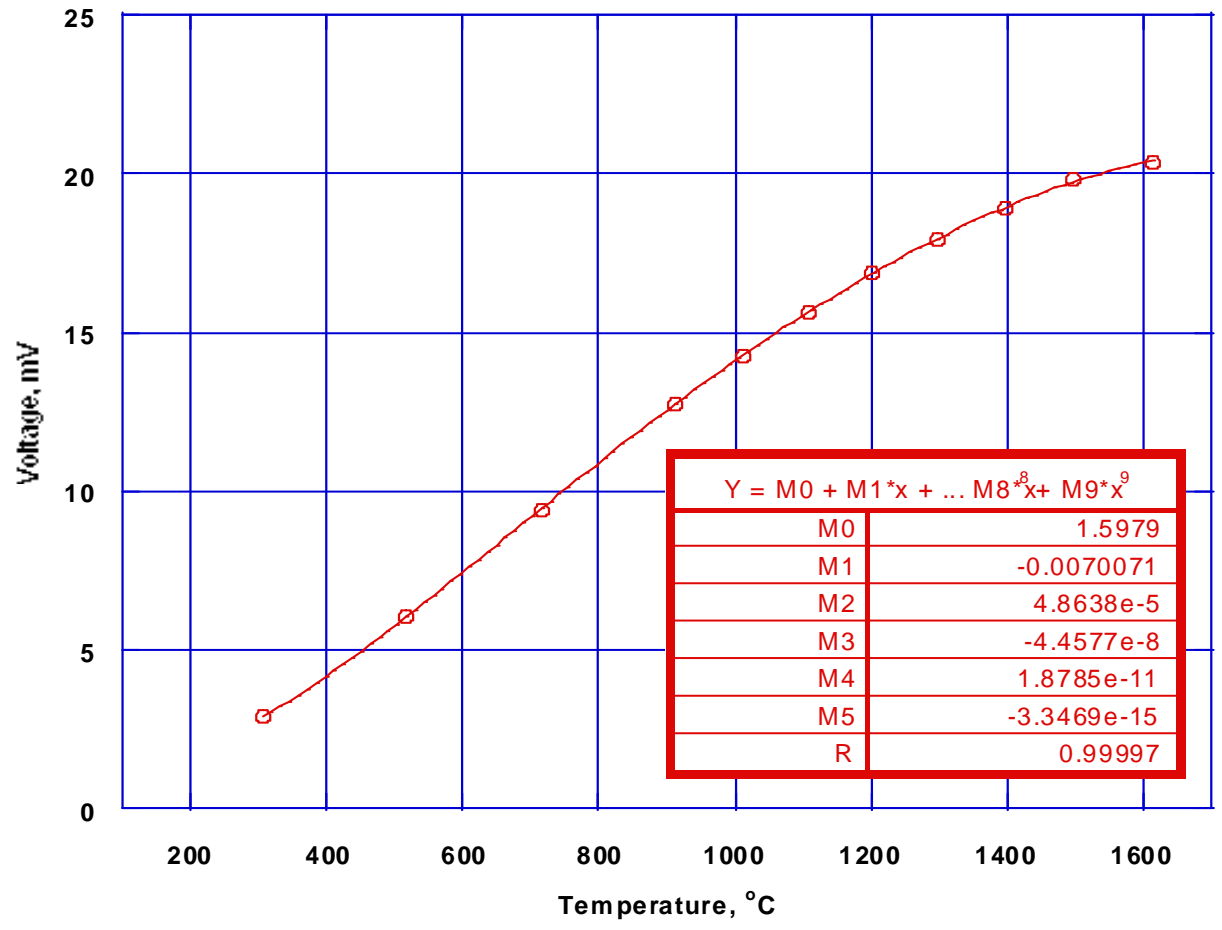

Figure 4-16. Initial emf versus temperature for ARBW Mo-3\%Nb/Nb-4\%Mo thermocouple

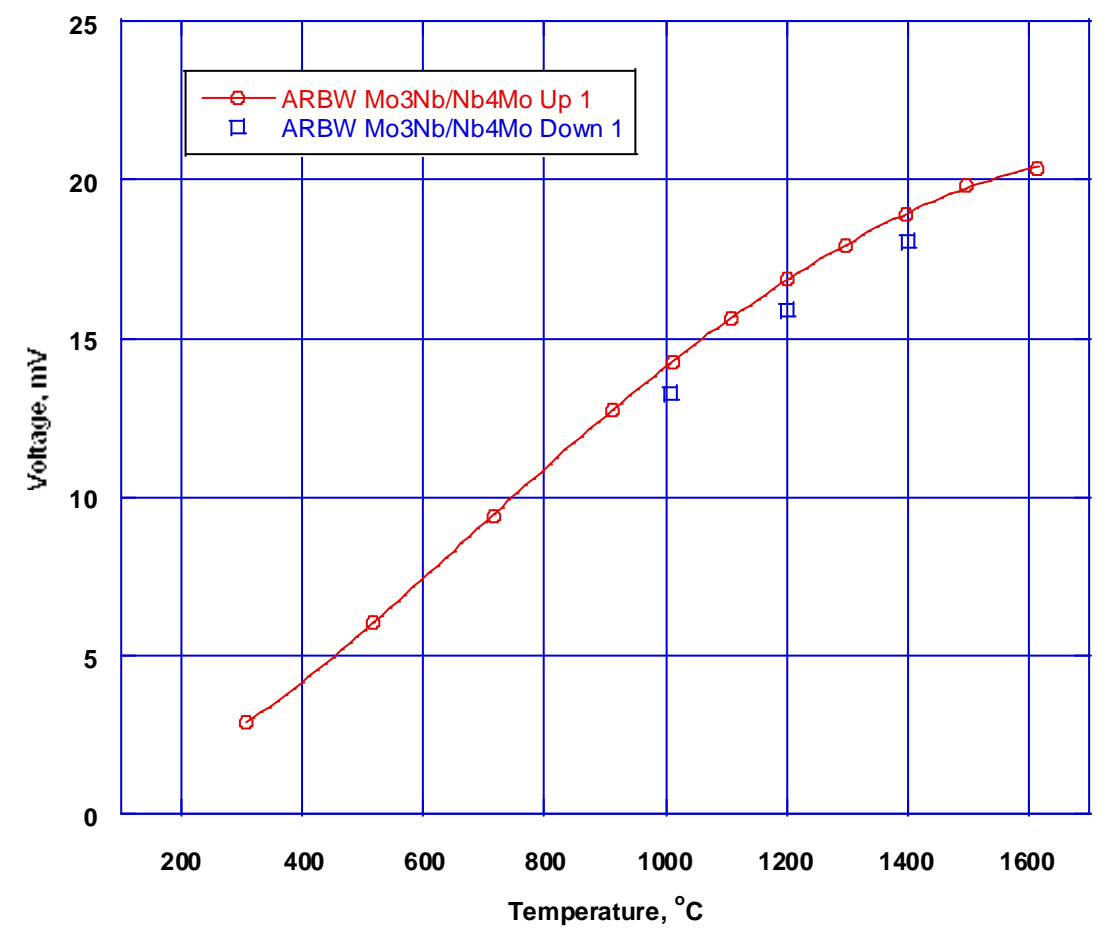

Figure 4-17. Comparison of measured emf during first heating and cooling cycle for ARBW Mo$3 \% \mathrm{Nb} / \mathrm{Nb}-4 \% \mathrm{Mo}$ thermocouple 


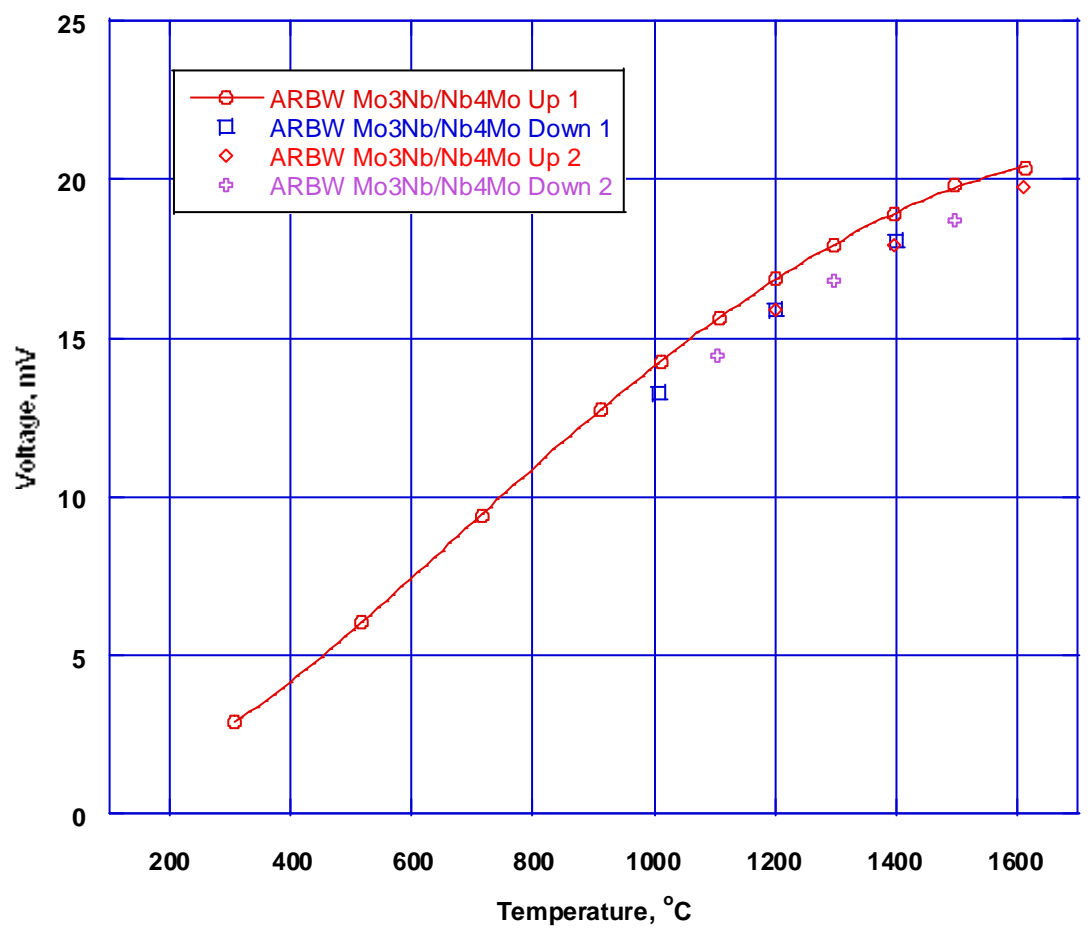

Figure 4-18. Measured emf for two heating and cooling cycles for ARBW Mo-3\%Nb/Nb-4\%Mo thermocouple.

Figures 4-19 through 4-21 show the output voltage generated by the "as received bare wire" Mo-1.6\% Nb/Nb-4\%Mo test thermocouple plotted against the applied temperature for calibration to $1600{ }^{\circ} \mathrm{C}$. Figure 4-19 is the calibration curve for the first heating cycle to $1600{ }^{\circ} \mathrm{C}$, with the calibration equation displayed. Figure 4-20 shows the heating calibration curve along with data from the first cooling cycle to $1000{ }^{\circ} \mathrm{C}$. As with the previous thermocouples, the emf produced by the thermocouple during the cooling cycle is slightly less than that shown for the initial heating cycle. Figure 4-21 shows the heating cycle calibration curve along with data from the first cooling cycle to $1000{ }^{\circ} \mathrm{C}$, and the second heating and cooling cycles, to $1600{ }^{\circ} \mathrm{C}$ and $1000^{\circ} \mathrm{C}$, respectively. The emf, after two heating cycles, seems to have stabilized. 


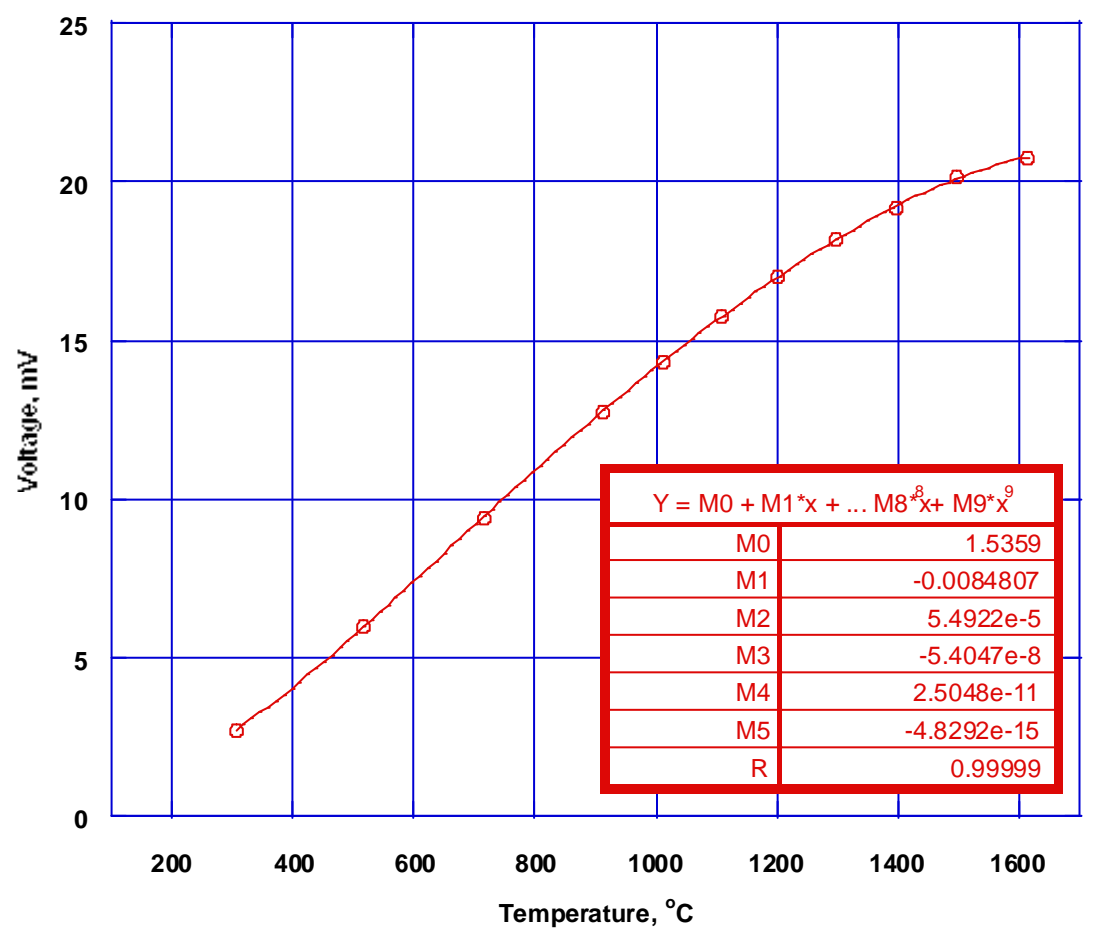

Figure 4-19. Initial emf versus temperature for ARBW Mo-1.6\%Nb/Nb-4\%Mo thermocouple

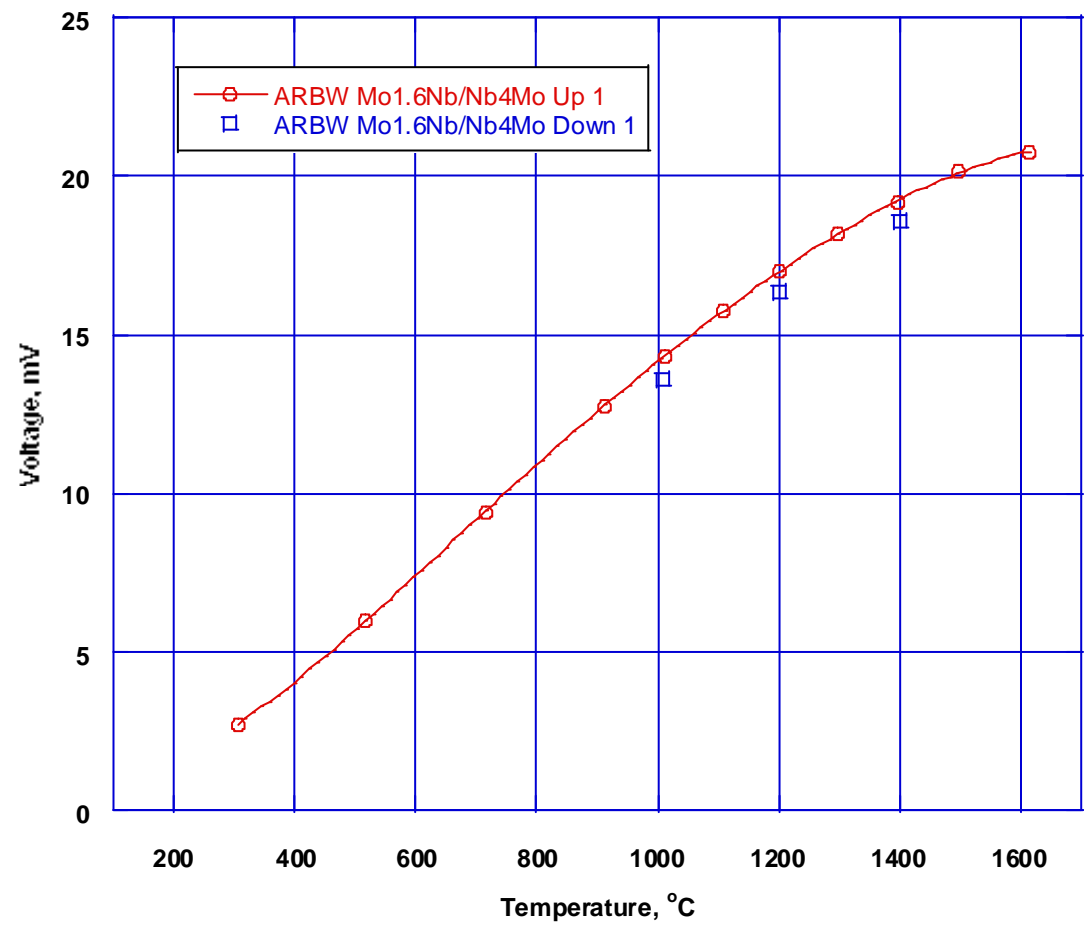

Figure 4-20. Comparison of measured emf during first heating and cooling cycle for ARBW Mo$1.6 \% \mathrm{Nb} / \mathrm{Nb}-4 \% \mathrm{Mo}$ thermocouple 


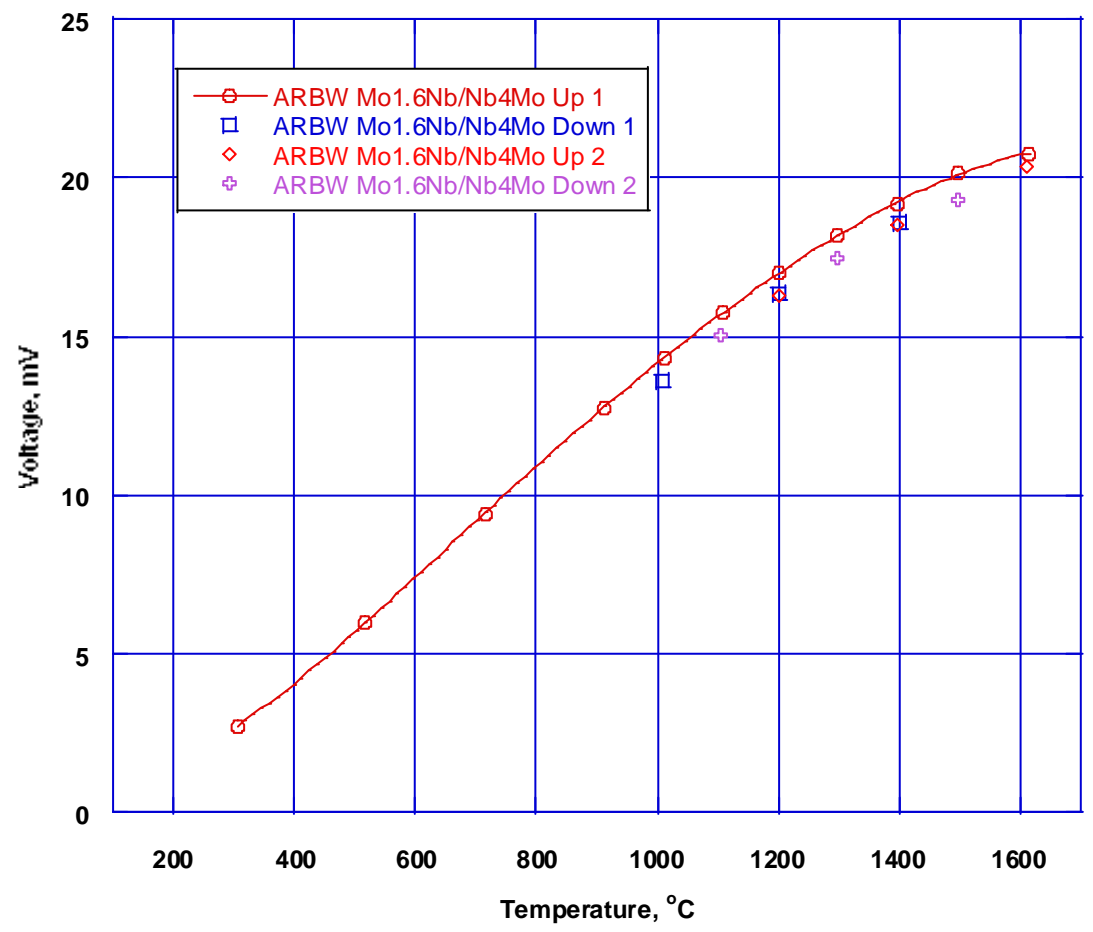

Figure 4-21. Measured emf for two heating and cooling cycles for ARBW Mo1.6\%Nb/Nb4\%Mo thermocouple.

Figures 4-22 through 4-24 show the output voltage generated by the "as received bare wire” KW-Mo/Nb-6\%Mo test thermocouple plotted against the applied temperature for calibration to $1600{ }^{\circ} \mathrm{C}$. Figure $4-22$ is the calibration curve for the first heating cycle to $1600{ }^{\circ} \mathrm{C}$, with the calibration equation displayed. Figure 4-23 shows the heating calibration curve along with data from the first cooling cycle to $1000{ }^{\circ} \mathrm{C}$. As with the previous thermocouples, the emf produced by the thermocouple during the cooling cycle is slightly less than that shown for the initial heating cycle. Figure 4-24 shows the heating cycle calibration curve along with data from the first cooling cycle to $1000{ }^{\circ} \mathrm{C}$, and the second heating and cooling cycles, to $1600{ }^{\circ} \mathrm{C}$ and $1000^{\circ} \mathrm{C}$, respectively. The emf, after two heating cycles, seems to have stabilized. 


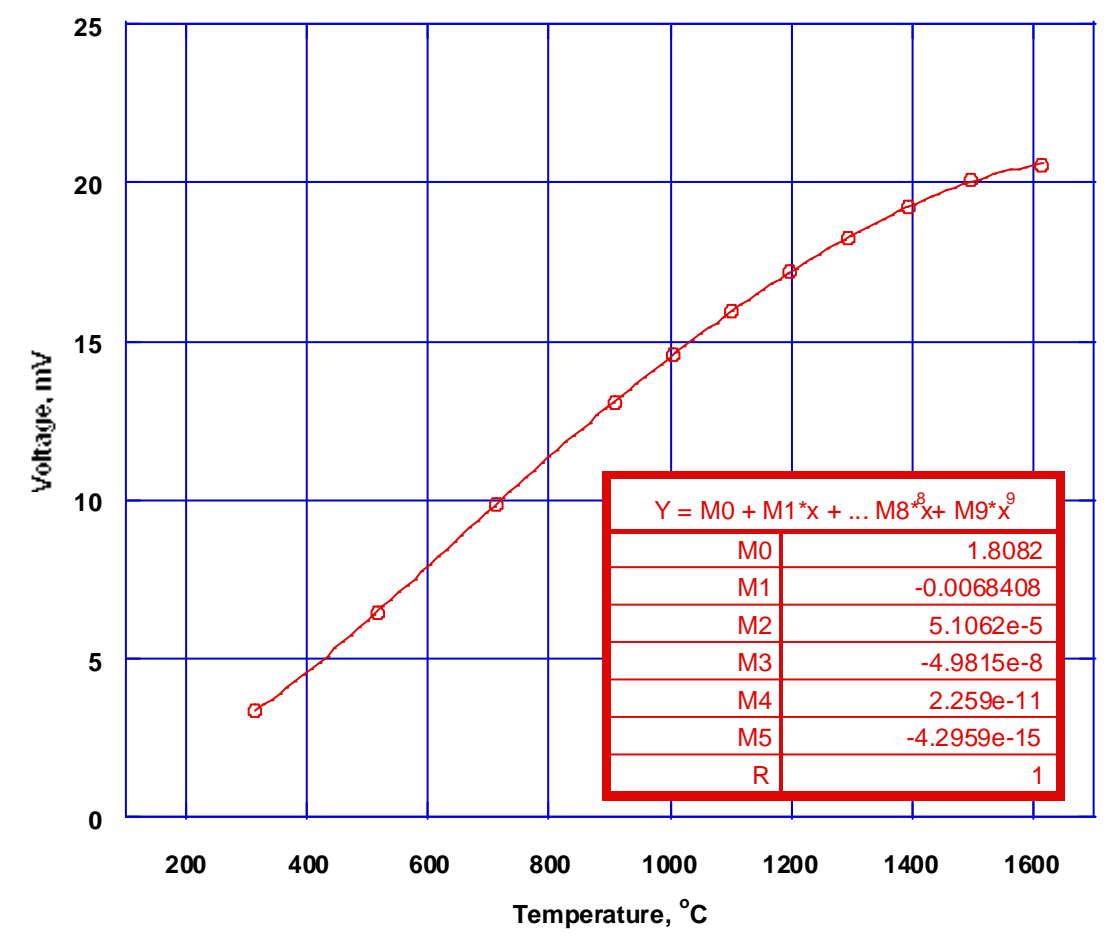

Figure 4-22. Initial emf versus temperature for ARBW KW-Mo/Nb6\%Mo thermocouple

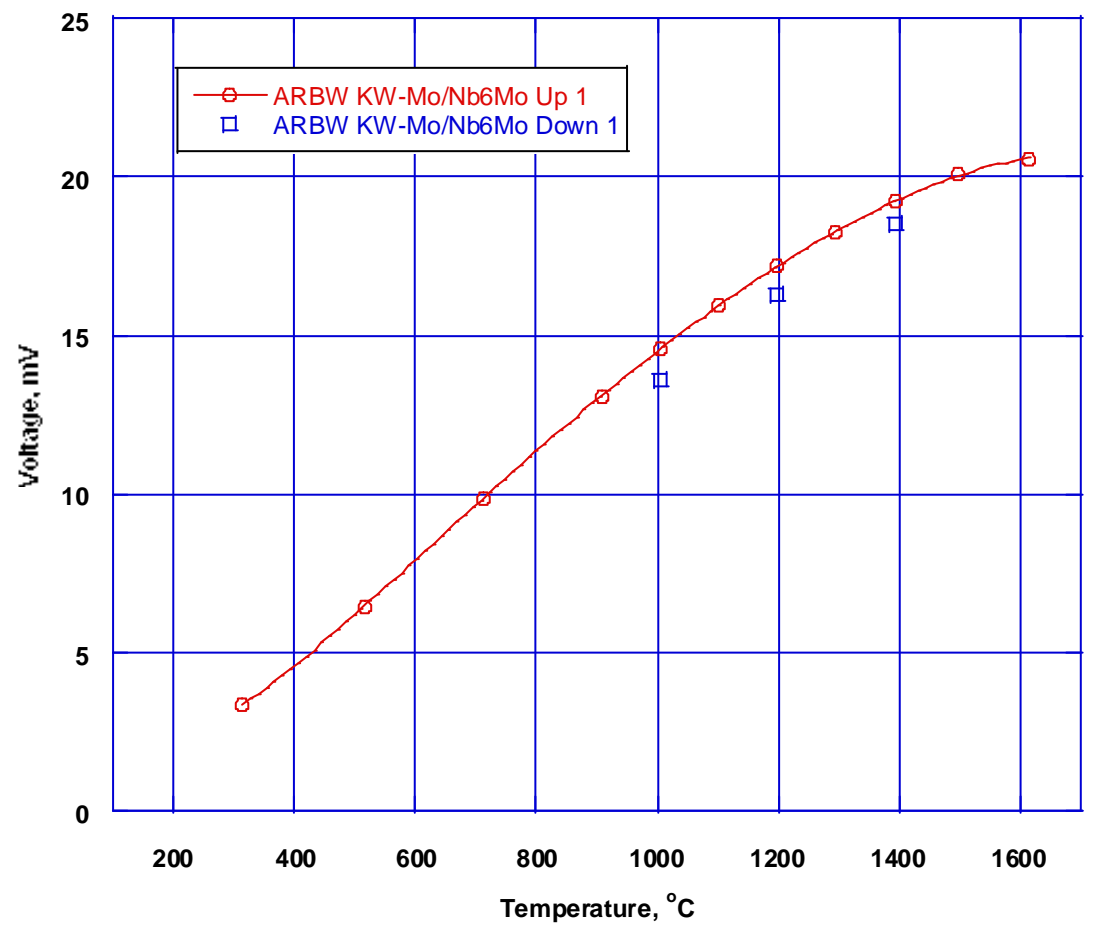

Figure 4-23. Comparison of measured emf during first heating and cooling cycle for ARBW KWMo/Nb-6\%Mo thermocouple 


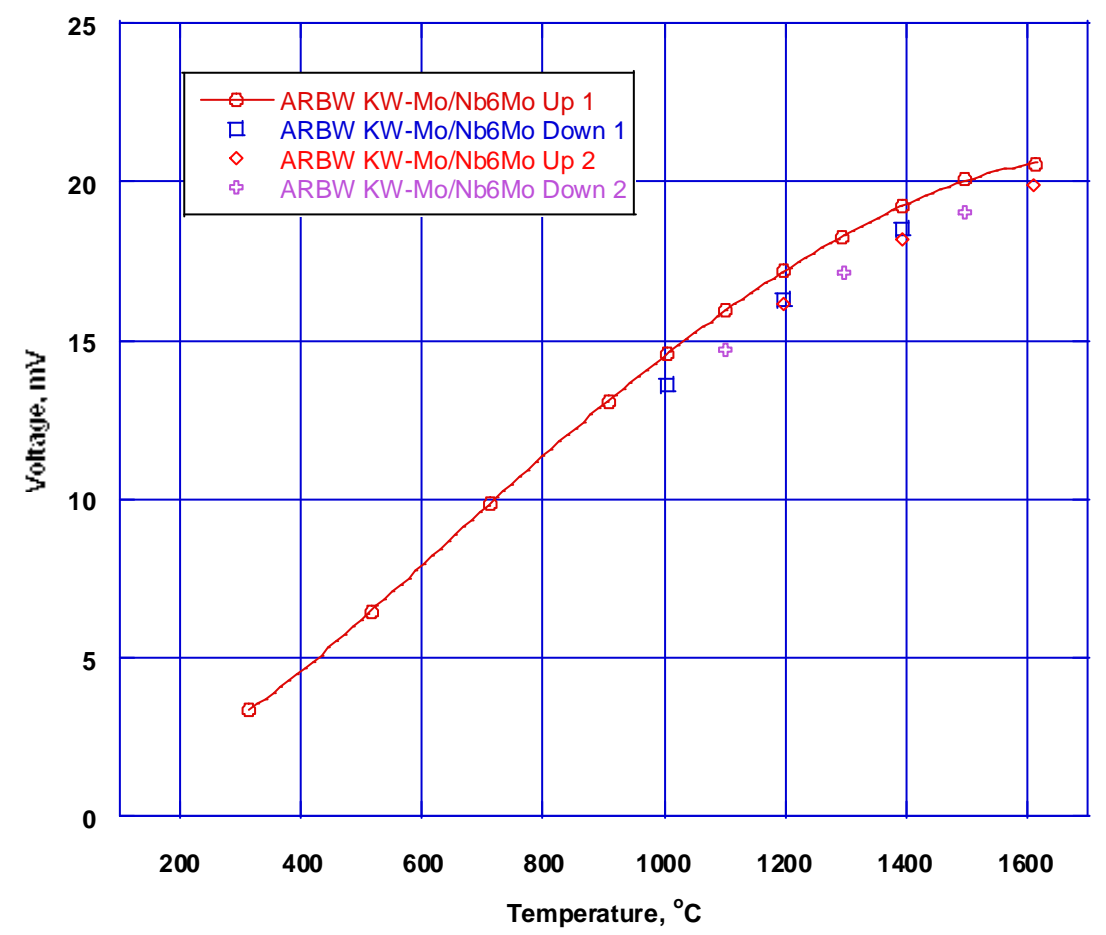

Figure 4-24. Measured emf for two heating and cooling cycles for ARBW KW-Mo/Nb-6\%Mo thermocouple.

Figures 4-25 through 4-27 show the output voltage generated by the "as received bare wire” Mo-3\%Nb/Nb-6\%Mo test thermocouple plotted against the applied temperature for calibration to $1600{ }^{\circ} \mathrm{C}$. Figure $4-25$ is the calibration curve for the first heating cycle to $1600{ }^{\circ} \mathrm{C}$, with the calibration equation displayed. Figure 4-26 shows the heating calibration curve along with data from the first cooling cycle to $1000{ }^{\circ} \mathrm{C}$. As with the previous thermocouples, the emf produced by the thermocouple during the cooling cycle is slightly less than that shown for the initial heating cycle. Figure 4-27 shows the heating cycle calibration curve along with data from the first cooling cycle to $1000{ }^{\circ} \mathrm{C}$, and the second heating and cooling cycles, to $1600{ }^{\circ} \mathrm{C}$ and $1000^{\circ} \mathrm{C}$, respectively. The emf, after two heating cycles, seems to have stabilized. 


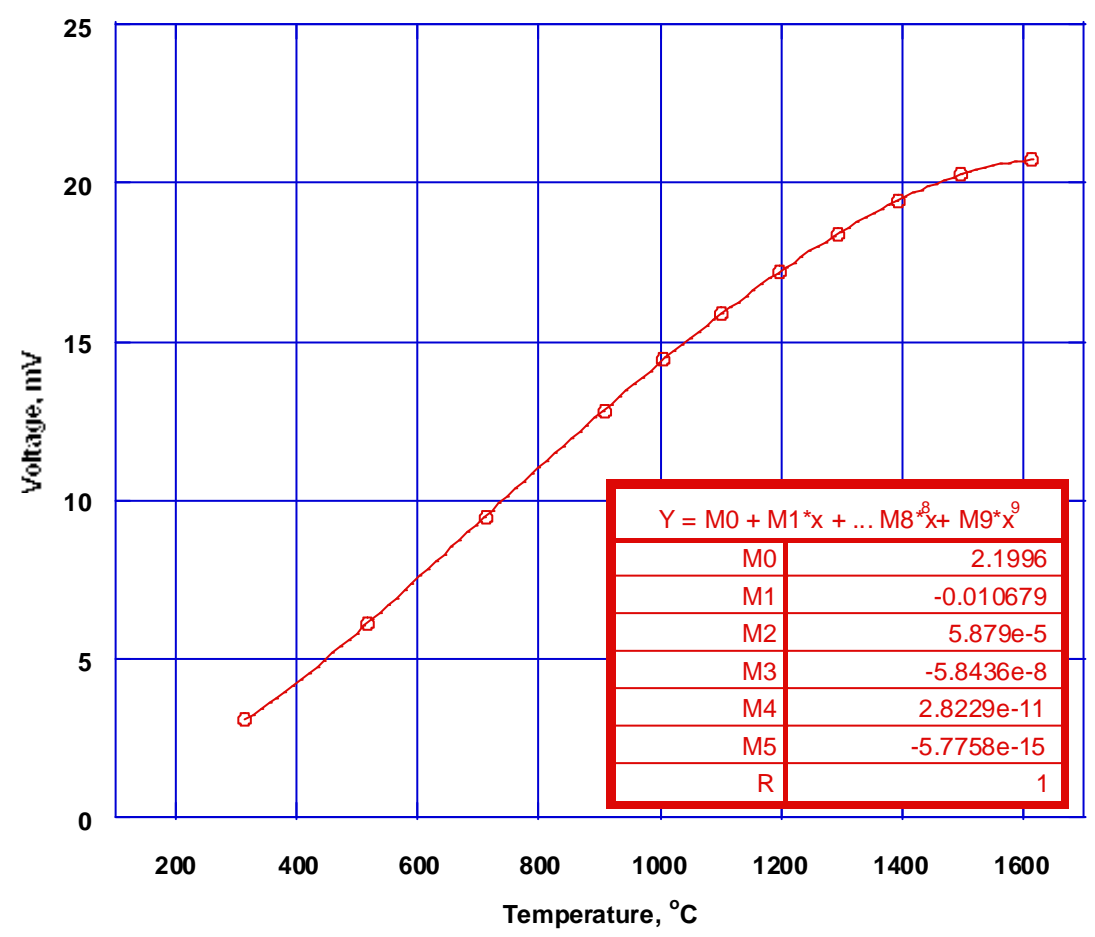

Figure 4-25. Initial emf versus temperature for ARBW Mo-3\%Nb/Nb-6\%Mo thermocouple

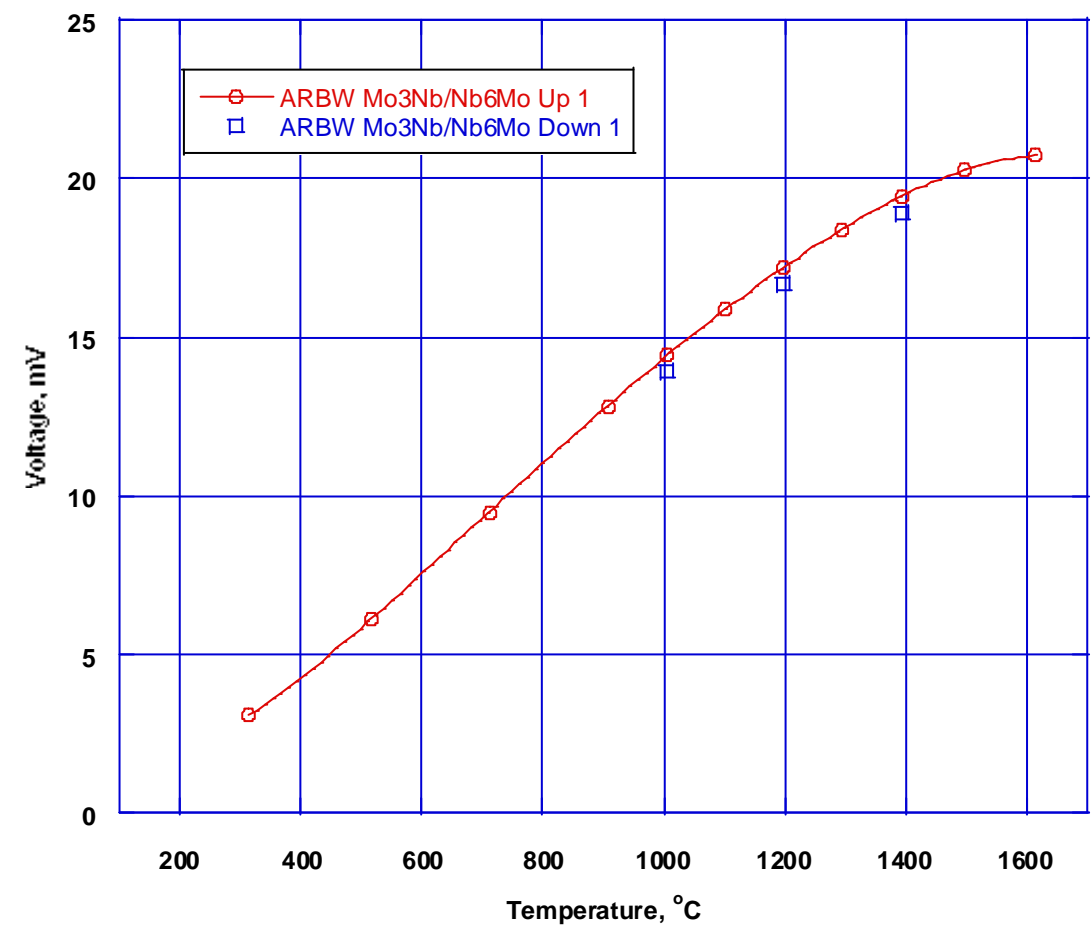

Figure 4-26. Comparison of measured emf during first heating and cooling cycle for ARBW Mo$3 \% \mathrm{Nb} / \mathrm{Nb}-6 \% \mathrm{Mo}$ thermocouple 


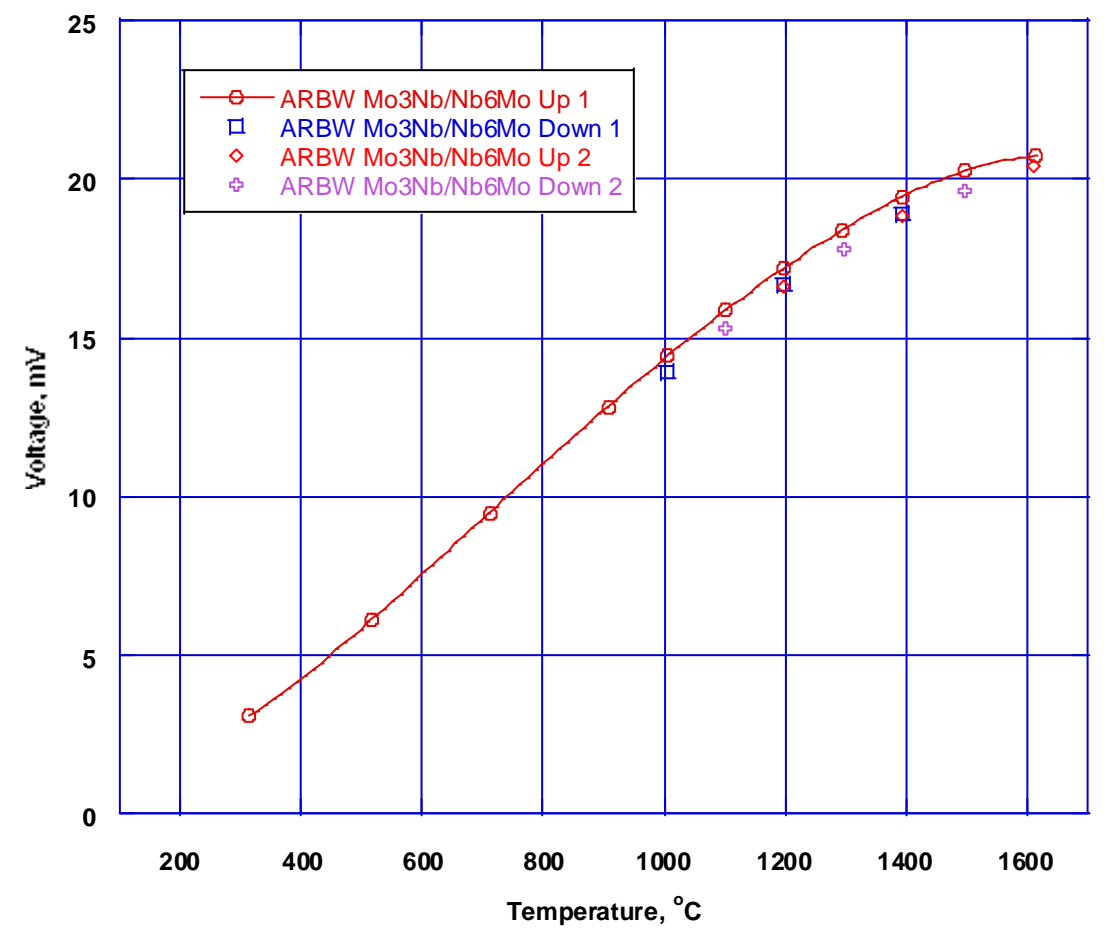

Figure 4-27. Measured emf for two heating and cooling cycles for ARBW Mo-3\%Nb/Nb-6\%Mo thermocouple.

Figures 4-28 through 4-30 show the output voltage generated by the "as received bare wire” Mo-1.6\%Nb/Nb-6\%Mo test thermocouple plotted against the applied temperature for calibration to $1600{ }^{\circ} \mathrm{C}$. Figure $4-28$ is the calibration curve for the first heating cycle to $1600{ }^{\circ} \mathrm{C}$, with the calibration equation displayed. Figure 4-29 shows the heating calibration curve along with data from the first cooling cycle to $1000{ }^{\circ} \mathrm{C}$. As with the previous thermocouples, the emf produced by the thermocouple during the cooling cycle is slightly less than that shown for the initial heating cycle. Figure 4-30 shows the heating cycle calibration curve along with data from the first cooling cycle to $1000^{\circ} \mathrm{C}$, and the second heating and cooling cycles, to $1600{ }^{\circ} \mathrm{C}$ and $1000^{\circ} \mathrm{C}$, respectively. The emf, after two heating cycles, seems to have stabilized. 


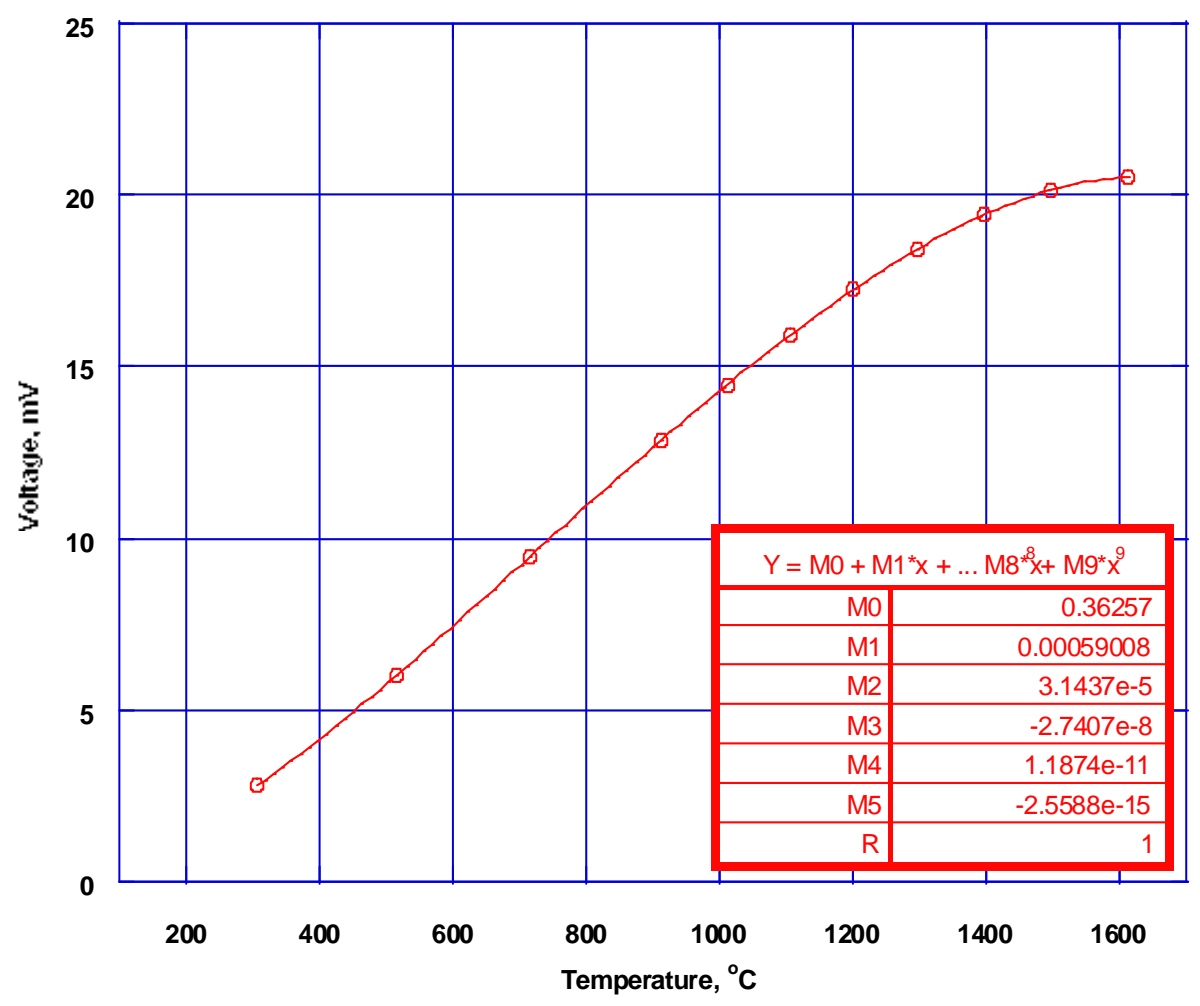

Figure 4-28. Initial emf versus temperature for ARBW Mo-1.6\%Nb/Nb-6\%Mo thermocouple

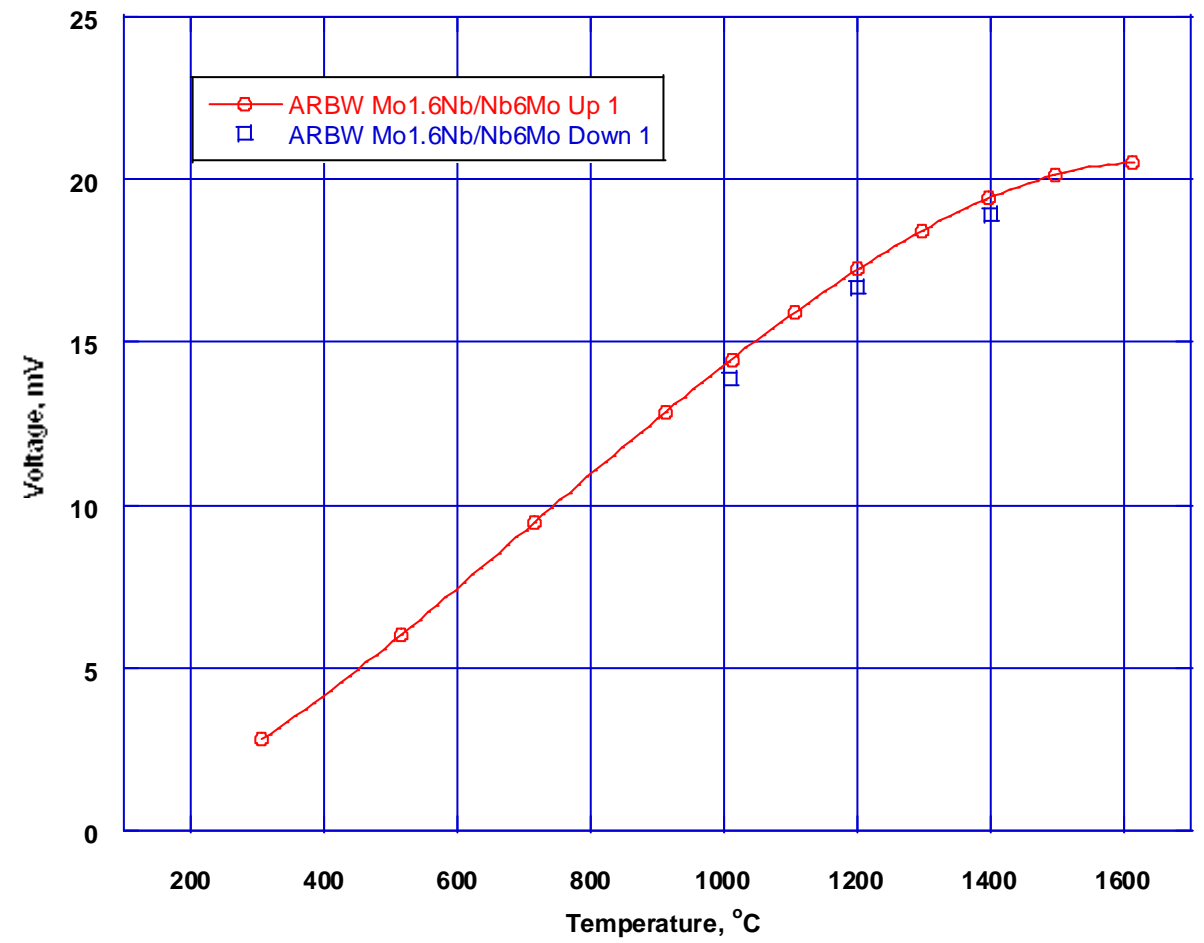

Figure 4-29. Comparison of measured emf during first heating and cooling cycle for ARBW Mo$1.6 \% \mathrm{Nb} / \mathrm{Nb}-6 \% \mathrm{Mo}$ thermocouple 


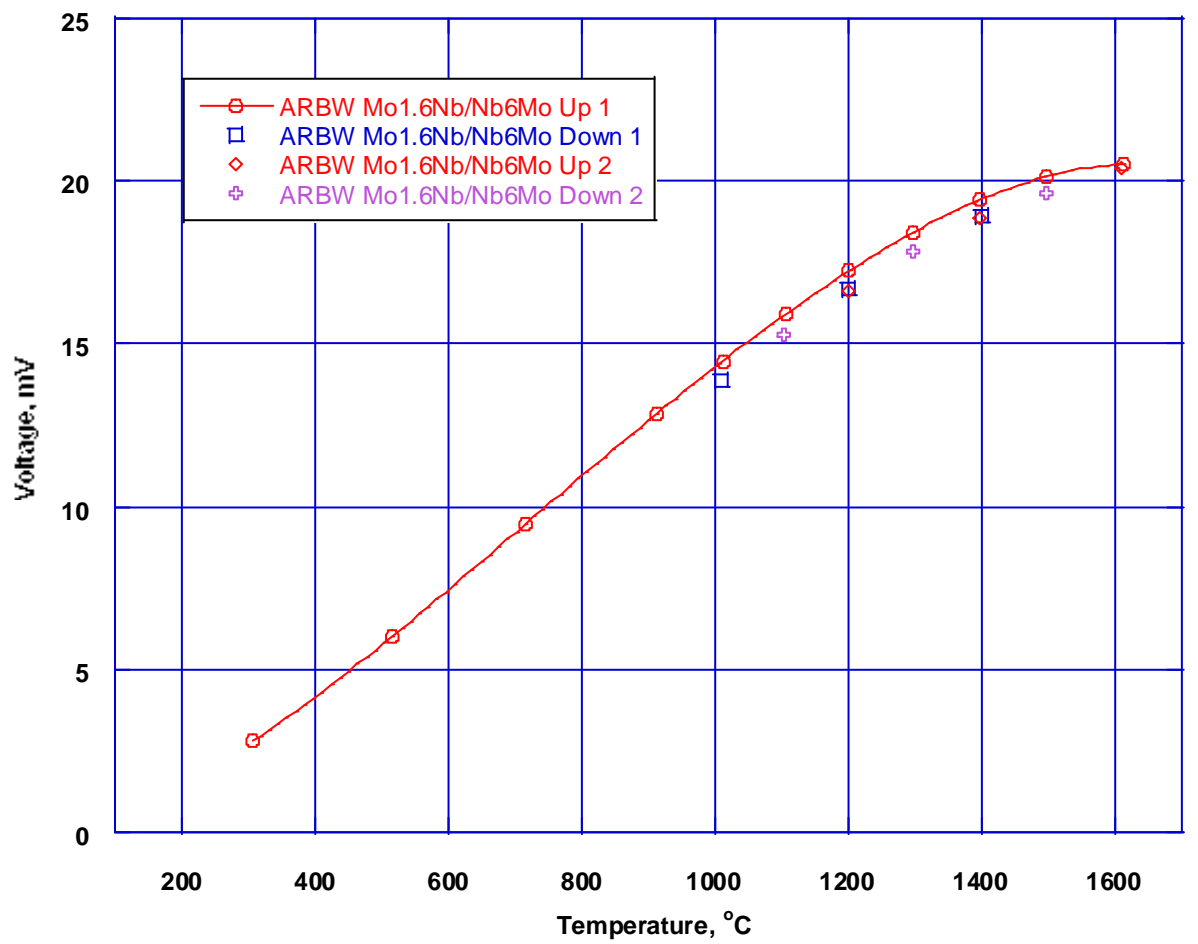

Figure 4-30. Measured emf for two heating and cooling cycles for ARBW Mo-1.6\%Nb/Nb-6\%Mo thermocouple.

Figures 4-31 through 4-33 show the output voltage generated by the "as received bare wire” KW-Mo/Nb-8\%Mo test thermocouple plotted against the applied temperature for calibration to $1600{ }^{\circ} \mathrm{C}$. Figure $4-31$ is the calibration curve for the first heating cycle to $1600{ }^{\circ} \mathrm{C}$, with the calibration equation displayed. It is notable that the curve becomes flat at the highest temperatures. This causes the calibration to become non-single valued. This is an undesirable quality for a thermoelement combination. Figure 4-32 shows the heating calibration curve along with data from the first cooling cycle to $1000{ }^{\circ} \mathrm{C}$. As with the previous thermocouples, the emf produced by the thermocouple during the cooling cycle is slightly less than that shown for the initial heating cycle. Figure 4-33 shows the heating cycle calibration curve along with data from the first cooling cycle to $1000{ }^{\circ} \mathrm{C}$, and the second heating and cooling cycles, to $1600{ }^{\circ} \mathrm{C}$ and $1000{ }^{\circ} \mathrm{C}$, respectively. The emf, after two heating cycles, seems to have stabilized, although the signal is not single valued. 


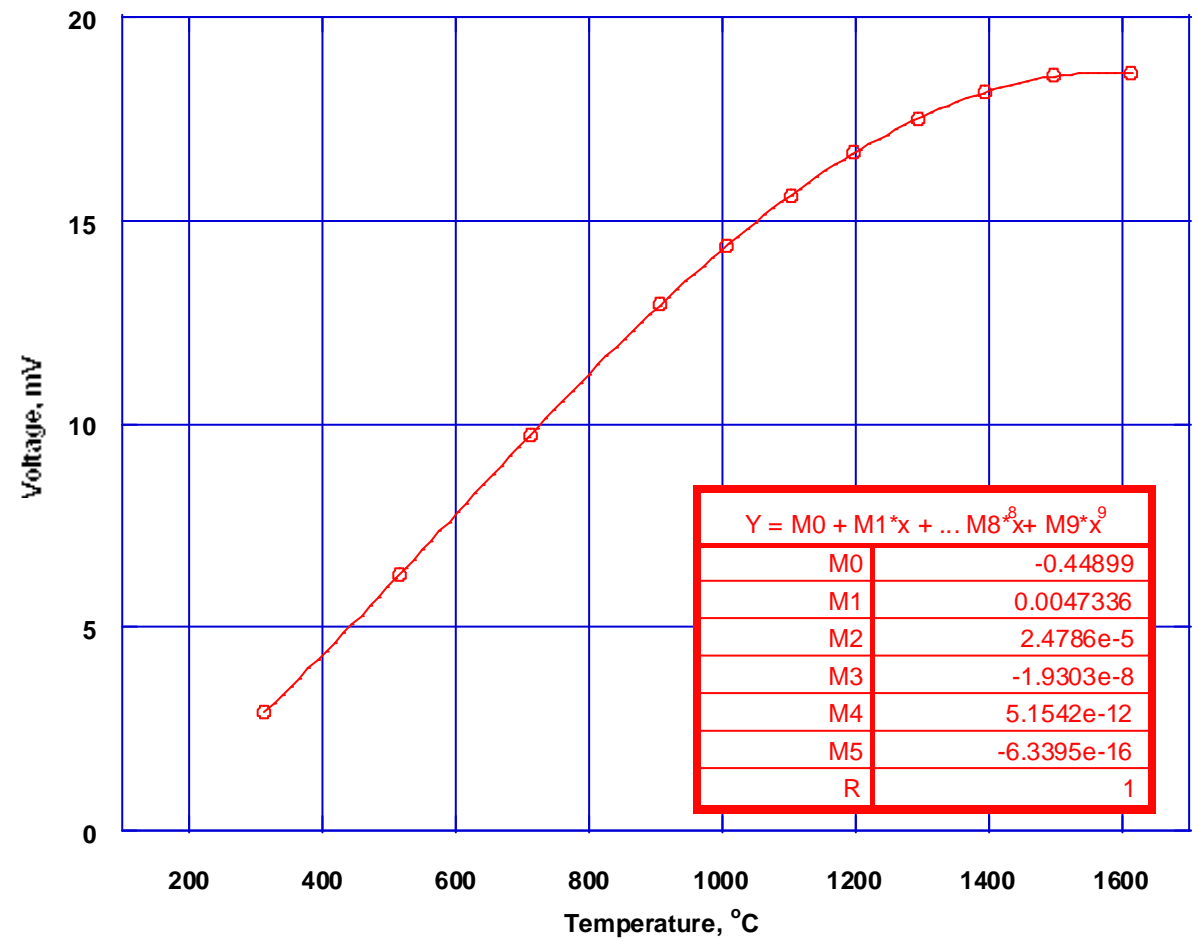

Figure 4-31. Initial emf versus temperature for ARBW KW-Mo/Nb-8\%Mo thermocouple

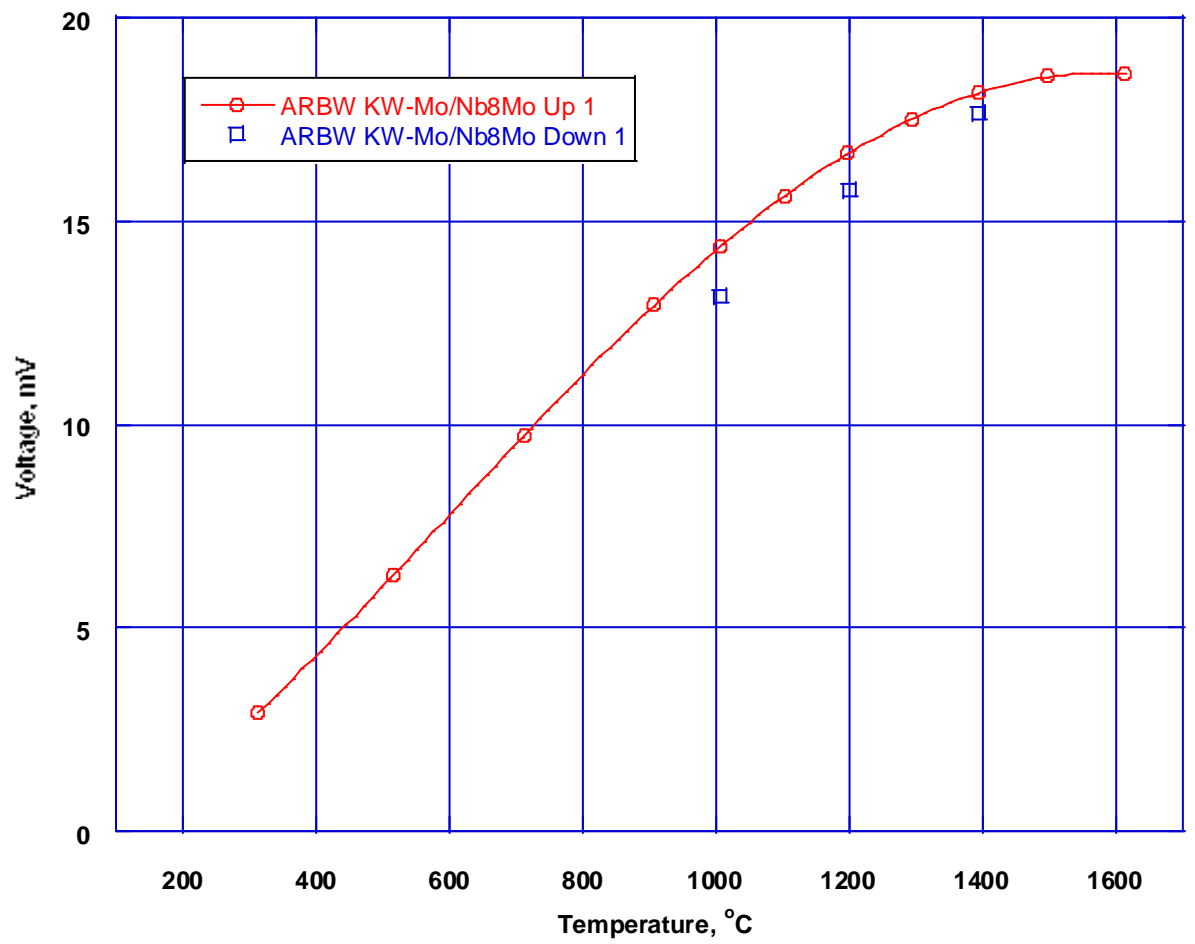

Figure 4-32. Comparison of measured emf during first heating and cooling cycle for ARBW KW$\mathrm{Mo} / \mathrm{Nb}-8 \% \mathrm{Mo}$ thermocouple 


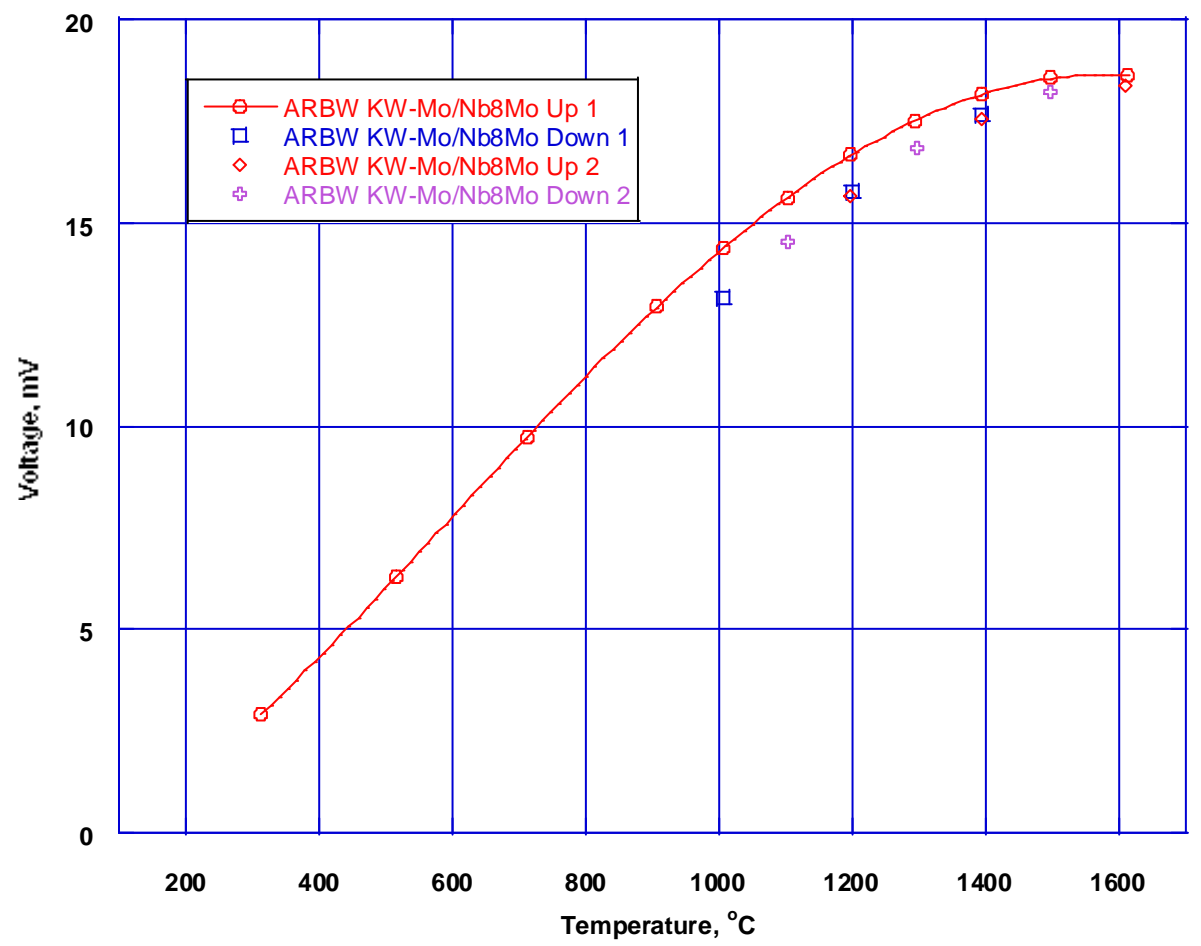

Figure 4-33. Measured emf for two heating and cooling cycles for ARBW KW-Mo/Nb-8\%Mo thermocouple.

Figures 4-34 through 4-36 show the output voltage generated by the "as received bare wire” Mo-3\%Nb/Nb-8\%Mo test thermocouple plotted against the applied temperature for calibration to $1600^{\circ} \mathrm{C}$. Figure $4-34$ is the calibration curve for the first heating cycle to $1600{ }^{\circ} \mathrm{C}$, with the calibration equation displayed. Figure 4-35 shows the heating calibration curve along with data from the first cooling cycle to $1000{ }^{\circ} \mathrm{C}$. As with the previous thermocouples, the emf produced by the thermocouple during the cooling cycle is slightly less than that shown for the initial heating cycle. Figure 4-36 shows the heating cycle calibration curve along with data from the first cooling cycle to $1000{ }^{\circ} \mathrm{C}$, and the second heating and cooling cycles, to $1600{ }^{\circ} \mathrm{C}$ and $1000^{\circ} \mathrm{C}$, respectively. This thermocouple experienced an open circuit failure near the end of the calibration test, so stability after two full cycles is difficult to quantify. 


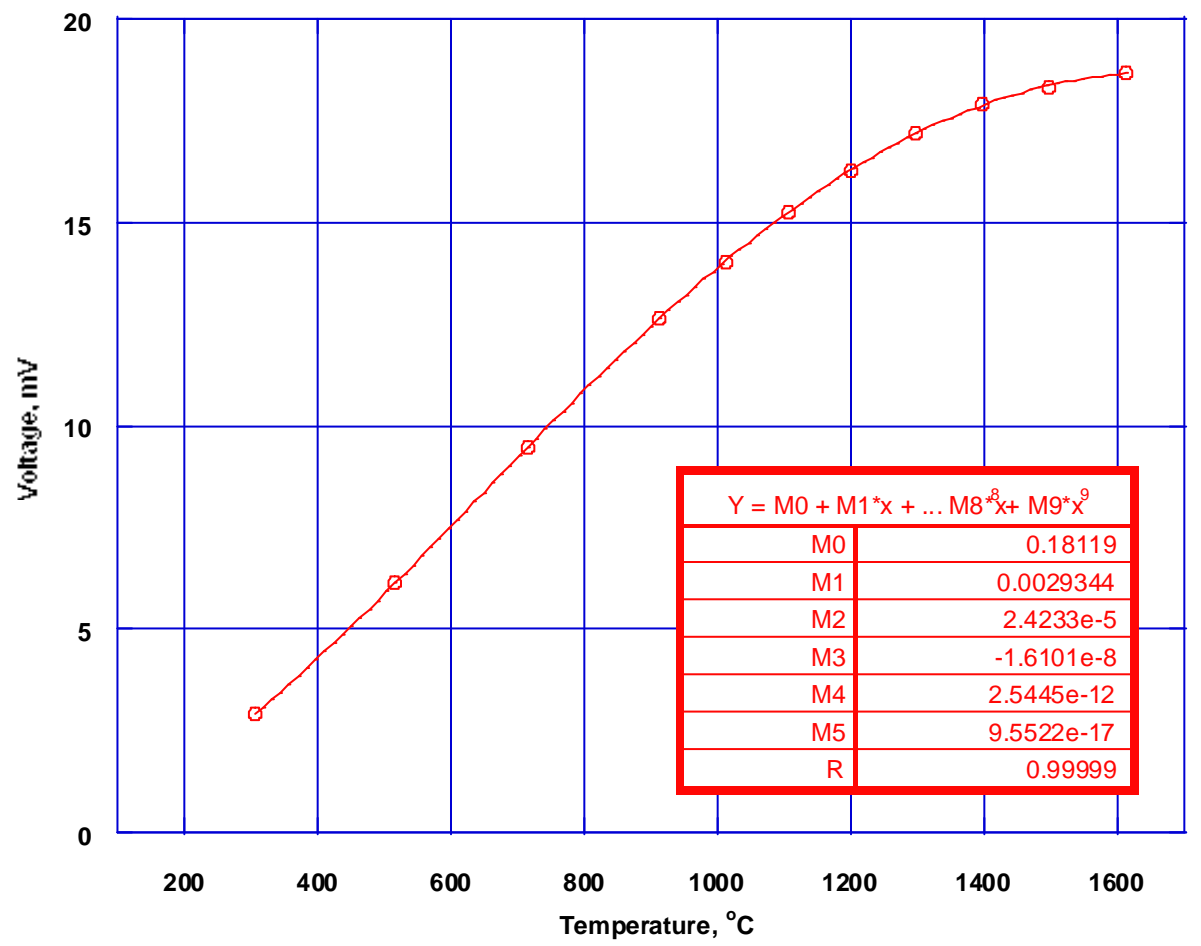

Figure 4-34. Initial emf versus temperature for ARBW Mo-3\%Nb/Nb-8\%Mo thermocouple

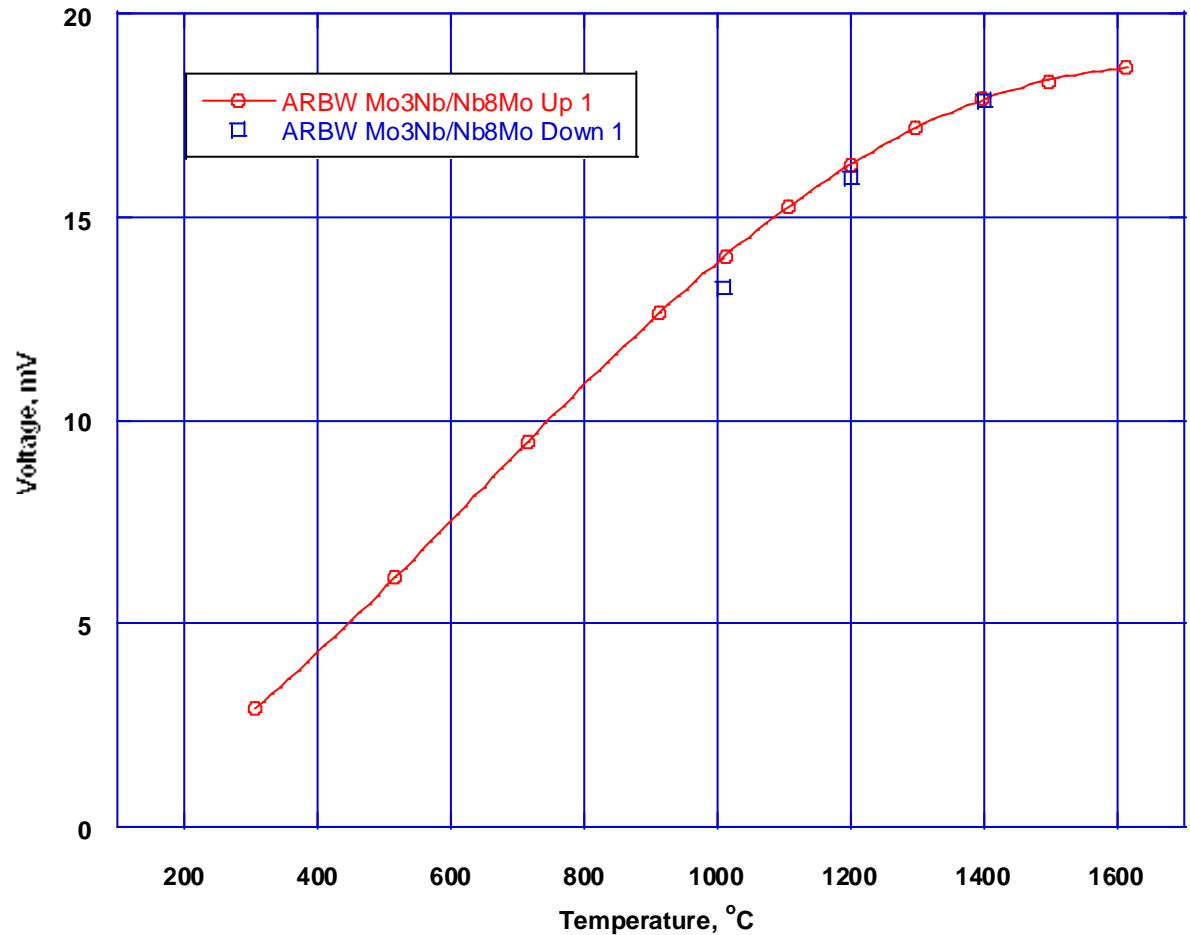

Figure 4-35. Comparison of measured emf during first heating and cooling cycle for ARBW Mo$3 \% \mathrm{Nb} / \mathrm{Nb}-8 \% \mathrm{Mo}$ thermocouple 


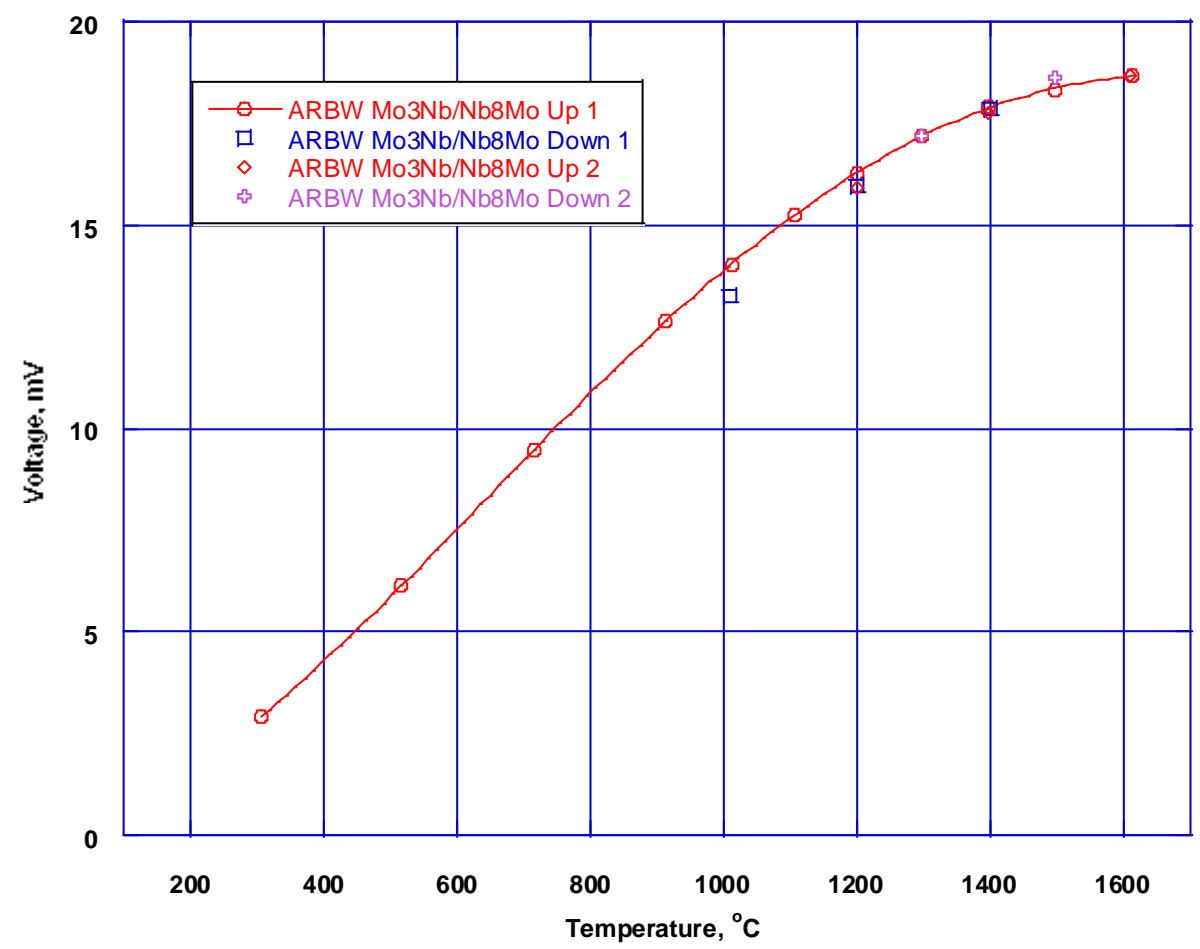

Figure 4-36. Measured emf for two heating and cooling cycles for ARBW Mo-3\%Nb/Nb-8\%Mo thermocouple.

Figures 4-37 through 4-39 show the output voltage generated by the "as received bare wire" Mo-1.6\% Nb/Nb-8\%Mo test thermocouple plotted against the applied temperature for calibration to $1600{ }^{\circ} \mathrm{C}$. Figure 4-37 is the calibration curve for the first heating cycle to $1600^{\circ} \mathrm{C}$, with the calibration equation displayed. It is notable that the curve becomes flat and the signal actually begins to decrease at the highest temperatures. This causes the calibration to become nonsingle valued. Figure 4-38 shows the heating calibration curve along with data from the first cooling cycle to $1000^{\circ} \mathrm{C}$. The signal shows the same trends as for the first heating cycle but to a greater degree. Figure 4-39 shows the heating cycle calibration curve along with data from the first cooling cycle to $1000{ }^{\circ} \mathrm{C}$, and the second heating and cooling cycles, to $1600{ }^{\circ} \mathrm{C}$ and $1000^{\circ} \mathrm{C}$, respectively. The unusual signal trends seem even more exaggerated for the second full cycle. 


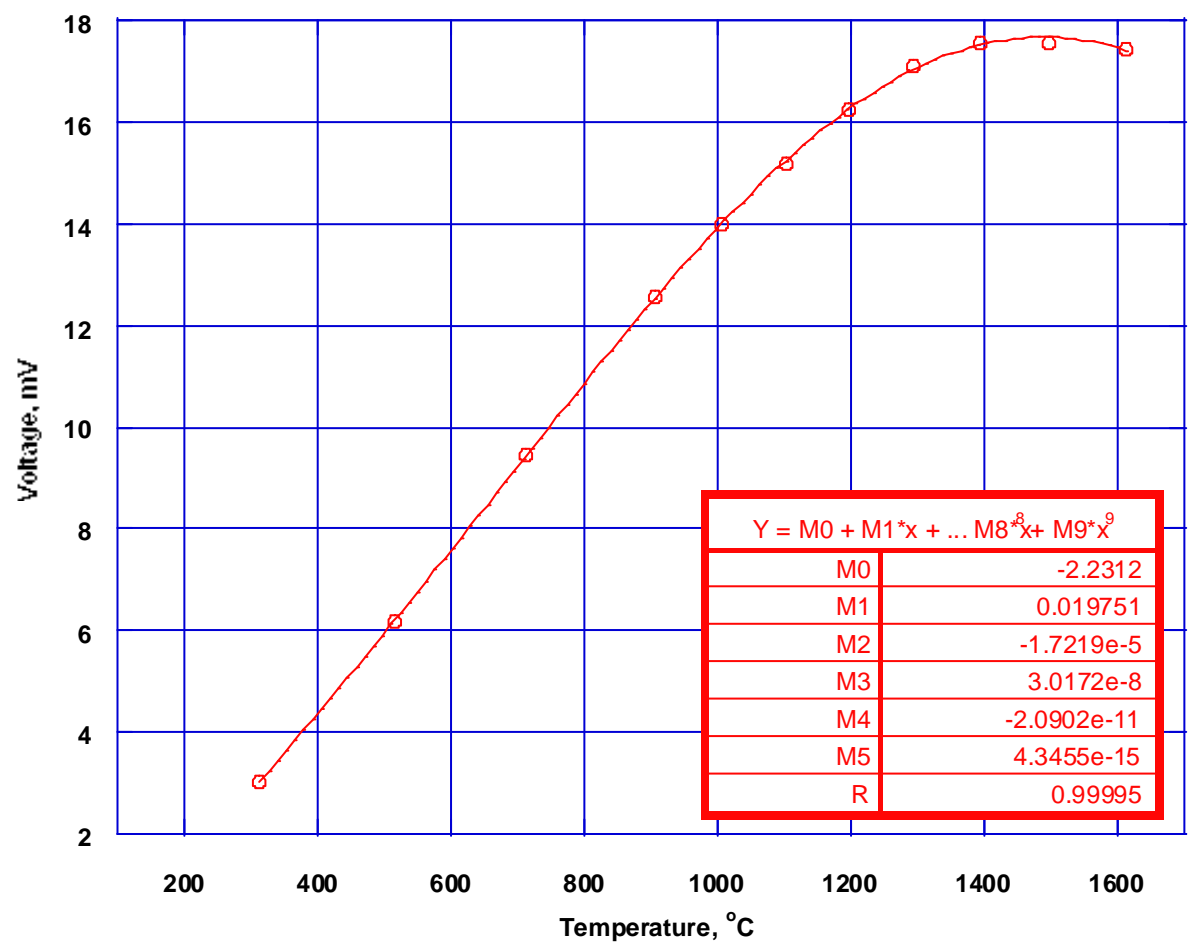

Figure 4-37. Initial emf versus temperature for ARBW Mo-1.6\%Nb/Nb-8\%Mo thermocouple

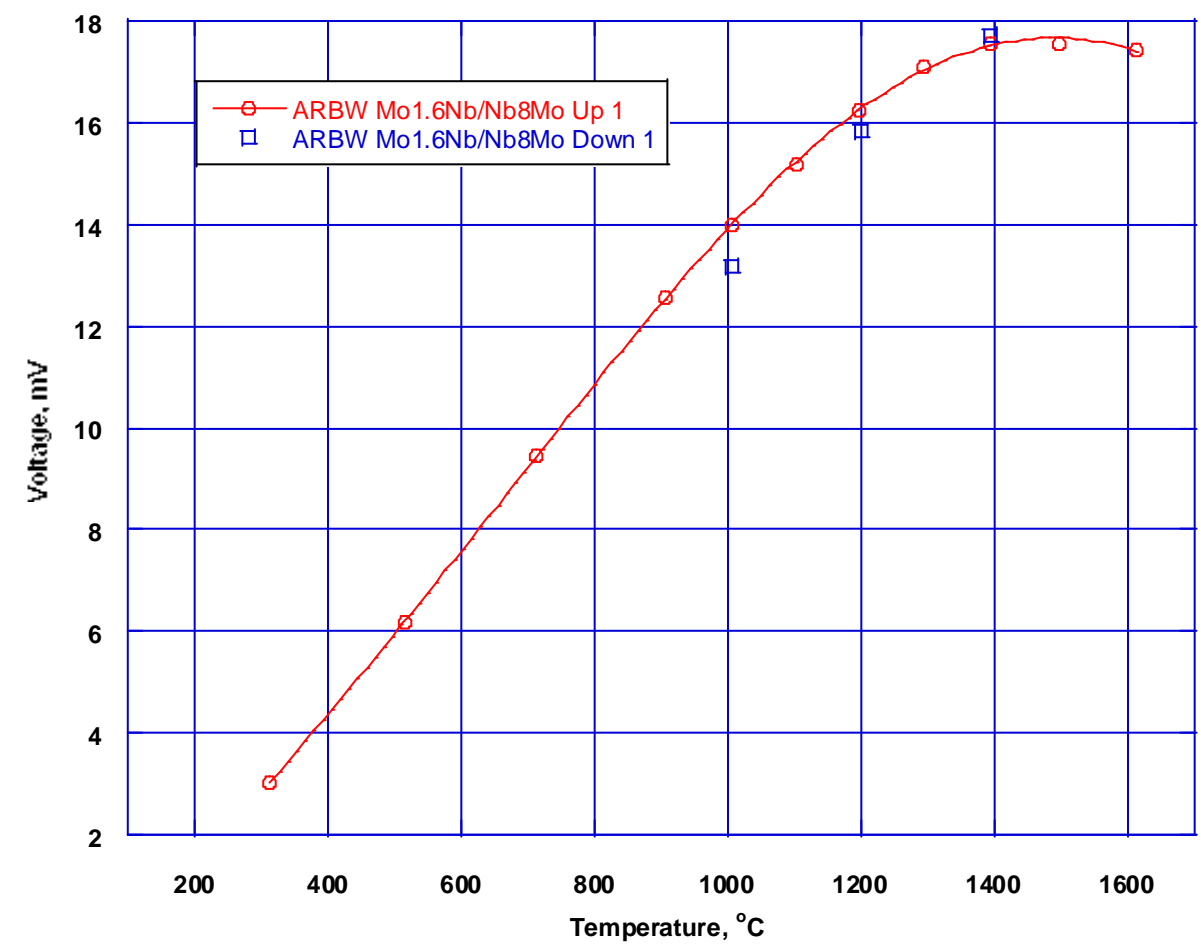

Figure 4-38. Comparison of measured emf during first heating and cooling cycle for ARBW Mo$1.6 \% \mathrm{Nb} / \mathrm{Nb}-8 \% \mathrm{Mo}$ thermocouple 


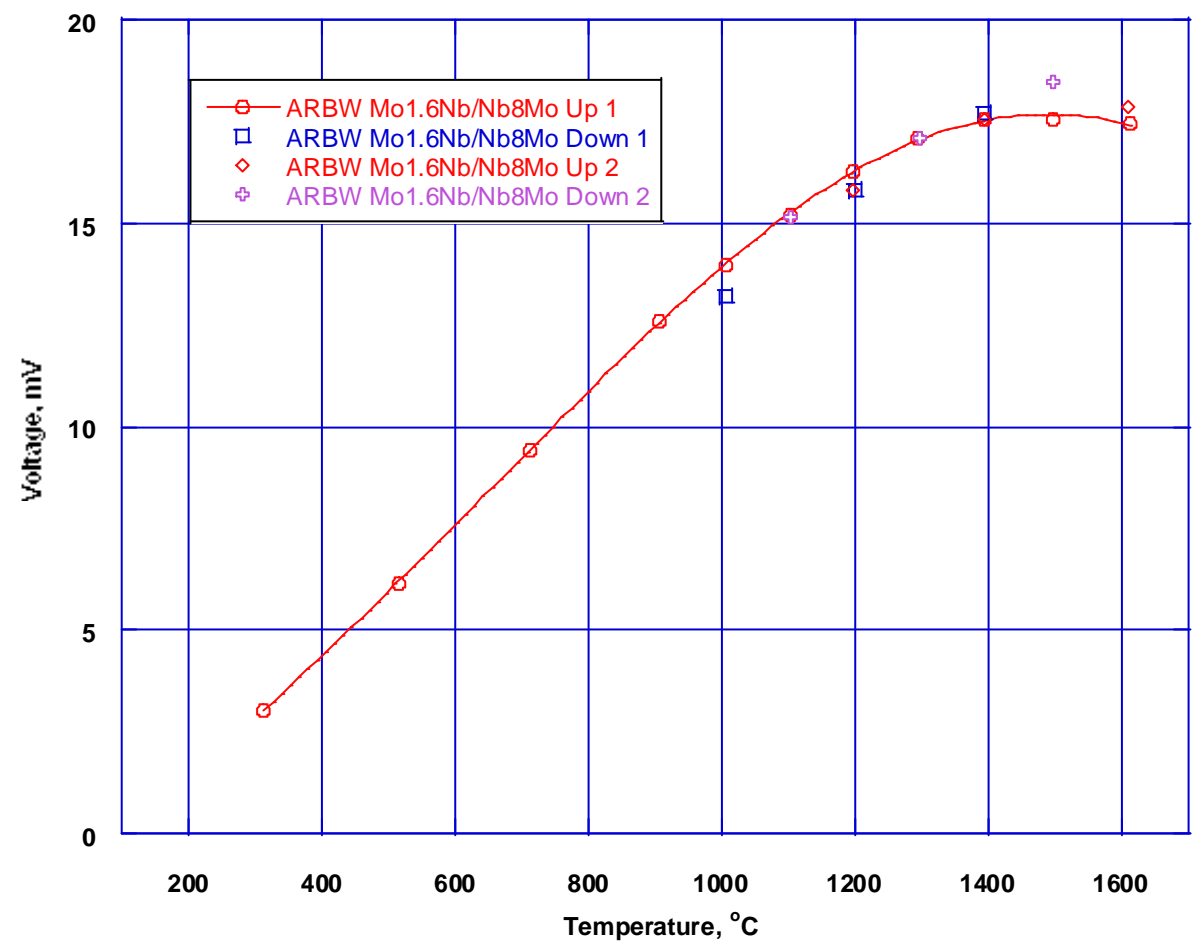

Figure 4-39. Measured emf for two heating and cooling cycles for ARBW Mo-1.6\%Nb/Nb-8\%Mo thermocouple.

\subsection{As Received Swaged (ARS)}

Figures 4-40 through 4-42 show the output voltage generated by the "as received swaged" $\mathrm{KW}-\mathrm{Mo} / \mathrm{Nb}-1 \% \mathrm{Zr}$ test thermocouple plotted against the applied temperature for the first heating cycle up to $1600{ }^{\circ} \mathrm{C}$. Figure $4-40$ is the calibration curve for the heating cycle, with the calibration equation displayed. Figure 4-41 shows the heating calibration curve along with data from the first cooling cycle to $1000{ }^{\circ} \mathrm{C}$. There is a clear difference between the emf values measured during the initial heating and cooling cycle. It is suspected that this difference is due to grain growth that occurred from the heating during this first cycle of this calibration test. Figure 4-42 shows the heating cycle calibration curve along with data from the first cooling cycle to $1000{ }^{\circ} \mathrm{C}$, and the second heating and cooling cycles, to $1600^{\circ} \mathrm{C}$ and $1000^{\circ} \mathrm{C}$, respectively. Because there is less difference in the measured emf during the second cycle, it appears that the thermocouple response has stabilized due to the heating-induced grain growth that occurred during the first cycle. 


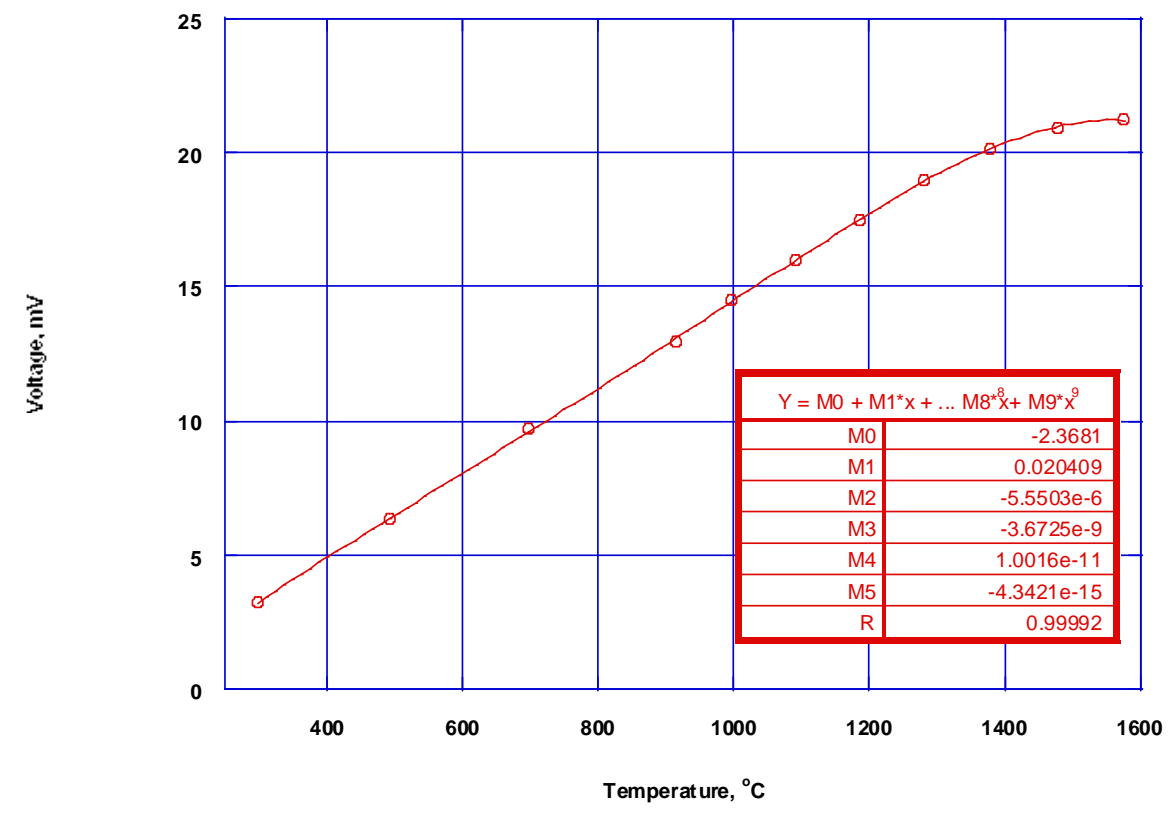

Figure 4-40. Initial emf versus temperature for ARS KW-Mo/Nb-1\%Zr thermocouple

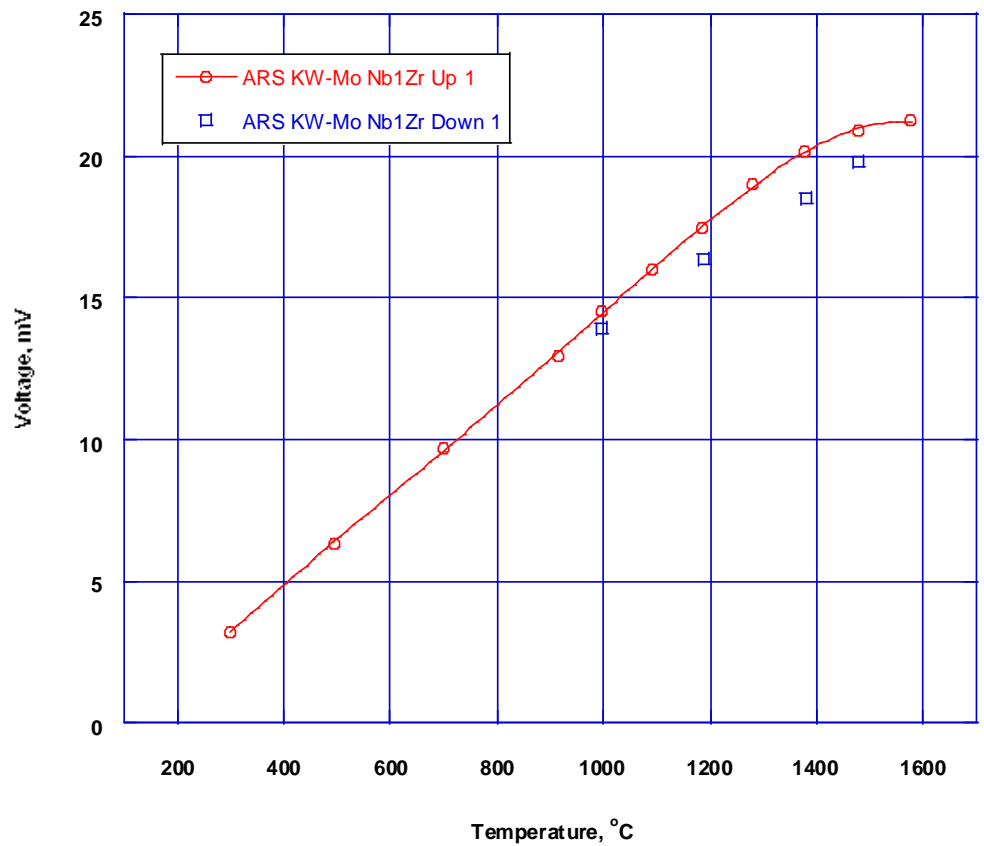

Figure 4-41. Comparison of measured emf during first heating and cooling cycle for ARS KW-Mo/Nb$1 \% \mathrm{Zr}$ thermocouple. 


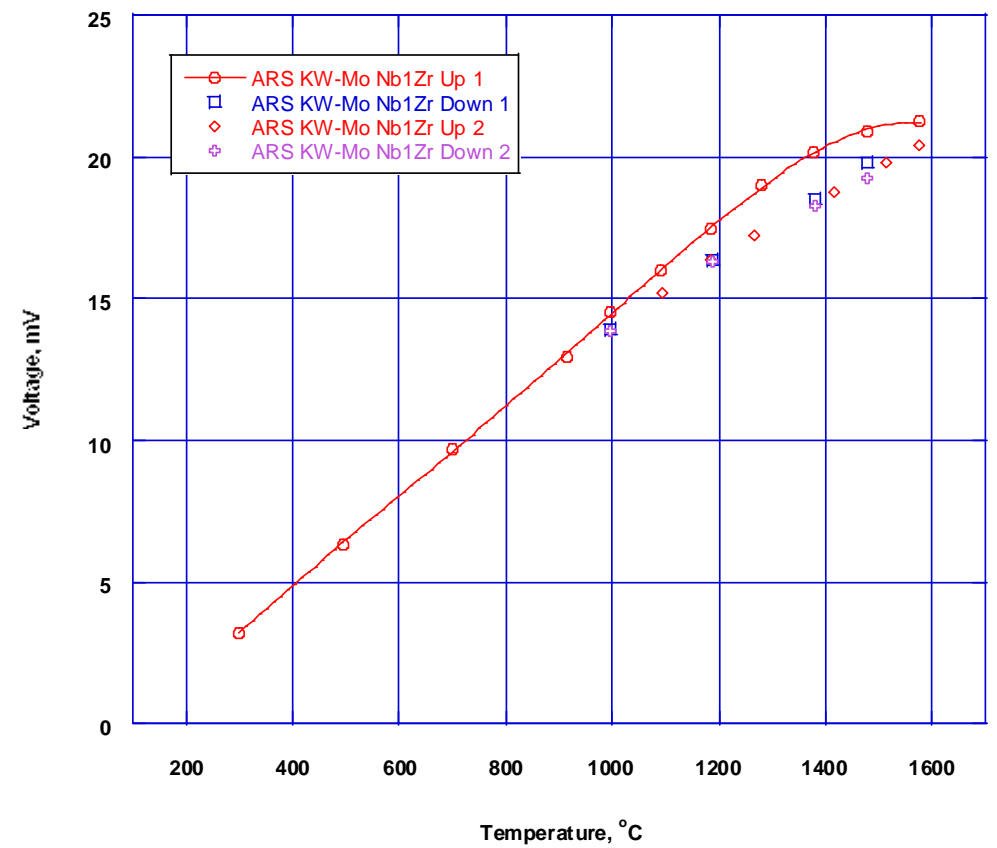

Figure 4-42. Measured emf for two heating and cooling cycles for ARS KW-Mo/Nb-1\%Zr thermocouple.

Figures 4-43 through 4-45 show the output voltage generated by the ARS Mo-3\%Nb/Nb$1 \% \mathrm{Zr}$ test thermocouple plotted against the applied temperature for the first heating cycle up to $1600{ }^{\circ} \mathrm{C}$. Figure $4-43$ is the calibration curve for the heating cycle, with the calibration equation displayed. Figure 4-44 shows the heating calibration curve along with data from the first cooling cycle to $1000{ }^{\circ} \mathrm{C}$. Significant differences between the emf values measured during the initial heating and cooling cycles for this thermocouple are also attributed to grain growth that occurred during the first heating cycle. Figure 4-45 shows the heating cycle calibration curve along with data from the first cooling cycle to $1000{ }^{\circ} \mathrm{C}$ and the second heating and cooling cycles, to $1600{ }^{\circ} \mathrm{C}$ and $1000^{\circ} \mathrm{C}$, respectively. It appears that this thermocouple also stabilized after the first heating cycle, as the measured emf values for the second cycle show less discrepancy between the heating and cooling cycles. 


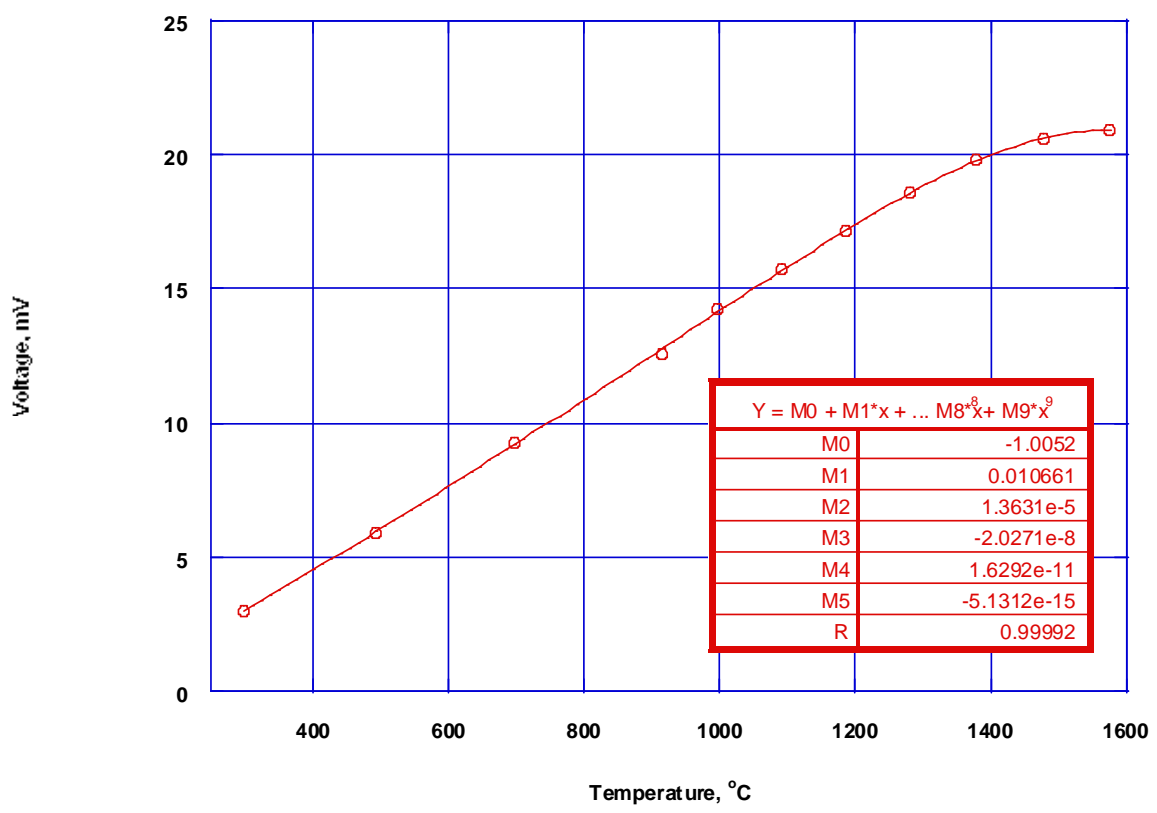

Figure 4-43. Initial emf versus temperature for ARS Mo-3\%Nb/Nb-1\%Zr thermocouple

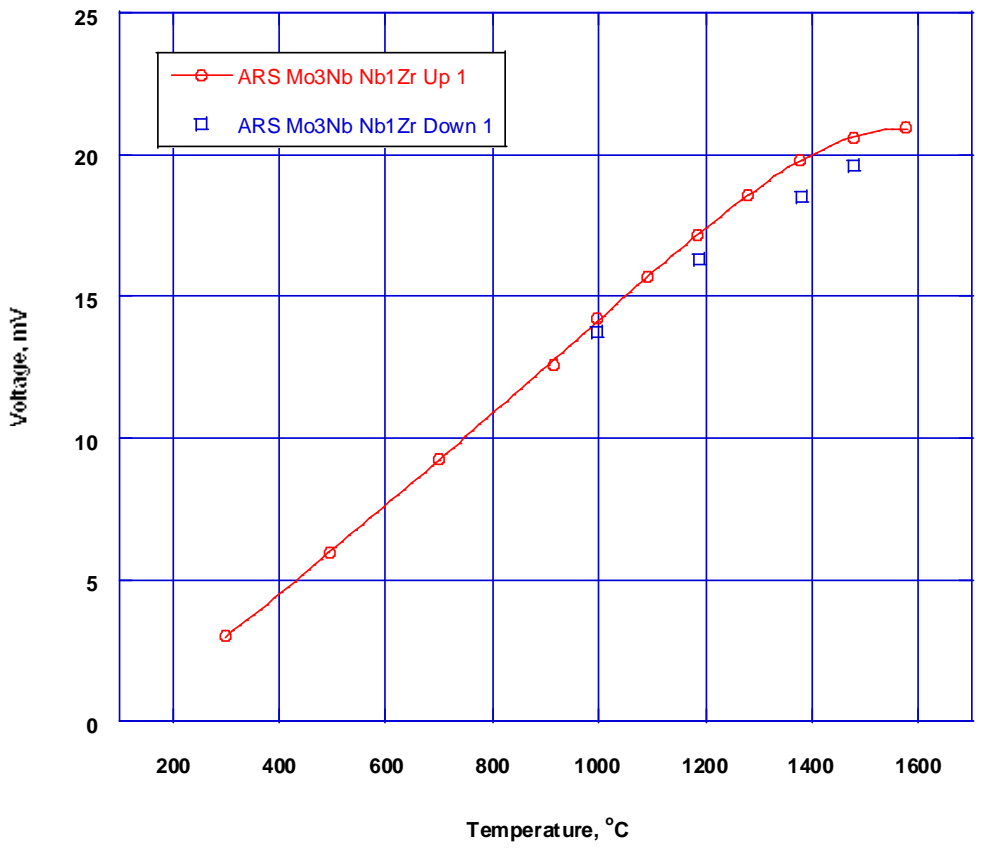

Figure 4-44. First heating and cooling cycle for ARS Mo-3\%Nb/Nb-1\%Zr thermocouple. 


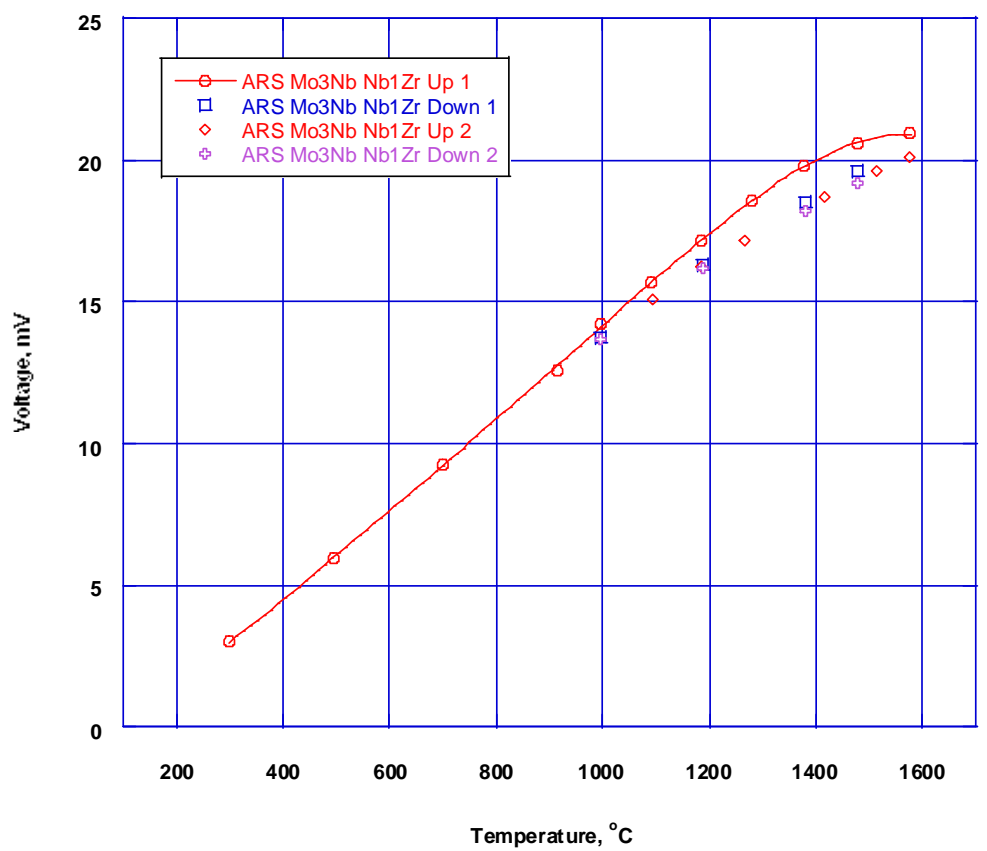

Figure 4-45. Two heating and cooling cycles for ARS Mo-3\%Nb/Nb-1\%Zr thermocouple.

Figures 4-46 through 4-48 show the measured emf values for the ARS Mo-1.6\%Nb/Nb$1 \% \mathrm{Zr}$ test thermocouple plotted for the first heating cycle up to $1600{ }^{\circ} \mathrm{C}$. Figure $4-46$ is the calibration curve for the heating cycle, with the calibration equation displayed. Figure 4-47 shows the heating calibration curve along with data from the first cooling cycle to $1000{ }^{\circ} \mathrm{C}$. Significant differences between the emf values measured during the initial heating and cooling cycles for this thermocouple are also attributed to grain growth that occurred during the first heating cycle. Figure 4-48 shows the heating cycle calibration curve along with data from the first cooling cycle to $1000{ }^{\circ} \mathrm{C}$ and the second heating and cooling cycles, to $1600^{\circ} \mathrm{C}$ and $1000{ }^{\circ} \mathrm{C}$, respectively. It appears that this thermocouple also stabilized after the first heating cycle, as the measured emf values for the second cycle show less discrepancy between the heating and cooling cycles. 


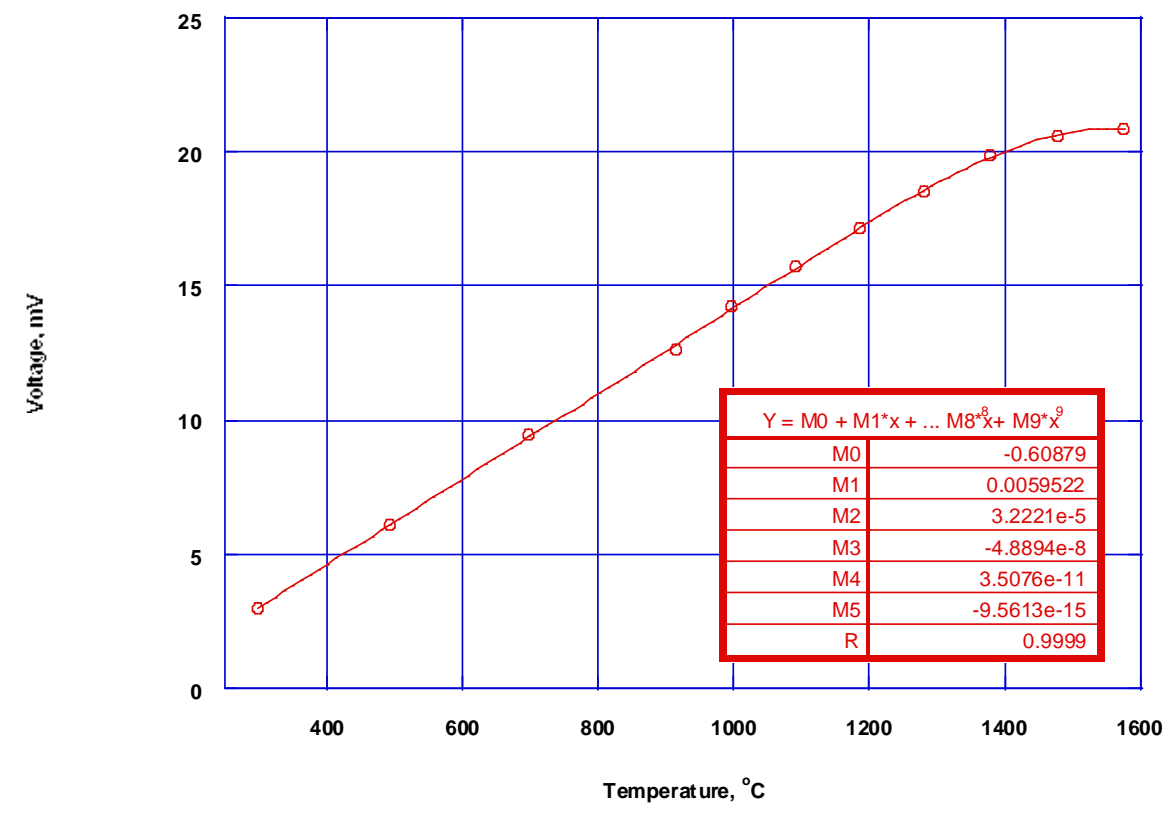

Figure 4-46. initial emf versus temperature for ARS Mo-1.6\%Nb/Nb-1\%Zr thermocouple.

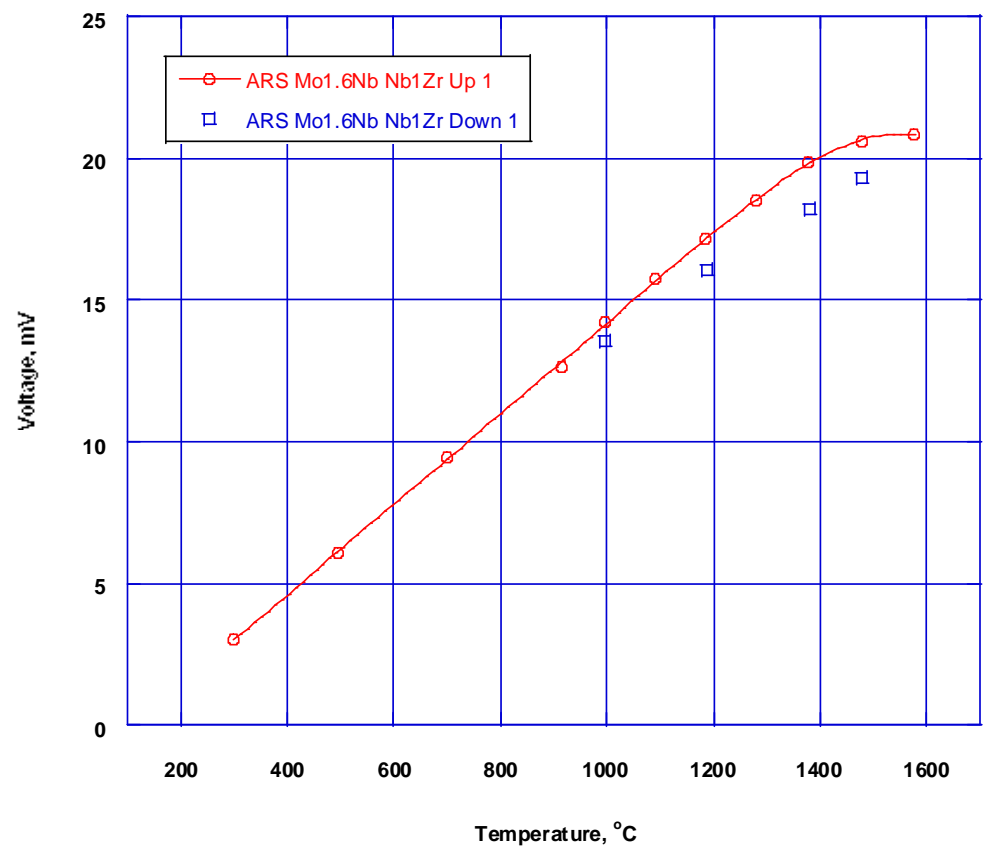

Figure 4-47. First heating and cooling cycle for ARS Mo-1.6\%Nb/Nb-1\%Zr thermocouple. 


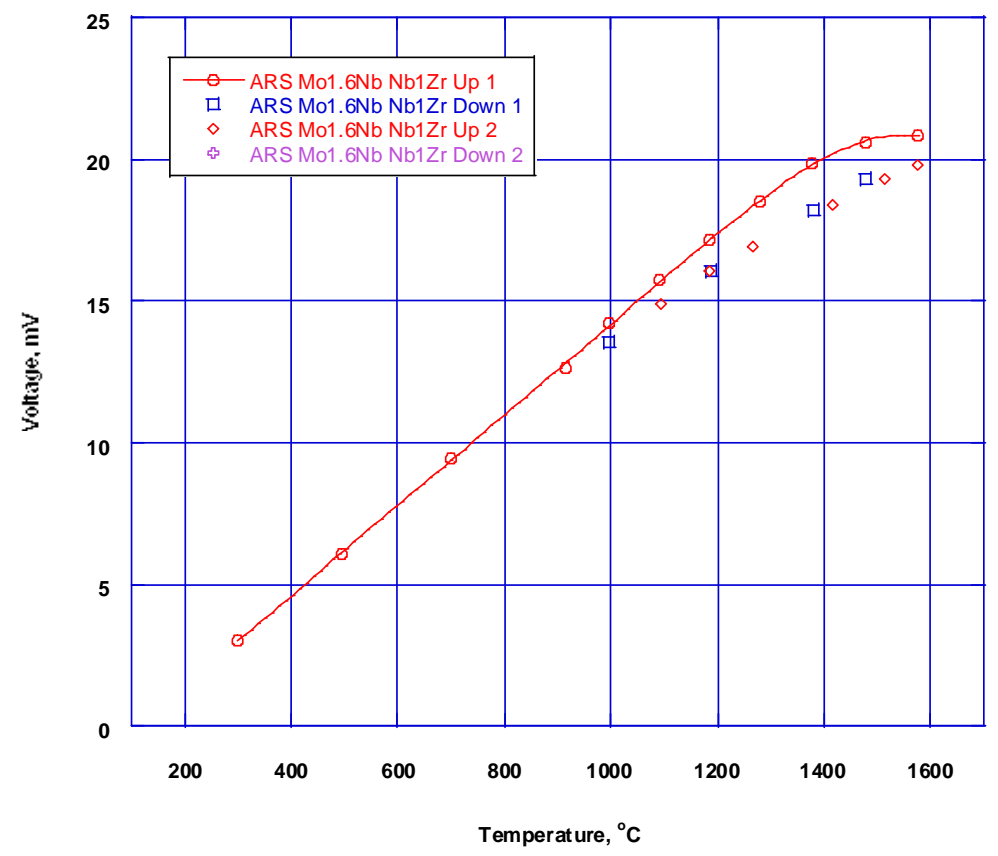

Figure 4-48. Two heating and cooling cycles for ARS Mo-1.6\%Nb/Nb-1\%Zr thermocouple.

\subsection{Swaged Then Heat Treated (SHT)}

Figures 4-49 through 4-51 show the calibration curves generated for the "swaged then heat treated" or SHT KW-Mo/Nb-1\%Zr thermocouple plotted against the applied temperature for the first heating cycle up to $1600{ }^{\circ} \mathrm{C}$. Figure 4-49 is the calibration curve for the heating cycle, with the calibration equation displayed. Figure 4-50 shows the heating calibration curve along with data from the first cooling cycle to $1000^{\circ} \mathrm{C}$. This curve shows little change from the heating cycle to the cooling cycle, unlike the "as received swaged" thermocouple of the same materials. This indicates that the heat treating process significantly improves the performance consistency of the thermocouple. Figure 4-51 shows the heating cycle calibration curve along with data from the first cooling cycle to $1000{ }^{\circ} \mathrm{C}$ and the second heating and cooling cycles, to $1600{ }^{\circ} \mathrm{C}$ and $1000{ }^{\circ} \mathrm{C}$, respectively. It is clear that the heat treated thermocouple performs more consistently than the non-heat treated thermocouple of the same materials. 


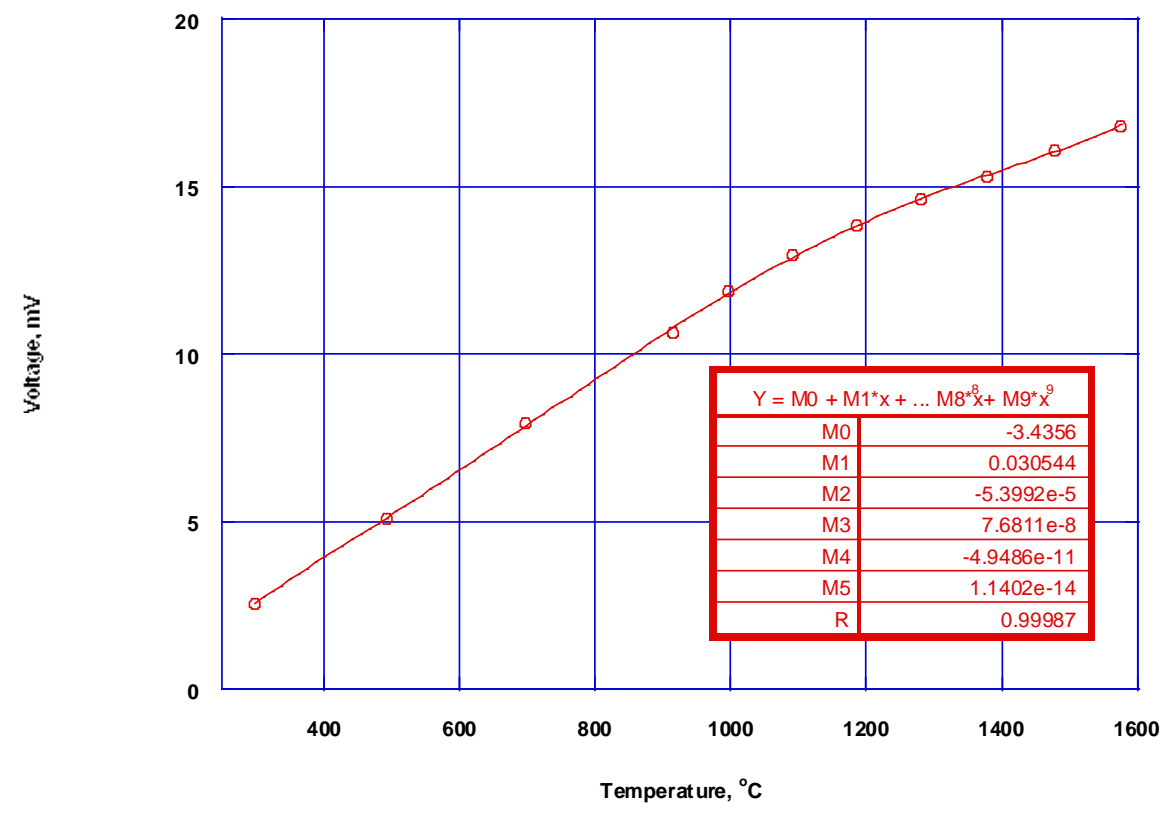

Figure 4-49. Initial emf versus temperature for SHT KW-Mo/Nb-1\%Zr thermocouple

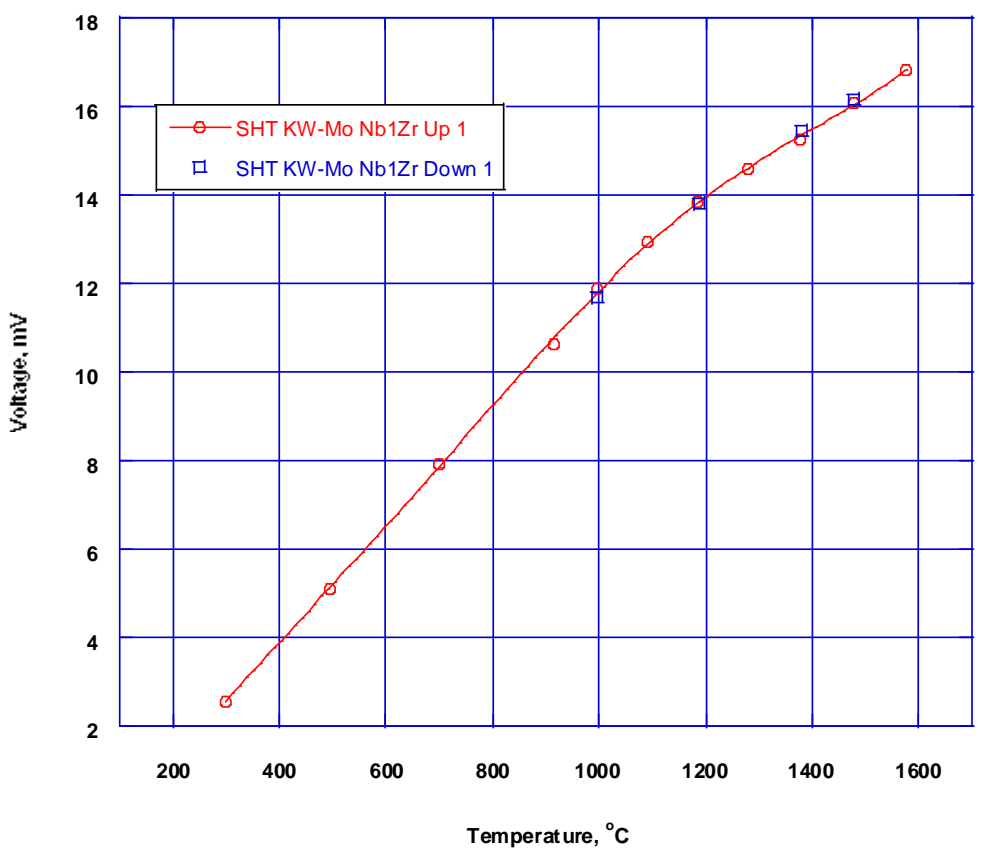

Figure 4-50. First heating and cooling cycle for SHT KW-Mo/Nb-1\%Zr thermocouple. 


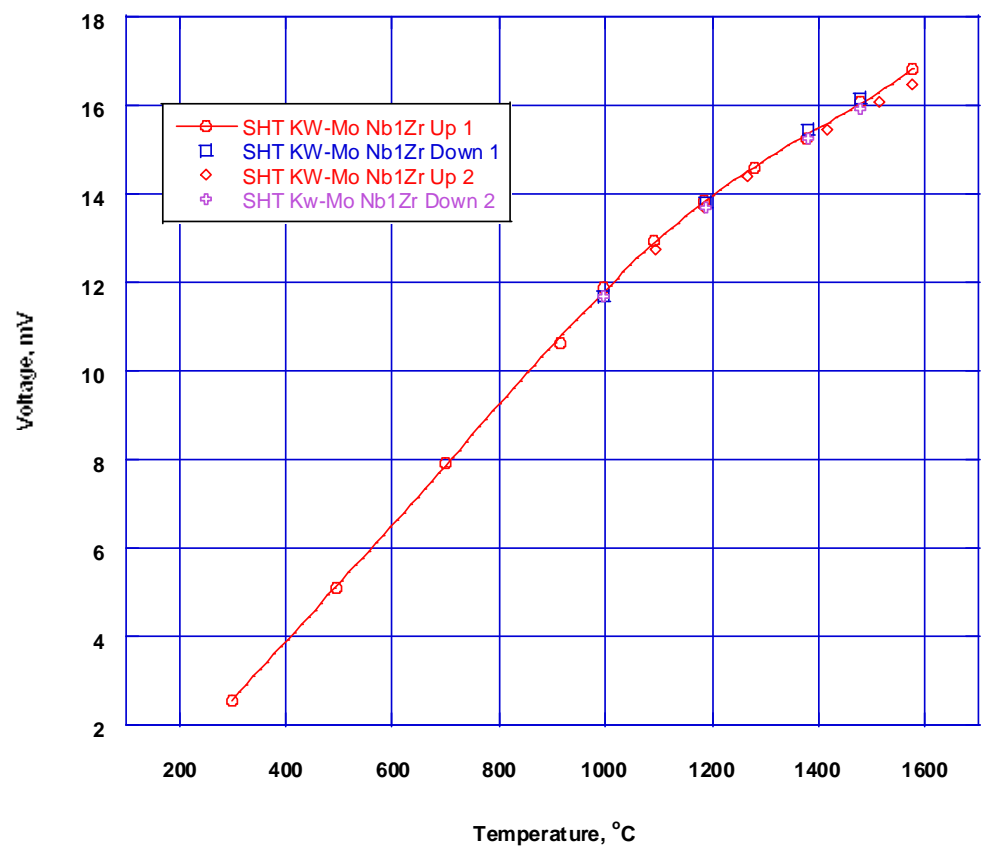

Figure 4-51. Two heating and cooling cycles for SHT KW-Mo/Nb-1\%Zr thermocouple.

Figures 4-52 through 4-54 show the calibration curves generated for the SHT Mo$3 \% \mathrm{Nb} / \mathrm{Nb}-1 \% \mathrm{Zr}$ thermocouple plotted against the applied temperature for the first heating cycle up to $1600{ }^{\circ} \mathrm{C}$. Figure 4-52 is the calibration curve for the first heating cycle with the calibration equation displayed. Figure 4-53 shows the first heating cycle as well as the first cooling cycle to $1000^{\circ} \mathrm{C}$. This figure is significantly different than the same data plot for the "as received swaged" Mo-3\%Nb thermocouple. The plot for the ARS thermocouple (Figure 4-44). revealed a drop in measured emf values between the first heating and cooling cycles, possibly caused by grain growth that occurred due to heating in the heating cycle. The SHT thermocouple curve shows a slight increase in emf, the cause for this is unclear though the discrepancy is much smaller than that measured for the ARS thermocouple. Figure 4-54 shows the first and second heating, to $1600{ }^{\circ} \mathrm{C}$, and cooling cycles, to $100{ }^{\circ} \mathrm{C}$. The data plot indicates that the elevated emf generated during the first cooling cycle is not present during subsequent heating and cooling. This may indicate some continued heat treating during the test, beyond that performed in advance of the test. However, heat treating induces grain growth which subsequently causes a drop in voltage. Hence, the data from the cooling run are suspect. The second cycle heating and cooling data are consistent with the first cycle heating data, implying that stability was achieved. 


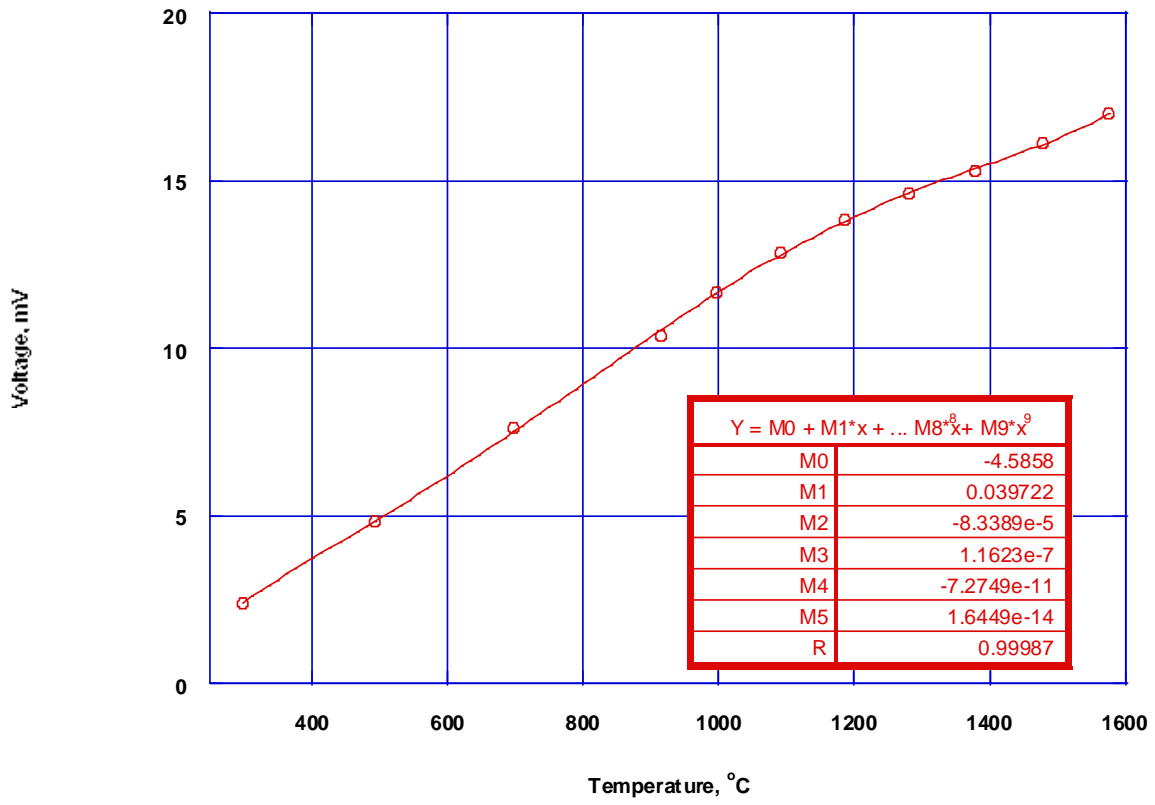

Figure 4-52. Initial emf versus temperature for SHT Mo3\%Nb/Nb1\%Zr thermocouple

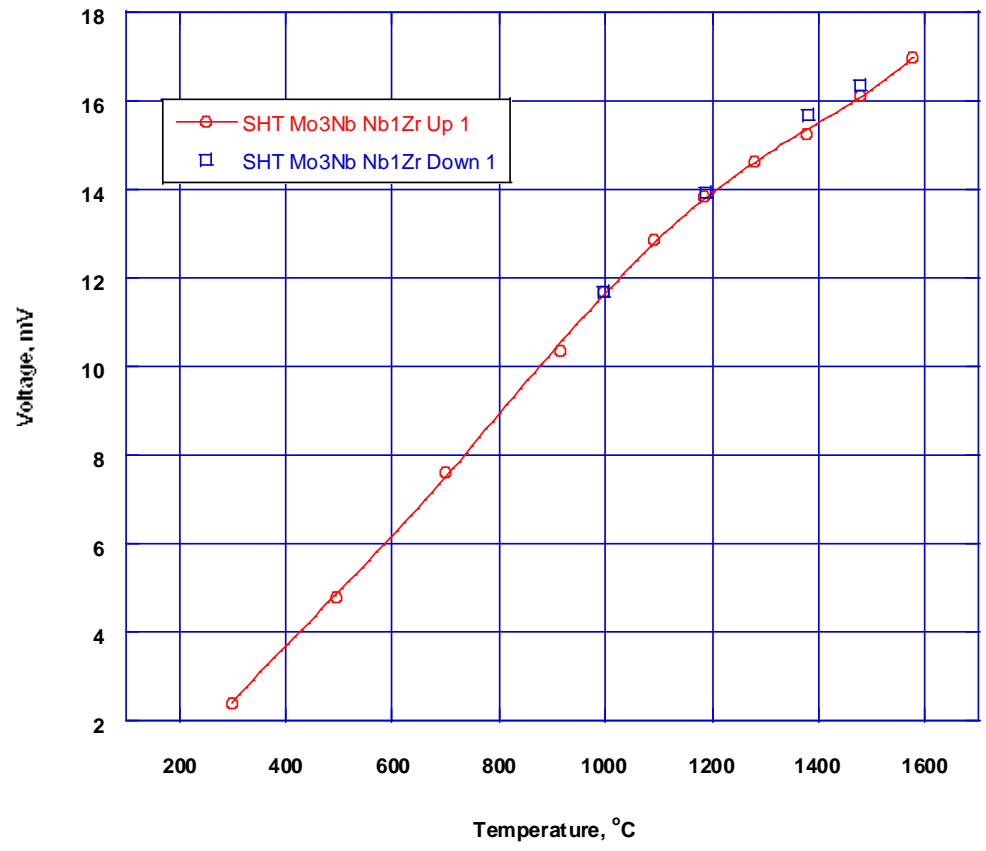

Figure 4-53. First heating and cooling cycle for SHT Mo-3\%Nb/Nb-1\%Zr thermocouple. 


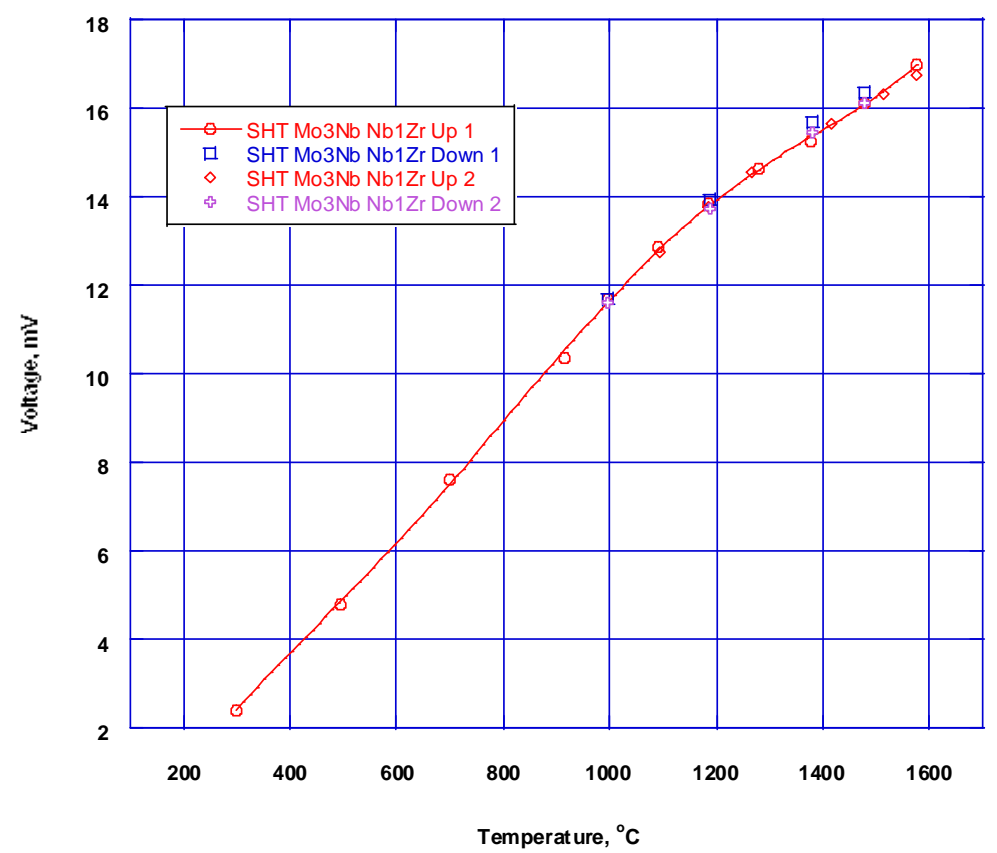

Figure 4-54. Two heating and cooling cycles for SHT Mo-3\%Nb/Nb-1\%Zr thermocouple.

Figures 4-55 through 4-57 show the calibration curves generated for the SHT Mo$1.6 \% \mathrm{Nb} / \mathrm{Nb}-1 \% \mathrm{Zr}$ thermocouple plotted against the applied temperature for the first heating cycle up to $1600{ }^{\circ} \mathrm{C}$. Figure $4-55$ shows the calibration curve for the first heating, to $1600{ }^{\circ} \mathrm{C}$, as well as the calibration equation. Figure 4-56 shows the first heating, to $1600{ }^{\circ} \mathrm{C}$, and cooling, to $1000{ }^{\circ} \mathrm{C}$ cycles. This plot is very similar to the plot in Figure 4-53, for one heating and cooling cycle, for the SHT Mo-3\%Nb thermocouple in that an elevated emf is present during the first cooling cycle. Figure 4-57 shows two heating, to $1600{ }^{\circ} \mathrm{C}$, and cooling, to $1000{ }^{\circ} \mathrm{C}$, cycles. This plot shows that some variation is still present for the second full cycle. Whether this can be attributed to further heat treating during testing is unclear. 


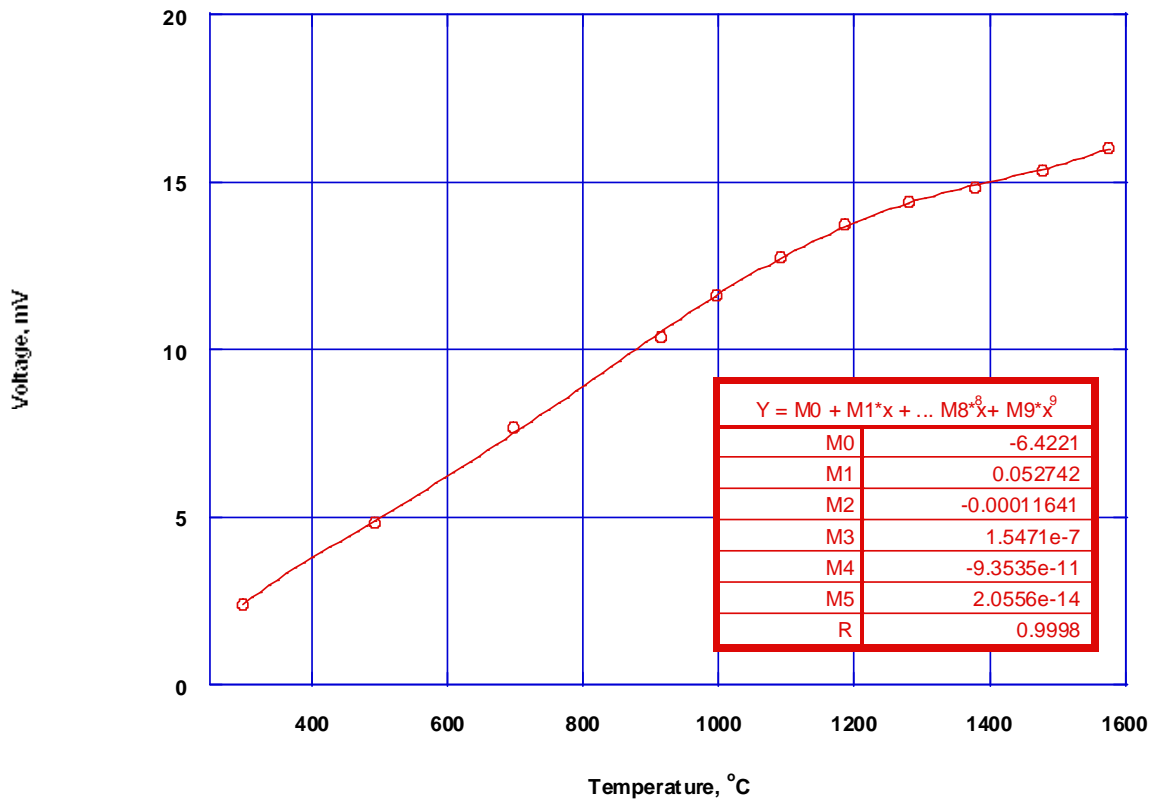

Figure 4-55. Initial emf versus temperature for SHT Mo-1.6\%Nb/Nb-1\%Zr thermocouple

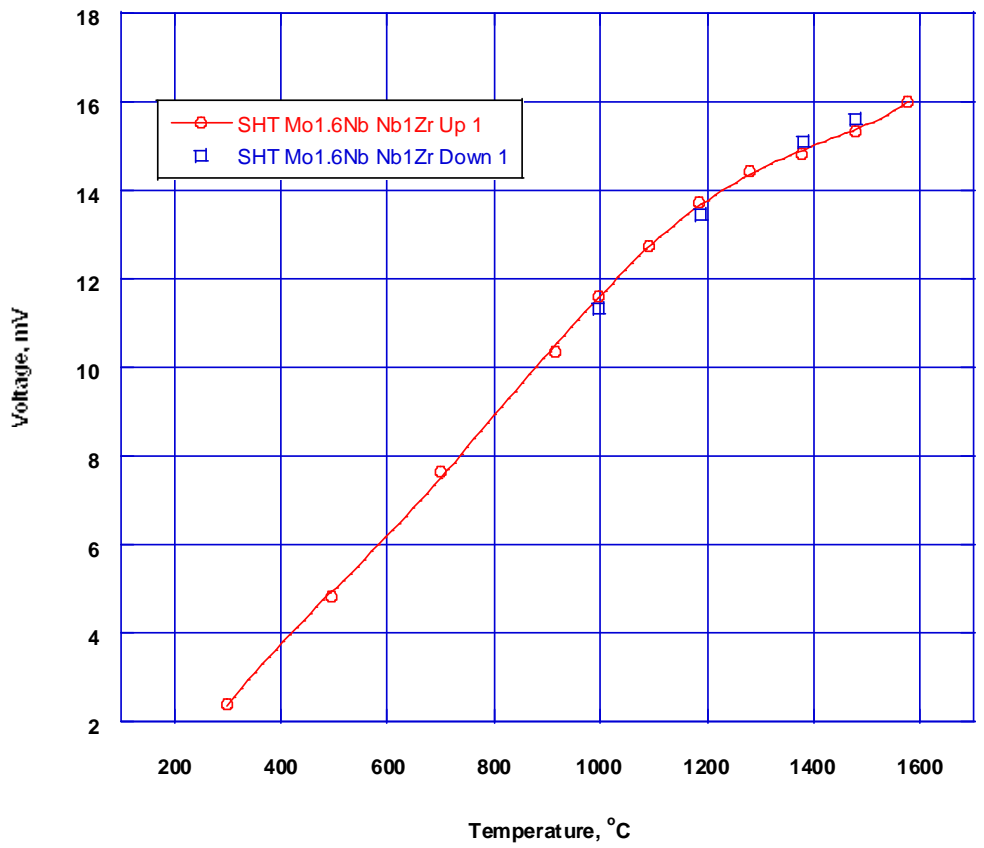

Figure 4-56. First heating and cooling cycle for SHT Mo-1.6\%Nb/Nb-1\%Zr thermocouple. 


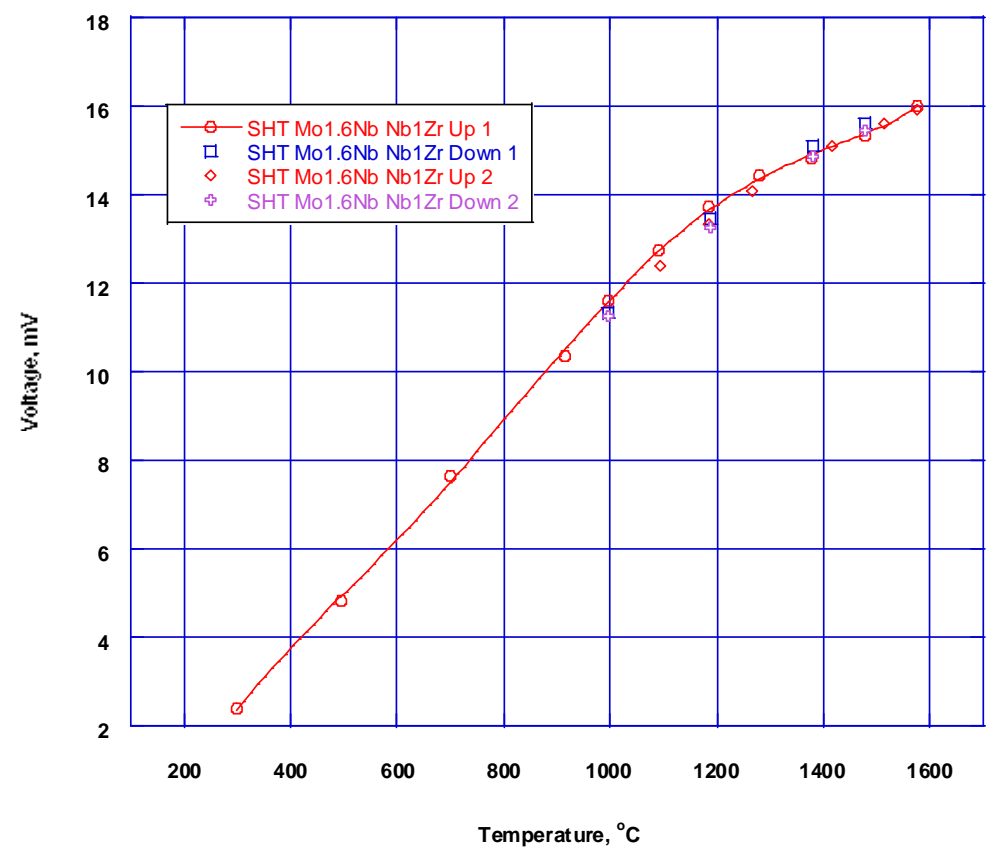

Figure 4-57. Two heating and cooling cycles for SHT Mo-1.6\%Nb/Nb-1\%Zr thermocouple.

\subsection{Summary and Insights}

Figures 4-58 and 4-59 show curves obtained for ARBW, ARS, and SHT KW-Mo/Nb$1 \% \mathrm{Zr}$ thermocouples. Figure 4-58 compares curves for the first heating cycle. It is clear that heat treating the SHT thermocouple prior to testing has significantly reduced its sensitivity. The ARBW and ARS thermocouples have significantly higher sensitivity than the SHT thermocouple, and there is little difference between them. The curve for the ARBW thermocouple is somewhat more linear than that of the ARS. It should be noted the ARBW testing began at $200{ }^{\circ} \mathrm{C}$, while tests for the ARS and SHT thermocouples began at $300{ }^{\circ} \mathrm{C}$. Figure 4-59 compares curves obtained for first and second heating and cooling cycles at high temperatures. The ARS thermocouple shows a significant drop in emf, though it still has higher sensitivity than the SHT thermocouple. Hence, it is suspected that the ARS thermocouple was not completely stabilized, The emf may continue to drop with more heating time, but it does not change much between the first and second cooling cycles. The ARBW thermocouple shows a similar drop in emf to the ARS, though to a lesser degree. The SHT thermocouple is the most stable over the two heating and cooling cycles, although it shows significantly reduced sensitivity.

Figures 4-60 and 4-61 show curves for ARBW, ARS, and SHT Mo-3\%Nb/Nb-1\%Zr thermocouples. Trends for this alloy are the same as for the KW-Mo thermocouples. Figure 4-60 compares curves obtained for the first heating cycle. It is clear that heat treating the SHT thermocouple prior to testing has significantly reduced its sensitivity. The ARBW and ARS 


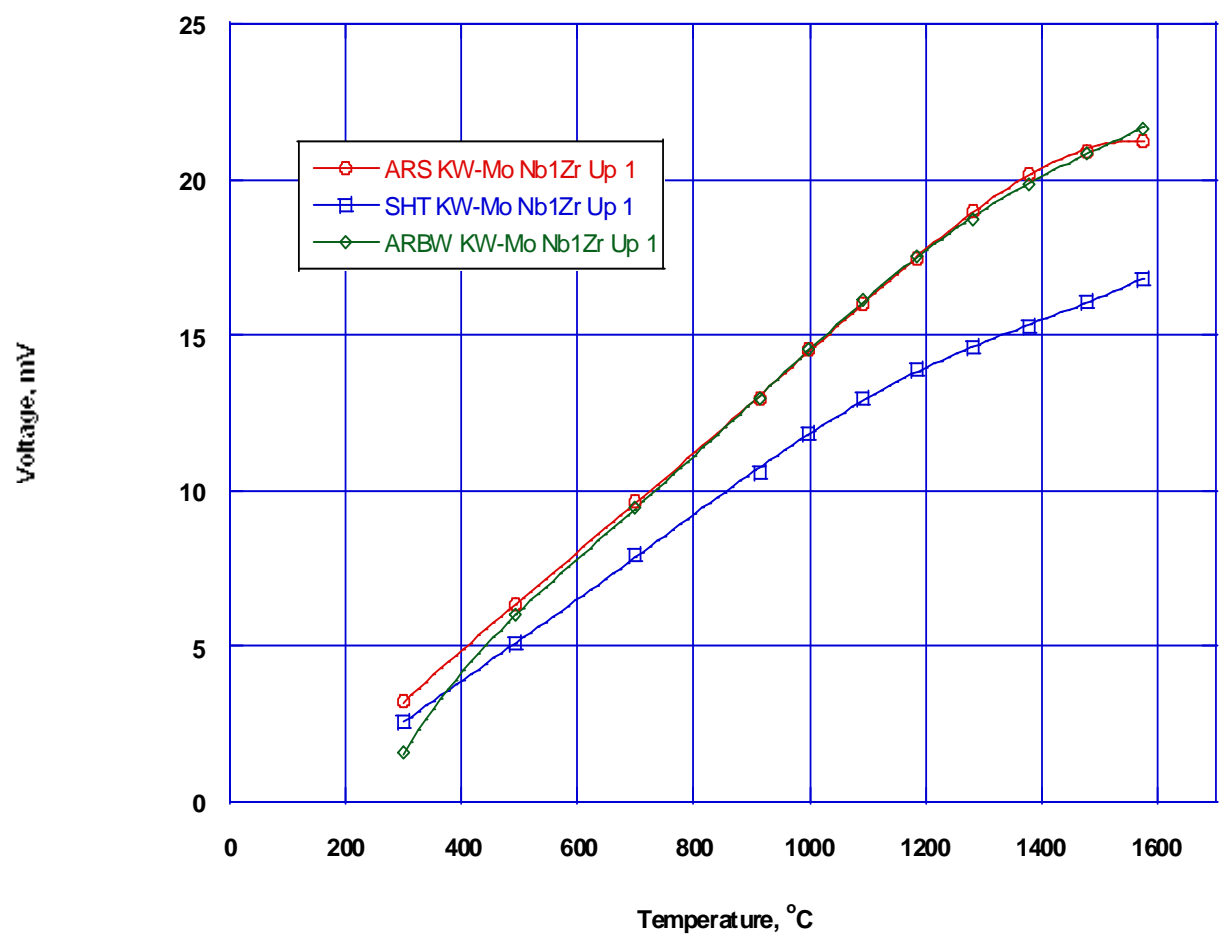

Figure 4-58. Comparison of first heating cycle for ARS, SHT, and ARBW KW-Mo Nb1\%Zr thermocouples

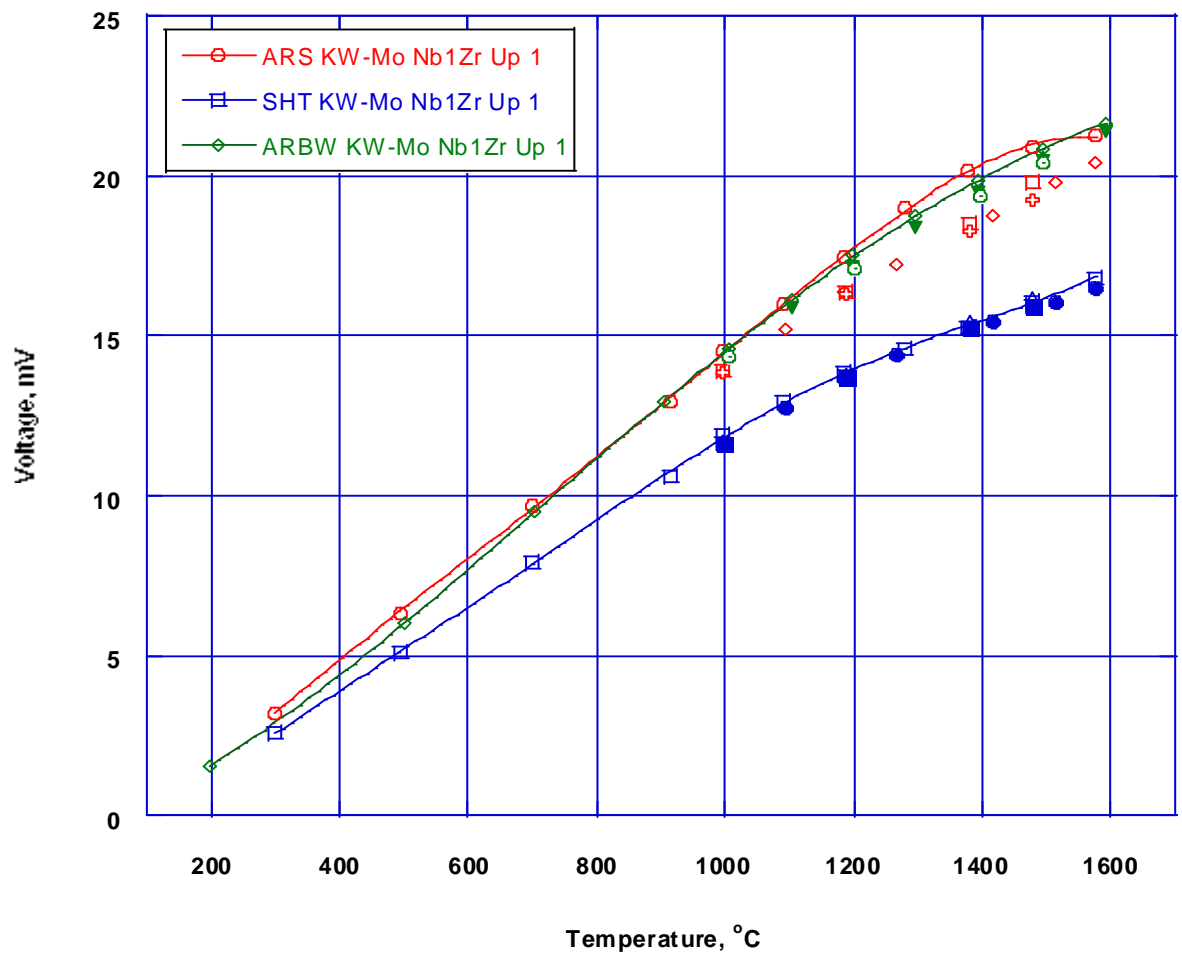

Figure 4-59. Comparison of ARS, SHT, and ARBW KW-Mo Nb1\%Zr thermocouples at high temperatures for two heating and cooling cycles. 
thermocouples have significantly higher sensitivity than the SHT thermocouple, and there is little difference between them. The curve for the ARBW thermocouple is somewhat more linear than that of the ARS. Figure 4-61 shows the curves for the first and second heating and cooling cycles at high temperatures. The ARS thermocouple shows a significant drop in emf, though it still has higher sensitivity than the SHT thermocouple. It is possible that the ARS thermocouple has not completely stabilized, the emf may continue to drop with more heating time, but it does not change much between the first cooling cycle and the second. The ARBW thermocouple shows a similar drop in emf to the ARS, though to a lesser degree. The SHT thermocouple is the most stable over the two heating and cooling cycles, although it shows significantly reduced sensitivity.

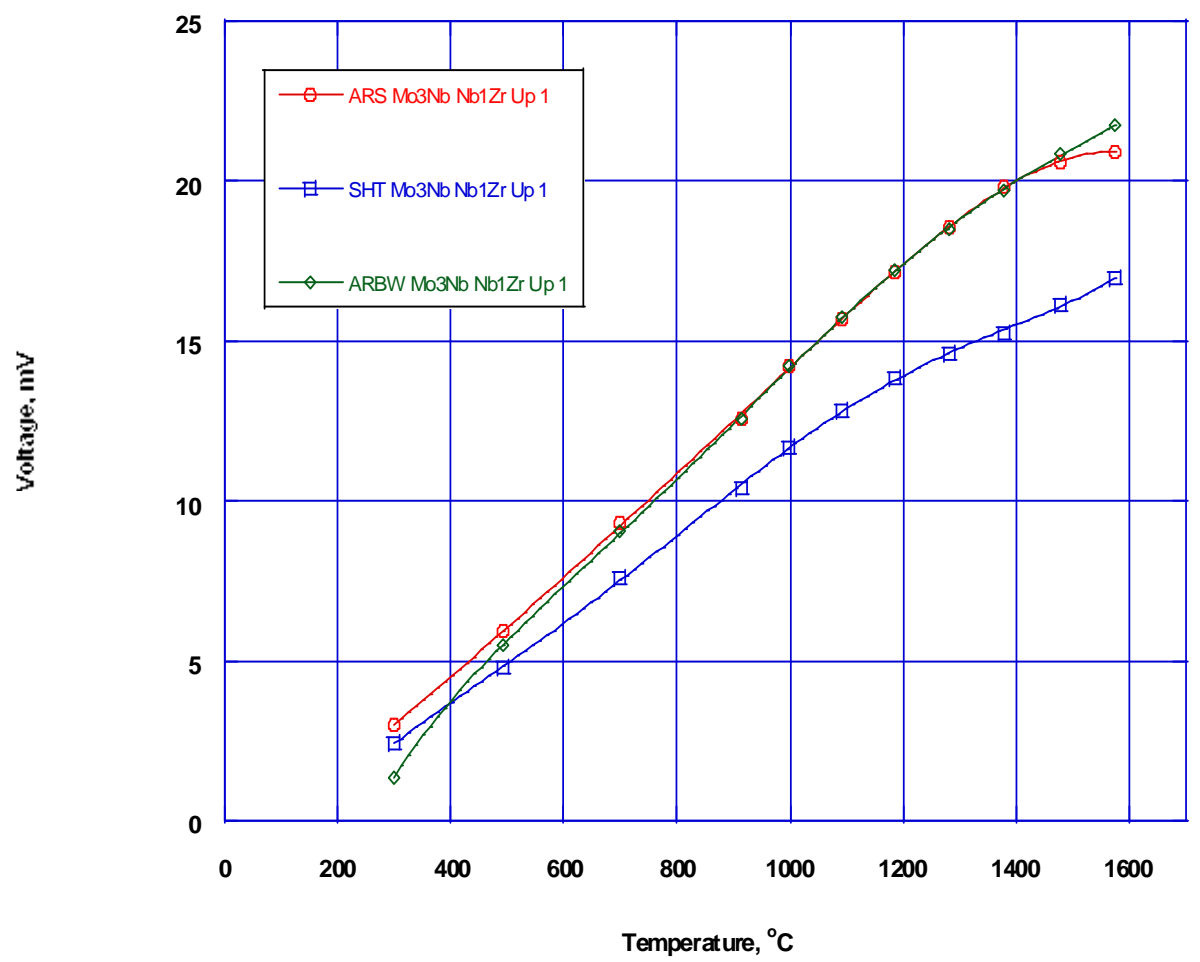

Figure 4-60. Comparison of first heating cycle for ARS, SHT, and ARBW Mo3\%Nb/ Nb1\%Zr thermocouples

Figures 4-62 and 4-63 compare curves for ARBW, ARS, and SHT Mo-1.6\%Nb/ Nb-1\%Zr thermocouples. Trends for this alloy are the same as for the KW-Mo/ Nb-1\%Z and Mo-3\%Nb/ $\mathrm{Nb}-1 \% \mathrm{Z}$ thermocouples. Figure 4-62 shows the curves for the first heating cycle. It is clear that heat treating the SHT thermocouple prior to testing significantly reduced its sensitivity. The ARBW and ARS thermocouples have significantly higher sensitivity than the SHT thermocouple, and there is little difference between them. The curve for the ARBW thermocouple is somewhat more linear than that of the ARS. Figure 4-63 shows the curves for the first and second heating and cooling cycles at high temperatures. The ARS thermocouple shows a significant drop in emf, though it still has higher sensitivity than the SHT thermocouple. It is possible that the ARS thermocouple has not completely stabilized, and the emf may continue to drop with more heating time. However, no significant changes in emf values were observed between the first and second 


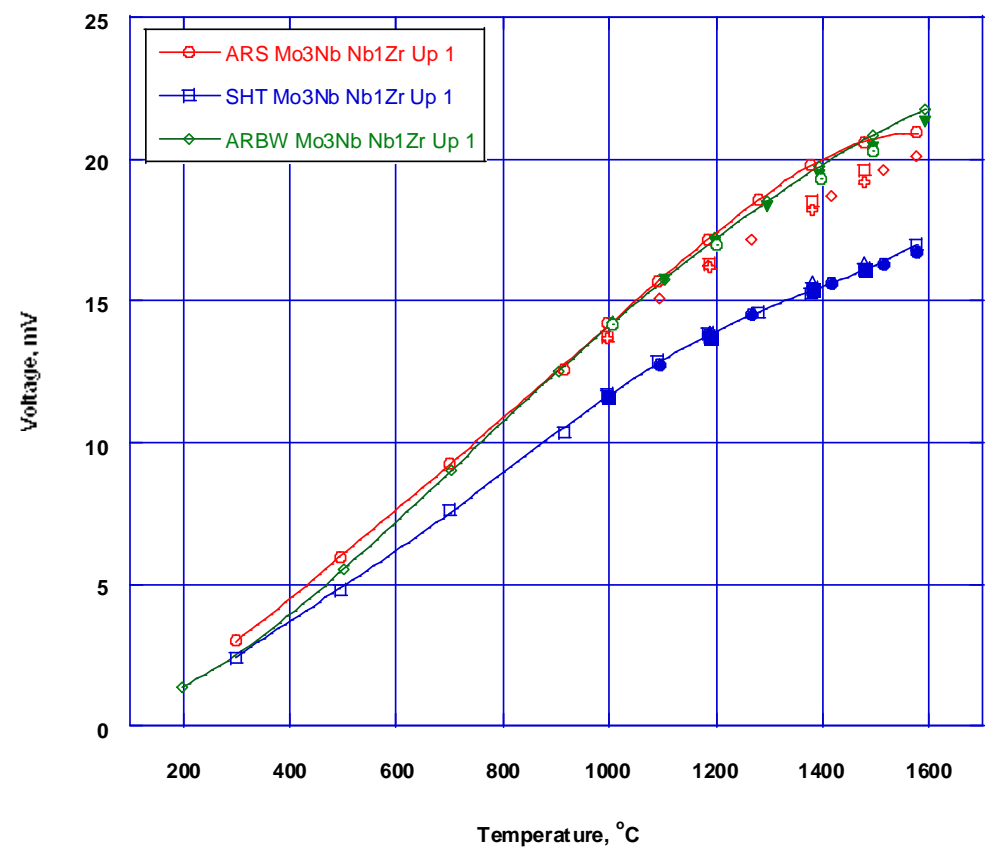

Figure 4-61. Comparison of ARS, SHT, and ARBW Mo3\%Nb Nb1\%Zr thermocouples at high temperatures for two heating and cooling cycles

cooling cycles. Similar decreases in emf values were observed for the ARBW and ARS thermocouples, although decreases were slightly smaller in the ARS thermocouple. The SHT thermocouple is the most stable over the two heating and cooling cycles, although it shows significantly reduced sensitivity.

Figure 4-64 compares first heating cycle curves for ARBW ODS-Mo/Nb1\%Zr, KW-Mo/ $\mathrm{Nb}-1 \% \mathrm{Zr}, \mathrm{Mo}-4 \% \mathrm{Nb} / \mathrm{Nb}-1 \% \mathrm{Zr}$, and Mo-1.6\%Nb/Nb-1\%Zr thermocouples. This curve gives a basis of comparison for the sensitivity of the thermocouple constructed with ODS-Mo, since no other thermocouples could be made from this material due to its limited availability. The ODSMo thermocouple does have higher sensitivity than the others, which are all very close when compared to each other. It should be noted that the drop in emf during subsequent cycles was approximately the same for these thermocouples.

Figures 4-65 through 4-67 compare emf values obtained from the first heating cycles for ARBW thermocouples constructed from KW-Mo, Mo-3\%Nb, and Mo-1.6\% Nb positive thermoelements matched with $\mathrm{Nb}-1 \% \mathrm{Zr}$, Nb-4\%Mo, Nb-6\%Mo, and $\mathrm{Nb}-8 \% \mathrm{Mo}$ negative thermoelements. Figure 4-65 shows the thermocouples constructed with KW-Mo positive thermoelements. A key observation is that the Nb-8\%Mo negative thermoelement shows reduced sensitivity compared to the other negative thermoelements, as well as a flat (non-single valued) response at high temperatures. The signal from the thermocouple constructed with the Nb-1\% $\mathrm{Zr}$ negative thermoelement shows the best resolution. Figure 4-66 shows the thermocouples constructed with Mo-3\%Nb positive thermoelements. The trends detailed for the KW-Mo thermocouple are also present for this thermocouple group. Figure 4-67 shows the thermocouples 


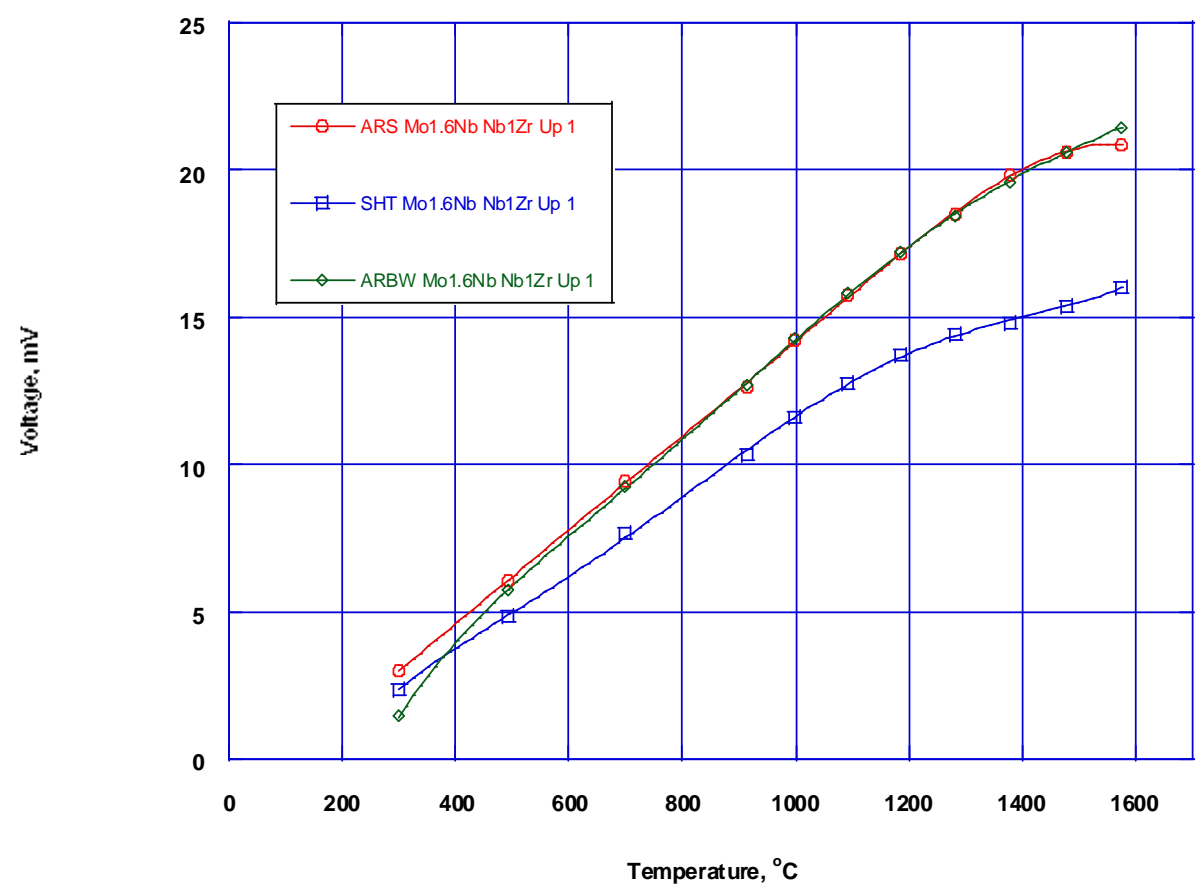

Figure 4-62. Comparison of first heating cycle for ARS, SHT, and ARBW Mo1.6\%Nb Nb1\%Zr thermocouples

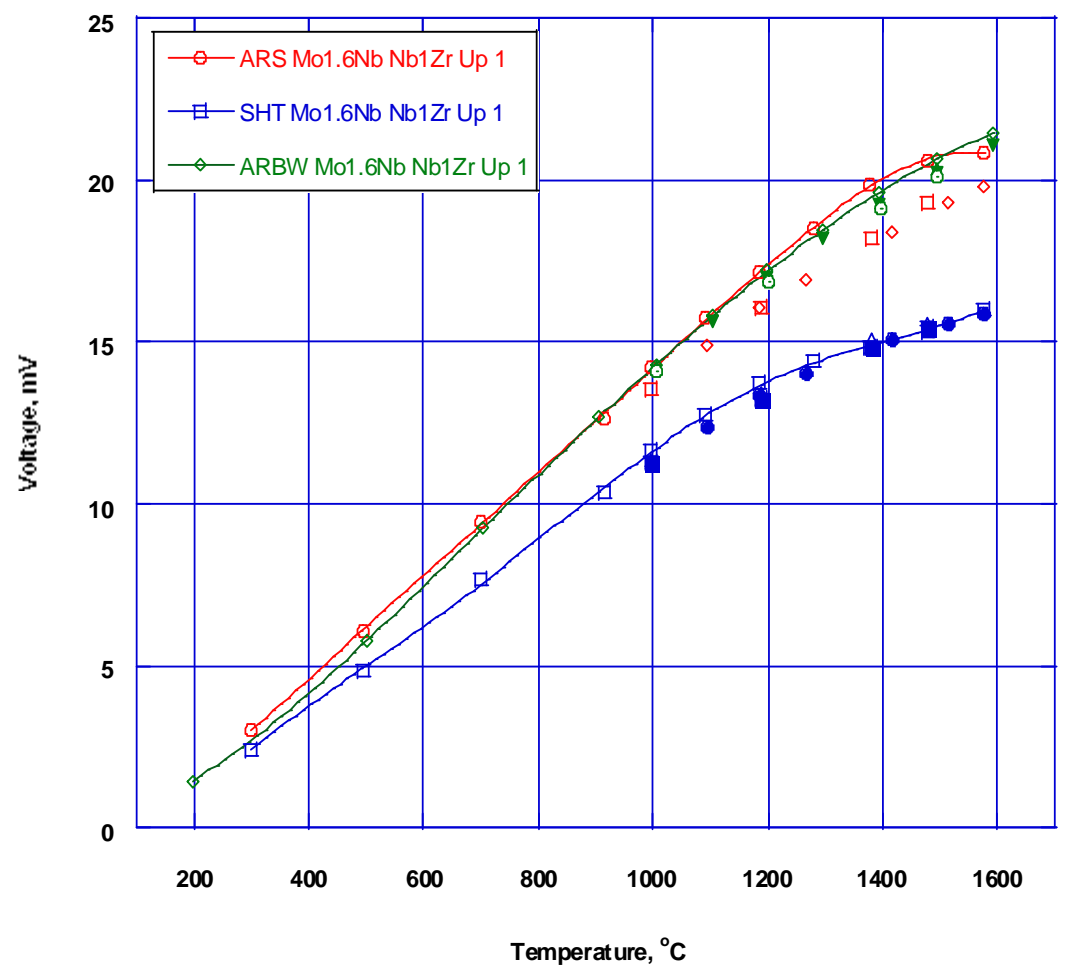

Figure 4-63. Comparison of ARS, SHT, and ARBW Mo1.6\%Nb Nb1\%Zr thermocouples at high temperatures for two heating and cooling cycles. 


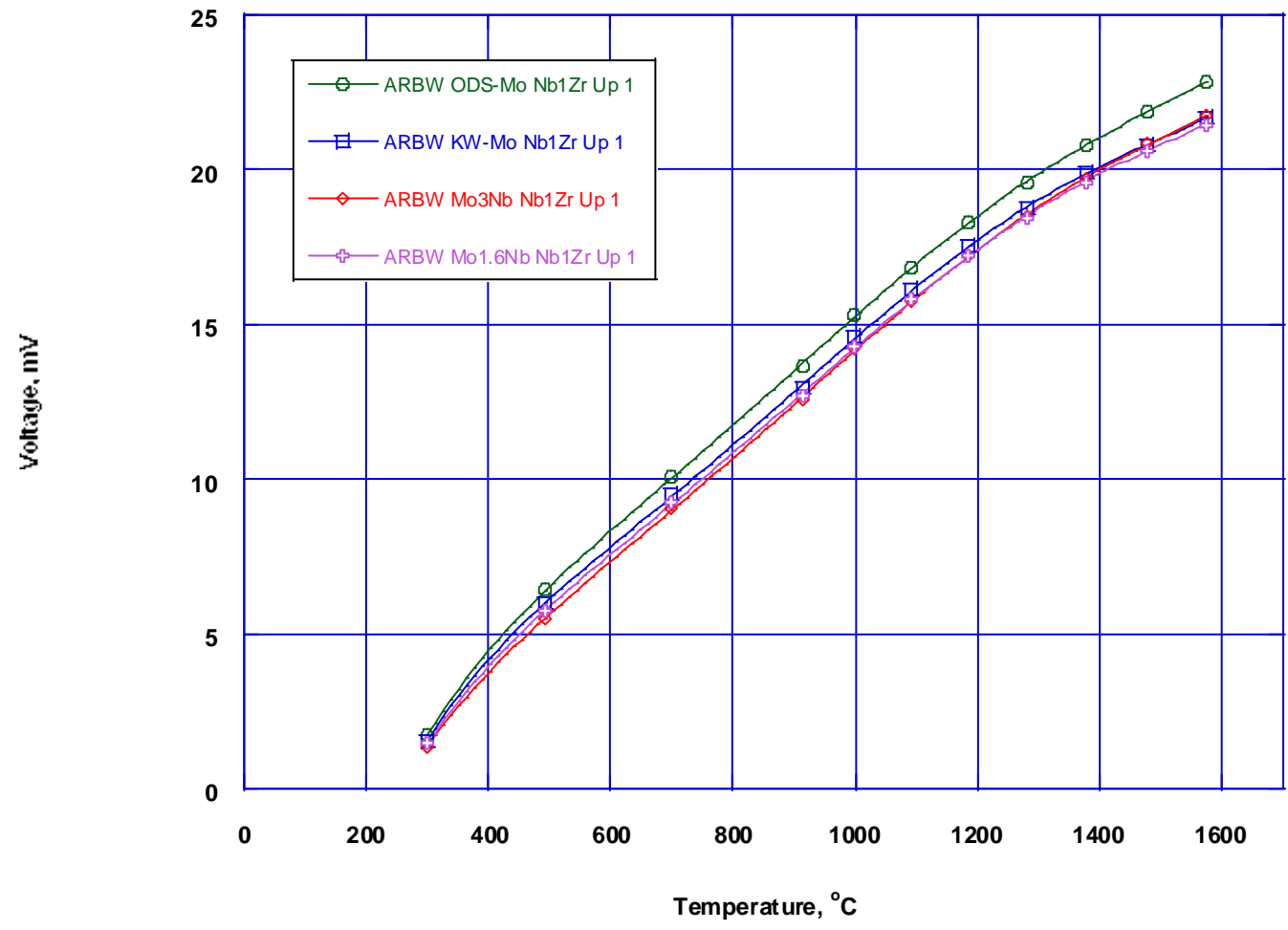

Figure 4-64. Comparison of ARBW thermocouples constructed with Nb1\%Zr negative thermoelements constructed with Mo-1.6\%Nb positive thermoelements. The trends from the two previous thermocouples are still evident. The difference between the signal from the thermocouple constructed with the $\mathrm{Nb}-1 \% \mathrm{Zr}$ negative thermoelement and the others is not as large, but the Nb8\%Mo negative thermoelement shows an even greater degree of emf drop at high temperatures.

Figure 4-68 shows a comparison of all ARBW thermocouples at high temperatures. The thermocouples with $\mathrm{Nb}-1 \% \mathrm{Zr}$ negative thermoelements all show higher sensitivity than any thermocouples constructed with different negative thermoelements, with the ODS-Mo/Nb-1\%Zr thermocouple showing the best sensitivity by a significant margin. All thermocouples constructed with Nb-8\%Mo negative thermoelements show lower sensitivity than any others and show a flattening of the output signal over the high temperature range. The signals from thermocouples constructed with $\mathrm{Nb}-6 \% \mathrm{Mo}$ and Nb-8\%Mo negative thermoelements all lie between the Nb$8 \% \mathrm{Mo}$ and $\mathrm{Nb}-1 \% \mathrm{Zr}$ thermocouple signals, with no definitive trends setting them apart from each other. 


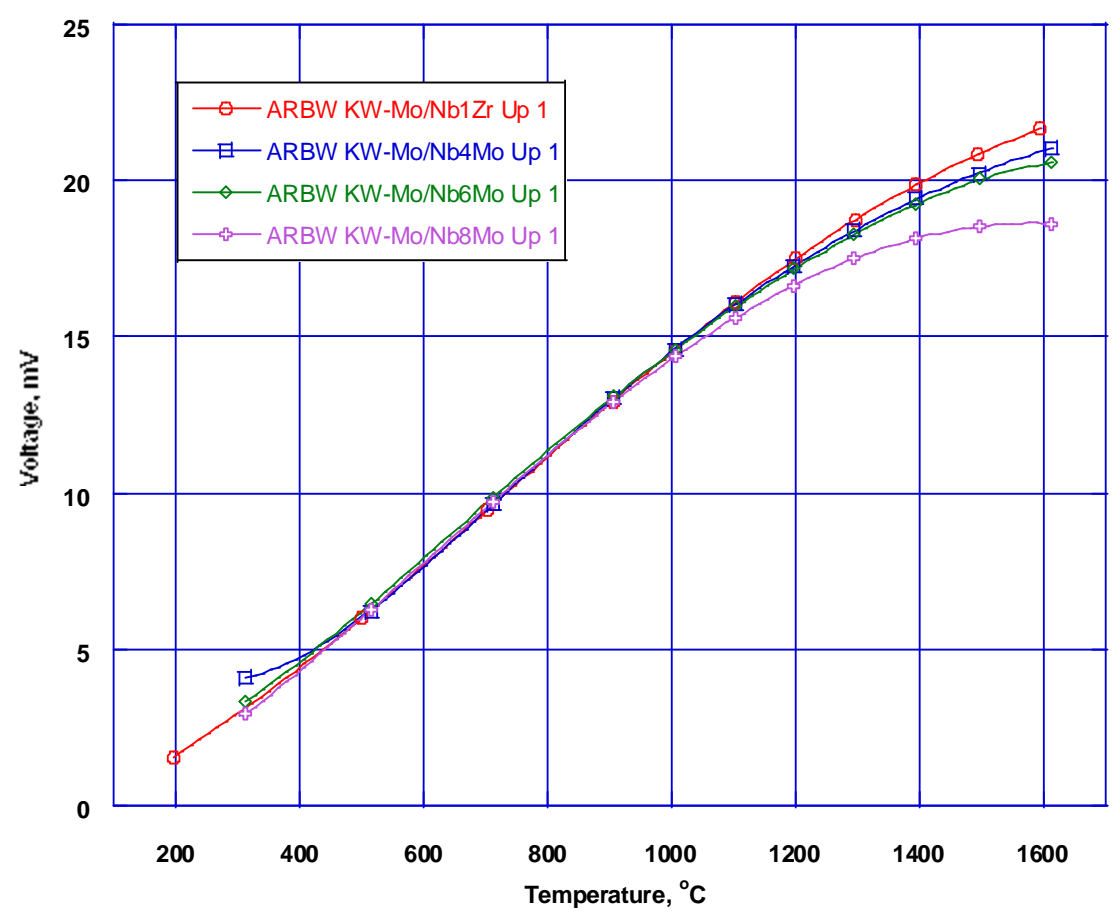

Figure 4-65. Comparison of ARBW thermocouples constructed with KW-Mo positive thermoelements

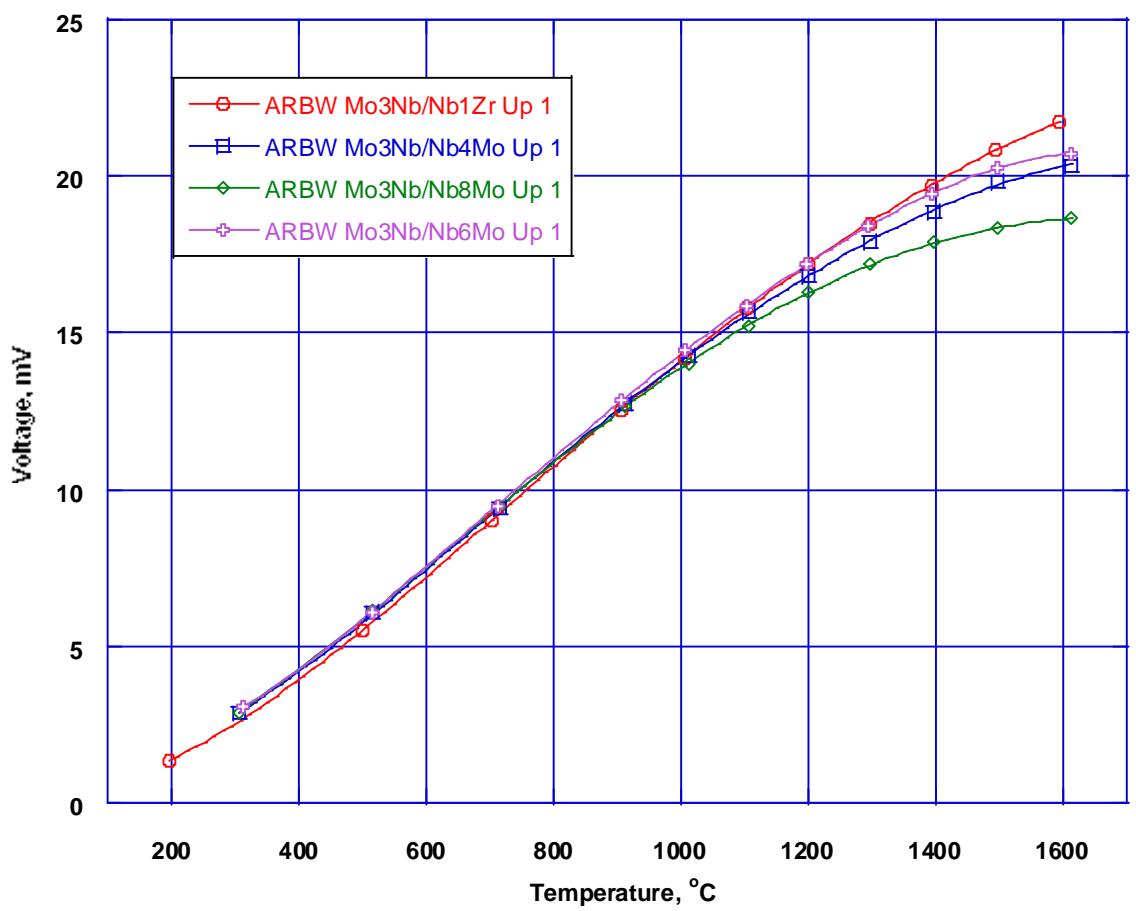

Figure 4-66. Comparison of ARBW thermocouples constructed with Mo3\%Nb positive thermoelements 


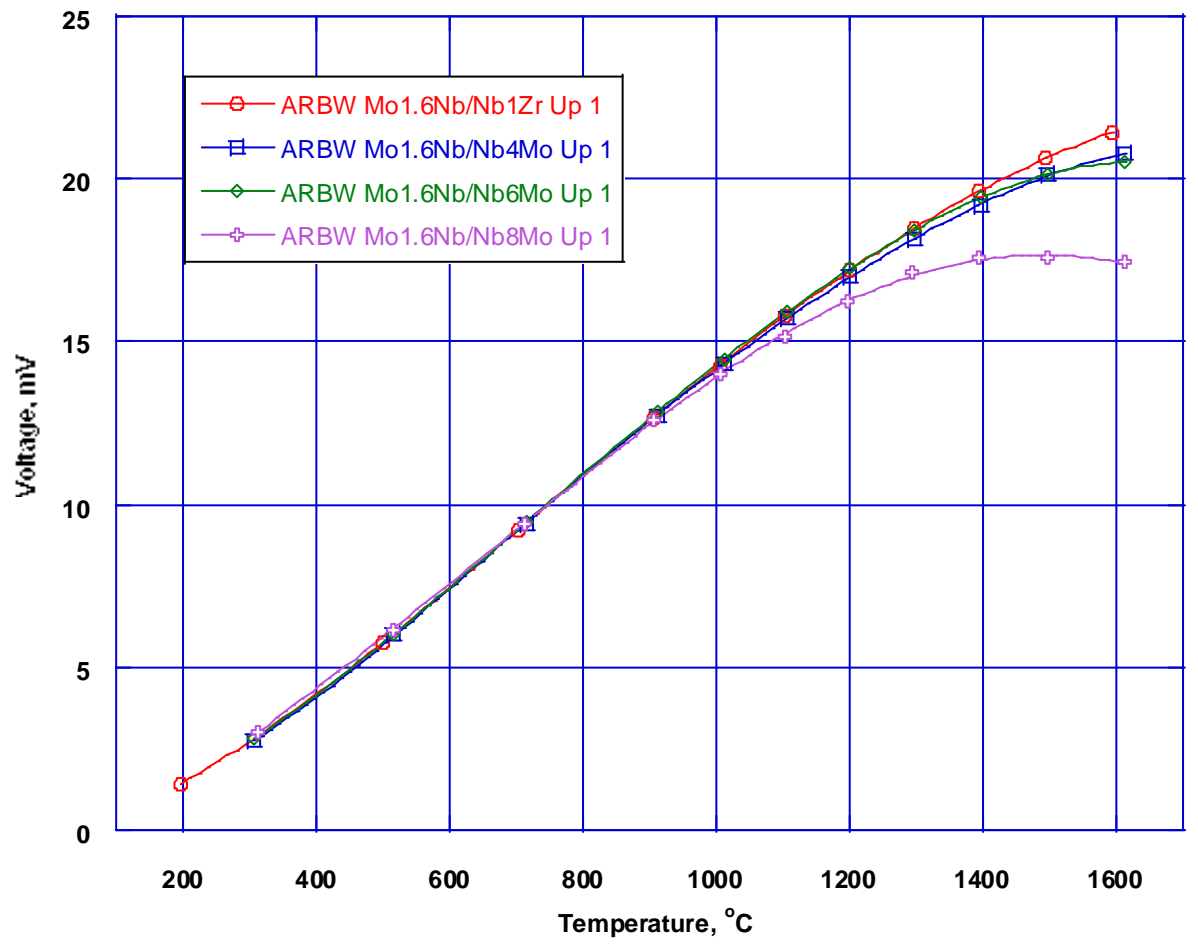

Figure 4-67. Comparison of ARBW thermocouples constructed with Mo1.6\%Nb positive thermoelements

Figure 4-69 compares first heating cycle curves for SHT KW-Mo/Nb-1\%Zr, Mo$3 \% \mathrm{Nb} / \mathrm{Nb}-1 \% \mathrm{Zr}$, and Mo-1.6\%Nb/Nb-1\%Zr thermocouples. The sensitivity of the KW-Mo and Mo-3\%Nb thermocouples is approximately equal, with that of the Mo-1.6\%Nb thermocouple being slightly lower. The KW-Mo thermocouple curve seems to be slightly more linear than the Mo-3\%Nb curve. 


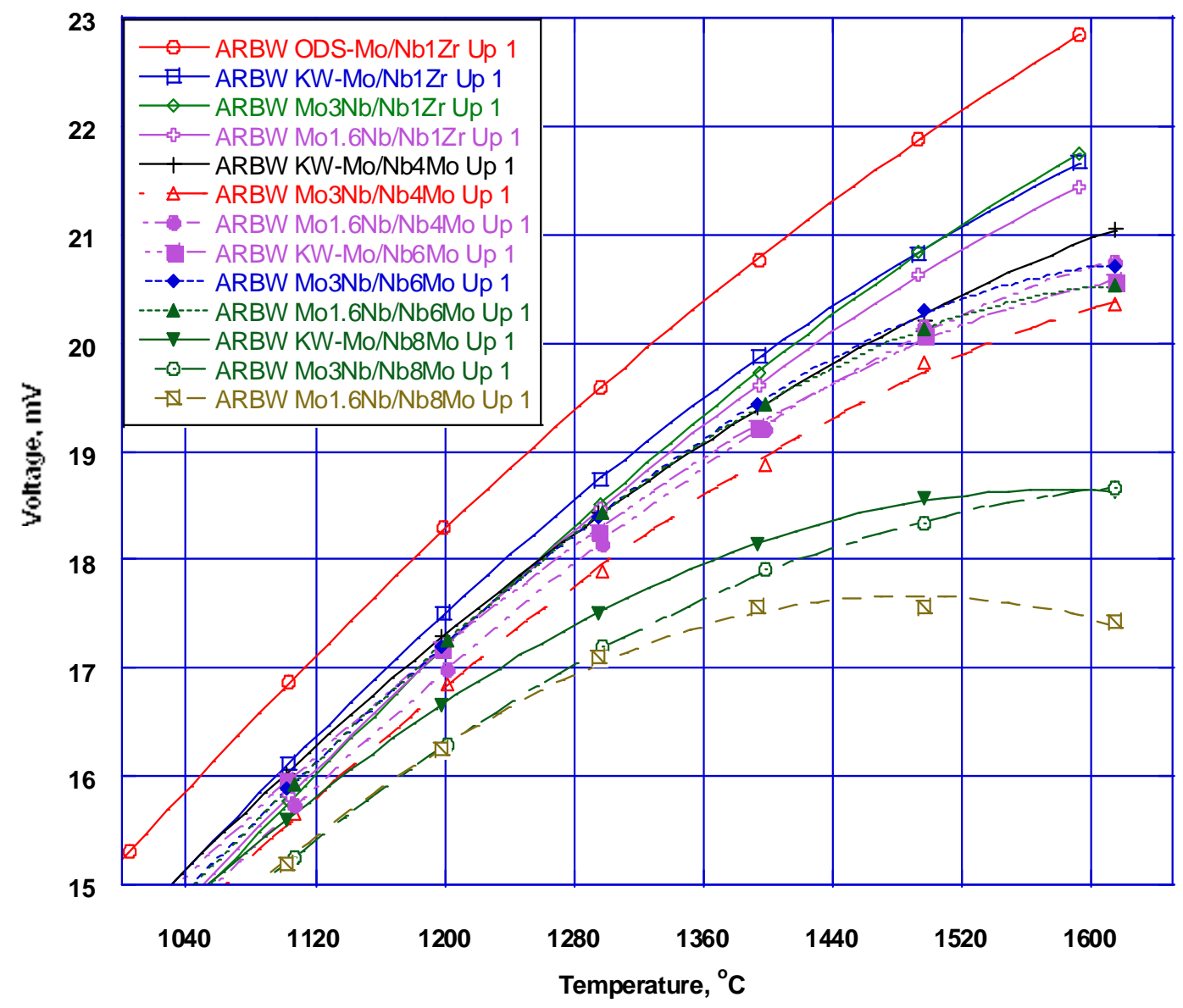

Figure 4-68. High temperature comparison of all ARBW thermocouples tested 


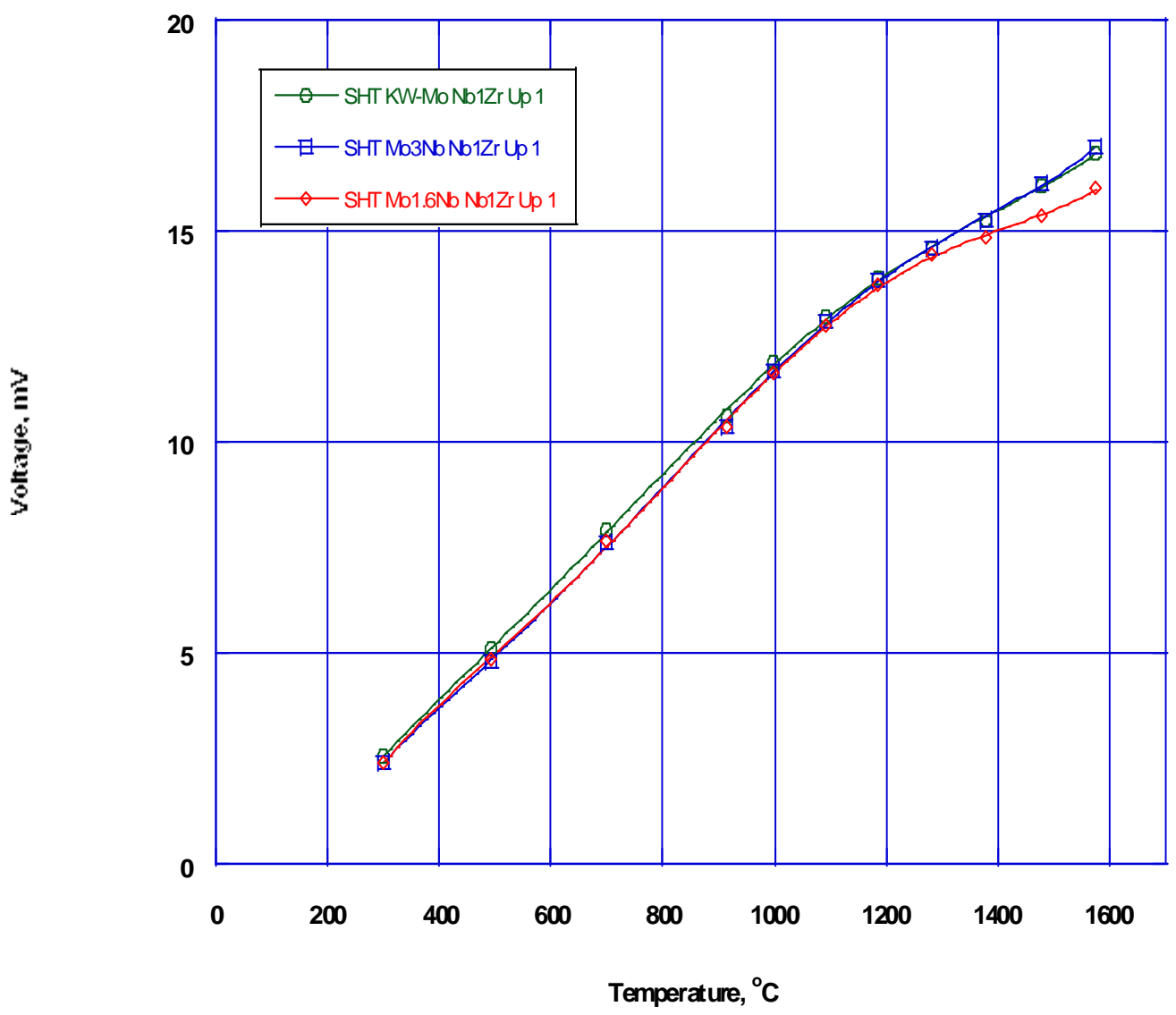

Figure 4-69. Comparison of sensitivity between SHT thermocouples 


\section{Long Duration and Transient Evaluations (Task 1.3)}

The performance of these thermocouples at elevated temperatures for long durations and during transients must be verified. Long duration tests at elevated temperatures (ranging from $1200{ }^{\circ} \mathrm{C}$ to $1500{ }^{\circ} \mathrm{C}$ ) for up to 6 months are being completed using the setup shown in Figure 5-1. Thermocouples were inserted into alumina tubes in a tube furnace configured with a continuous flow of gettered argon. Test data were automatically recorded at frequent intervals and stored on a computer. It should be noted that lower temperature, long duration tests were initiated prior to the start of this UNERI. Sponsors of these earlier tests requested certain conditions, such as temperature transients or special materials, as part of the tests to address their requirements. However, it is of interest to review these earlier results along with high temperature tests conducted as part of this UNERI.

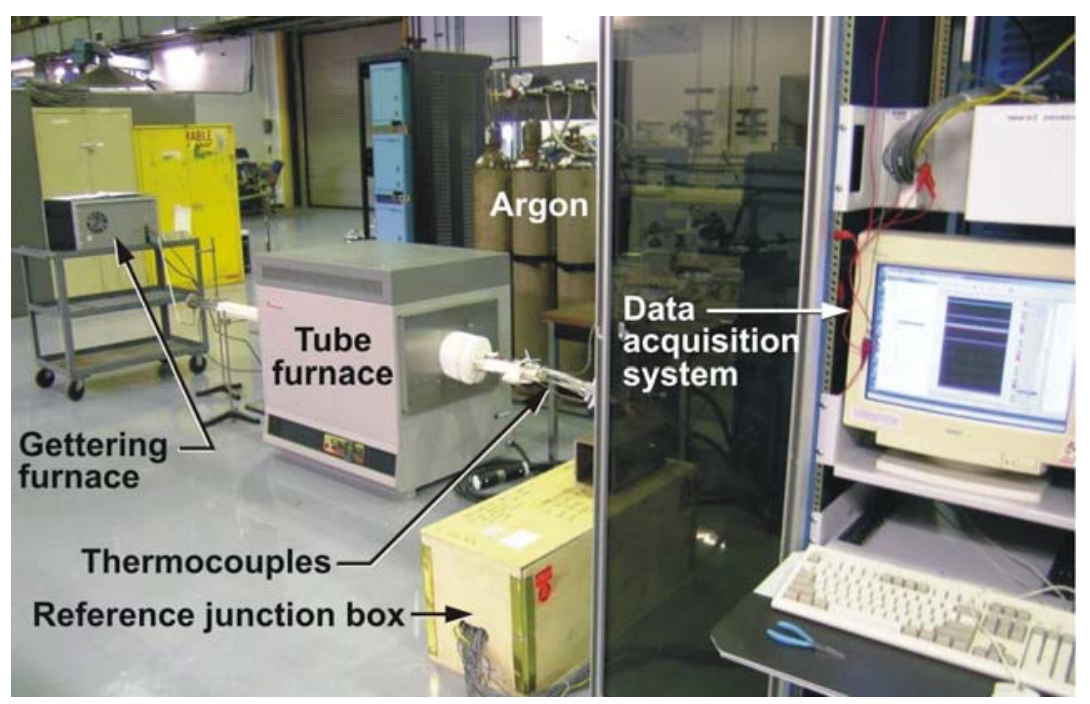

Figure 5-1. Typical setup for long duration tests.

\section{1. $1200^{\circ} \mathrm{C}$}

The first long duration test, which was conducted at $1200{ }^{\circ} \mathrm{C}$, was sponsored by the Advanced Gas Reactor test program. The objective of this test was to evaluate the performance of candidate Type $\mathrm{N}$ and K commercial thermocouples and INL-developed HTIR-TCs when subjected to $1200{ }^{\circ} \mathrm{C}$ for long time periods (over 4000 hours). In addition to assessing thermocouple performance at high temperatures, the test included transients to assess the impact of reactor shutdowns and graphite holders to address concerns about materials that were included as part of a planned irradiation. 


\subsubsection{Approach}

At the beginning of the $1200{ }^{\circ} \mathrm{C}$ test, nineteen commercially-available Type $\mathrm{N}$ thermocouples, three commercially-available Type K thermocouples, and nine of the INLdeveloped $\mathrm{KW}-\mathrm{Mo} / \mathrm{Nb}-1 \% \mathrm{Zr}$ thermocouples were inserted into a tube furnace that was configured similarly to the setup shown in Figure 5-1. During testing, additional commercial thermocouples were also added for shorter time periods. Several transients were included in this test to address the impact of expected reactor shutdowns. Table 5-1 summarizes characteristics of thermocouples included in the $1200{ }^{\circ} \mathrm{C}$ test. Thermocouples were placed in different alumina flow tubes in a larger furnace muffle tube. Figure 5-2 illustrates the placement of the thermocouples.

Table 5-1. Characteristics of thermocouples tested at $1200{ }^{\circ} \mathrm{C}$ for 4000 hours.

\begin{tabular}{|c|c|c|c|c|c|c|c|c|c|}
\hline \multirow{2}{*}{ Tube } & \multirow{2}{*}{ TC ID } & \multirow{2}{*}{ Type } & \multirow{2}{*}{ TC OD, in. } & \multirow{2}{*}{ Sheath Material } & \multirow{2}{*}{$\begin{array}{l}\text { Insulator } \\
\text { Material }\end{array}$} & \multicolumn{2}{|c|}{ Initial Resistance ${ }^{a}$} & \multicolumn{2}{|c|}{ Final Resistance $^{\mathrm{a}}$} \\
\hline & & & & & & Loop, $\Omega$ & Insulation, $\mathrm{M} \Omega$ & Loop, $\Omega$ & Insulation, $\mathrm{M} \Omega$ \\
\hline \multirow[t]{7}{*}{1} & \multirow[t]{3}{*}{$\mathrm{D} 2-\mathrm{N} 1^{\mathrm{b}}$} & \multirow[t]{3}{*}{ N Multipoint } & \multirow[t]{3}{*}{$3 / 32 "$} & \multirow[t]{3}{*}{ Inconel-600 } & $\mathrm{MgO}$ & 101 & 2E10 & NA & NA \\
\hline & & & & & $\mathrm{MgO}$ & 100 & $2 \mathrm{E} 10$ & NA & NA \\
\hline & & & & & $\mathrm{MgO}$ & 97.5 & 2E10 & NA & NA \\
\hline & \multirow[t]{3}{*}{$\mathrm{D} 2-\mathrm{N} 2^{\mathrm{b}}$} & \multirow[t]{3}{*}{ N } & \multirow[t]{4}{*}{ 3/32" } & \multirow[t]{3}{*}{ Inconel-600 } & $\mathrm{MgO}$ & 101 & 4E10 & NA & NA \\
\hline & & & & & $\mathrm{MgO}$ & 99.9 & $5 \mathrm{E} 10$ & NA & NA \\
\hline & & & & & $\mathrm{MgO}$ & 98.2 & $5 \mathrm{E} 10$ & NA & NA \\
\hline & Ref TC & $\mathrm{s}$ & & Molybdenum & $\mathrm{MgO}$ & NA & NA & NA & NA \\
\hline \multirow[t]{5}{*}{2} & O2-N2 & $\mathrm{N}$ & $1 / 16^{\prime \prime}$ & $\mathrm{c}$ & $\mathrm{MgO}$ & 47.6 & $2 \mathrm{E} 6$ & 41.8 & 14.2 \\
\hline & O2-N3 & N & $1 / 16^{\prime \prime}$ & c & $\mathrm{MgO}$ & 47.8 & $5 \mathrm{E} 9$ & 42.4 & 16.1 \\
\hline & $\mathrm{A} 2-\mathrm{N} 1$ & N & $1 / 16^{\prime \prime}$ & $d$ & $\mathrm{MgO}$ & 30.9 & 3E9 & 28.1 & 12.1 \\
\hline & A2-N2 & N & $1 / 16^{\prime \prime}$ & d & $\mathrm{MgO}$ & 30.7 & 3E11 & 28.2 & 11.9 \\
\hline & A2-N3 & $\mathrm{N}$ & $1 / 16^{\prime \prime}$ & d & $\mathrm{MgO}$ & 30.1 & 2E9 & 31.7 & $1 \mathrm{E} 10$ \\
\hline \multirow[t]{5}{*}{3} & 12-C1 & Inc 600 vs NN & $1 / 16^{\prime \prime}$ & Inconel-600 & $\mathrm{MgO}$ & 28.7 & $N A^{e}$ & 27.0 & $N A^{e}$ \\
\hline & $12-\mathrm{C} 2$ & Inc 600 vs NN & $1 / 16^{\prime \prime}$ & Inconel-600 & $\mathrm{MgO}$ & 29.0 & $N A^{e}$ & 26.9 & $N A^{e}$ \\
\hline & 12-C3 & Inc 600 vs NN & $1 / 16^{\prime \prime}$ & Inconel-600 & $\mathrm{MgO}$ & 28.9 & $N A^{e}$ & 27.2 & $N A^{e}$ \\
\hline & I2-N1 & N & $1 / 16^{\prime \prime}$ & Haynes-230 & $\mathrm{MgO}$ & 21.3 & $2 \mathrm{E} 10$ & 19.9 & 17.1 \\
\hline & 12-N3 & $\mathrm{N}$ & $1 / 16^{\prime \prime}$ & Haynes-230 & $\mathrm{MgO}$ & 21.2 & 2E10 & 21.7 & $1 \mathrm{E} 12$ \\
\hline \multirow[t]{4}{*}{4} & 12-N4 & $\mathrm{N}$ & $1 / 8^{\prime \prime}$ & Inconel-600 & $\mathrm{MgO}$ & 26.6 & 1E10 & 28.1 & 8E8 \\
\hline & 12-N6 & N & $1 / 8 "$ & Inconel-600 & $\mathrm{MgO}$ & 26.7 & $1 \mathrm{E} 9$ & 28.0 & $1 \mathrm{E} 12$ \\
\hline & 12-N7 & $\mathrm{N}$ & $1 / 16^{\prime \prime}$ & Inconel-600 & $\mathrm{MgO}$ & 10.7 & 2E10 & 11.0 & 4E8 \\
\hline & 12-N9 & $\mathrm{N}$ & $1 / 16^{\prime \prime}$ & Inconel-600 & $\mathrm{MgO}$ & 10.9 & $1 \mathrm{E} 10$ & 11.0 & 7E9 \\
\hline \multirow[t]{6}{*}{5} & INL2-CA1 & KW-Mo vs Nb-1Zr & $1 / 16^{\prime \prime}$ & $\mathrm{Nb}-1 \mathrm{Zr}$ & $\mathrm{Al}_{2} \mathrm{O}_{3}$ & 8.2 & 1E10 & 7.9 & 1E12 \\
\hline & INL2-CA2 & KW-Mo vs Nb- $1 Z r$ & $1 / 16 "$ & $\mathrm{Nb}-1 \mathrm{Zr}$ & $\mathrm{Al}_{2} \mathrm{O}_{3}$ & 7.8 & $1 \mathrm{E} 10$ & 7.3 & $8 \mathrm{E} 11$ \\
\hline & INL2-CA3 & KW-Mo vs Nb-1Zr & $1 / 16^{\prime \prime}$ & $\mathrm{Nb}-1 \mathrm{Zr}$ & $\mathrm{Al}_{2} \mathrm{O}_{3}$ & 8.7 & $2 \mathrm{E} 9$ & 8.8 & $1 \mathrm{E} 12$ \\
\hline & INL2-CH1 & KW-Mo vs Nb-1Zr & $1 / 16^{\prime \prime}$ & $\mathrm{Nb}-1 \mathrm{Zr}$ & $\mathrm{HfO}_{2}$ & 8.4 & $2 \mathrm{E} 7$ & 8.6 & 2E10 \\
\hline & INL2-CH2 & KW-Mo vs Nb-1Zr & $1 / 16^{\prime \prime}$ & $\mathrm{Nb}-1 \mathrm{Zr}$ & $\mathrm{HfO}_{2}$ & 8.1 & 3E8 & 8.4 & $6 \mathrm{E} 10$ \\
\hline & INL2-CH3 & KW-Mo vs Nb- $1 Z r$ & $1 / 16^{\prime \prime}$ & $\mathrm{Nb}-1 \mathrm{Zr}$ & $\mathrm{HfO}_{2}$ & 8.1 & $8 \mathrm{E} 7$ & 8.5 & $1 \mathrm{E} 12$ \\
\hline \multirow[t]{6}{*}{6} & P2-K1 & $\mathrm{K}$ & $1 / 16^{\prime \prime}$ & t & $\mathrm{MgO}$ & 37.7 & 2E10 & 43.3 & 2E10 \\
\hline & $\mathrm{P} 2-\mathrm{K} 2$ & K & $1 / 16^{\prime \prime}$ & $f$ & $\mathrm{MgO}$ & 37.6 & $1 \mathrm{E} 10$ & 36.7 & 15.7 \\
\hline & $\mathrm{P} 2-\mathrm{K} 3$ & K & $1 / 16^{\prime \prime}$ & $f$ & $\mathrm{MgO}$ & 37.9 & $1 \mathrm{E} 10$ & 42.5 & 3E10 \\
\hline & P2-N1 & N & $1 / 16^{\prime \prime}$ & $f$ & $\mathrm{MgO}$ & 53.7 & 2E10 & 48.3 & 19.4 \\
\hline & P2-N2 & N & $1 / 16^{\prime \prime}$ & $f$ & $\mathrm{MgO}$ & 53.8 & $2 \mathrm{E} 10$ & 56.9 & $6 \mathrm{E} 9$ \\
\hline & P2-N3 & $\mathrm{N}$ & $1 / 16^{\prime \prime}$ & $f$ & $\mathrm{MgO}$ & 54.4 & $1 \mathrm{E} 10$ & 57.9 & 4E10 \\
\hline \multirow[t]{3}{*}{7} & INL2-IM1 & KW-Mo vs Nb-1Zr & $1 / 16^{\prime \prime}$ & Inconel-600 & $\mathrm{MgO}$ & 7.8 & $5 E 8$ & 8.6 & $4 \mathrm{E} 9$ \\
\hline & INL2-IM2 & KW-Mo vs Nb- $1 \mathrm{Zr}$ & $1 / 16^{\prime \prime}$ & Inconel-600 & $\mathrm{MgO}$ & 8.6 & 9E9 & 8.2 & 7E9 \\
\hline & INL2-IM3 & KW-Mo vs Nb-1Zr & $1 / 16^{\prime \prime}$ & Inconel-600 & $\mathrm{MgO}$ & 7.6 & $1 \mathrm{E} 8$ & 8.7 & $4 \mathrm{E} 9$ \\
\hline
\end{tabular}

a. Taken at room temperature.

b. Multi-point thermocouple.

c. Special Ni-based alloy sheath.

d. Special ceramic insulator designed to reduce degradation of thermoelements

e. Co-axial thermocouple design.

f. Sheath contains $73 \% \mathrm{Ni}, 22 \% \mathrm{Cr}, 3 \% \mathrm{Mo}$, and $1.4 \% \mathrm{Si}$. 


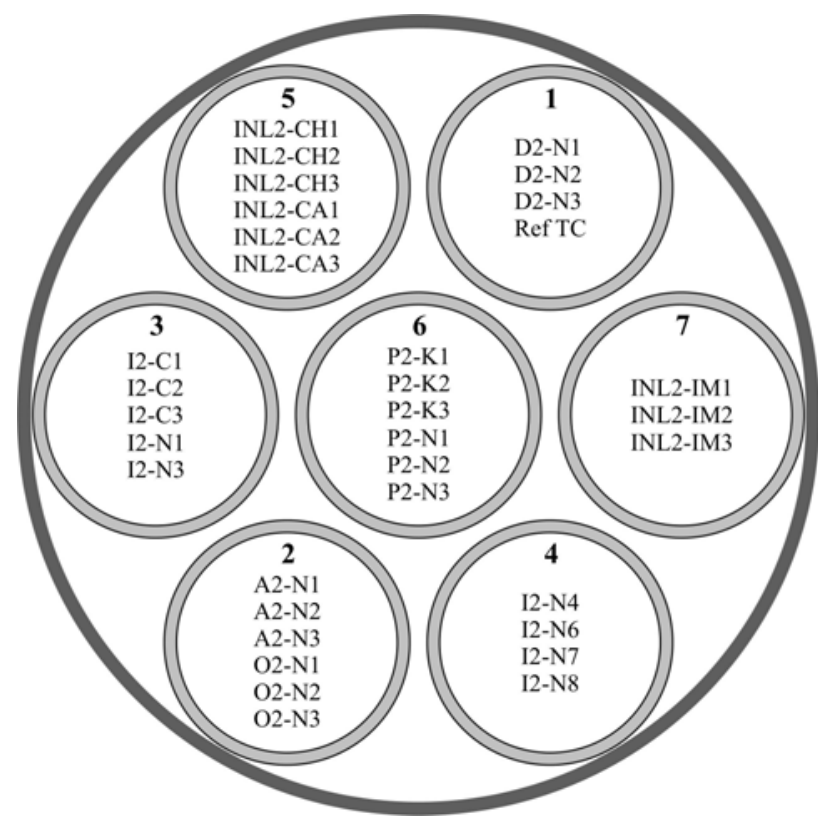

Figure 5-2. Placement of thermocouples in $1200{ }^{\circ} \mathrm{C}$ test.

\subsubsection{Results}

The measured emf voltages from thermocouples that remained in the $1200{ }^{\circ} \mathrm{C}$ test for the entire test period are shown in Figures 5-3 through 5-5. Several transients were included in this test to assess their effect on the thermocouples' behavior. As indicated in these figures, the measured emf of some of these thermocouples (e.g., the Type K thermocouple designated P2K1) started to drift downward from the onset of testing. Note that this downward drift wasn't influenced by the transients; nor did the transients produce open-circuit failures. The emf of the INL-developed thermocouples appears very stable (see the curves labeled, "INL CH2 Mo/Nb" and "INL CH2 Mo/Nb", which correspond to two of the doped Mo-Nb1\%Zr thermocouples with $\mathrm{Nb}-1 \% \mathrm{Zr}$ sheaths and $\mathrm{HfO}_{2}$ insulation and the curves labeled, "INL2-IM2 Mo/Nb" and "INL2IM3 Mo/Nb", which correspond to two of the Mo-Nb1\%Zr thermocouples with Inconel 600 sheaths and $\mathrm{MgO}$ insulation). Although the Inconel 600 sheath and $\mathrm{MgO}$ insulator materials are not proposed for applications above $1300{ }^{\circ} \mathrm{C}$, the test sponsor requested that they be included because of interest in using these thermocouples at $1200{ }^{\circ} \mathrm{C}$. The emf corresponding to $1200{ }^{\circ} \mathrm{C}$ for the $\mathrm{MgO}$-insulated and $\mathrm{HfO}_{2}$-insulated thermocouples differed. This is primarily attributed to the lower heat treatment temperature selected for the MgO-insulated thermocouples (Because of temperature limitations associated with materials included in these thermocouples, Inconel 600 thermocouples were heat treated at $1300{ }^{\circ} \mathrm{C}$ for 18.5 hours, and thermocouples with niobium-1\% zirconium sheaths were heat treated for approximately 20 hours at $1500{ }^{\circ} \mathrm{C}$.) 

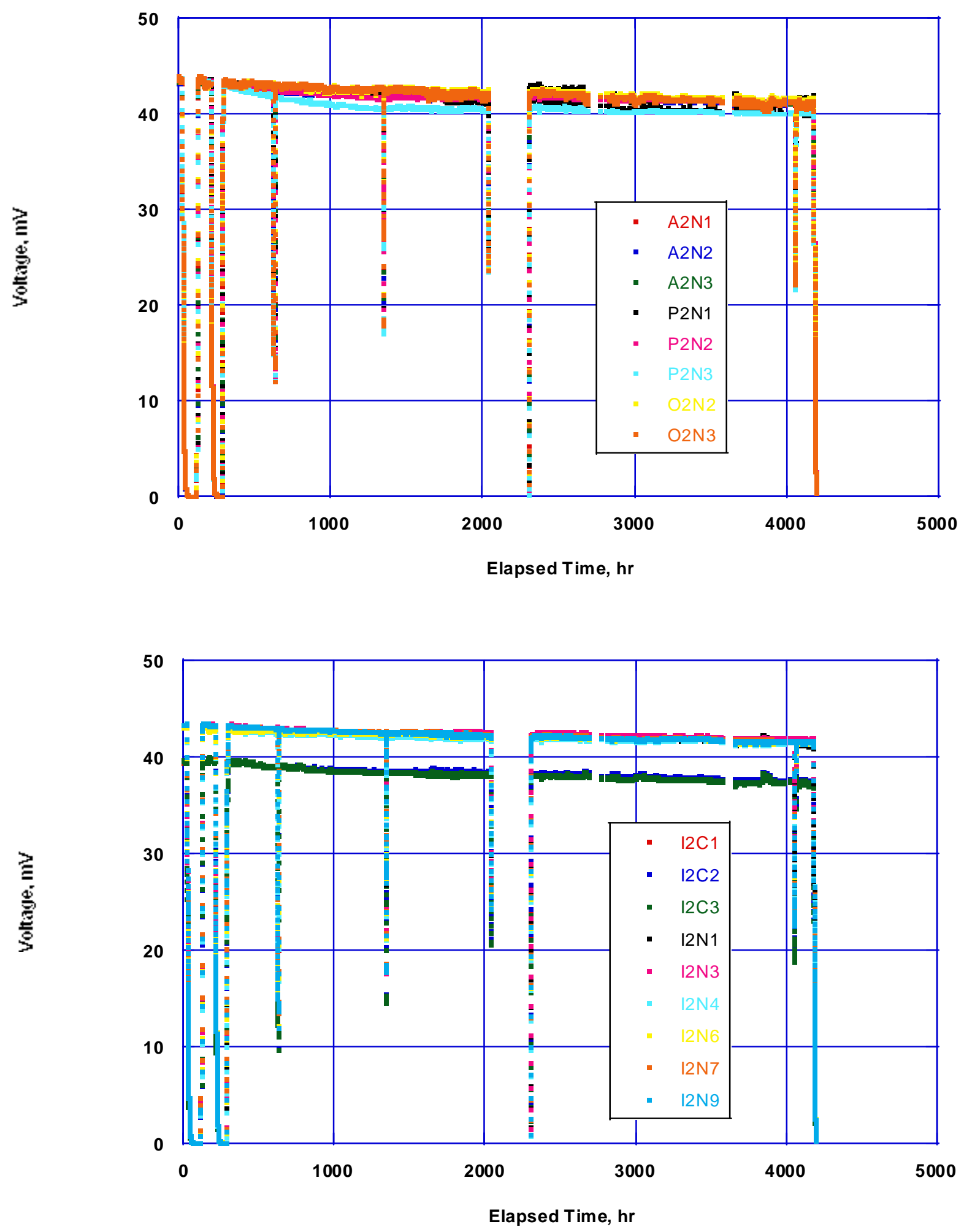

Figure 5-3. Measured emf of Type $\mathrm{N}$ and "coaxial” NN versus Inconel 600 thermocouples included in $1200{ }^{\circ} \mathrm{C}$ test. 


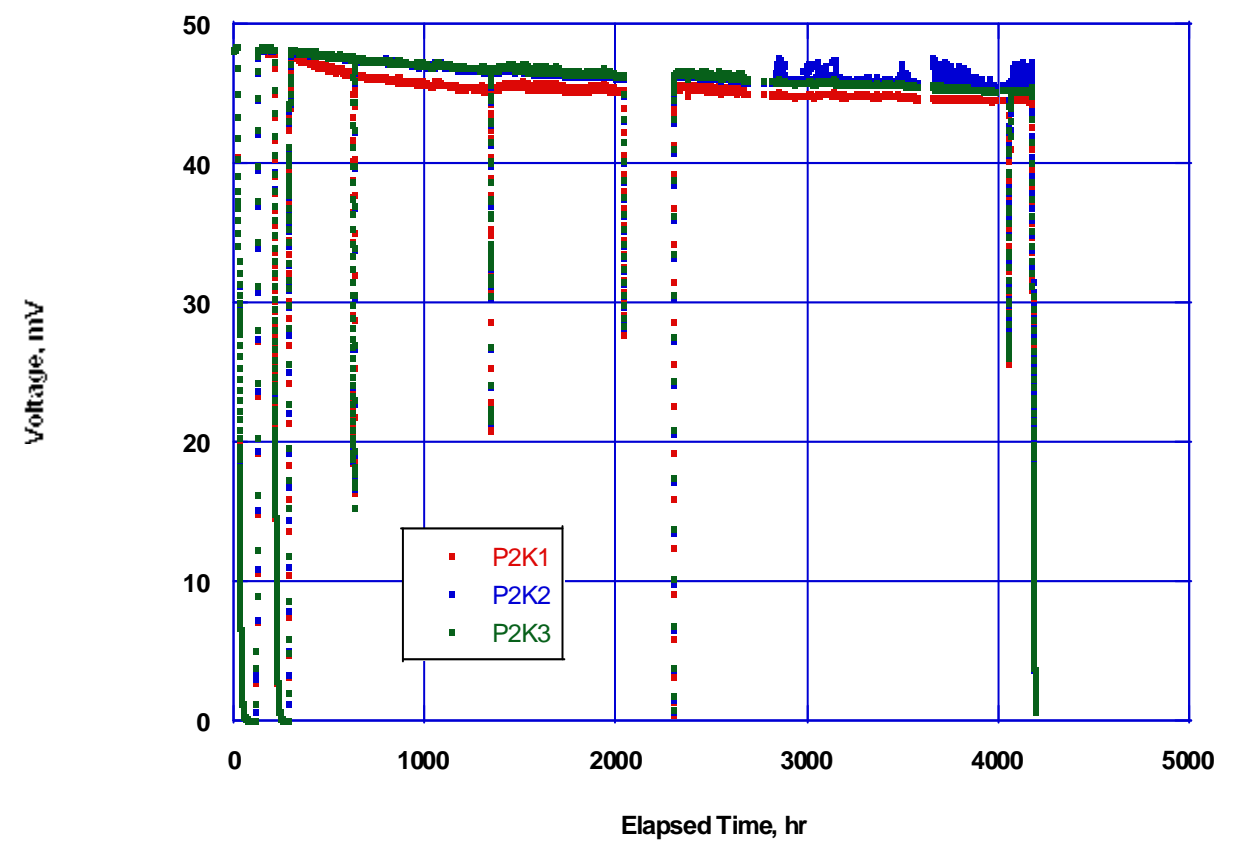

Figure 5-4. Measured emf of Type K thermocouples included in $1200{ }^{\circ} \mathrm{C}$ test

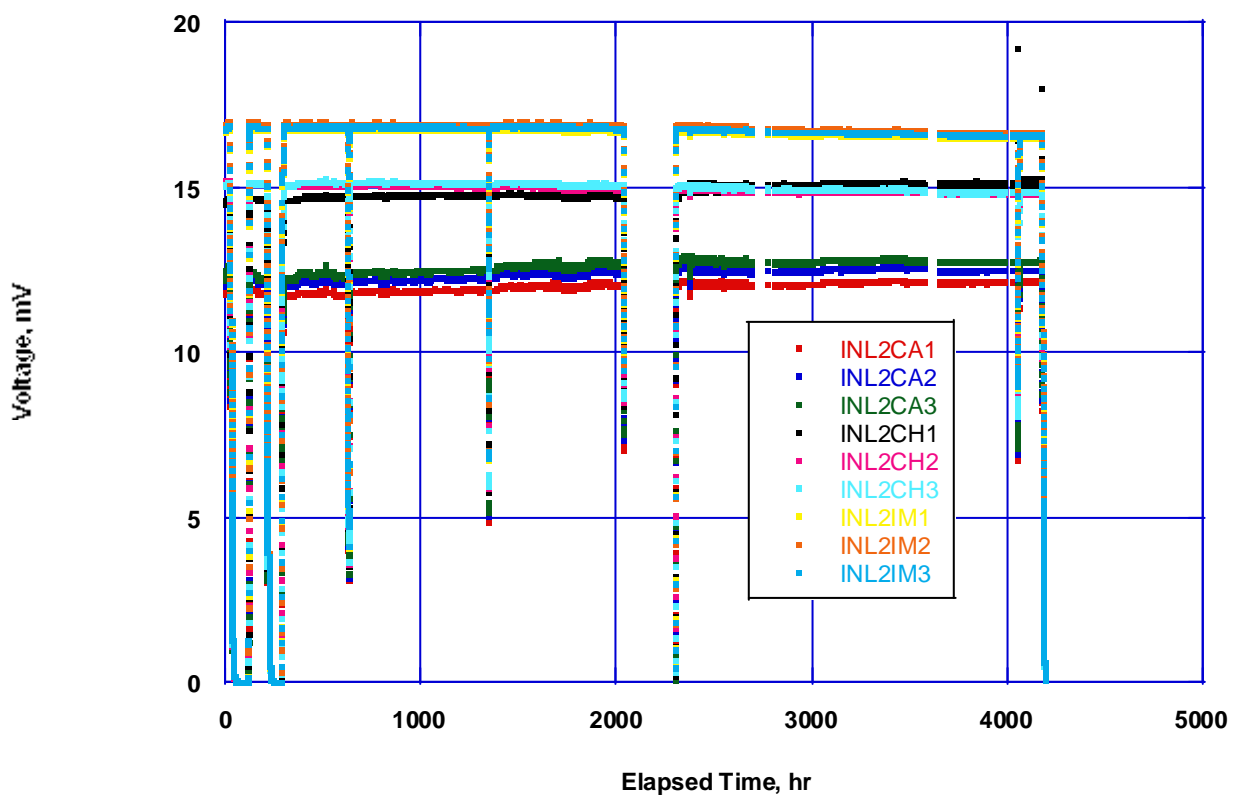

Figure 5-5. Measured emf of INL-developed Mo/Nb alloy thermocouples included in $1200{ }^{\circ} \mathrm{C}$ test

Figure 5-6 compares the emfs measured for representative thermocouples, and Figure 5-7 plots the corresponding temperatures for each of the thermocouple emfs plotted in Figure 5-6 (with the transients omitted to better reflect the observed trends). During this 4000 hour test, some of the Type K and N thermocouples (e.g., see the curves labeled, "P2K1 Type K” and "P2N2 Type 
N") drifted by over $100^{\circ} \mathrm{C}$. Much smaller drifts (typically, less than $20^{\circ} \mathrm{C}$ ) are observed in the INL-developed thermocouples with $\mathrm{HfO}_{2}$ and $\mathrm{MgO}$ insulation (e.g., see the curves labeled, "”INL CH2 Mo/Nb”, “INL CH2 Mo/Nb”, “INL2-IM2 Mo/Nb”, and “INL2-IM3 Mo/Nb”).

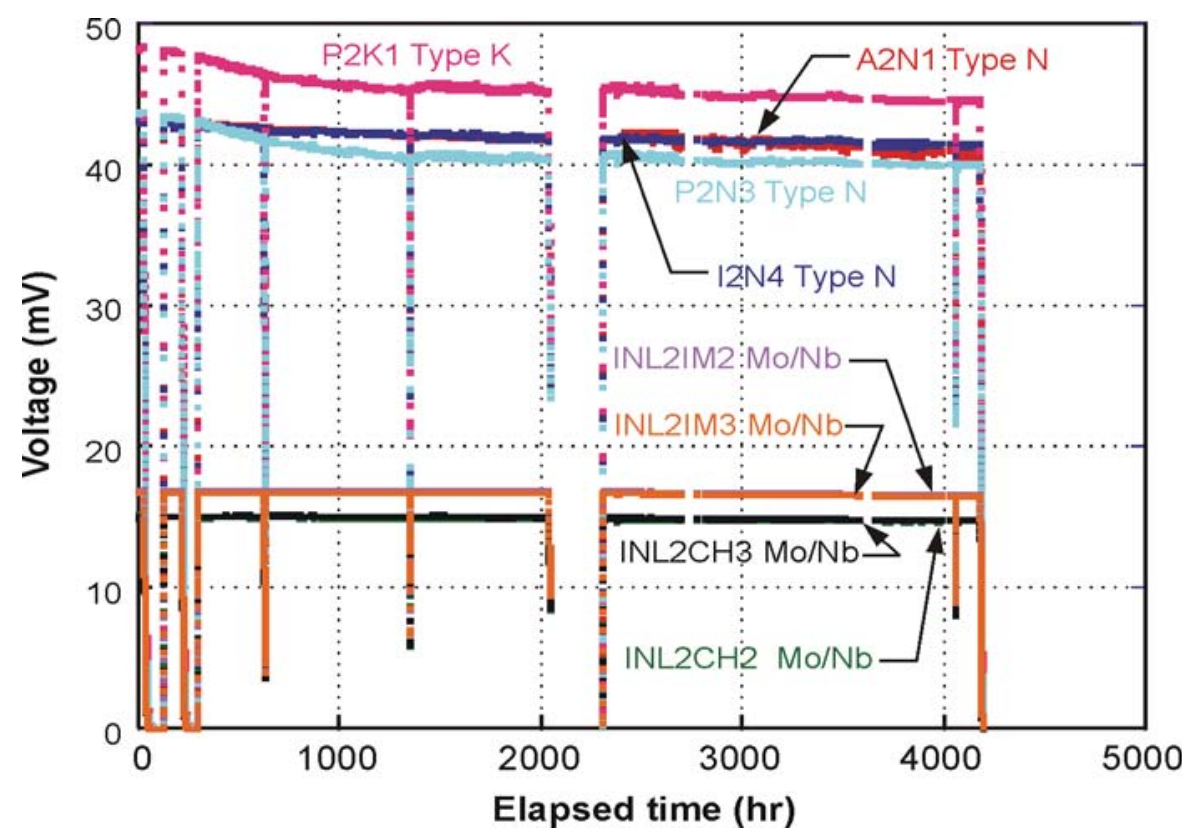

Figure 5-6. Comparison of representative thermocouples included in $1200^{\circ} \mathrm{C}$ test.

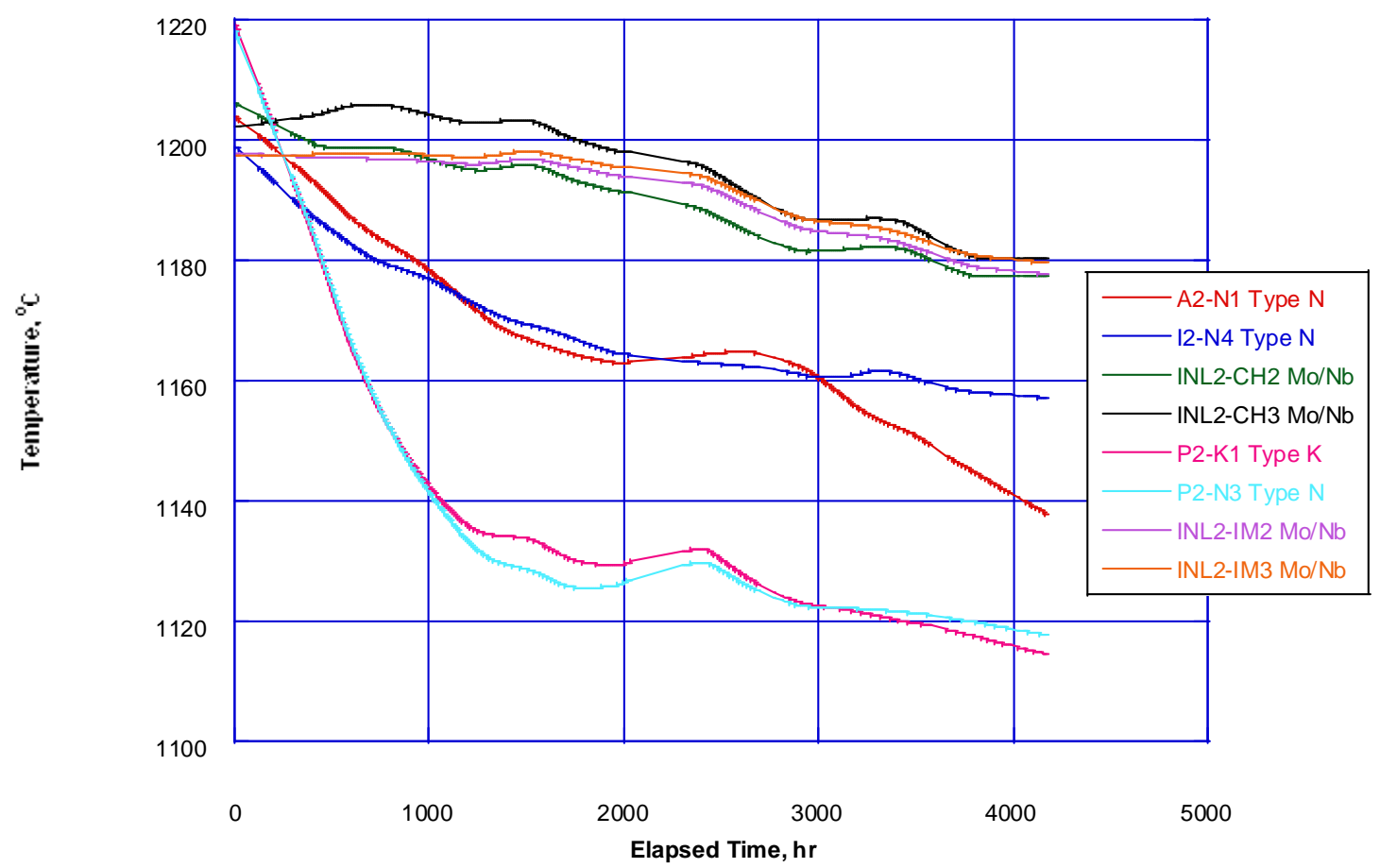

Figure 5-7. Corresponding temperatures of representative thermocouples included in $1200^{\circ} \mathrm{C}$ test 


\subsubsection{Post-test Evaluations}

Post-test SEM assessments were completed to evaluate the ability of selected thermocouple materials to resist interactions and to determine, if possible, the cause of drift observed in some of the commercial thermocouples. As shown in Table 5-2, thermocouples included in these examinations were representative of each type of thermocouple in the $1200{ }^{\circ} \mathrm{C}$ test. Several types of examinations were completed. For example, quantitative linescans and semi-quantitative composition point profiles were used to determine changes in elemental concentration across interfaces.

Table 5-2. $1200^{\circ} \mathrm{C}$ thermocouples evaluated with SEM.

\begin{tabular}{|c|c|}
\hline TC ID & Description \\
\hline I2-N1 & $\begin{array}{l}\text { Standard type } \mathrm{N} \text { thermocouple with } 1 / 16^{\prime} \text { ' Inconel } 600 \text { sheath and MgO insulation (Vendor I). TC } \\
\text { experienced approximately } 60^{\circ} \mathrm{C} \text { drift. }\end{array}$ \\
\hline I2-C2 & $\begin{array}{l}\text { Inconel versus NN thermocouple with 1/16” Inconel } 600 \text { sheath and MgO insulation (Vendor I). } \\
\text { TC experienced approximately } 70^{\circ} \mathrm{C} \text { drift. }\end{array}$ \\
\hline I2-N3 & $\begin{array}{l}\text { Standard type } \mathrm{N} \text { thermocouple with 1/16” Inconel } 600 \text { sheath and MgO insulation (Vendor I). TC } \\
\text { experienced approximately } 40^{\circ} \mathrm{C} \text { drift. }\end{array}$ \\
\hline P2-N3 & $\begin{array}{l}\text { Standard type } \mathrm{N} \text { thermocouple with } 1 / 16^{\prime \prime} \text { with proprietary nickel-based sheath and } \mathrm{MgO} \\
\text { insulation (Vendor P). TC experienced approximately } 70^{\circ} \mathrm{C} \text { drift. }\end{array}$ \\
\hline A2-N3 & $\begin{array}{l}\text { Standard type } \mathrm{N} \text { thermocouple with } 1 / 16^{\prime \prime} \text { with proprietary nickel-based sheath and } \mathrm{MgO} \\
\text { insulation (Vendor A). TC experienced approximately } 100^{\circ} \mathrm{C} \text { drift. }\end{array}$ \\
\hline P2-K1 & $\begin{array}{l}\text { Standard type K thermocouple with } 1 / 16^{\prime \prime} \text { with proprietary nickel-based sheath and MgO } \\
\text { insulation (Vendor P). TC experienced approximately } 100^{\circ} \mathrm{C} \text { drift. }\end{array}$ \\
\hline INL2-IM2 & $\begin{array}{l}\text { INL Mo/Nb alloy thermocouple with } 1 / 16 ” \text { Inconel } 600 \text { sheath and MgO insulation. TC } \\
\text { experienced approximately } 20^{\circ} \mathrm{C} \text { drift. }\end{array}$ \\
\hline INL2-CA3 & $\begin{array}{l}\text { INL Mo/Nb alloy thermocouple with } 1 / 16 ” \text { Nb1Zr sheath and } \mathrm{Al}_{2} \mathrm{O}_{3} \text { insulation. TC experienced } \\
\text { approximately } 50^{\circ} \mathrm{C} \text { drift. }\end{array}$ \\
\hline INL2-CH1 & $\begin{array}{l}\text { INL Mo/Nb alloy thermocouple with } 1 / 16 \text { ” Nb1Zr sheath and } \mathrm{HfO}_{2} \text { insulation. TC experienced } \\
\text { approximately } 50^{\circ} \mathrm{C} \text { shift after long duration "shutdown" at } 2000 \text { hours. }\end{array}$ \\
\hline INL2-CH3 & $\begin{array}{l}\text { INL Mo/Nb alloy thermocouple with } 1 / 16^{\prime} \text { Nb1Zr sheath and } \mathrm{HfO}_{2} \text { insulation. TC experienced } \\
\text { approximately } 20^{\circ} \mathrm{C} \text { drift. }\end{array}$ \\
\hline
\end{tabular}

\subsubsection{INL2-CH1}

Images of the whole thermocouple cross section are shown in Figure 5-8. The left image was taken using the secondary electron detector (SE) that emphasizes surface topography while the right image was taken using the backscatter electron detector that emphasizes compositional differences, with darker areas representing lighter elements. One of the wires appears to have been deformed and is no longer circular. The insulator in this sample is also broken up. The images reveal an outer reaction layer along the perimeter of the TC sheath. Within the sheath, there appears to be two types of reaction phases, one slightly darker in contrast than the other (see Figure 5-9 for higher magnification images of the sheath). The cavities at the junction of the two phases appear to be the result of material fallout during sample polishing. X-ray maps of individual elements in the sheath are shown in Figure 5-10. In general, darker phases in these 
maps indicate lower elemental concentrations. Hence, the maps reveal that the darker reaction phase in the sheath has a lower Nb concentration than the matrix. Because of masking by the palladium coating used to eliminate sample charging, oxygen is not very pronounced but faint contrast in the map suggests that the darker reaction phase is enriched in oxygen. Palladium also masks the carbon, yet faint contrast in the carbon map reveals that the outer rind and the lighter reaction phases in the sheath are enriched in carbon. Hence, it is suspected that the different regions of $\mathrm{Nb}$ concentration observed in this sample were due to the formation of different types of niobium carbide. The maps indicate that there is little or no hafnium diffusion into the sheath from the insulator. A region of fine porosity appears to have formed around the inner perimeter of the sheath adjacent to the interface with the insulator.

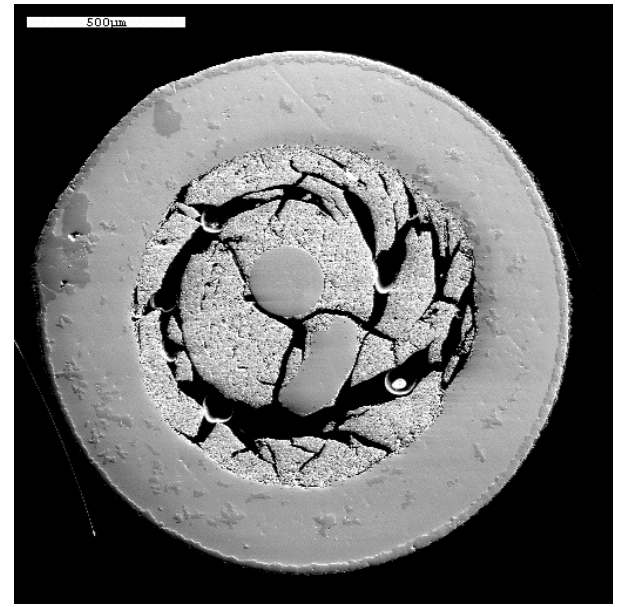

BSE

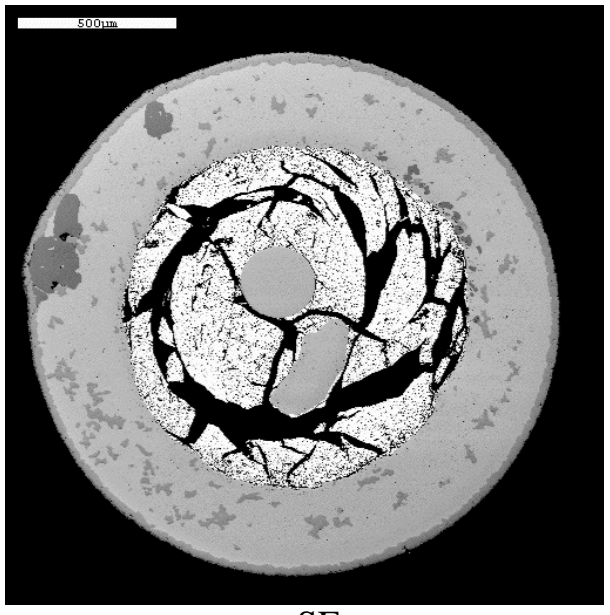

SE

Figure 5-8. BSE (left) and SE (right) images of INL2 CH1 thermocouple.

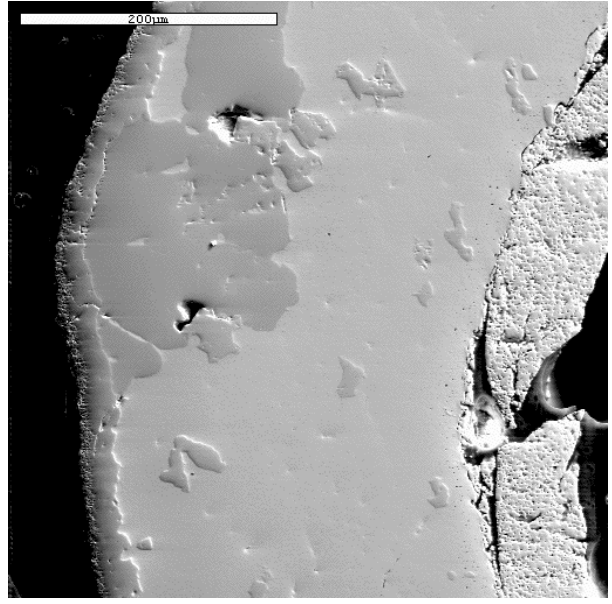

Secondary electron image

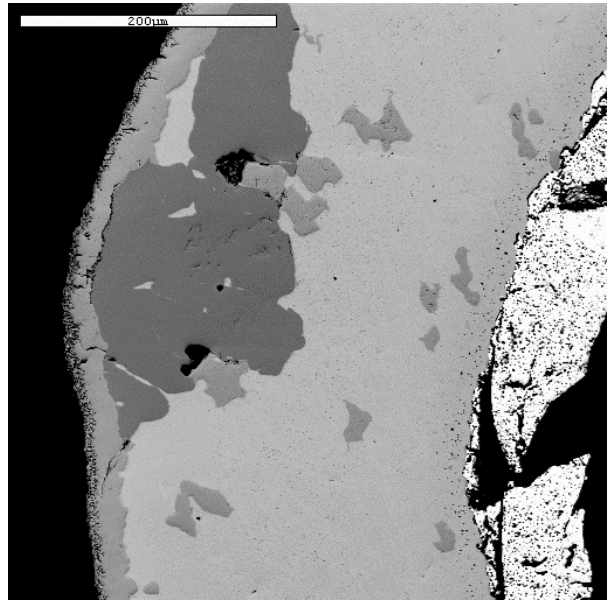

Backscatter electron image

Figure 5-9. Higher magnification images of the sheath cross section for sample INL2 CH1 


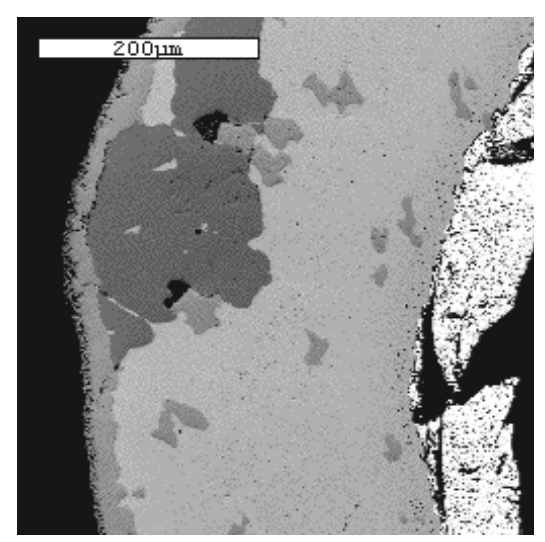

BSE Image

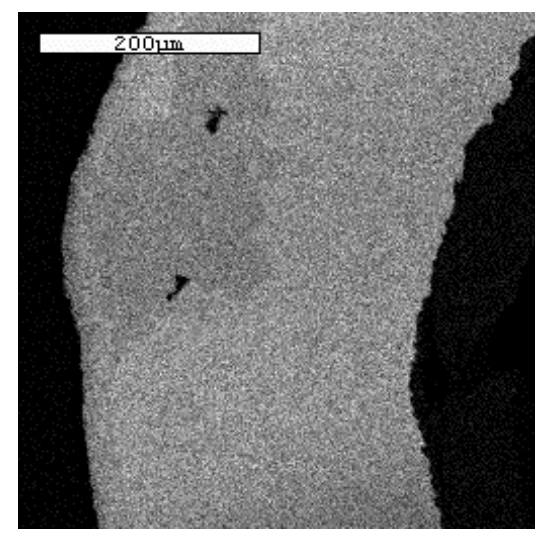

Nb X-Ray Map

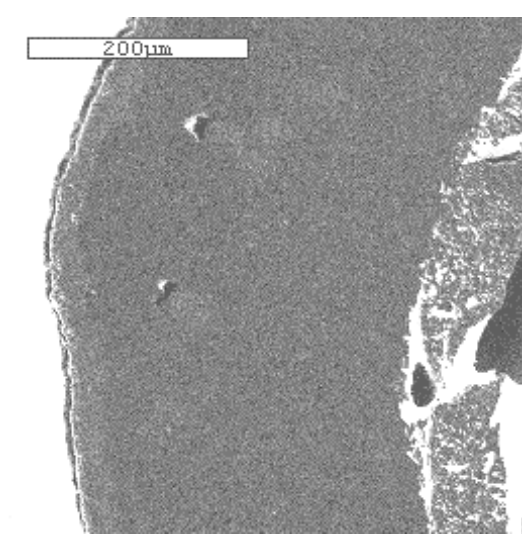

C X-Ray Map

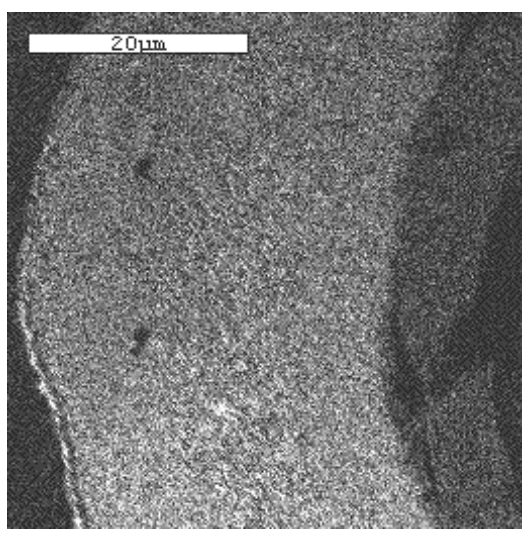

Zr X-Ray Map

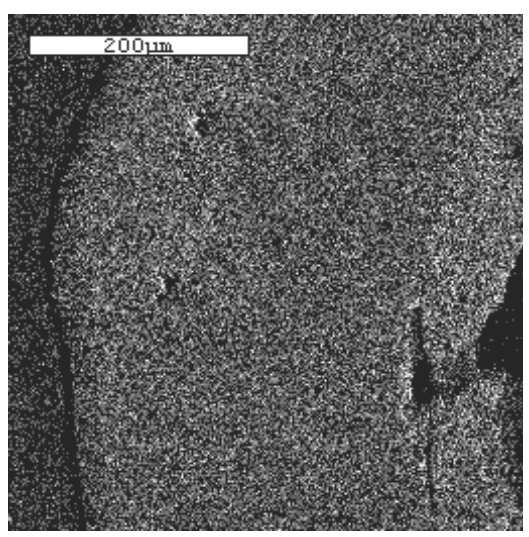

O X-Ray Map

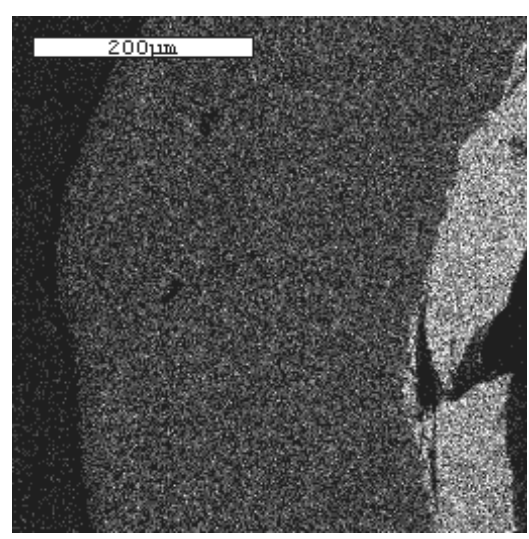

Hf X-Ray Map

Figure 5-10. X-ray maps of the individual elements in the sheath.

X-ray maps of the elemental constituents in the wires and insulator are shown in Figure 511. The top circular wire is the Mo wire, while the deformed wire is the Nb-1\%Zr wire. As with the sheath, there does not appear to be significant interdiffusion of the hafnium into the wires or niobium into the insulator. Similarly, there is a region of porosity around the outer perimeter of the Nb-1\%Zr wire. Figure 5-12 shows a higher magnification image of the Nb-1\%Zr wire along with elemental profiles across the insulator wire interface. The $\mathrm{x}$-axis represents distance along the line length $(170 \mu \mathrm{m}$ total) and the $\mathrm{y}$-axis represents $\mathrm{x}$-ray counts. The most noticeable feature of the profiles is that the $\mathrm{Zr}$ concentration in the wire begins to drop off well before the interface; an indication that $\mathrm{Zr}$ is diffusing into the insulator. Although there appears to be a small $\mathrm{Zr}$ concentration in the insulator, the amount is below the statistical detection limit for semi quantitative analysis. A profile for the Mo wire is shown in Figure 5-13. The even distribution of Mo concentration in the wire suggests that the darker region in Figure 5-13 was associated with sample preparation. The Mo concentration drops to near zero at the interface and likewise Hf does not appear to be diffusing into the wire. No porosity is seen at the perimeter of the Mo wire. 


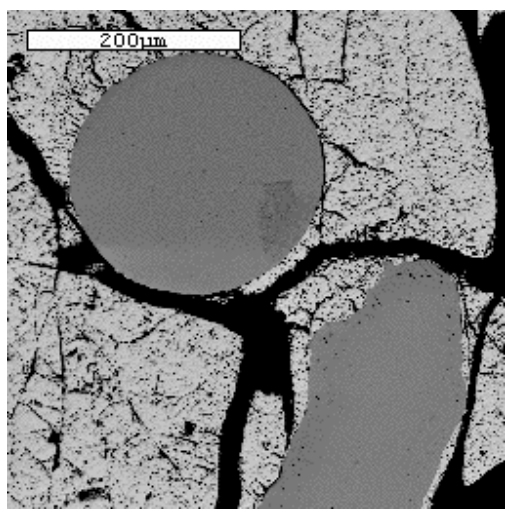

BSE Image

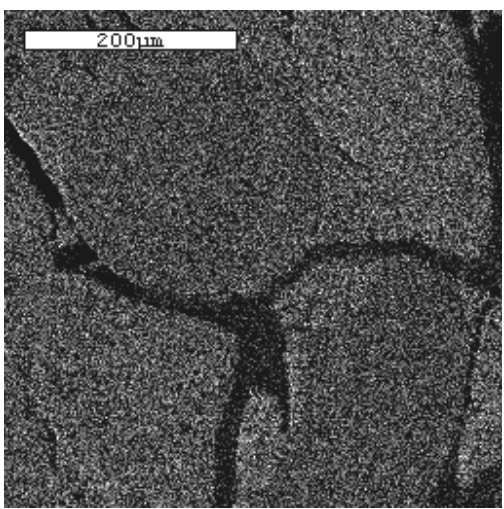

O X-Ray Map

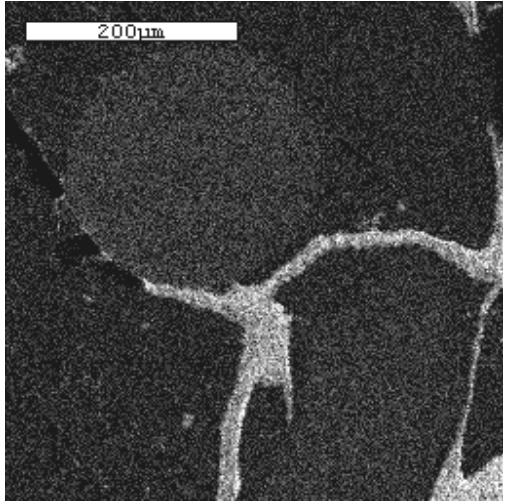

C X-Ray Map

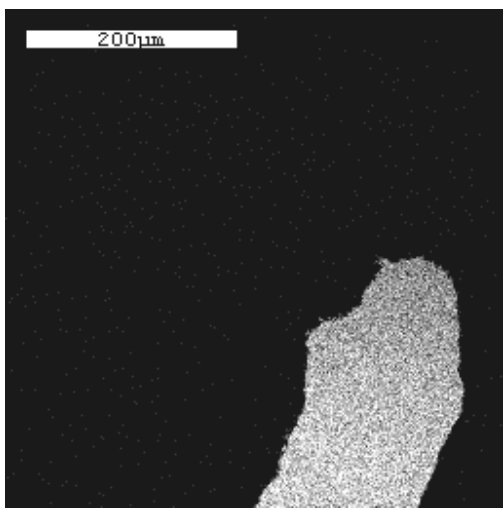

Nb X-Ray Map

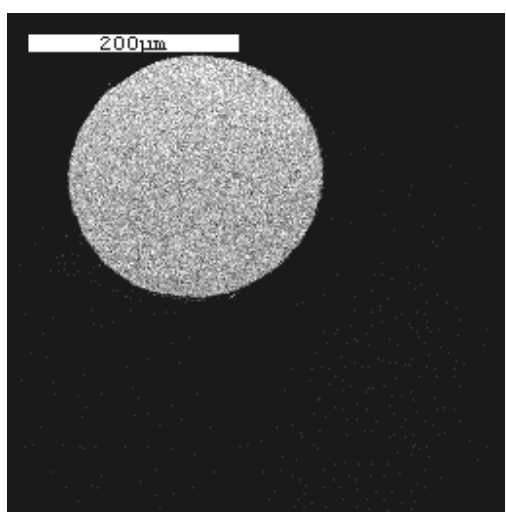

Mo X-Ray Map

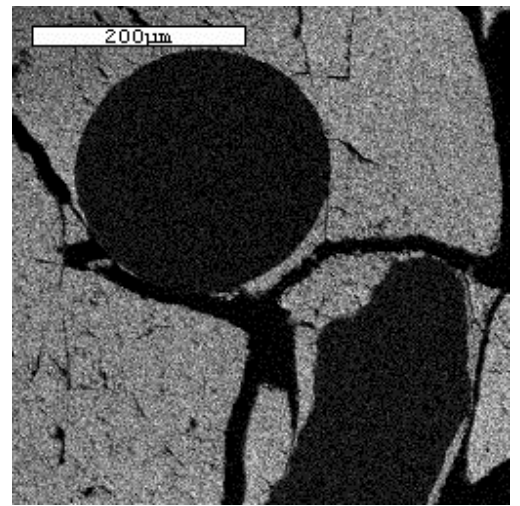

Hf X-Ray Map

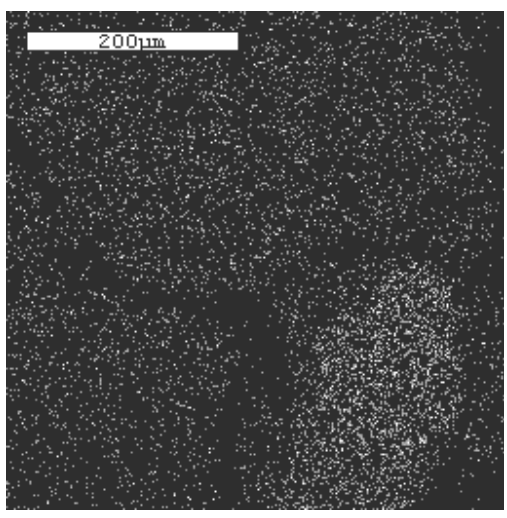

Zr X-Ray Map

Figure 5-11. X-ray maps of the individual elements in the insulator and wires. 

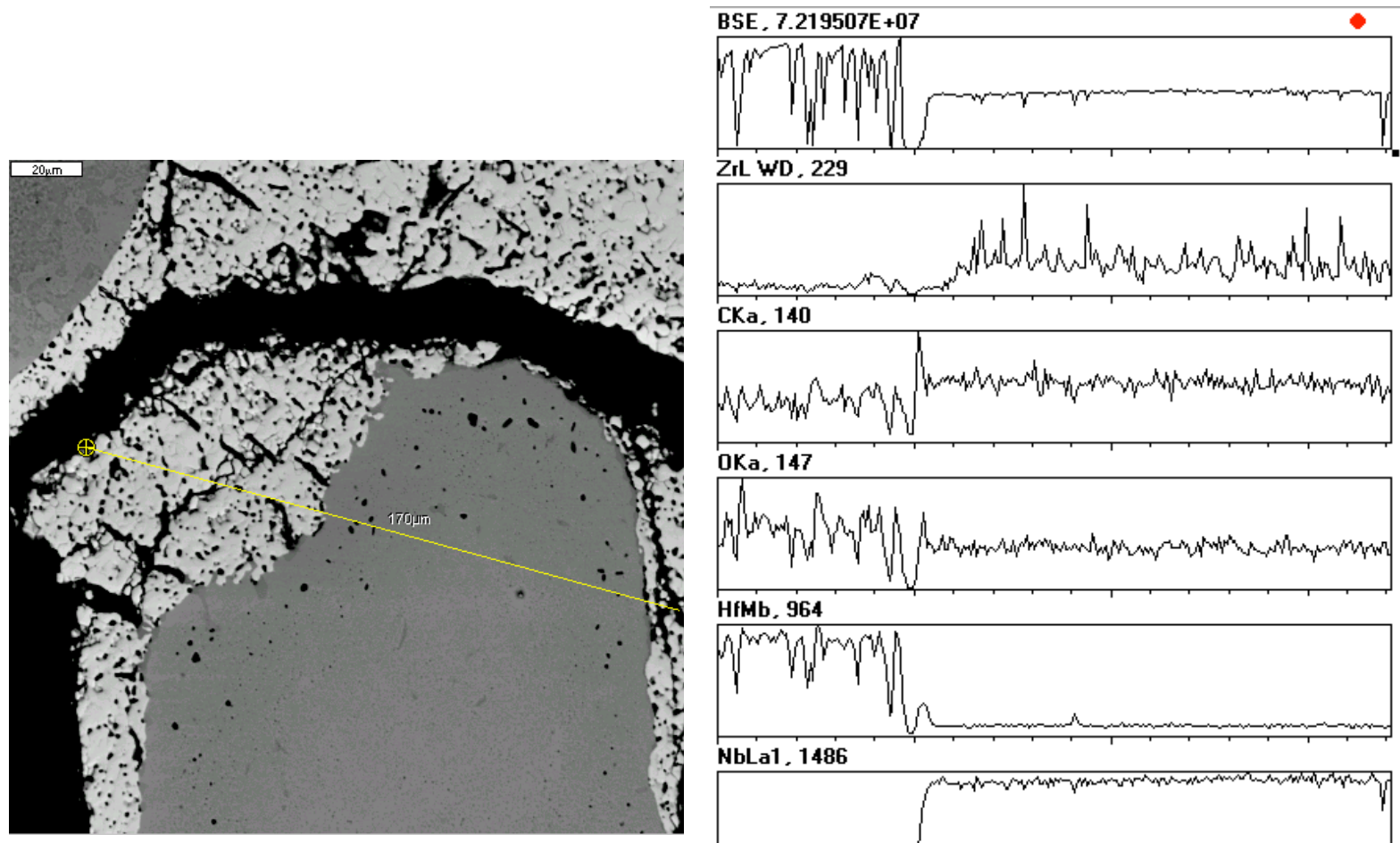

NbLa1, 1486

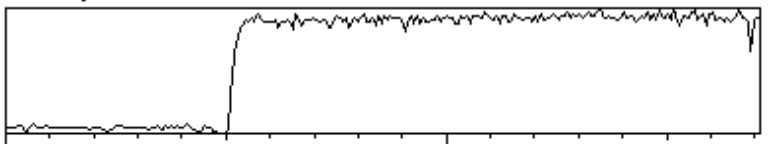

Figure 5-12. BSE image and elemental profiles across Nb1\%Zr wire in sample INL2 CH1
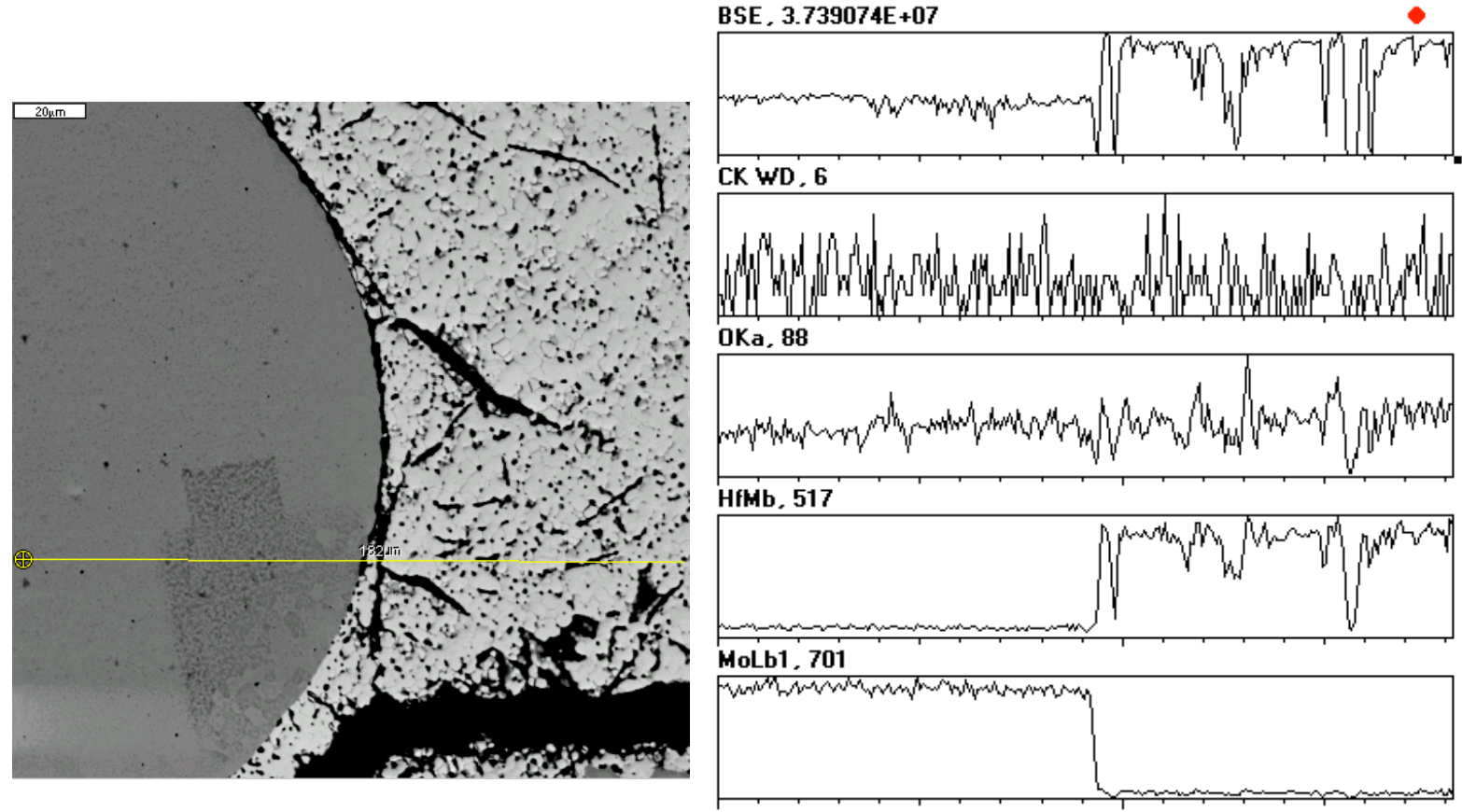

Figure 5-13. BSE Image and elemental profiles across Mo wire. 


\subsubsection{INL2-CH3}

Whole thermocouple images from this sample are shown in Figure 5-14. As with the previous sample, there is an outer perimeter of reaction phase and two reaction phases within the sheath. The insulator in this sample is also broken up. The X-ray maps shown in Figure 5-15 also reveal similar behavior, with masking of carbon and oxygen occurring due to the palladium coating. A higher magnification image and carbon X-ray map (Figure 5-16) reveals the enrichment of carbon in the perimeter of the sheath. Similarly, a higher magnification X-ray map of the three phase regions present in the sheath (lightest contrast being the matrix) shows fairly clearly the constituents of the reaction phases (Figure 5-17). Compared to the matrix, carbon is enriching in the light grey phase, oxygen is enriching in the dark phase, $\mathrm{Nb}$ is very slightly depleted in the light gray phase and more so in the darker phase, and $\mathrm{Zr}$ appears to be forming small precipitates throughout all three phases.

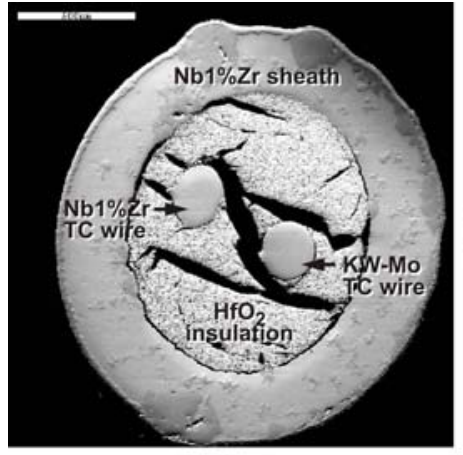

SE image

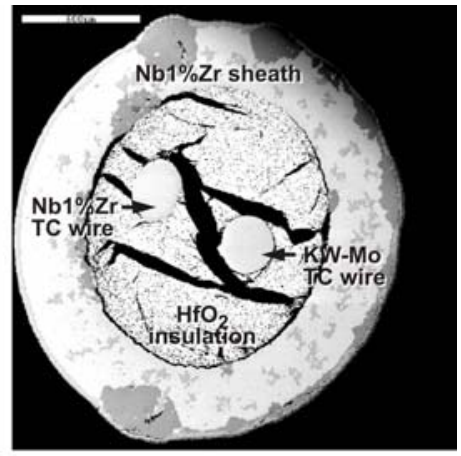

BSE image

Figure 5-14. BSE (left) and SE (right) images of INL2 CH3 thermocouple.

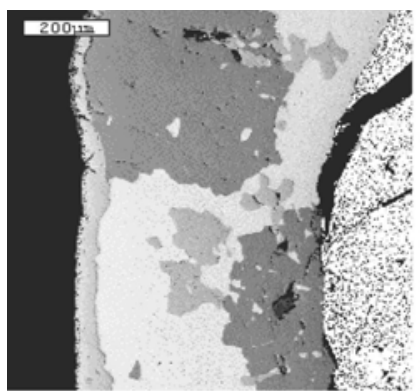

BSE Image

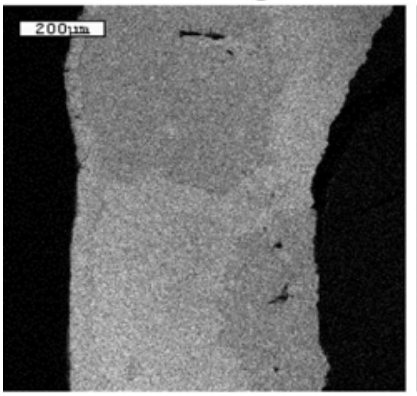

$\mathrm{Nb}$ X-Ray Map

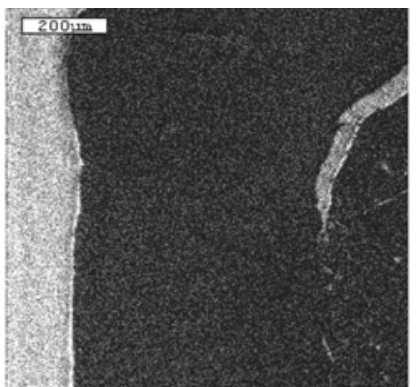

C X-Ray Map

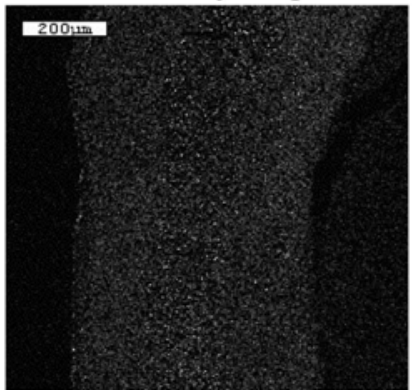

Zr X-Ray Map

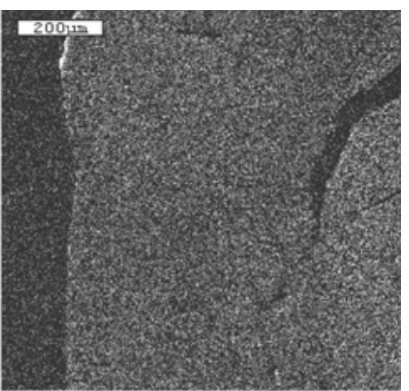

O X-Ray Map

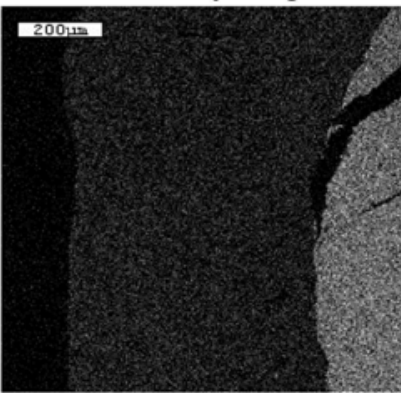

Hf X-Ray Map

Figure 5-15. X-ray maps of the individual elements in the sheath. 

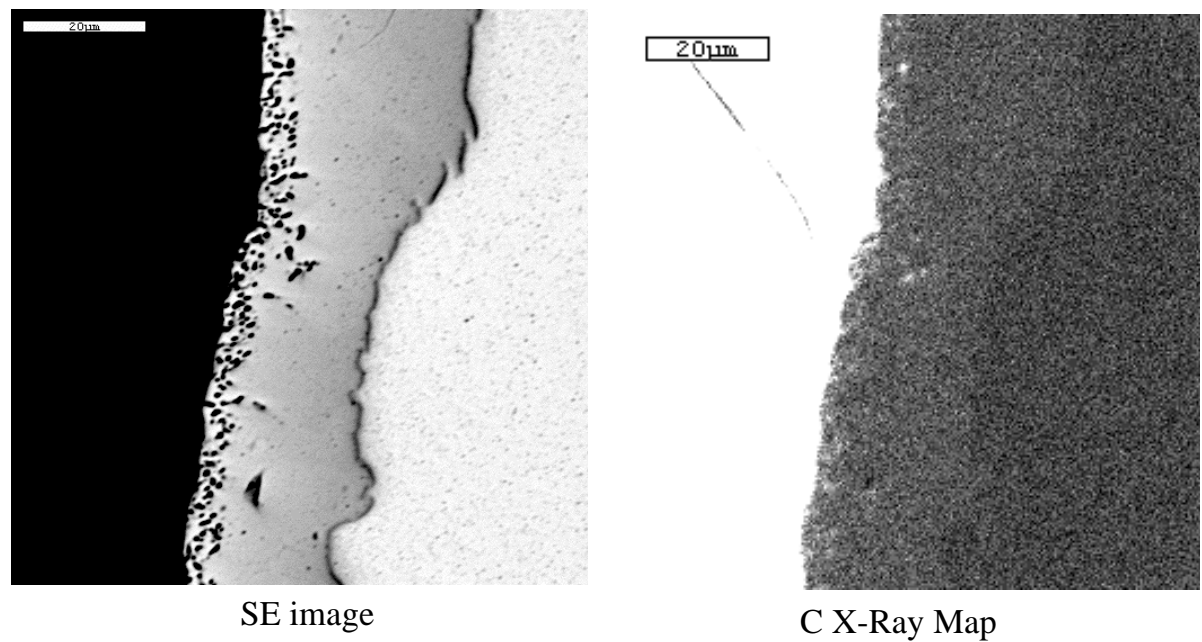

Figure 5-16. SE image and carbon X-ray map of reaction layer on outer perimeter of sheath.

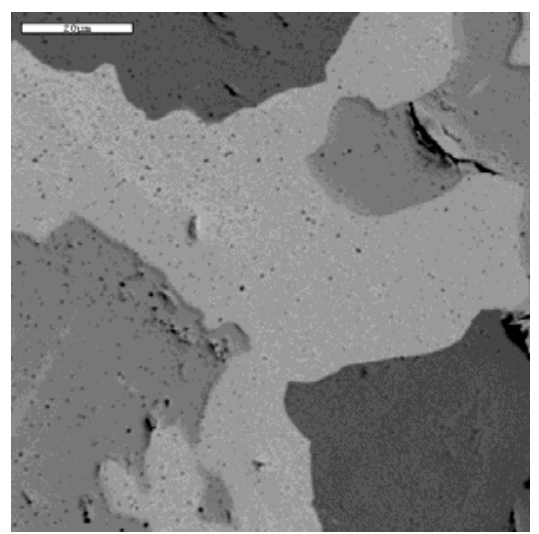

BSE Image

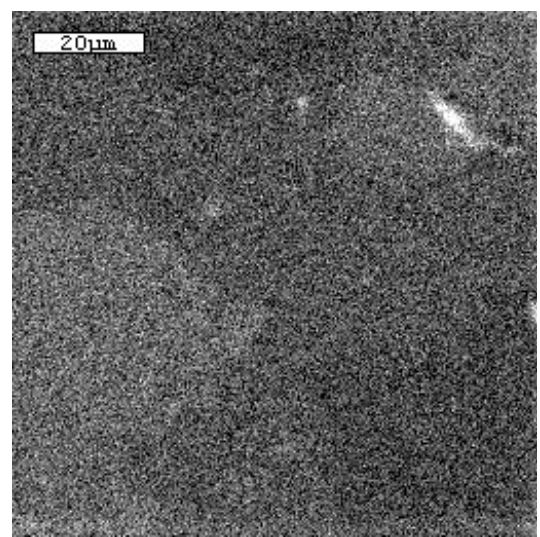

C X-Ray Map

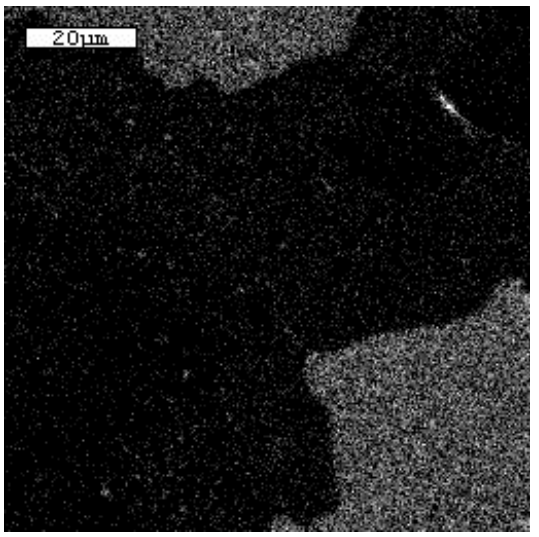

O X-Ray Map

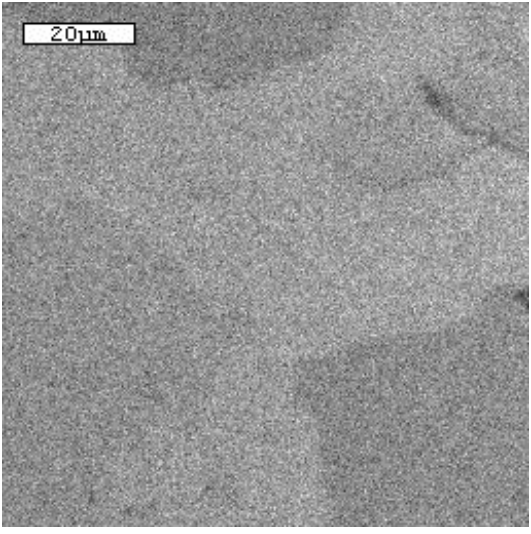

Nb X-Ray Map

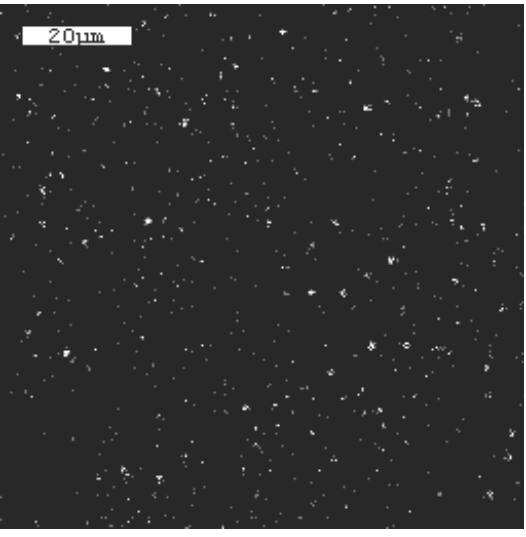

Zr X-Ray Map

Figure 5-17. Elemental x-ray maps of three major phases present in sheath, matrix, oxygen enriched phase and carbon enriched phase. Note: Zr-rich precipitates also observed. 
Porosity is still observed near the perimeter of the $\mathrm{Nb}-1 \% \mathrm{Zr}$ wire, but it is much finer scale than the earlier sample (Figure 5-18). The drop off in $\mathrm{Zr}$ at the wire perimeter is also less pronounced in the line profile shown in the figure. In addition to the line scan, which gives relative changes in elemental concentration, a point composition profile scan was performed (Figure 5-19) which provides semi quantitative elemental concentrations at the points indicated by a + sign on the image and listed in table. Negative values for concentration mean the element is not present. Negative values, which originate from the way the software calculates concentration, tend to skew concentrations of the other elements present to higher values. Only one point (point 9) contained nonzero concentrations of both $\mathrm{Nb}$ and Hf. This point is located in the insulator. Also, within the statistical variation of the measurements, there does not appear to be any clear depletion of $\mathrm{Zr}$ going from the center of the wire to the edge. The concentration of oxygen, while less than the insulator, is still quite high, indicating oxygen is diffusing into the wire. A point composition profile across the Mo wire is provided in the image and table of Figure 5-20. In this case there does not seem to be any points where both the Hf and Mo concentrations are nonzero, indicating negligible interdiffusion of these elements. Oxygen is once again relatively high in the wire.
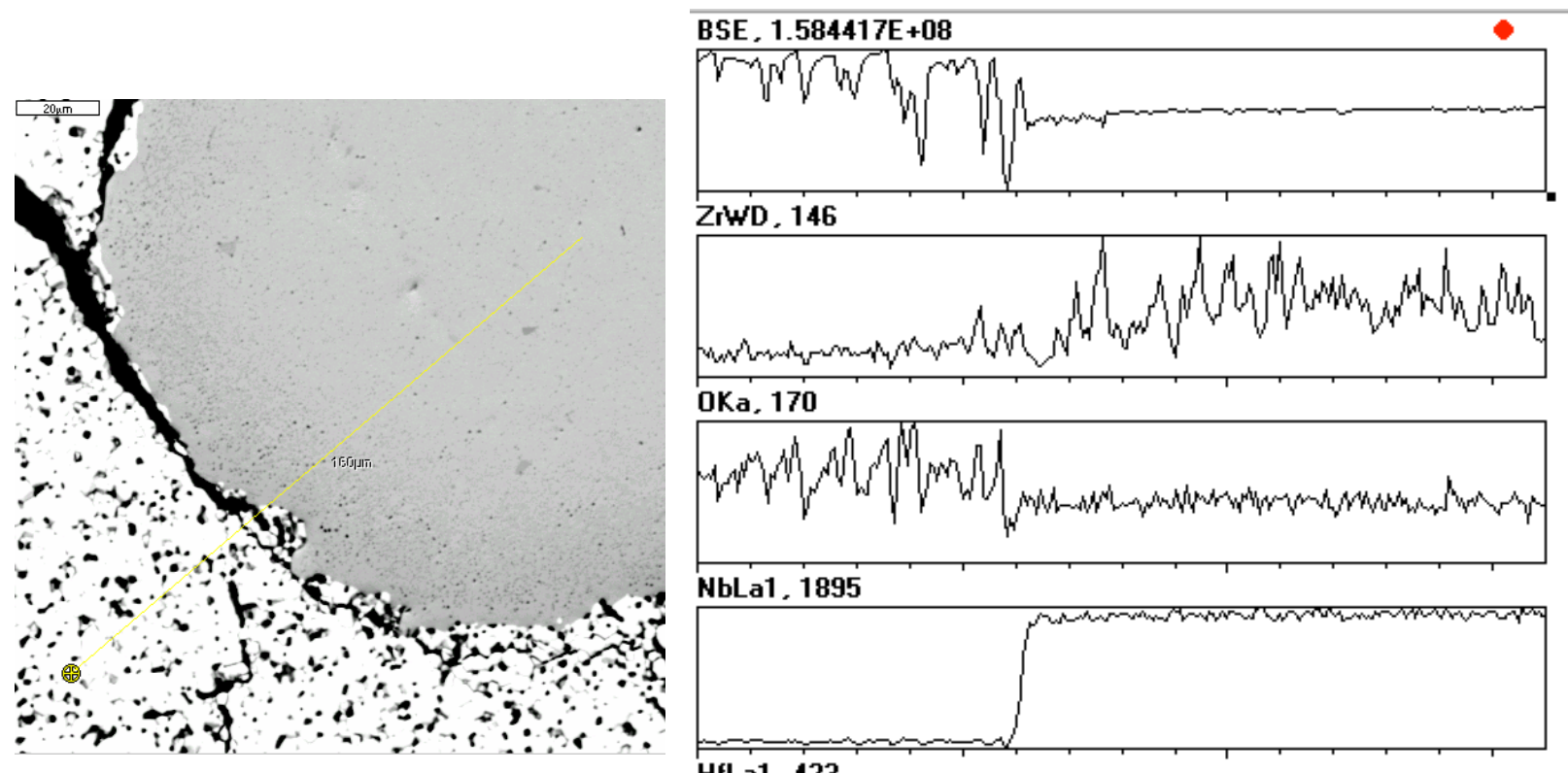

ZrwD, 146

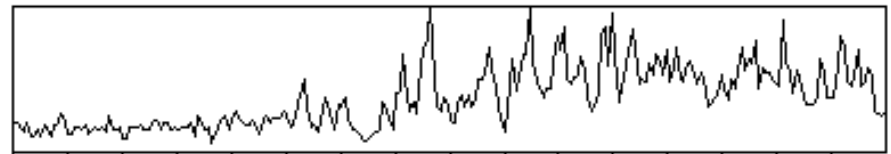

OKa, 170

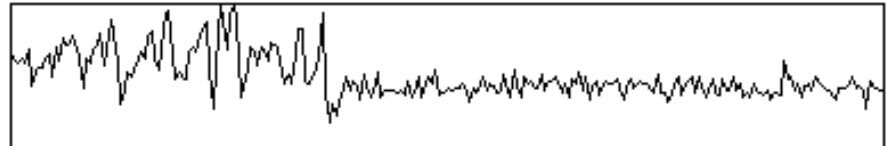

NbLa1, 1895

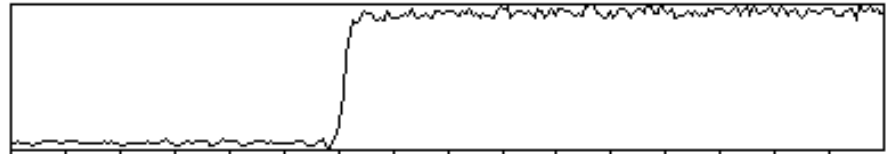

HfLa1, 423

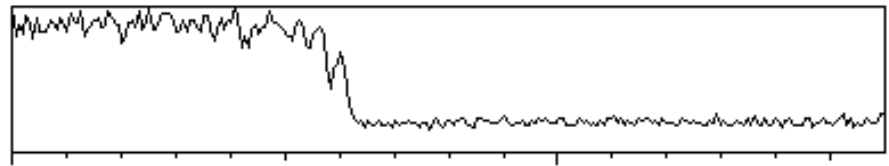

Figure 5-18. Elemental profiles across Nb1\%Zr wire in sample INL2 CH3. 


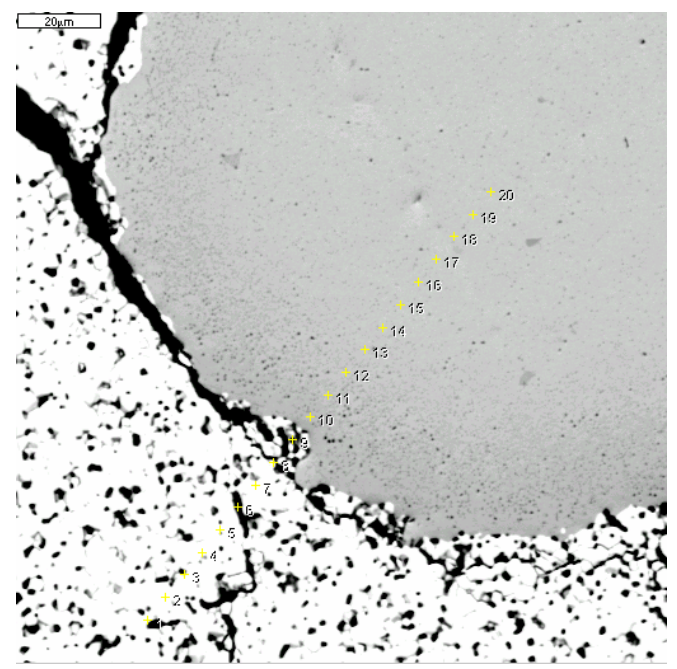

\begin{tabular}{|c|c|c|c|c|}
\hline \# & Elem\% & Elem\% & Elem\% & Elem\% \\
\hline 1 & 13.35 & 0.61 & 0.14 & 85.9 \\
\hline 2 & 12.87 & 1.24 & 0.47 & 85.42 \\
\hline 3 & 10.31 & 0.48 & -0.25 & 89.46 \\
\hline 4 & 11.16 & 0.57 & -0.24 & 88.51 \\
\hline 5 & 11.13 & 1.05 & 0.01 & 87.81 \\
\hline 6 & 12.89 & 0.29 & -0.65 & 87.47 \\
\hline 7 & 13.06 & 0.13 & -0.27 & 87.07 \\
\hline 8 & 14.04 & 0.94 & 0.8 & 84.22 \\
\hline 9 & 7.46 & 1.6 & 24.16 & 66.77 \\
\hline 10 & 9.02 & 4.47 & 88.45 & -1.94 \\
\hline 11 & 8.1 & 6.14 & 89.62 & -3.86 \\
\hline 12 & 8.14 & 4.18 & 88.79 & -1.11 \\
\hline 13 & 6.45 & 3.7 & 90.54 & -0.7 \\
\hline 14 & 9.65 & 4.62 & 86.55 & -0.83 \\
\hline 15 & 6.98 & 5.17 & 88.54 & -0.69 \\
\hline 16 & 8.87 & 5.23 & 85.74 & 0.16 \\
\hline 17 & 7.77 & 4.37 & 88.4 & -0.54 \\
\hline 18 & 7.77 & 4.2 & 88.62 & -0.59 \\
\hline 19 & 8.21 & 4.59 & 87.5 & -0.3 \\
\hline 20 & 8.03 & 4.15 & 88.49 & -0.66 \\
\hline
\end{tabular}

Figure 5-19. Point composition profiles across Nb1\%Zr wire in sample INL2 CH3.

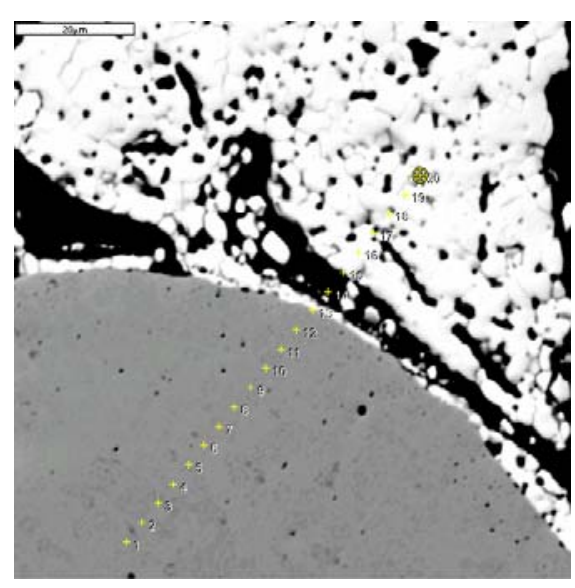

\begin{tabular}{|c|c|c|c|c|}
\hline Point \# & Elem\% & Elem\% & Elem $\%$ & Hf M \\
\hline 1 & 5.51 & 94.98 & & -0.49 \\
\hline 2 & 12.12 & 88.4 & & -0.52 \\
\hline 3 & 10.06 & 90.43 & & -0.49 \\
\hline 4 & 7.1 & 93.69 & & -0.79 \\
\hline 5 & 8.95 & 92.58 & & -1.53 \\
\hline 6 & 8.67 & 94.08 & & -2.75 \\
\hline 7 & 11.05 & 89.49 & & -0.54 \\
\hline 8 & 7.44 & 93.17 & & -0.61 \\
\hline 9 & 10.17 & 90.4 & & -0.57 \\
\hline 10 & 11.43 & 88.96 & & -0.39 \\
\hline 11 & 10.45 & 88.91 & & 0.64 \\
\hline 12 & 9.91 & 90.76 & & -0.67 \\
\hline 13 & 15.88 & -0.28 & & 84.4 \\
\hline 14 & 18.07 & 4.9 & & 77.03 \\
\hline 15 & 10.02 & -0.01 & & 89.99 \\
\hline 16 & 12.68 & -0.39 & & 87.71 \\
\hline 17 & 16.87 & 0.01 & & 83.12 \\
\hline 18 & 12.34 & -0.28 & & 87.94 \\
\hline 19 & 10.14 & 0.13 & & 89.72 \\
\hline 20 & 9.38 & -0.3 & & 90.91 \\
\hline
\end{tabular}

Figure 5-20. Point composition profiles across Mo wire in sample INL2 CH3.

\subsubsection{I2-N3}

Images of the whole thermocouple are shown in Figure 5-21. The sheath has multiple phases and the insulator, unlike the two previous samples, is relatively intact. X-ray maps of the sheath (Figure 5-22) reveal the elements present and their distribution. The large bright block inclusions are composed primarily of tungsten and carbon. The lighter matrix phase is primarily nickel, while the darker secondary phase is composed of carbon and chromium. Although not 
shown, iron is present in both the matrix and secondary phases in similar levels. The profiles shown in Figure 5-23 show the change in elemental concentrations along the scan line drawn on the image. The phase rich in nickel has little chromium and vice versa. The inclusions rich in tungsten are puzzling and will be investigated further.

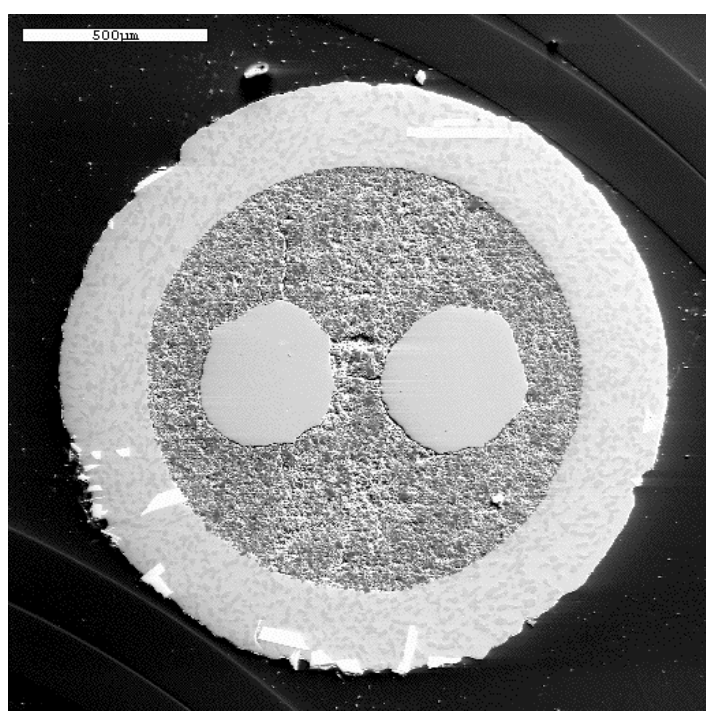

SE image

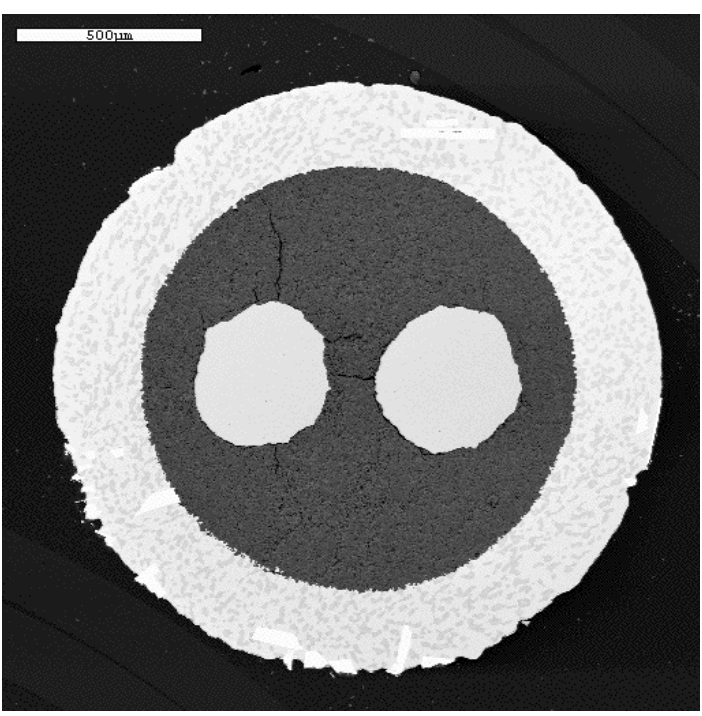

BSE image

Figure 5-21. BSE (left) and SE (right) images of I2 N3 thermocouple. 


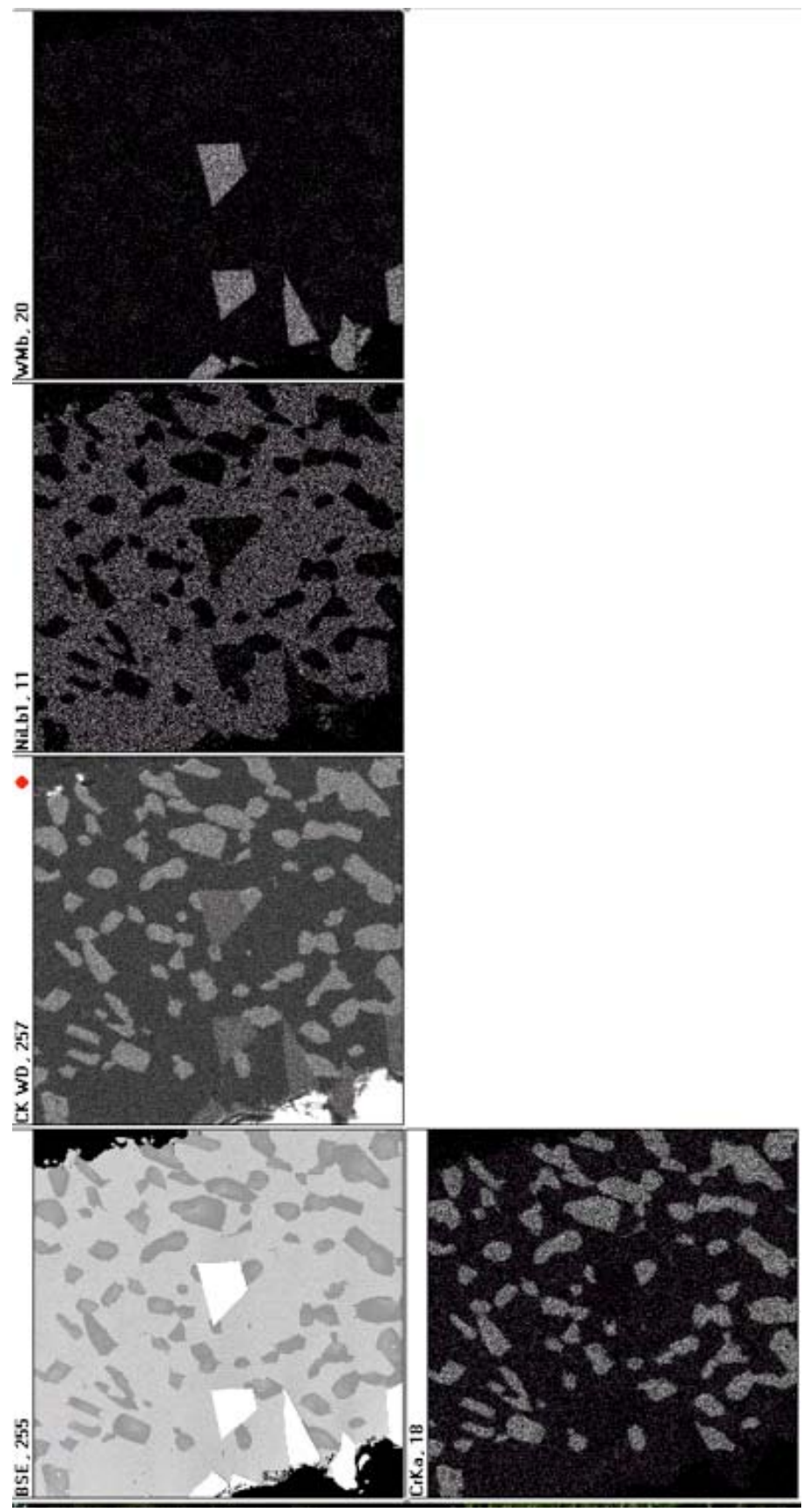

Figure 5-22. X-ray maps of the individual elements in the sheath. 

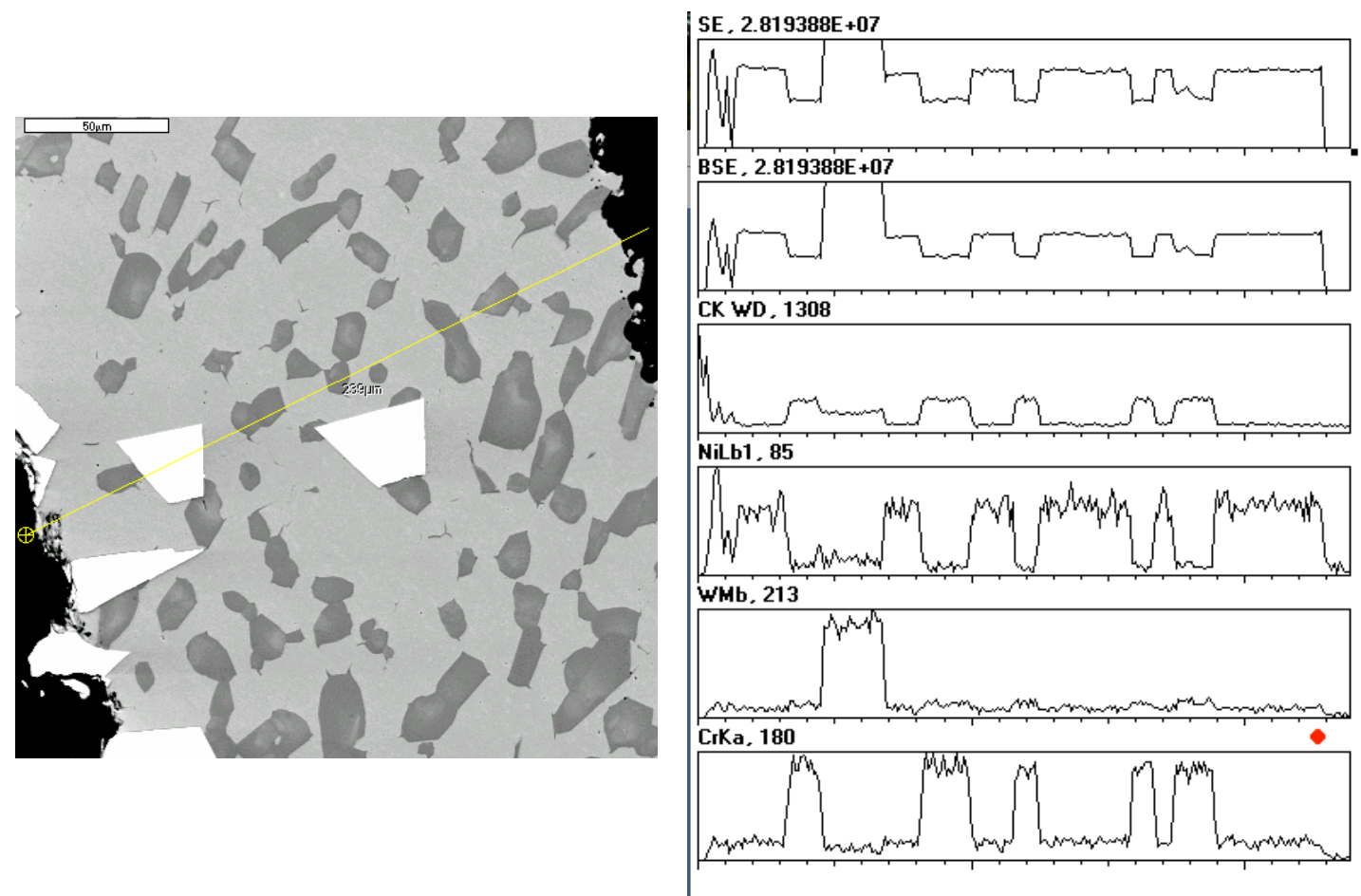

Figure 5-23. Elemental profiles across sheath in sample I2 N3.

A linescan across the insulator and into the wire on the left (see Figure 5-21 for location) is shown in Figure 5-24. The insulator is composed of MgO (oxygen is not shown here), while the wire is appears to be composed of Ni, Si and to a lesser extent Fe. There also appears to be a small amount of iron in the insulator. Another linescan is shown in Figure 5-25 for the wire on the right in Figure 5-21. Significant magnesium and oxygen concentrations appear to be limited to the insulator. Carbon is present throughout the sample and the wire contains concentrations of chromium and silicon. Further analysis needs to be performed to determine if other elements are present in the wire. 

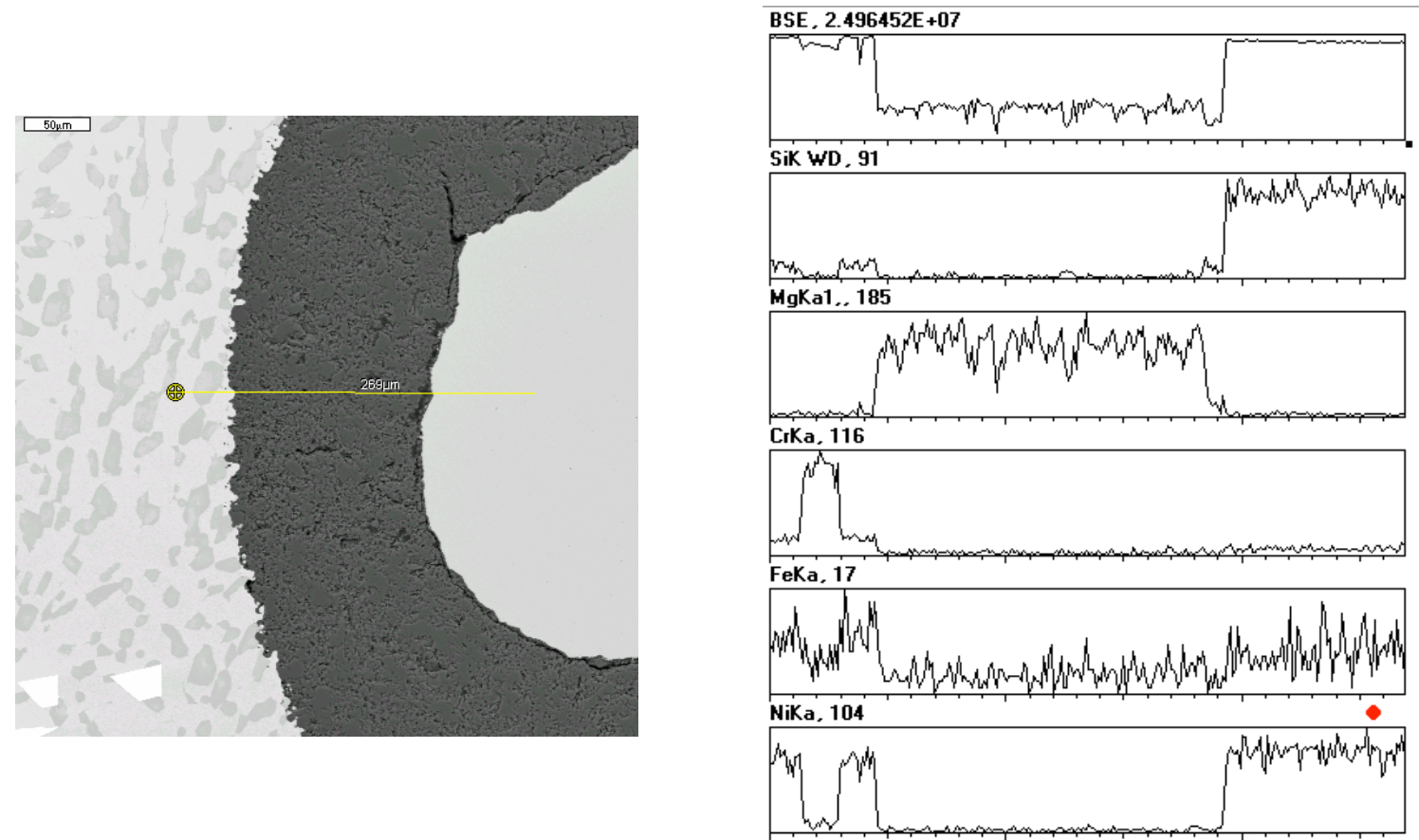

Figure 5-24. Elemental profiles across second wire in sample I2 N3.
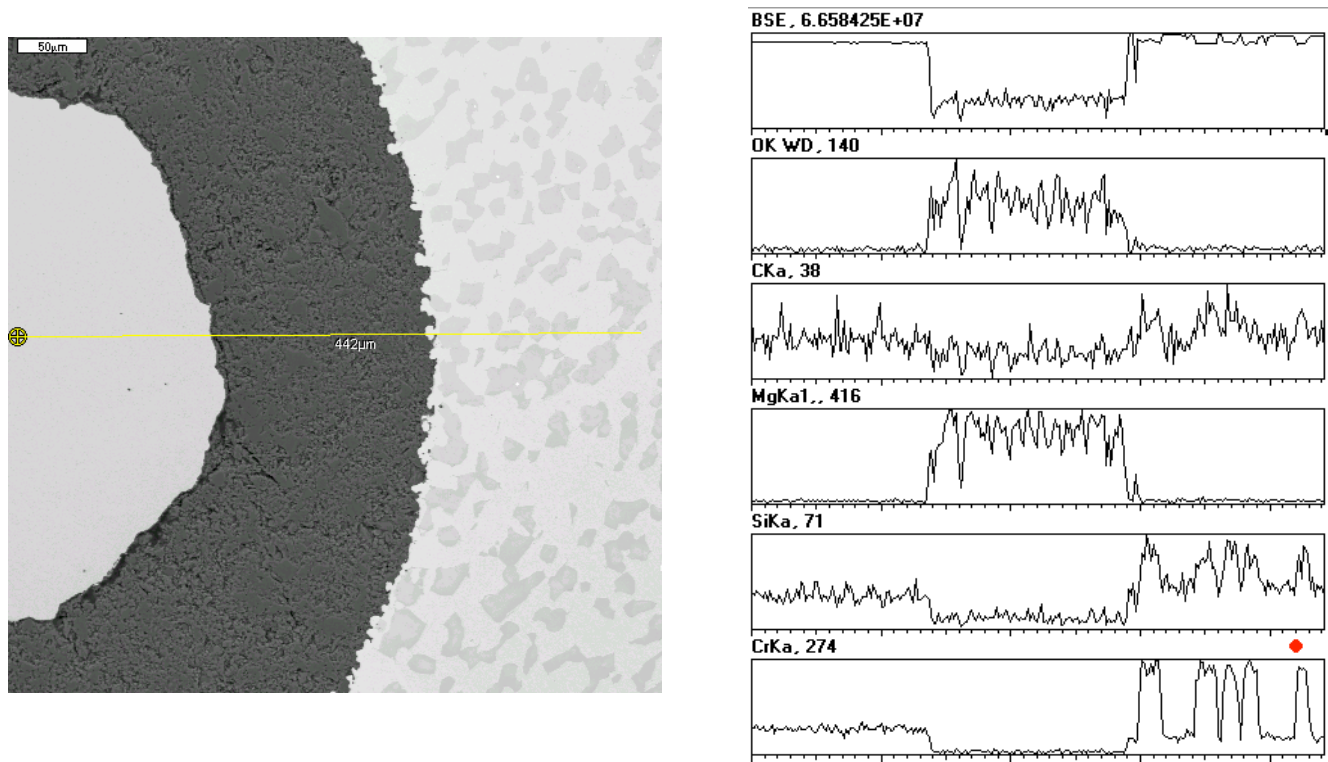

Figure 5-25. Elemental profiles across first wire in sample I2 N3.

\section{2. $1400^{\circ} \mathrm{C}$}

The $1400{ }^{\circ} \mathrm{C}$ long duration test was primarily sponsored by the Gas Test Loop program. The objective of this test was to evaluate the performance of the INL proposed thermocouples 
when heated at $1400{ }^{\circ} \mathrm{C}$ for long time periods (over 4000 hours). In addition to assessing thermocouple performance at high temperatures, the test included one transient to assess the impact of reactor shutdown.

\subsubsection{Approach}

As shown in Figure 5-1, this test was conducted by placing thermocouples in a tube furnace held at $1400{ }^{\circ} \mathrm{C}$ that was continuously purged with gettered high purity argon. Data were recorded using LabView-based software on a computer. The test included six of the INLdeveloped doped molybdenum - niobium alloy thermocouples: two using commercially available thermoelement wires KW-Mo/Nb-1\%Zr and four containing a developmental Mo-low Nb alloy from Sylvania. All of these thermocouples were fabricated with hafnia insulation and $\mathrm{Nb}-1 \% \mathrm{Zr}$ sheaths. Characteristics of each thermocouple are listed in Table 5-3. Prior to the start of the test, all six thermocouples were heat treated at $1600{ }^{\circ} \mathrm{C}$ for 18 hours.

Table 5-3. Characteristics of thermocouples tested at $1400{ }^{\circ} \mathrm{C}$ for 4000 hours.

\begin{tabular}{|c|c|c|c|c|c|c|}
\hline & 1 & 2 & 3 & 4 & 5 & 6 \\
\hline \multicolumn{7}{|l|}{ Material Composition } \\
\hline Positive Thermoelement & KW-Mo & KW-Mo & Mo1.6Nb & Mo1.6Nb & $\mathrm{Mo3Nb}$ & Mo3Nb \\
\hline Negative Thermoelement & $\mathrm{Nb} 1 \mathrm{Zr}$ & $\mathrm{Nb} 1 \mathrm{Zr}$ & $\mathrm{Nb} 1 \mathrm{Zr}$ & $\mathrm{Nb} 1 \mathrm{Zr}$ & $\mathrm{Nb} 1 \mathrm{Zr}$ & $\mathrm{Nb} 1 \mathrm{Zr}$ \\
\hline Swaged Diameter (inches) & 0.0626 & 0.0626 & 0.0693 & 0.0633 & 0.0736 & 0.0736 \\
\hline \multicolumn{7}{|l|}{ Loop Resistance, $\mathrm{W}^{\mathrm{a}}$} \\
\hline Initial $-4 / 11 / 2006$ (at $\sim 20^{\circ} \mathrm{C}$ ) & 7.77 & 8.60 & 6.23 & 8.43 & 6.63 & 6.06 \\
\hline $5 / 02 / 2006$ (at $1400^{\circ} \mathrm{C}$ & 32.21 & 35.12 & 31.29 & 33.91 & 30.74 & 29.78 \\
\hline $5 / 23 / 2006$ (at $1400^{\circ} \mathrm{C}$ ) & 18.42 & 35.15 & 31.29 & 34.06 & 30.74 & 29.71 \\
\hline Final - 10/3/2006 (at $\left.\sim 20^{\circ} \mathrm{C}\right)$ & 7.90 & 8.97 & 6.19 & 8.73 & 6.65 & 6.06 \\
\hline \multicolumn{7}{|l|}{ Insulation Resistance, $\mathrm{MW}^{\mathrm{b}}$} \\
\hline \multicolumn{7}{|l|}{ Initial (4/11/2006) } \\
\hline Positive Thermoelement & $1 \mathrm{e} 6$ & $5 e 9$ & $1 \mathrm{e} 8$ & $5 e 6$ & $8 e 9$ & $8 e 9$ \\
\hline Negative Thermoelement & $1 \mathrm{e} 6$ & $5 e 9$ & $1 \mathrm{e} 8$ & $5 e 6$ & $8 e 9$ & $8 e 9$ \\
\hline \multicolumn{7}{|l|}{ Final $(10 / 3 / 2006)$} \\
\hline Positive Thermoelement & 29.59 & $2 e 10$ & $2 \mathrm{e} 9$ & $9 e 5$ & $6 e 7$ & $3 e 9$ \\
\hline Negative Thermoelement & 29.21 & $2 e 10$ & $4 \mathrm{e} 9$ & $9 e 5$ & $7 e 7$ & $3 e 9$ \\
\hline
\end{tabular}

a. Taken with Fluke 723767. Initial and final values taken at room temperature. Intermediate values at furnace temperature.

b. Taken with Hewlett-Packard 214021 at 50 V unless value was below 1 MW. Then, taken with Fluke 723767.

\subsubsection{Results}

As shown in Figure 5-26 the drift measured for the emf of most of the thermocouples tested after 4000 hours of testing is minimal. The KW-Mo 1 thermocouple failed after 900 hours. However, remaining KW-Mo thermocouple (KW-Mo 2) and the thermocouples made with noncommercial alloys of Mo produced specially for INL by Sylvania appeared extremely stable. 


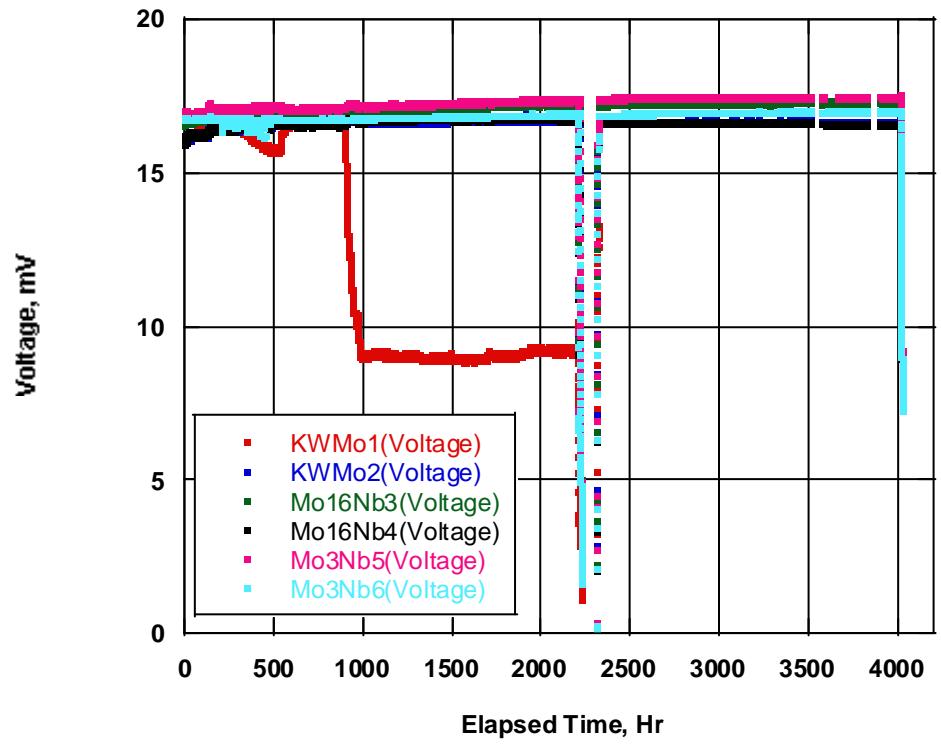

Figure 5-26. Measured emf of INL-developed Mo/Nb alloy thermocouples included in $1400{ }^{\circ} \mathrm{C}$ test

\subsubsection{Post Test Evaluations}

Selected thermocouples from the $1400{ }^{\circ} \mathrm{C}$ test were examined using x-ray and SEM evaluation techniques. Results from these exams are reported in this section.

\subsubsection{X-Ray Examinations}

An x-ray of the KW Mo-1 thermocouple revealed that cracks were present in the insulation of the thermocouple exposed to high temperatures (see Figure 5-27). In addition, the insulation near the junction of the Mo-3\%Nb-6 had degraded. The insulation of the remaining thermocouples was fairly undamaged. It should be noted that the similar insulation was used in all of these thermocouples (e.g., hafnia was made from the same powder from the same vendor). 


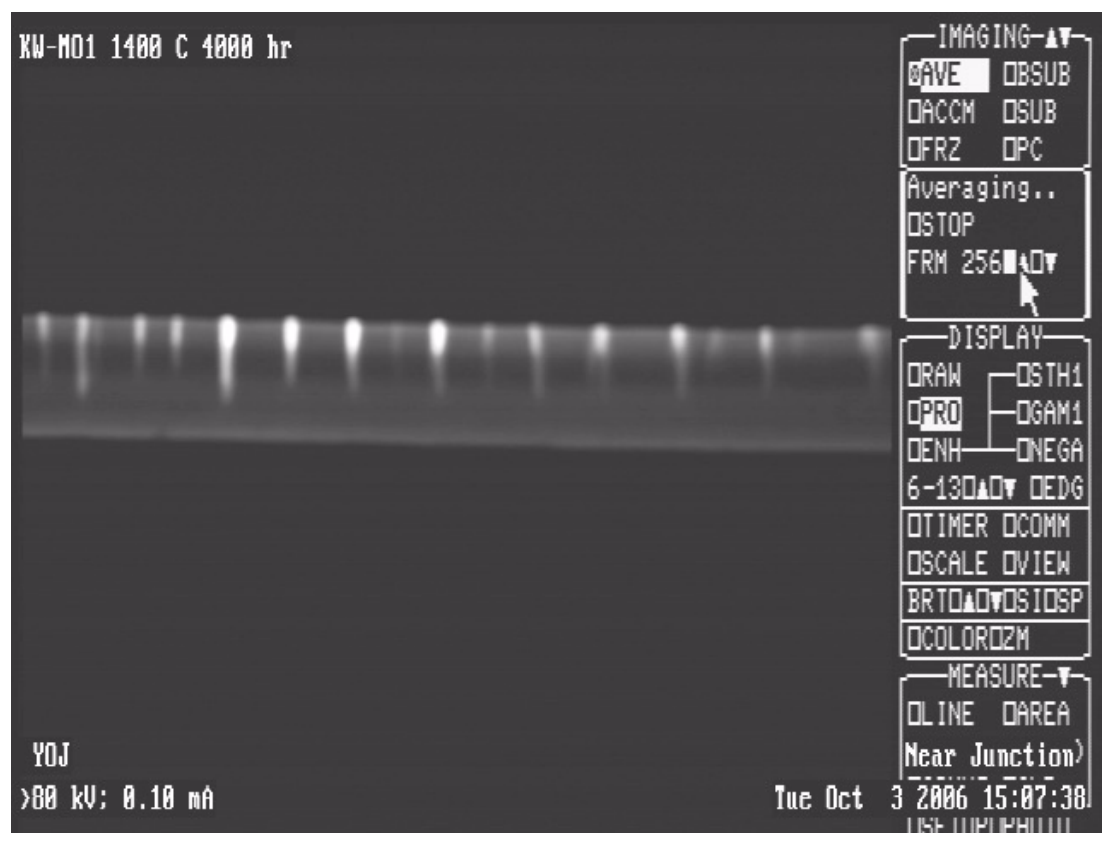

Figure 5-27. X-ray of KW Mo-1 after 4000 hour test at $1400^{\circ} \mathrm{C}$ (near junction).

\subsubsection{SEM Examinations}

SEM examinations for the $1400{ }^{\circ} \mathrm{C}$ test were performed on the $\mathrm{KW}-\mathrm{Mo}-2$ thermocouple. Images (SE and BSE) images of the full thermocouple cross section for KW-Mo-2 (containing KW-Mo and Nb-1\%Zr wires with $\mathrm{HfO} 2$ insulation and a Nb-1\%Zr sheath) are shown in Figure 528. Although the insulator in this sample is cracked, it is suspected that this cracking occurred during sample preparation for SEM analysis because the insulation wasn't cracked in the x-ray of this thermocouple. As in Figure 5-14, the images reveal an outer reaction layer along the perimeter of the TC sheath and there appear to be two reaction phases, one slightly darker in contrast than the other. X-ray maps of individual elements in the sheath and thermoelement wires for this thermocouple were not completed. However, results from Figure 5-15 suggest that the darker reaction phase in the sheath has a lower $\mathrm{Nb}$ concentration than the surrounding sheath material. In addition, thermocouple wires shown in Figure 5-28 suggest that little, if any, reactions occurred between the hafnia insulation and the wires. 


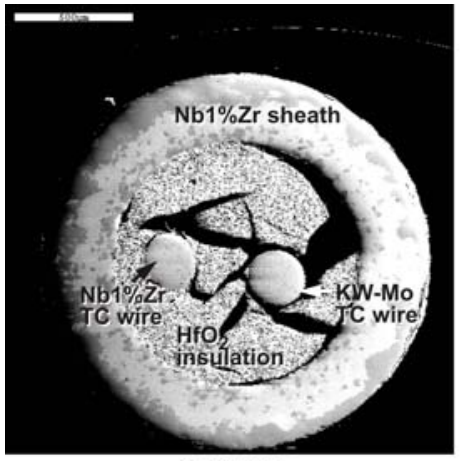

SE image

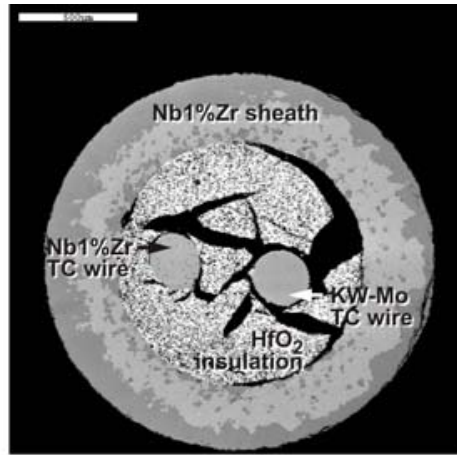

BSE image

Figure 5-28. SE (left) and BSE (right) images of KWMo-2 thermocouple after heating at $1400{ }^{\circ} \mathrm{C}$ for over 4000 hours.

\section{3. $1500^{\circ} \mathrm{C}$}

Long duration $1500{ }^{\circ} \mathrm{C}$ tests conducted at the HTTL were sponsored by this UNERI and an INL Laboratory Directed Research and Development (LDRD) program. The primary objective of these tests was to evaluate the long duration performance at $1500{ }^{\circ} \mathrm{C}$ of HTIR-TCs, including designs with alternate geometries and developmental alloys. In addition, the initial test also provided an opportunity to gain insights about the performance of commercial Type C thermocouples at this temperature. Results from evaluations of Type $C$ thermocouples included in the initial test are reported in Reference 35. Because air ingress occurred during the initial test at $1500{ }^{\circ} \mathrm{C}$, a second test at this temperature was conducted. This second test investigated several geometries of INL-developed HTIR-TCs.

\subsubsection{Approach}

Table 5-4 lists the INL-developed thermocouples included in the initial long duration test at $1500{ }^{\circ} \mathrm{C}$ (a second long duration test was performed at $1500{ }^{\circ} \mathrm{C}$ that included loose assembly thermocouples, results of this test are reported in section 8). In addition to the original INL design

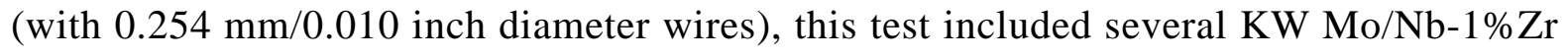
thermocouples of alternate diameters (made with $0.13 \mathrm{~mm} / 0.005$ inch and $0.51 \mathrm{~mm} / 0.020$ inch diameter wire and several thermocouples made with developmental Mo-low Nb alloys. Prior to testing, all of the INL-developed thermocouples were heat treated at $1600{ }^{\circ} \mathrm{C}$ for 4 hours 
Table 5-4. Initial INL thermocouples tested at $1500{ }^{\circ} \mathrm{C}$.

\begin{tabular}{|c|c|c|c|c|}
\hline \multirow[b]{2}{*}{ Designator } & \multirow[b]{2}{*}{ Description } & \multirow{2}{*}{$\begin{array}{l}\text { Room Temperature } \\
\text { Loop Resistance (ohm) }\end{array}$} & \multicolumn{2}{|c|}{$\begin{array}{c}\text { Room Temperature } \\
\text { Insulation Resistance (ohm) }\end{array}$} \\
\hline & & & “+” wire & “_” wire \\
\hline I15-01 & INL KW-Mo/Nb1Zr 0.13 mm wires & 21.50 & $>5 \mathrm{e} 08$ & $>5 \mathrm{e} 08$ \\
\hline I15-02 & INL KW-Mo/Nb1Zr $0.13 \mathrm{~mm}$ wires & 22.76 & $>4 \mathrm{e} 11$ & $>4 \mathrm{e} 11$ \\
\hline I15-03 & INL KW-Mo/Nb-1Zr & 11.04 & $>1 \mathrm{e} 09$ & $>1 \mathrm{e} 09$ \\
\hline I15-04 & INL KW-Mo/Nb-1Zr & 10.85 & $>5 \mathrm{e} 09$ & $>5 \mathrm{e} 09$ \\
\hline I15-05 & INL KW-Mo/Nb-1Zr & 11.92 & $>2 \mathrm{e} 06$ & $>1 \mathrm{e} 06$ \\
\hline I15-06 & INL KW-Mo/Nb-1Zr & 11.42 & $>3 e 06$ & $>3 \mathrm{e} 06$ \\
\hline I15-07 & INL Mo-1.6Nb/Nb-1Zr & 11.78 & $>5 \mathrm{e} 09$ & $>5 \mathrm{e} 09$ \\
\hline I15-08 & INL Mo-1.6Nb/Nb-1Zr & 11.48 & $>1 \mathrm{e} 09$ & $>1 \mathrm{e} 09$ \\
\hline I15-09 & INL Mo-3Nb/Nb-1Zr & 6.31 & $>8 \mathrm{e} 08$ & $>1 \mathrm{e} 09$ \\
\hline $\mathrm{I} 15-10$ & INL Mo-3Nb/Nb-1Zr & 6.28 & $>2 \mathrm{e} 12$ & $>3 \mathrm{e} 12$ \\
\hline $\mathrm{I} 15-11$ & INL KW-Mo/Nb-1Zr 0.51 mm wires & 2.67 & $>2 \mathrm{e} 07$ & $>2 \mathrm{e} 07$ \\
\hline $\mathrm{I} 15-12$ & INL KW-Mo/Nb-1Zr 0.51 mm wires & 3.63 & $>1 \mathrm{e} 11$ & $>1 \mathrm{e} 11$ \\
\hline
\end{tabular}

\subsection{2. $1500{ }^{\circ} \mathrm{C}$ Test Results and Post-test Evaluations}

Figure 5-29 shows the emf of INL-developed thermocouples included in this test. Because the signal from all the thermocouples exhibited such degradation, the test was truncated at 3000 hours. As discussed in this section, post-test evaluations revealed that the alumina tubes containing thermocouples failed during this test, allowing oxygen to attack the test thermocouples. Curves in Figure 5-29 suggest that significant air attack occurred at times after the first 1000 hours of the test. 


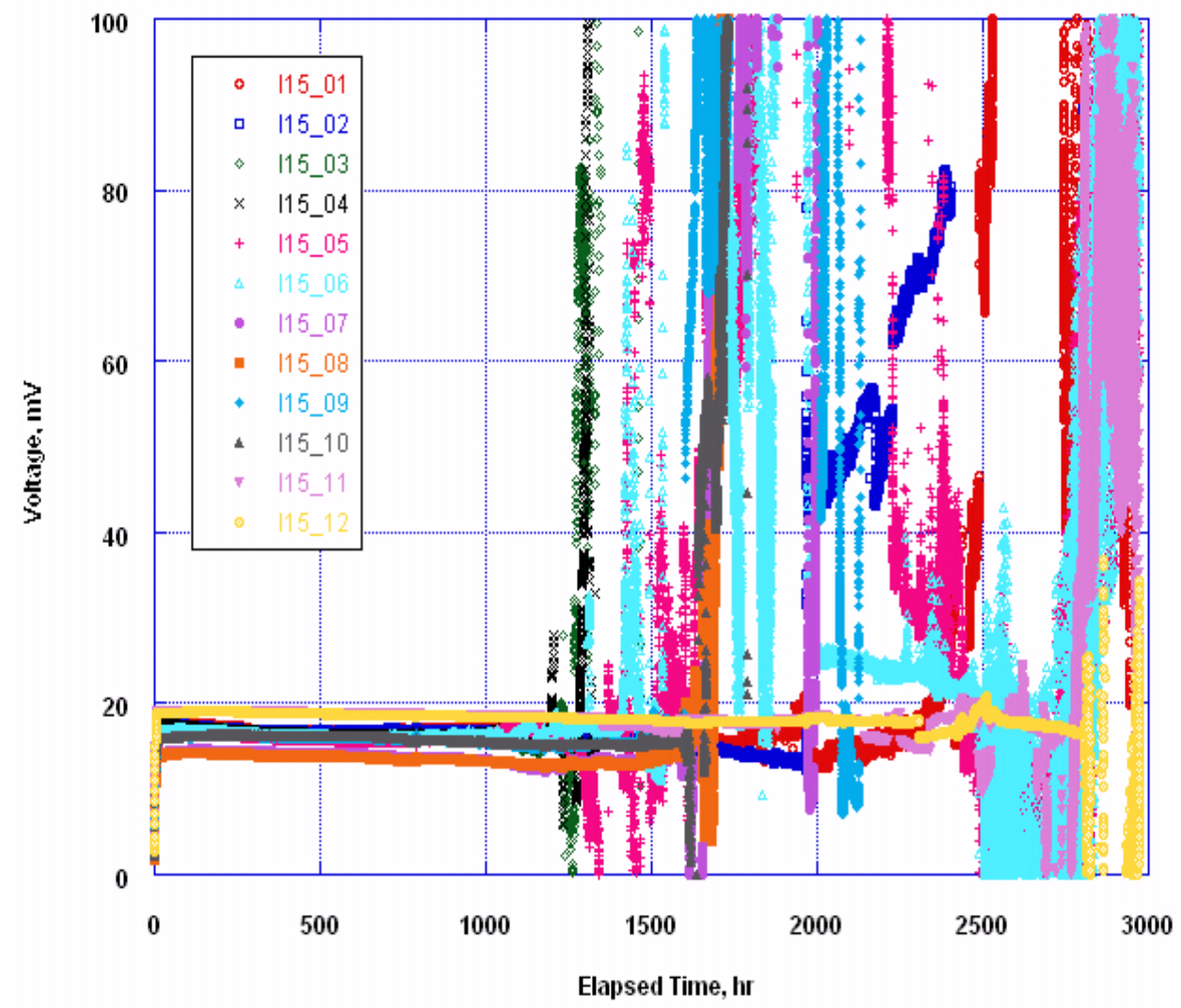

Figure 5-29. Measured emf of INL-developed Mo/Nb alloy thermocouples included in $1500{ }^{\circ} \mathrm{C}$ test

Figure 5-30 shows the emf of the INL-developed thermocouples for the initial 1000 hours of the test. The response of the INL thermocouples made with $(0.25 \mathrm{~mm} / 0.010$ inch $)$ wire from $\mathrm{KW}-\mathrm{Mo} / \mathrm{Nb}-1 \% \mathrm{Zr}$ and developmental alloys appear to experience similar drift during this initial 1000 hours. The developmental alloys did not appear to exhibit superior performance in this test. Figure 5-31 compares the emf of the thermocouples with smaller and larger diameter thermoelement wire. Clearly, the emfs of the INL thermocouples with larger diameter wire (I1511 and I15-12) exhibit less drift. 


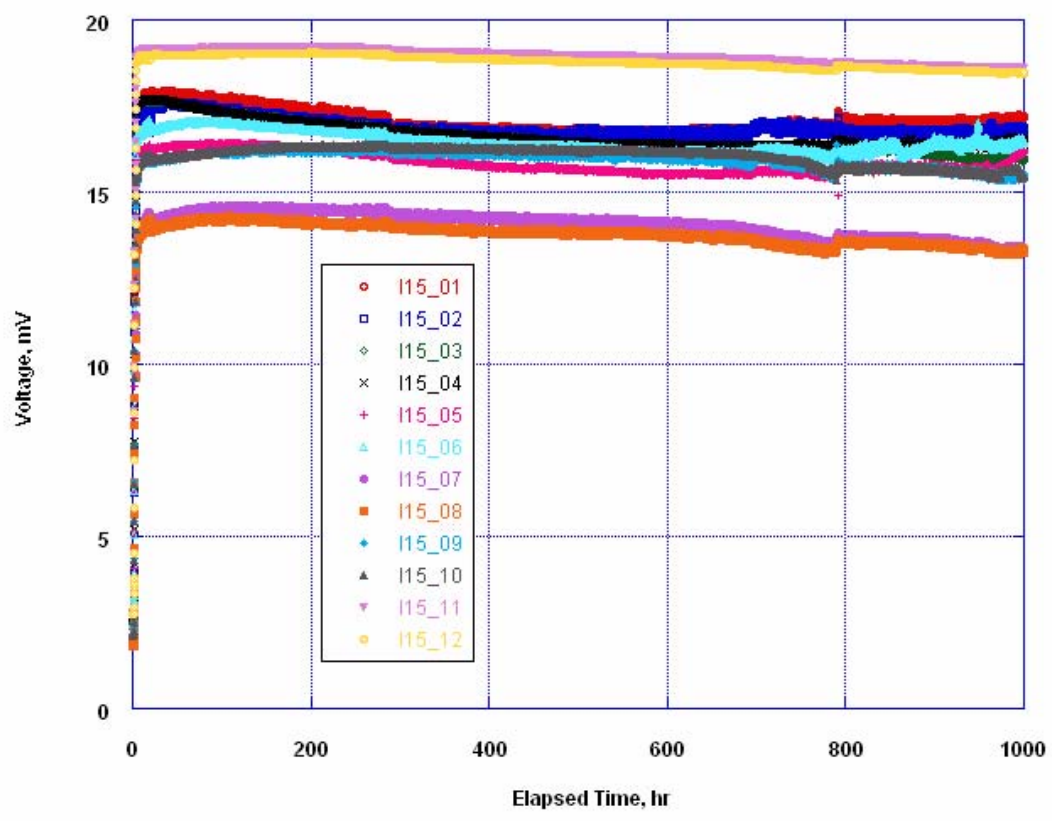

Figure 5-30. Measured emf of INL-developed thermocouples for first 1000 hours in $1500{ }^{\circ} \mathrm{C}$ test

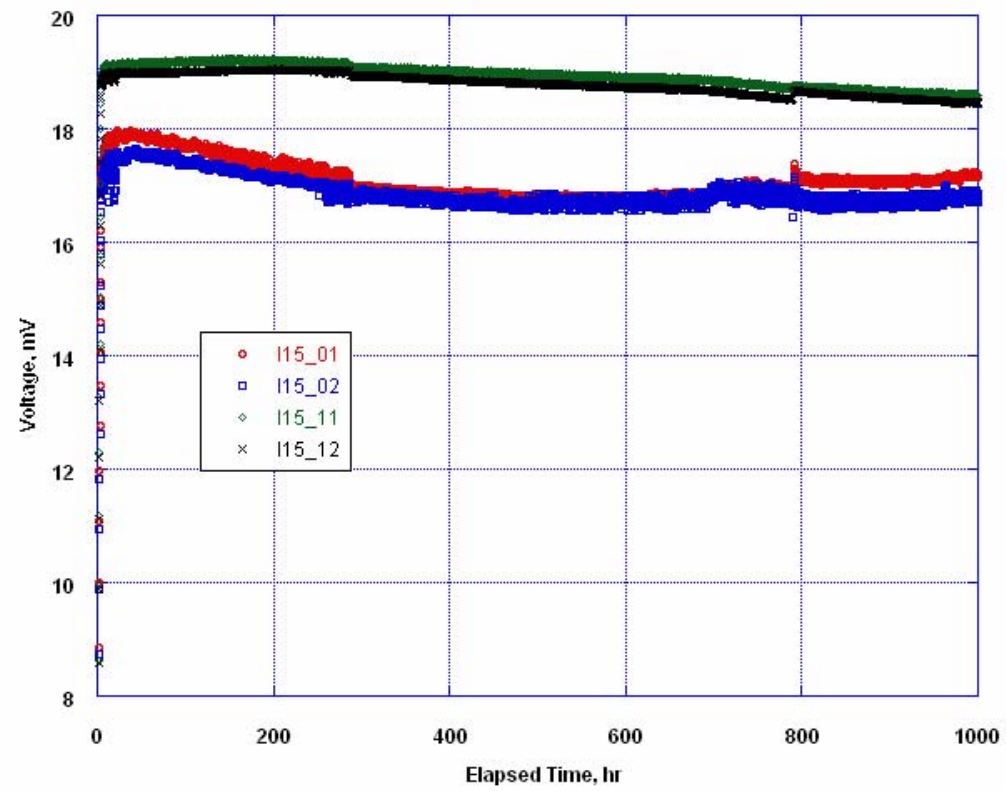

Figure 5-31. Diameter impact on measured emf of INL-developed Mo/Nb alloy thermocouples. 
During disassembly of the tube furnace, significant deposits of oxidized material was observed on the flow tubes containing the thermocouples (see Figure 5-32). After removal from the tube furnace, it was observed that these tubes were "bowed" and fractured at certain locations. Such fractures could have allowed oxygen to come into contact with the thermocouples during testing, although the time when oxygen ingress occurred was unknown. As shown in Figure 5-33 through 5-33, the INL-developed thermocouples had experienced significant oxidation by the time that the test was truncated.

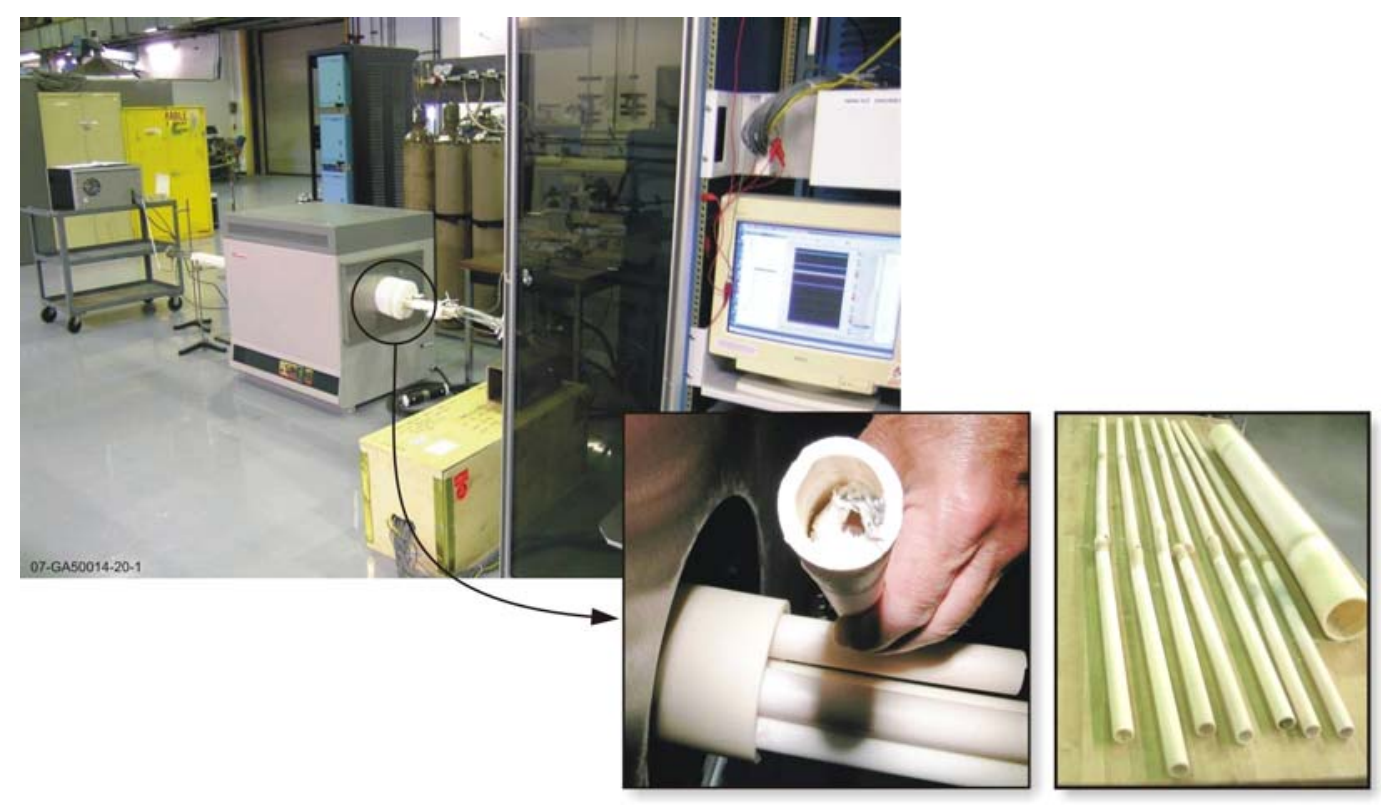

Figure 5-32. Tube furnace after $1500^{\circ} \mathrm{C}$ test.

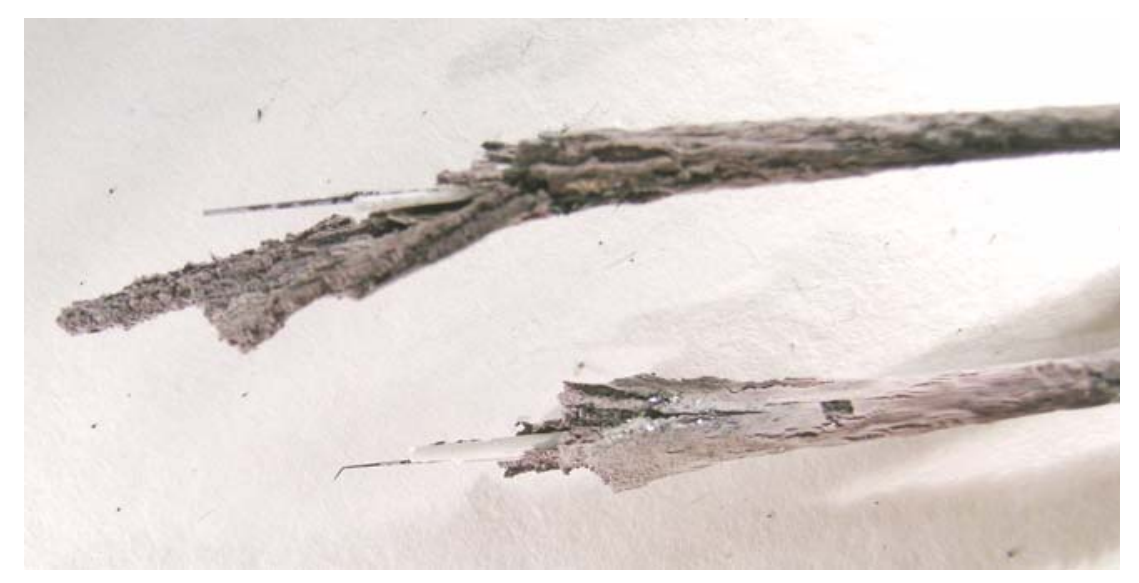

Figure 5-33. INL thermocouples (I15-11 and I15-12) after 3000 hours at $1500{ }^{\circ} \mathrm{C}$. 


\subsection{Summary}

Long duration (up to 4000 hour) tests were conducted at 1200,1400 , and $1500{ }^{\circ} \mathrm{C}$ to verify the performance of the HTIR-TC. During the $1200^{\circ} \mathrm{C}$ test, several commercial Type K and Type $\mathrm{N}$ thermocouples were observed to drift by up to $100^{\circ} \mathrm{C}$. INL developed $\mathrm{Mo} / \mathrm{Nb}$ thermocouples in the same test exhibited signal drift of less than $20^{\circ} \mathrm{C}$. After the 4000 hour test at $1400{ }^{\circ} \mathrm{C}$, drift measured for the INL thermocouples during the 4000 hours of testing was minimal. One $\mathrm{KW}-\mathrm{Mo} / \mathrm{Nb}-1 \% \mathrm{Zr}$ thermocouple failed during the test. However, the remaining $\mathrm{KW}-\mathrm{Mo} / \mathrm{Nb}-$ $1 \% \mathrm{Zr}$ thermocouple and the thermocouples made with developmental alloys of Mo appeared extremely stable. The $1500{ }^{\circ} \mathrm{C}$ test included thermocouples constructed from developmental thermoelement alloys, as well as $\mathrm{KW}-\mathrm{Mo} / \mathrm{Nb}-1 \% \mathrm{Zr}$ thermocouples with alternate thermoelement diameters. After the first 1000 hours of this test, several alumina tubes containing the thermocouples developed cracks, allowing oxygen to enter the tubes and degrade the thermocouples. However, data recorded prior to oxygen ingress indicated that all alternate materials provide similar levels of stability and that larger diameter thermoelement wires exhibited enhanced stability over smaller diameter wires. Note that the $1500{ }^{\circ} \mathrm{C}$ evaluation of HTIR-TCs was repeated. Results are reported in Section 8 of this report. 


\section{Alternate Geometry Evaluations (Task 2)}

As noted above, the reference INL design is a $1.57 \mathrm{~mm} / 0.062$ inch diameter thermocouple that is fabricated from thermoelement wires that are initially $0.254 \mathrm{~mm} / 0.010$ inch diameter. Future tests of GEN IV and AFCI fuels and materials may require thermocouples with other diameters (especially if it is shown that these larger diameters enhance thermocouple reliability). This section reports results from evaluations to assess the impact of diameter on thermocouple performance and fabrication. Specific areas addressed include thermoelement ductility, thermocouple fabrication, and long duration performance at elevated temperature.

\subsection{Ductility Evaluations}

To assess the impact of diameter on thermoelement ductility, mandrel wrap tests were completed. Figures 6-1 through 6-3 compare results from samples of 0.010 and 0.020 inch Nb$1 \% \mathrm{Zr}$ and $\mathrm{KW}$-Mo wire that were heated for selected durations at $1400{ }^{\circ} \mathrm{C}$ and $1600{ }^{\circ} \mathrm{C}$.Figure 61 shows results after heating wires for 5 hours at $140{ }^{\circ} \mathrm{C}$. In this test, both sizes of KW-Mo wires retained suitable ductility. However, the larger diameter $\mathrm{Nb}-1 \% \mathrm{Zr}$ wire better retained its ductility. Figure 6-2 shows the results after heating wires for 12 hours at $1400{ }^{\circ} \mathrm{C}$. The 0.020 ” samples are discolored, possibly a sign of contamination. The wire diameter does not appear to have had a significant effect during this test. Suitable ductility was observed in both sizes of KWMo wire tested, and both sizes of Nb-1\%Zr wire were brittle. As shown in Figure 6-3, similar results were observed for the wires that were heated 5 hours at $1600{ }^{\circ} \mathrm{C}$.
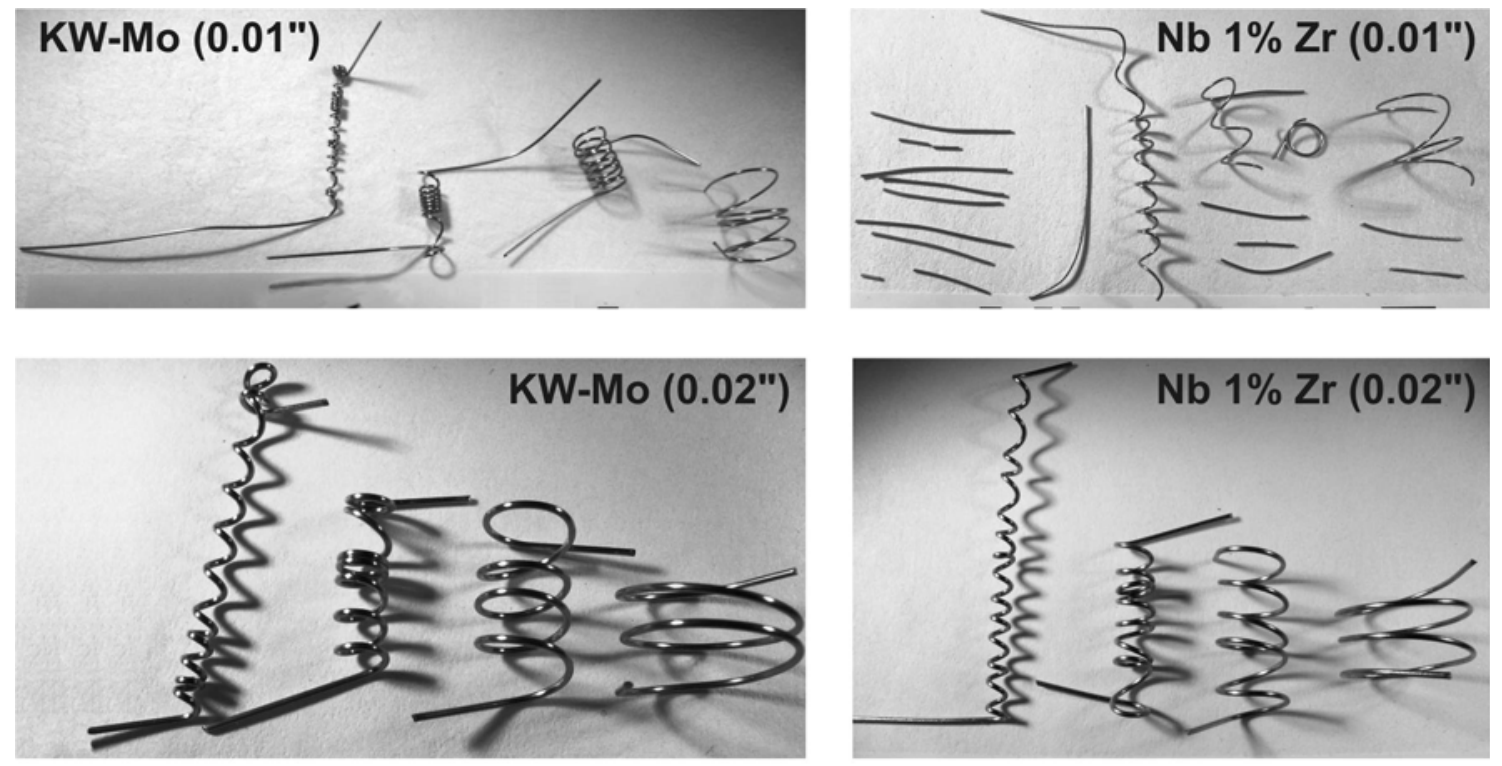

07-GA50014-15-1

Figure 6-1. Effect of wire diameter on samples heated at $1400{ }^{\circ} \mathrm{C}$ for 5 hours 

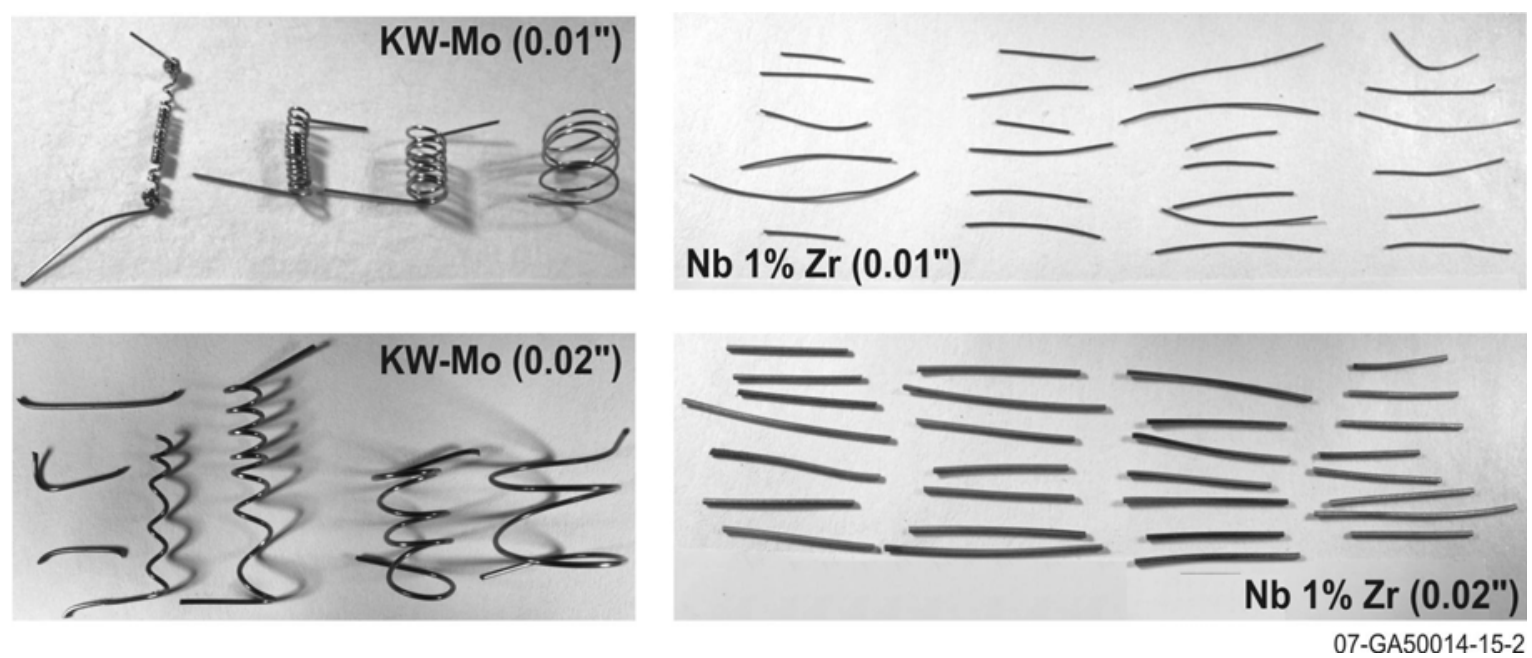

Figure 6-2. Effect of wire diameter on samples heated at $1400{ }^{\circ} \mathrm{C}$ for 12 hours
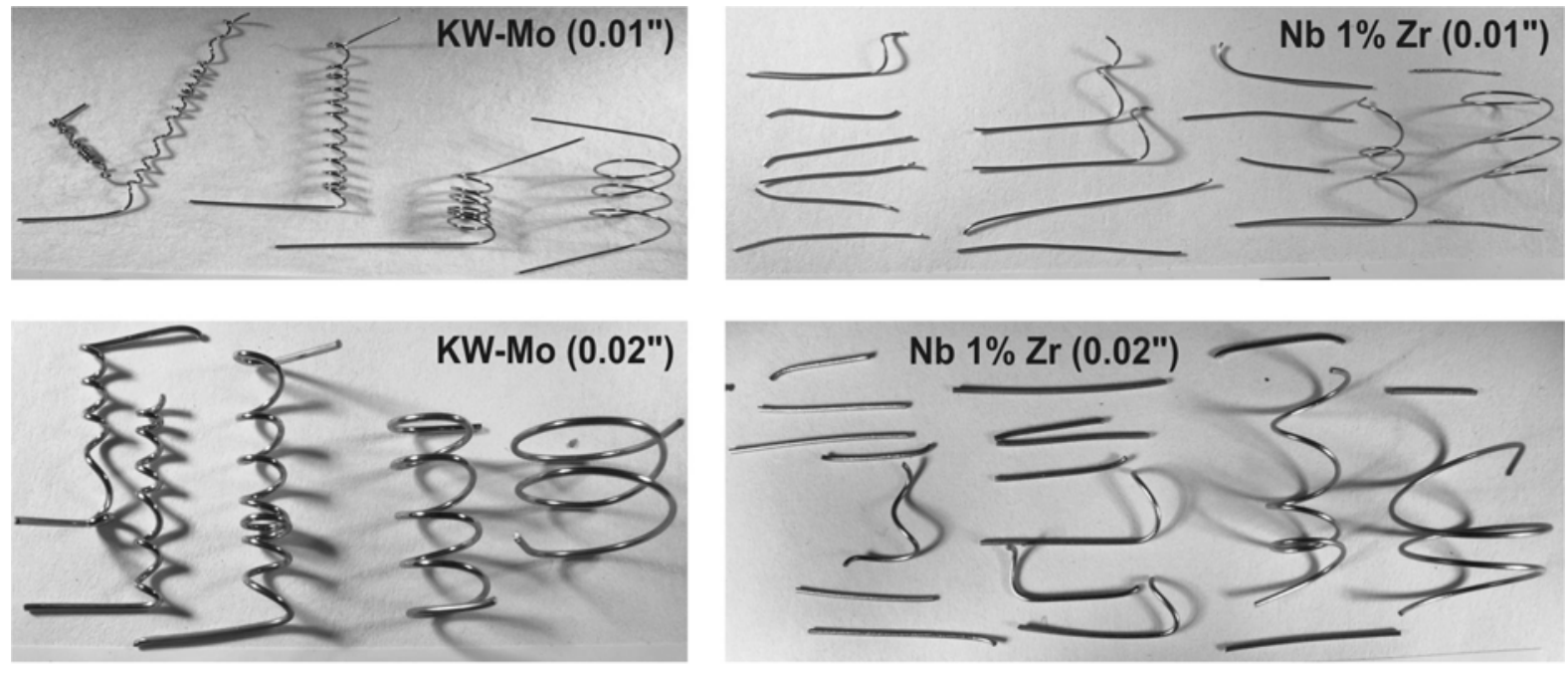

Figure 6-3. Effect of wire diameter on samples heated at $1600{ }^{\circ} \mathrm{C}$ for 5 hours

Hence, for shorter durations at $1400{ }^{\circ} \mathrm{C}$, the increased wire diameter remained more ductile. For longer heating durations and higher temperatures, the effect of wire diameter was diminished. It is speculated that this is because the increased heat treat temperature caused grains to grow sufficiently quickly that the ratio of grain size to wire diameter is similar in wires of either diameter. It should also be noted that the larger wire size may also improve thermocouple durability by increasing the thermoelements' resistance to bending.

\subsection{Fabrication Investigations}

This project investigated the three sizes of thermocouples listed in Table 6-1. In addition to the "Standard HTIR-TC" geometry, prototype thermocouples were fabricated for 
thermocouples with thermoelement wires ranging from $0.127 \mathrm{~mm}$ to $0.508 \mathrm{~mm}(0.005$ " to $0.020 ")$ in diameter. Note that commercially available materials (doped KW-Mo and Nb-1\%Zr) were used for this task because it is difficult to obtain alternate sizes of Task 1 non-commercial alloys. For each size of thermoelement wires, appropriate sizes of compressible $\mathrm{HfO}_{2}$ insulation and appropriate $\mathrm{Nb}-1 \% \mathrm{Zr}$ sheath tubing were obtained.

Table 6-1. Alternate Wire diameters Tested

\begin{tabular}{|c|c|c|c|c|}
\hline Wires & Wire Diameter, $\mathrm{mm} / \mathrm{in}$ & Insulation & Sheath & $\begin{array}{l}\text { Final outer diameter, } \\
\qquad \mathrm{mm} / \mathrm{in}\end{array}$ \\
\hline \multicolumn{5}{|c|}{ Standard INL-developed HTIR-TC } \\
\hline KW-Mo / Nb1\%Zr & $0.254 / 0.010$ & $\mathrm{HfO}_{2}$ & $\mathrm{Nb1 \% Zr}$ & $1.57 / 0.062$ \\
\hline \multicolumn{5}{|c|}{ Alternate Geometries Investigated } \\
\hline KW-Mo / Nb1\%Zr & $0.127 / 0.005$ & $\mathrm{HfO}_{2}$ & $\mathrm{Nb} 1 \% \mathrm{Zr}$ & $1.02 / 0.040$ \\
\hline KW-Mo / Nb1\%Zr & $0.508 / 0.020$ & $\mathrm{HfO}_{2}$ & $\mathrm{Nb} 1 \% \mathrm{Zr}$ & $2.36 / 0.093$ \\
\hline
\end{tabular}

Then, an appropriate process for fabricating these thermocouples were devised to obtain the final thermocouple diameters listed in Table 6-1. Table 6-2 outlines fabrication steps completed for each geometry evaluated. Steps were implemented to form a robust junction for each geometry, to ensure that each junction was surrounded by insulation, and to ensure that the thermocouple sheath was sufficiently swaged such that the insulation was compacted around the thermoelement wires. For each geometry, appropriate heat treatment temperatures and durations must be selected (based on the anticipated operating temperatures of the thermocouple) and an emf response curve must also be obtained.

Table 6-2. Steps completed to optimize alternate geometry thermocouples

\begin{tabular}{|l|}
\multicolumn{1}{|c|}{ Alternate Geometry Fabrication Steps } \\
\hline - Select appropriately sized wire, insulation, and sheath geometries. \\
- Devise approach for fabricating junction. \\
- Select appropriate swaging reduction techniques. \\
- Devise appropriate endcap and attachment techniques. \\
- Select appropriate heat treatment \\
- Develop emf response curve
\end{tabular}

\subsection{Heat Treatment Investigations}

Evaluations were conducted to develop a process for selecting an appropriate heat treatment duration. Assuming an operating temperatures of $1600^{\circ} \mathrm{C}$, heat treatment temperatures of $1700{ }^{\circ} \mathrm{C}$ were first evaluated. Two thermocouples were prepared for each geometry identified in Table 6-1. Although one of the smaller sized thermocouples failed during fabrication, the remaining thermocouples were heat treated for 20 hours at $1700{ }^{\circ} \mathrm{C}$ to stabilize grain growth. 
Measured emfs from each size of thermocouple are plotted in Figure 6-4. All thermocouples were inserted into a tube furnace at a time corresponding to 0 hours. As shown in Figure 6-4, the smaller diameter thermocouple is more susceptible to "noise" induced by the tube furnace to maintain the temperature at $1700^{\circ} \mathrm{C}$. Data, see Figure 6-4a, indicate that all three geometries stabilized within the first 4 hours of heat treatment. In fact, the drift observed after 4 hours at $1700{ }^{\circ} \mathrm{C}$ suggests that the heat treatment should be limited to 4 hours for thermocouples that will operate at temperatures at $1600{ }^{\circ} \mathrm{C}$.

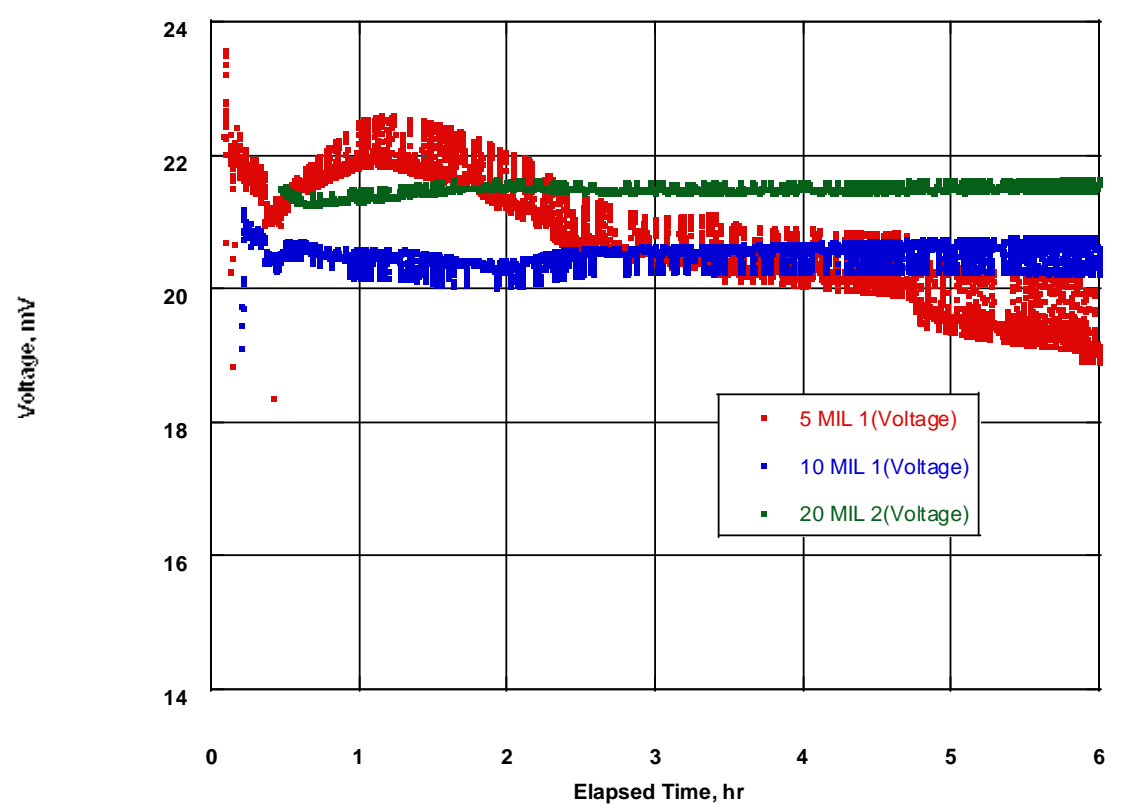

(a) Response during first 4 hours of heat treatment

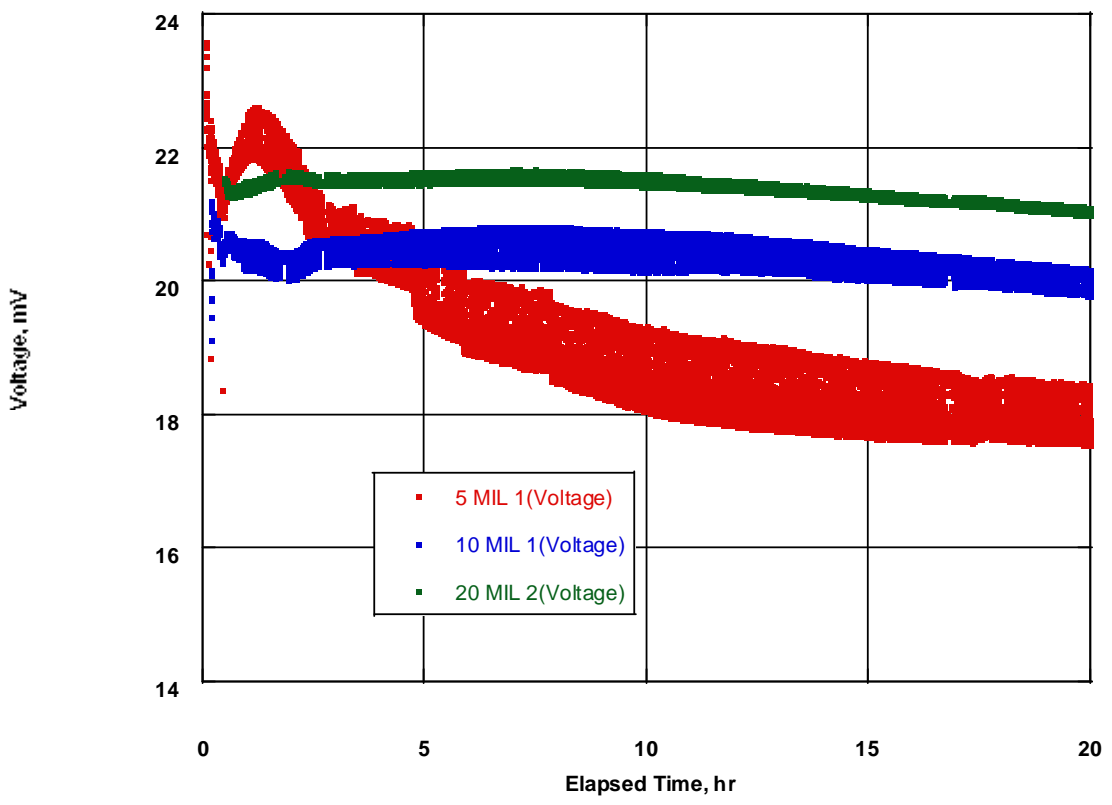

(b) Response during entire 20 hours of heat treatment

Figure 6-4. Response of representative thermocouples during $1700{ }^{\circ} \mathrm{C}$ heat treatment. 


\subsection{Thermal Cycling Evaluations}

Prototypes for each thermocouple size were prepared by heat treating for 20 hours at $1700{ }^{\circ} \mathrm{C}$. Prototypes were then subjected to thermal cycling tests (up to $1600{ }^{\circ} \mathrm{C}$ ). During the first cooldown, the remaining smaller thermocouple experienced an open circuit failure. However, the larger diameter and standard sized thermocouples remained stable. As shown in Figure 6-5, changes in emf were minimal (less than 1\%) for the larger diameter thermocouples after 2 cycles. Curves in Figure 6-6 show slightly larger drifts (up to 4\%) were observed in the standard sized thermocouples (up to $4 \%$ ).

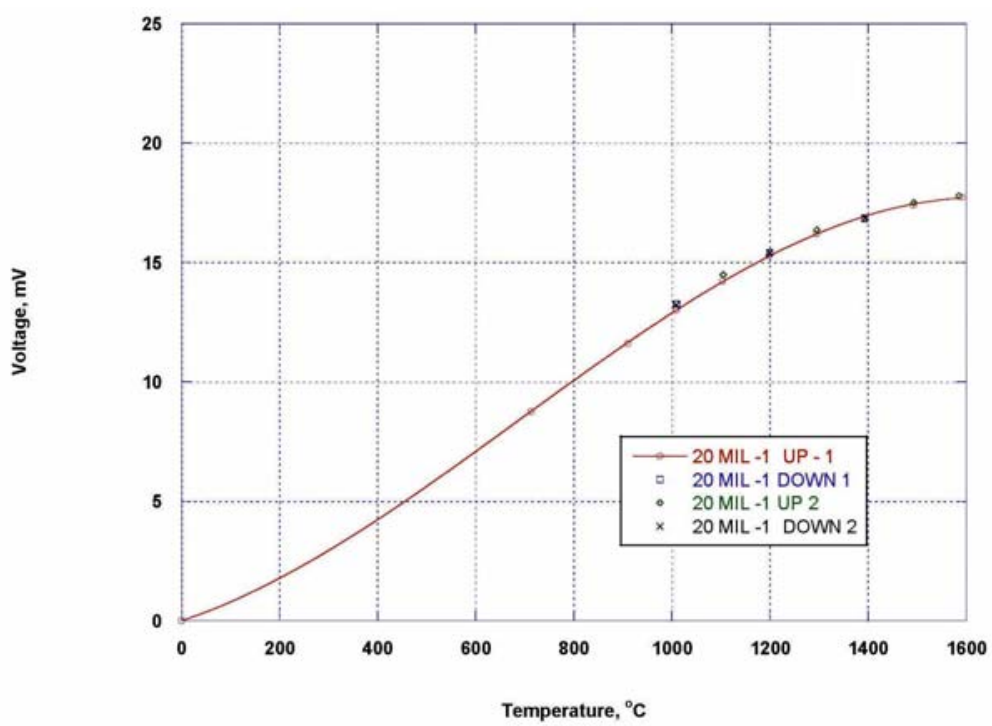

(a) $20 \mathrm{MIL}-1$

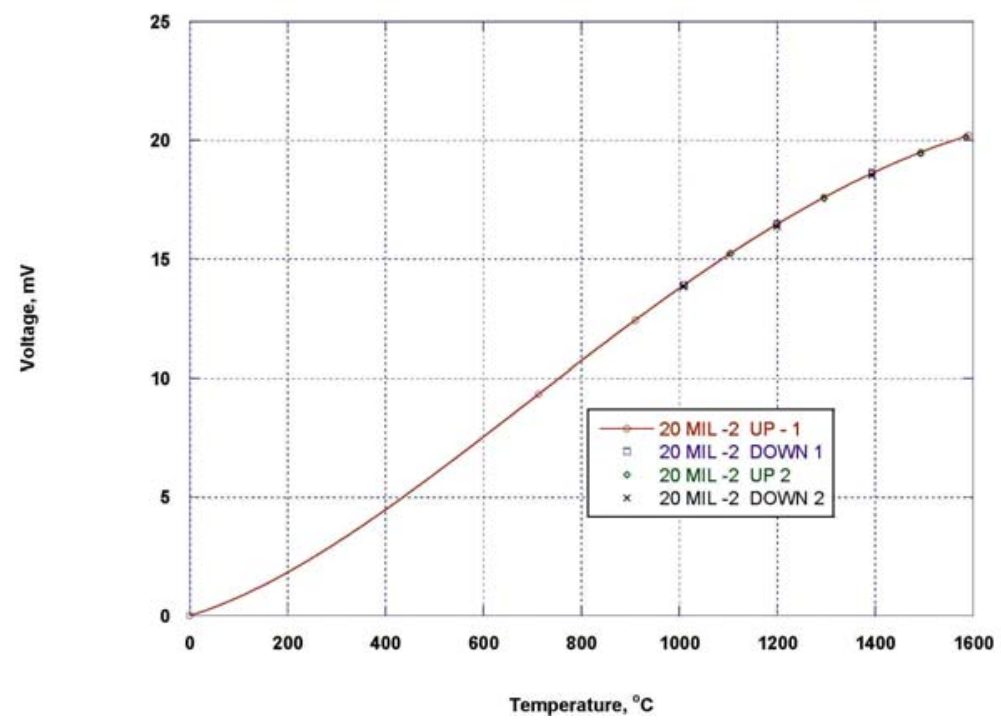

(b) 20 MIL -2

Figure 6-5. Measured emf for larger diameter thermocouple during thermal cycling tests. 


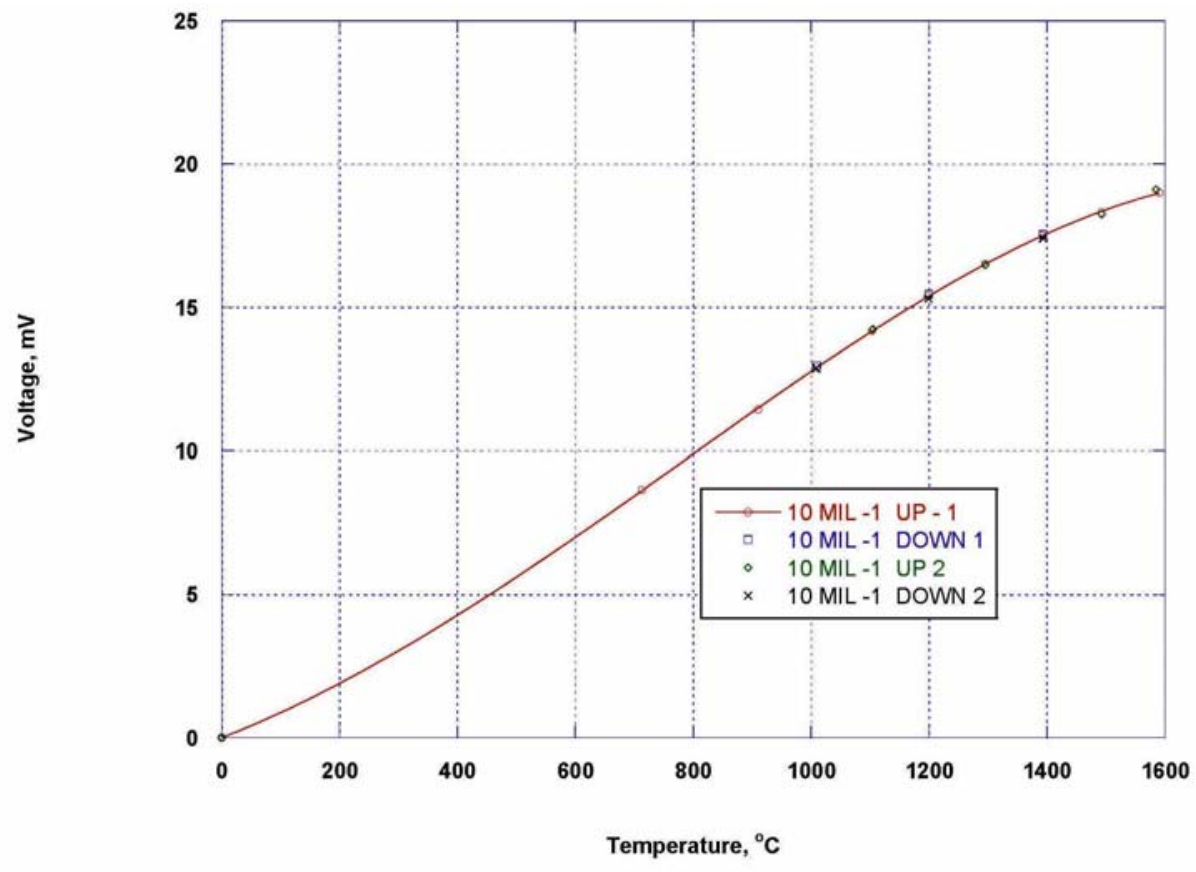

(a) 10 MIL -1

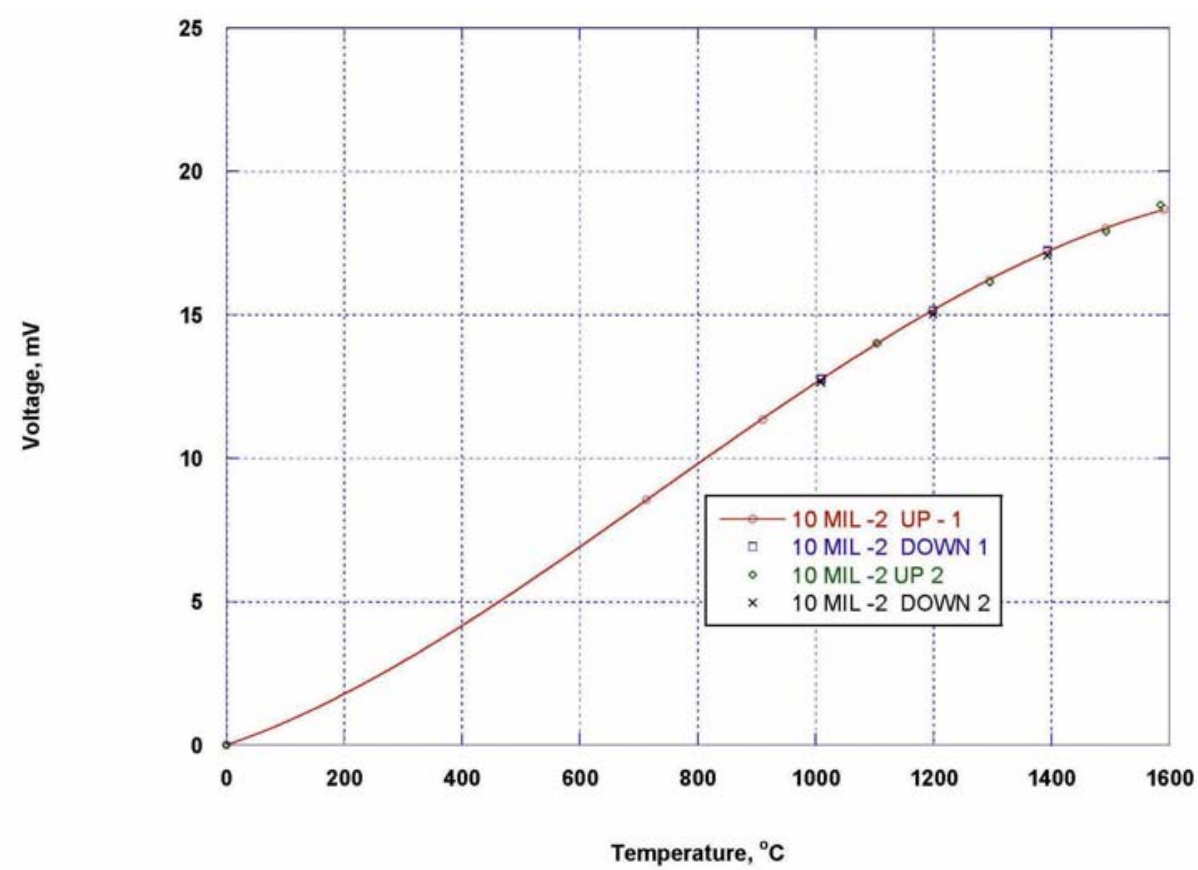

(b) $10 \mathrm{MIL}-2$

Figure 6-6. Measured emf for standard diameter thermocouple during thermal cycling tests. 
Table 6-3. Measured drift during transient testing.

\begin{tabular}{|c|c|c|c|}
\hline \multirow{2}{*}{ Thermocouple } & \multicolumn{3}{|c|}{ Maximum Drift, emf } \\
& 1st Cycle Down & 2nd Cycle - Up & 2nd Cycle - Down \\
\hline 10 MIL - 1 & 0.7 & 1.4 & 0.8 \\
10 MIL - 2 & 0.3 & 1.9 & 1.1 \\
20 MIL - 1 & 2.0 & 3.7 & 1.9 \\
20 MIL - 2 & 0.2 & 0.4 & 0.7 \\
\hline
\end{tabular}

\subsection{Long Duration Performance}

The long duration $1500{ }^{\circ} \mathrm{C}$ test discussed in Section 5 included prototypes for each thermocouple size listed in Table 6-1. Based on results from Section 6.3, these prototypes that were heat treated for 4 hours at $1600{ }^{\circ} \mathrm{C}$. Figure 6-7 compares the emf of representative thermocouples of each diameter tested. Clearly, the INL thermocouples with larger diameter wire exhibited less drift.

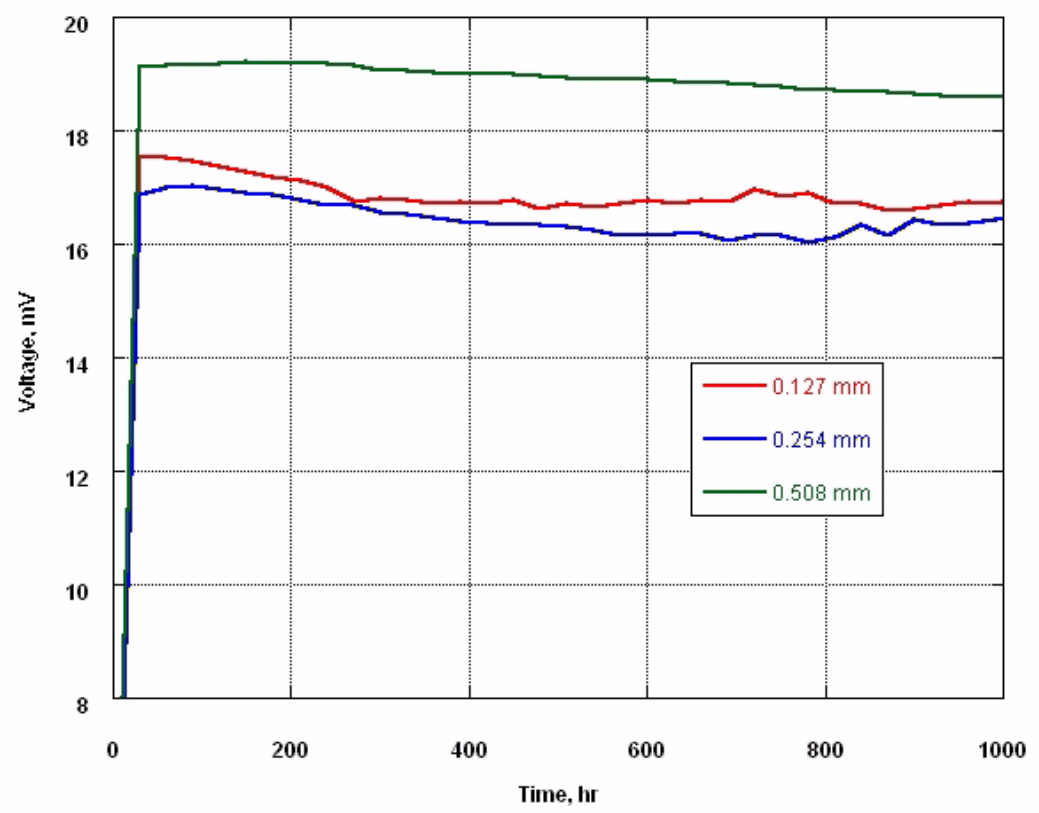

Figure 6-7. Measured emf for various HTIR-TC geometries in $1500{ }^{\circ} \mathrm{C}$ test. 


\subsection{Summary}

As discussed in this section, several types of evaluations were completed to gain insights about the impact of diameter on HTIR-TC performance.

To evaluate the impact on thermoelement ductility, mandrel wrap tests were completed on 0.254 to $0.508 \mathrm{~mm}$ (0.010 and 0.020 inch) samples of Nb-1\%Zr and KW-Mo wire. Tests were conducted at $1400{ }^{\circ} \mathrm{C}$ for 5 and 12 hours and at $1600{ }^{\circ} \mathrm{C}$ for 6 hours. Test results showed that for the shorter durations at $1400{ }^{\circ} \mathrm{C}$, the increased wire diameter remained more ductile. For longer heating durations and higher temperatures, the effect of wire diameter was diminished. Both sizes of KW-Mo wire remained ductile, whereas both sizes of Nb-1\%Zr were brittle. However, it should be noted that the larger wire size could still improve thermocouple durability by increasing the thermoelements' resistance to bending and fracture.

To assess the impact of diameter on transient response,prototype HTIR-TCs were fabricated with thermo-element wires of three different diameters $(0.127,0.254 \mathrm{~mm}$, and 0.508 mm wire). Although it was planned to test two thermocouples of each size, the thermocouples containing $0.127 \mathrm{~mm}$ wire failed during fabrication and heat treatment processes. Transient tests were performed on the remaining thermocouples made with larger diameter wires $(0.254$ and $0.508 \mathrm{~mm}$ wire). Results indicate that changes in emf were minimal (less than 1\%) for the thermocouples made with $0.508 \mathrm{~mm}$ wire. Larger drifts (up to $4 \%$ ) were observed in the thermocouples fabricated with $0.254 \mathrm{~mm}$ wires.

Long duration $1500{ }^{\circ} \mathrm{C}$ test were performed that included HTIR-TC prototypes fabricated with $0.127,0.254$, and $0.508 \mathrm{~mm}$ wires. Results indicate that the thermocouples with larger diameter wire exhibited less drift

Hence, initial geometry evaluations indicated that HTIR-TCs containing larger diameter thermoelement wires are even more stable and robust than thermocouples containing $0.254 \mathrm{~mm}$ diameter thermoelement wires. Several difficulties were experienced in initial efforts to develop thermocouples containing smaller diameter thermoelements $(0.127 \mathrm{~mm})$. Future efforts should focus on an improved fabrication process for these smaller diameter thermocouples so that they will be more robust. 


\section{Alternate Fabrication Techniques - Heat Treatment (Task 3.2)}

In initial INL efforts to fabricate these thermocouples, grain growth in the thermoelement wires was stabilized by heat treating. However, limited data were available to select appropriate temperatures and durations for this heat treatment. In this task, alternate heat treatment times, temperatures, and durations were explored for HTIR-TCs operating at 1200 and $1500{ }^{\circ} \mathrm{C}$.

\subsection{Heat Treatments for $1200{ }^{\circ} \mathrm{C}$ Operation}

Table 7-1 lists the heat treatment temperatures and durations explored for thermocouples fabricated to operate at $1200^{\circ} \mathrm{C}$. Table $7-1$ also lists the evaluations completed on these thermocouples to assess their performance. For the thermocouples heat treated at $1300{ }^{\circ} \mathrm{C}$, calibration cycles were completed on the thermocouples, followed by a 100 hour test at constant temperature to evaluate what drift may occur

Table 7-1. Heat treatment temperatures and durations explored for $1200{ }^{\circ} \mathrm{C}$ operation

\begin{tabular}{|c|l|l|l|}
\hline $\begin{array}{c}\text { Temperature, } \\
{ }^{\mathbf{0}} \mathrm{C}\end{array}$ & \multicolumn{1}{|c|}{$\begin{array}{c}\text { Duration, } \\
\text { Hours }\end{array}$} & \multicolumn{1}{|c|}{ Designator } & \multicolumn{1}{|c|}{ Evaluations Completed } \\
\hline \multirow{2}{*}{1300} & 0 & $12-1300-0$ & Calibration to $1200^{\circ} \mathrm{C}, 100$ hours at $1200^{\circ} \mathrm{C}$. \\
\cline { 2 - 3 } & 5 & $12-1300-5$ & \\
\cline { 2 - 3 } & 10 & $12-1300-10$ & \\
\cline { 2 - 3 } & 20 & $12-1300-20$ & Calibration to $1200^{\circ} \mathrm{C}$ \\
\hline 1400 & 20 & $12-1400-20$ & Calibration to $1200^{\circ} \mathrm{C}$ \\
\hline 1500 & 20 & $12-1500-20$ & \\
\hline
\end{tabular}

Figure 7-1 compares results from calibration runs obtained for thermocouples heat treated at various temperatures ( 1300 to $1500{ }^{\circ} \mathrm{C}$ ) for 20 hours. Results indicate that the peak emf is reduced as the heat treatment temperature increases, but that the decrease in emf is reduced at temperatures greater than $1400^{\circ} \mathrm{C}$. Figure 7-2 compares results from calibration runs obtained for thermocouples heat treated at $1300{ }^{\circ} \mathrm{C}$ for 5,10 , and 20 hours. Differences between the measured emf were not significantly impacted by differences in heat treatment duration. Figure 7-3 compares the drift measured in thermocouples heat treated at $1300{ }^{\circ} \mathrm{C}$ for various durations. Results indicate that the thermocouple without any heat treatment drifted more than the other thermocouples. However, the observed drift was minimal in all of the heat treated thermocouples. Hence, investigations suggest that heat treatment times of 5 hours at $1300{ }^{\circ} \mathrm{C}$ will stabilize thermocouples for operating temperatures of $120{ }^{\circ} \mathrm{C}$. 


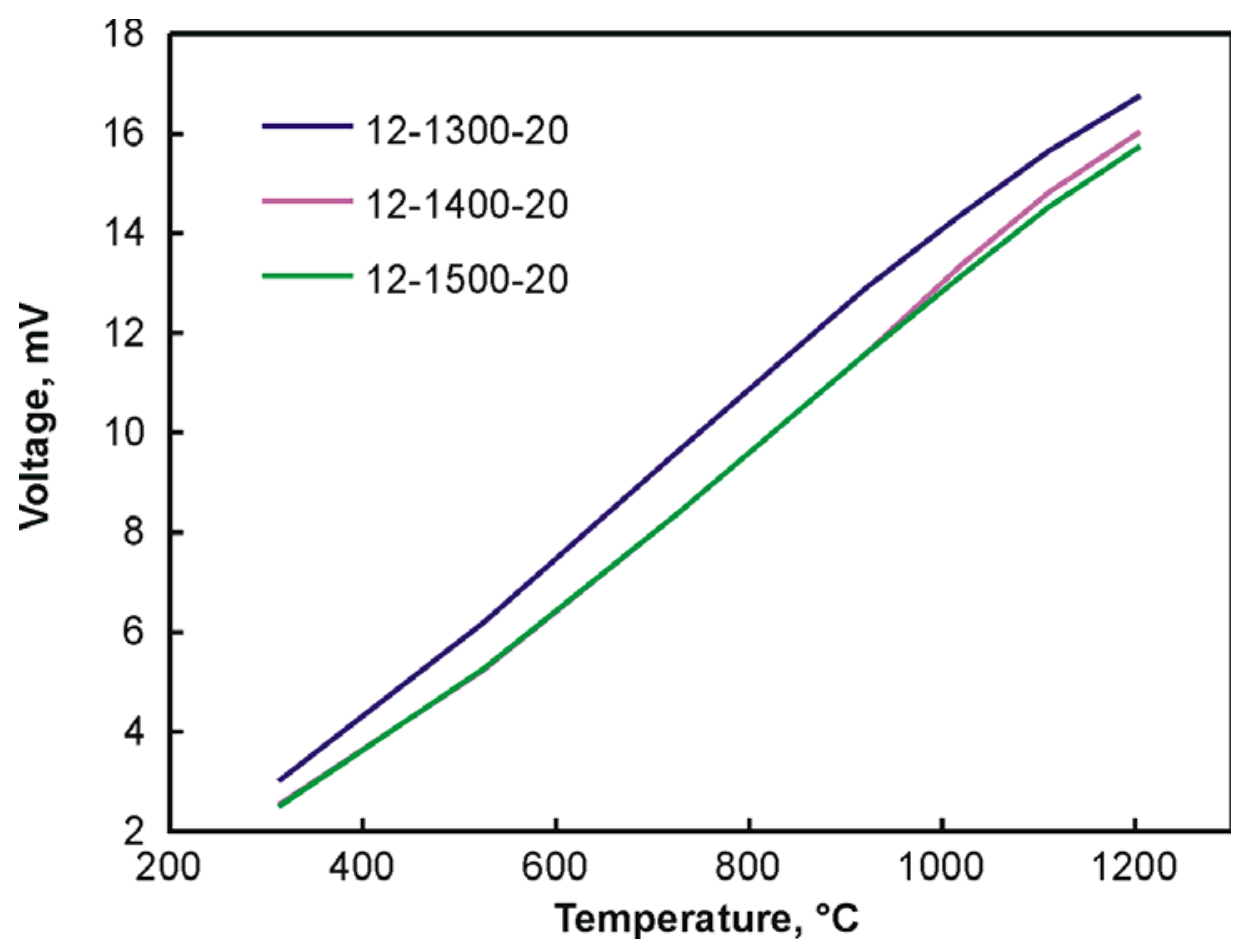

Figure 7-1. Calibration data obtained from thermocouples heat treated for 20 hours at $1300{ }^{\circ} \mathrm{C}(12-1300$ $20), 1400^{\circ} \mathrm{C} \quad(12-1400-20)$, and $1500^{\circ} \mathrm{C} \quad(12-1500-20)$.

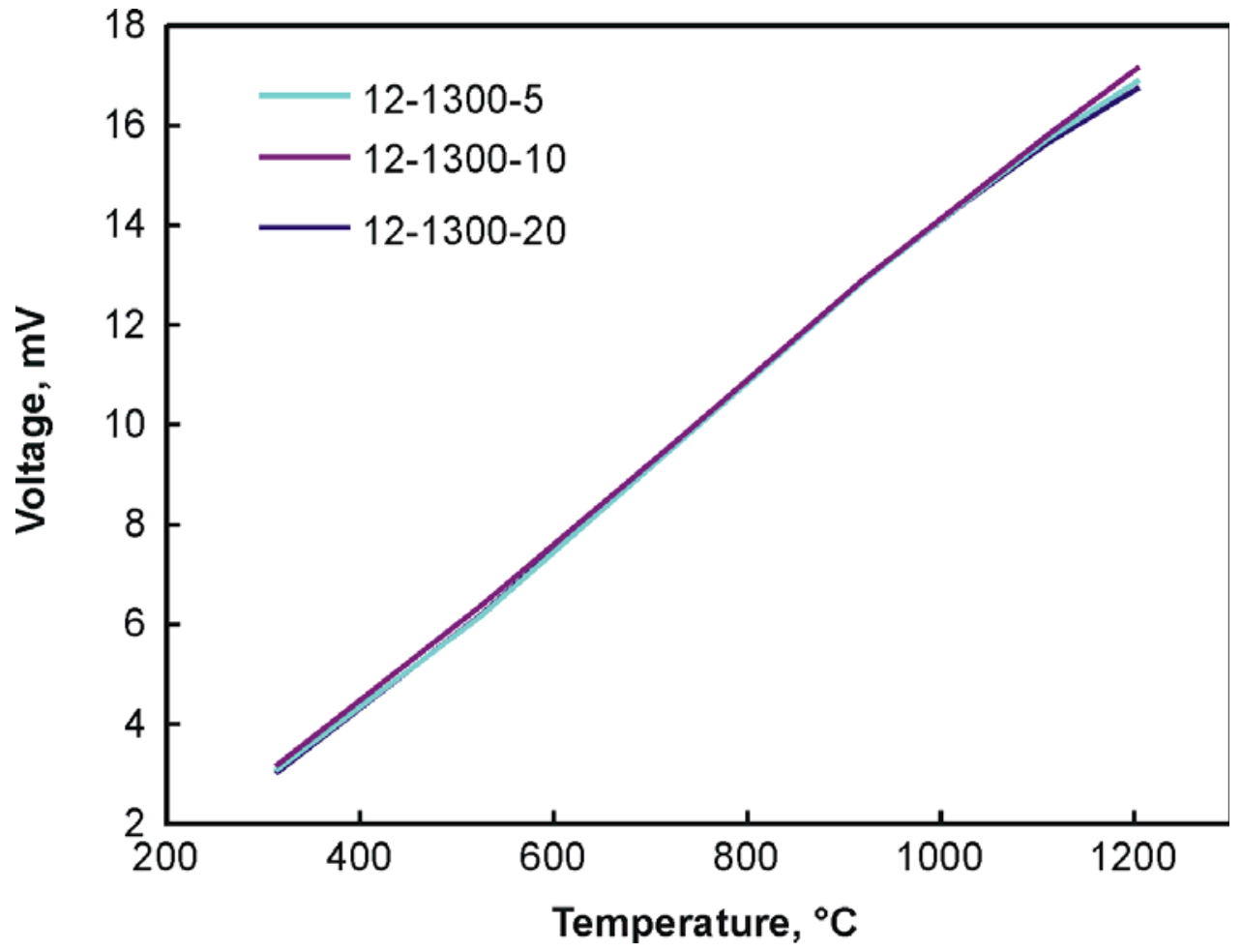

Figure 7-2. Comparison of calibration data obtained from thermocouples heat treated at $1300{ }^{\circ} \mathrm{C}$ for 5 (12-1300-5), 10 (12-1300-10), and 20 (12-1300-20) hours. 


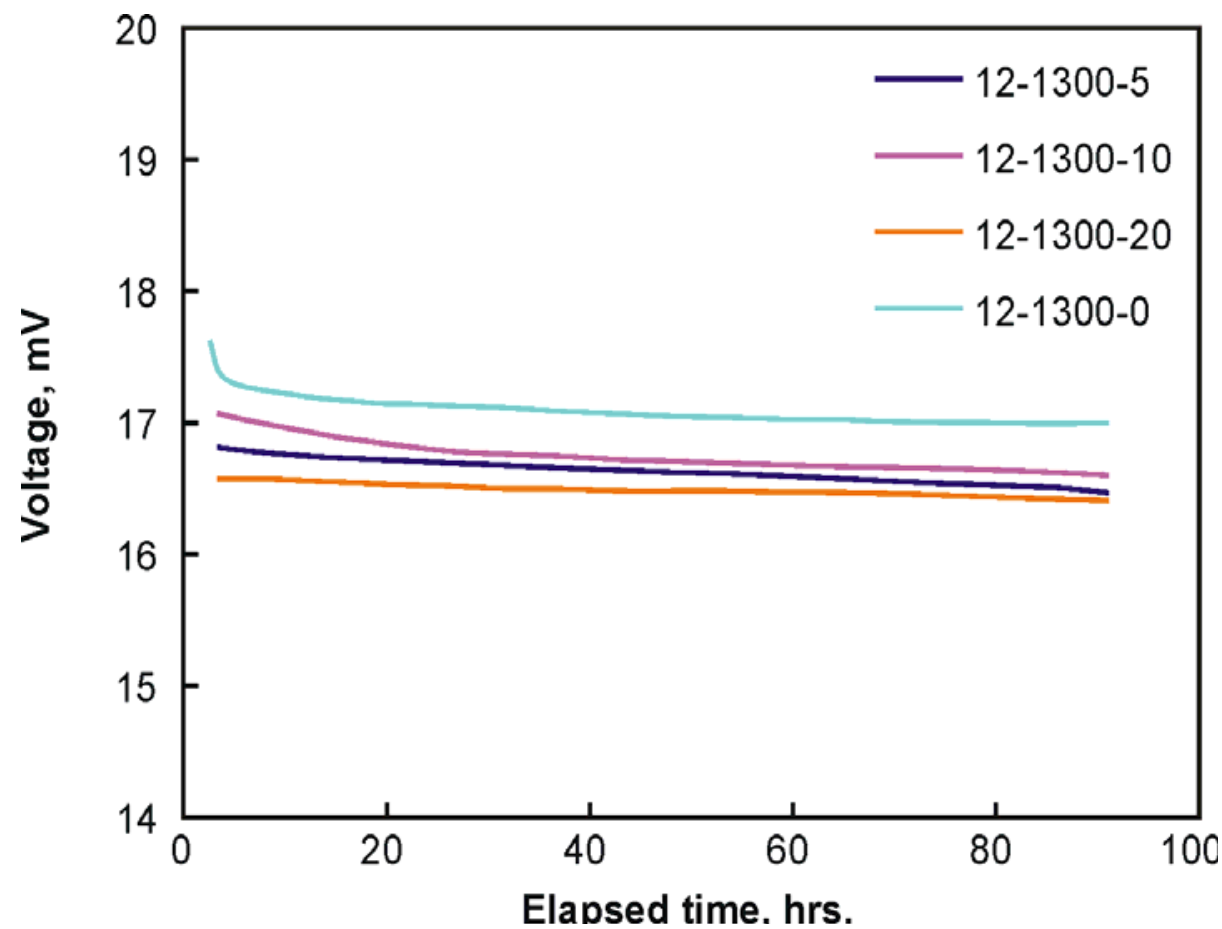

Figure 7-3. Measured drift of thermocouples heat treated at $1300^{\circ} \mathrm{C}$ at 0 (12-1300-0), 5 (12-1300-5), 10 (12-1300-10), and 20 (12-1300-20) hours in $1200^{\circ} \mathrm{C}$ constant temperature test.

\subsection{Heat Treatments for $1500{ }^{\circ} \mathrm{C}$ Operation}

Table 7-2 lists the heat treatment temperatures and durations explored for thermocouples fabricated to operate at $1500{ }^{\circ} \mathrm{C}$ and the evaluations completed on these thermocouples to assess their performance. Similar to the process used for thermocouples fabricated to operate at $1200{ }^{\circ} \mathrm{C}$, calibration cycles were completed on the thermocouples, followed by an approximately 100 hour test at constant temperature to quantify drift at $1500{ }^{\circ} \mathrm{C}$.

Table 7-2. Heat treatment temperatures and durations explored for $1500{ }^{\circ} \mathrm{C}$ operation

\begin{tabular}{|c|l|l|l|}
\hline $\begin{array}{c}\text { Temperature, } \\
{ }^{\mathbf{0}} \mathrm{C}\end{array}$ & \multicolumn{1}{|c|}{$\begin{array}{c}\text { Duration, } \\
\text { Hours }\end{array}$} & \multicolumn{1}{|c|}{ Designator } & \multicolumn{1}{|c}{ Evaluations Completed } \\
\hline 1600 & 0 & $15-1600-0$ & Calibration to $1500^{\circ} \mathrm{C}, 100$ hours at $1500^{\circ} \mathrm{C}$. \\
\cline { 2 - 3 } & 4 & $15-1600-4$ & \\
\cline { 2 - 3 } & 8 & $15-1600-8$ & \\
\cline { 2 - 3 } & 16 & $15-1600-16$ & Calibration to $1500^{\circ} \mathrm{C}$ \\
\hline 1700 & 4 & $15-1700-4$ & \\
\hline
\end{tabular}

Figure 7-4 compares calibration results of swaged thermocouples heat treated for 4, 8, and 16 hours at $1600{ }^{\circ} \mathrm{C}$ and for 4 hours at $1700^{\circ} \mathrm{C}$. The results indicate that emf is not significantly 
affected for any of these heat treat parameters, signals reducing slightly with increased heat treatment time and temperature.

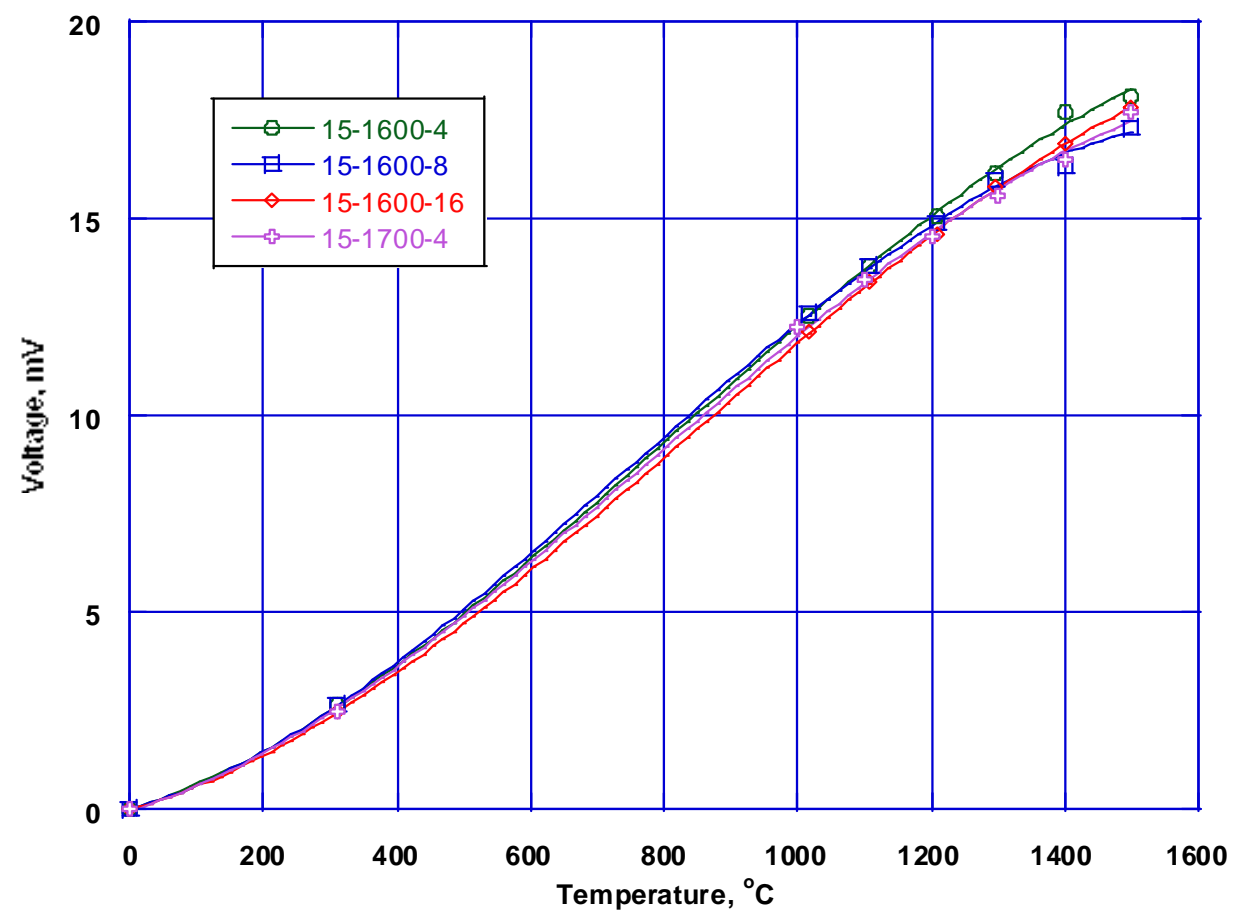

Figure 7-4. Calibration data obtained from thermocouples heat treated at $1600{ }^{\circ} \mathrm{C}$ for 4 (15-1600-4), 8 (15-1600-8), and 16 (15-1600-16) hours and $1700^{\circ} \mathrm{C}$ for 4 hours (15-1700-4).

Figure 7-5 compares drift for these swaged thermocouples at $1500{ }^{\circ} \mathrm{C}$ over 95 hours. Results from this test seem to indicate that increased heating time or temperature decreases emf but has minimal effect on stability. These results were deemed inconclusive as there were anomalous characteristics in the results. First, 15-1600-16 shows a sudden increase in emf at approximately 75 hours; this thermocouple later failed during cooldown. It is possible that the thermocouple developed a break with intermittent contact during the test. Also, 15-1600-4 and 15-1600-8 seem to mirror each other in terms of noise, e.g., when the noise observed in one increases, the noise observed in the other decreases. These thermocouples were placed in the same alumina tube in the furnace with a smaller alumina tube separating them. The cause for this effect is unknown. It is possible that the hafnia insulators deteriorated at high temperature causing poor performance. X-ray images of the 15-1600-4 thermocouple shown in Figure 7-6 suggest that significant degradation of the insulation occurred. However, X-ray analysis is inconclusive due to the difficulty in penetrating the sheaths once they have been heated.

Figures 7-7 through 7-11 show cross sections of thermocouple 15-1600-4. In Figure 7-7, the $\mathrm{Nb}-1 \% \mathrm{Zr}$ thermoelement wire is oval shaped because of deformation that occurs during the swaging process. The insulator appears cracked and missing portions filled with epoxy. However, 


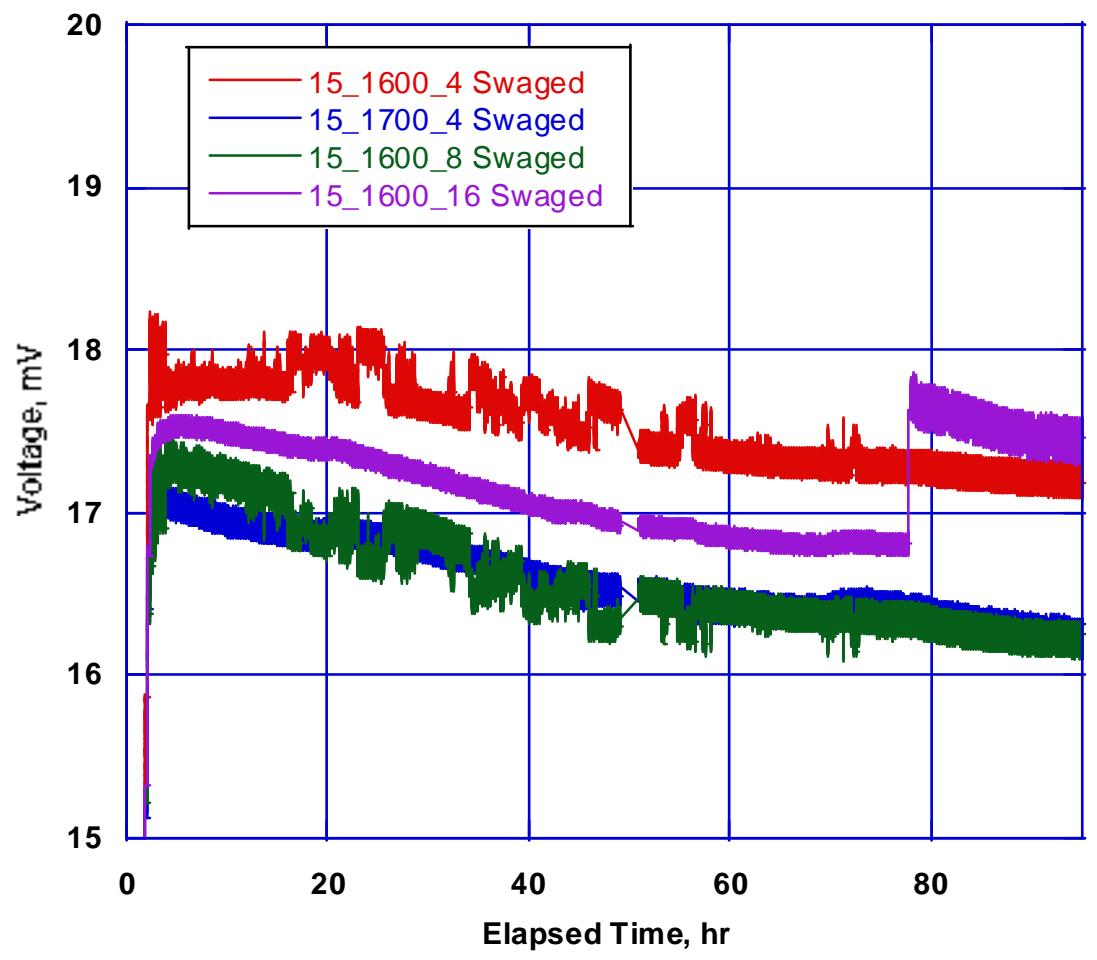

Figure 7-5. Drift exhibited in swaged thermocouples heat treated for service at $1500{ }^{\circ} \mathrm{C}$.

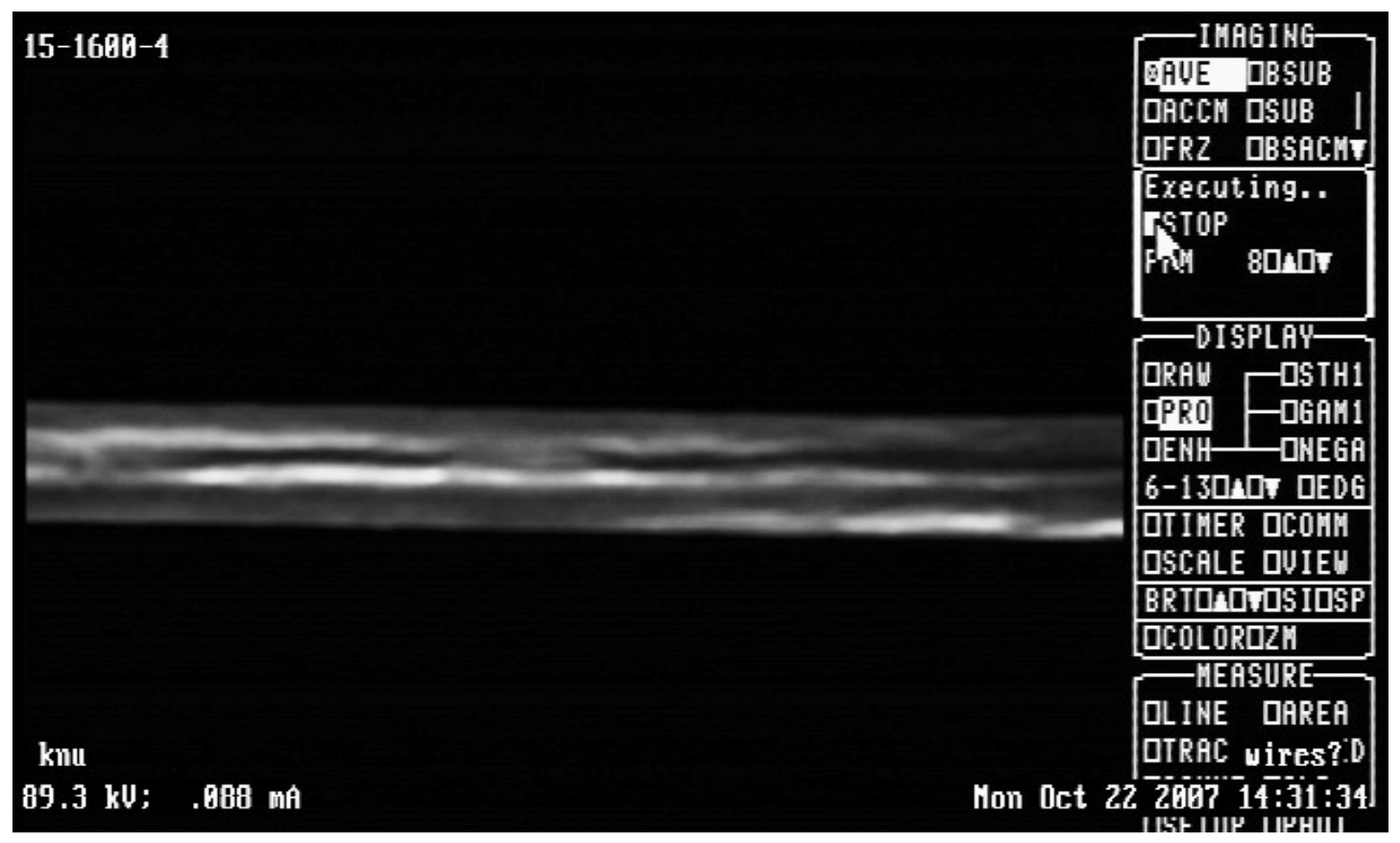

Figure 7-6. X-ray image of thermocouple $15-1600-4$ after 100 hour $1500{ }^{\circ} \mathrm{C}$ drift test 
it is suspected that this fragmentation occurred prior to sectioning. However, the endstate of the thermoelement wires and sheath suggest that no materials interactions occurred between these components and the insulation.

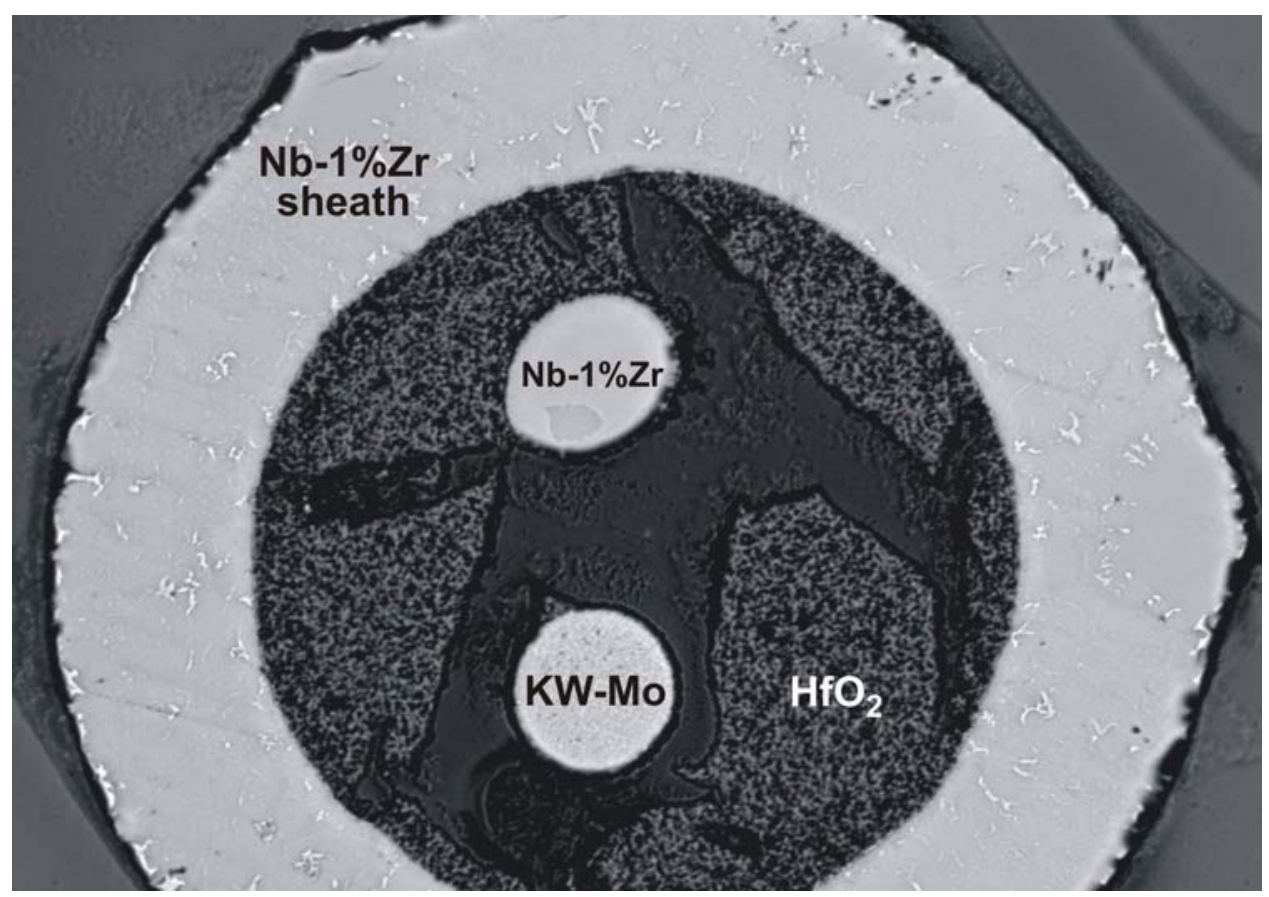

Figure 7-7. Cross-section of thermocouple 15-1600-4 (50X).

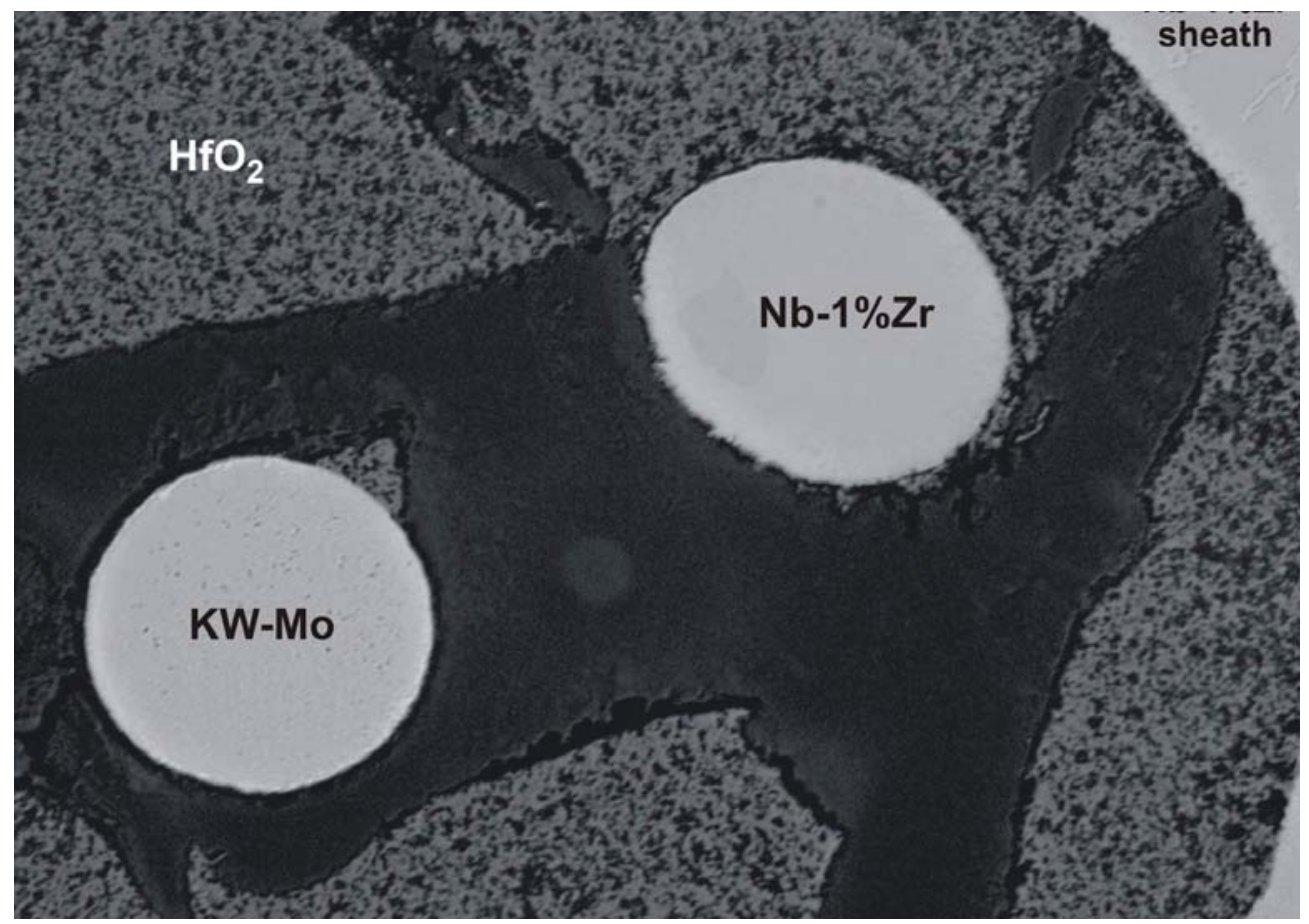

Figure 7-8. Cross-section of thermocouple 15-1600-4 (100X). 


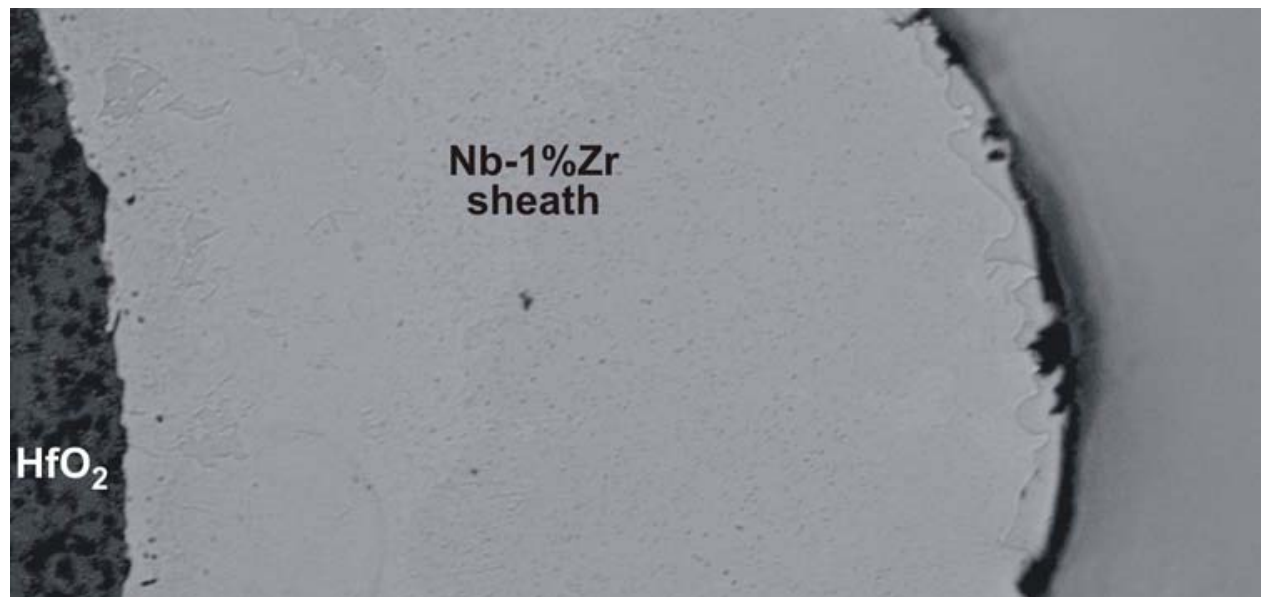

Figure 7-9. Cross-section of thermocouple 15-1600-4 sheath (200X).

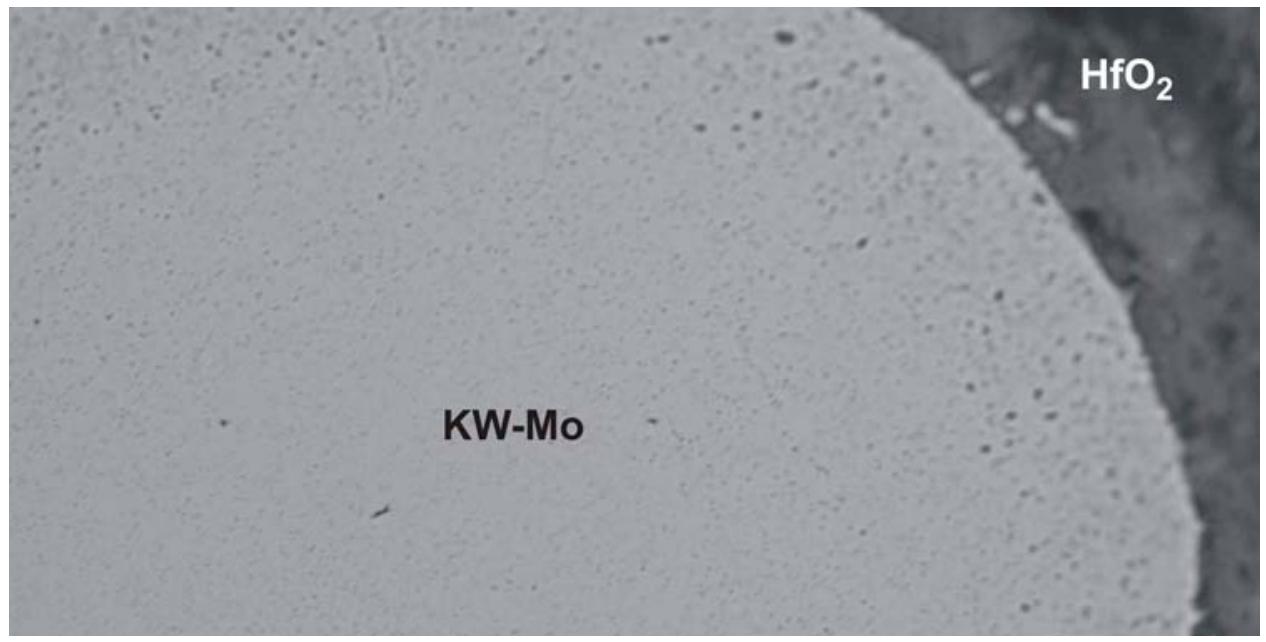

Figure 7-10. Thermocouple 15-1600-4 KW-Mo thermoelement (500X).

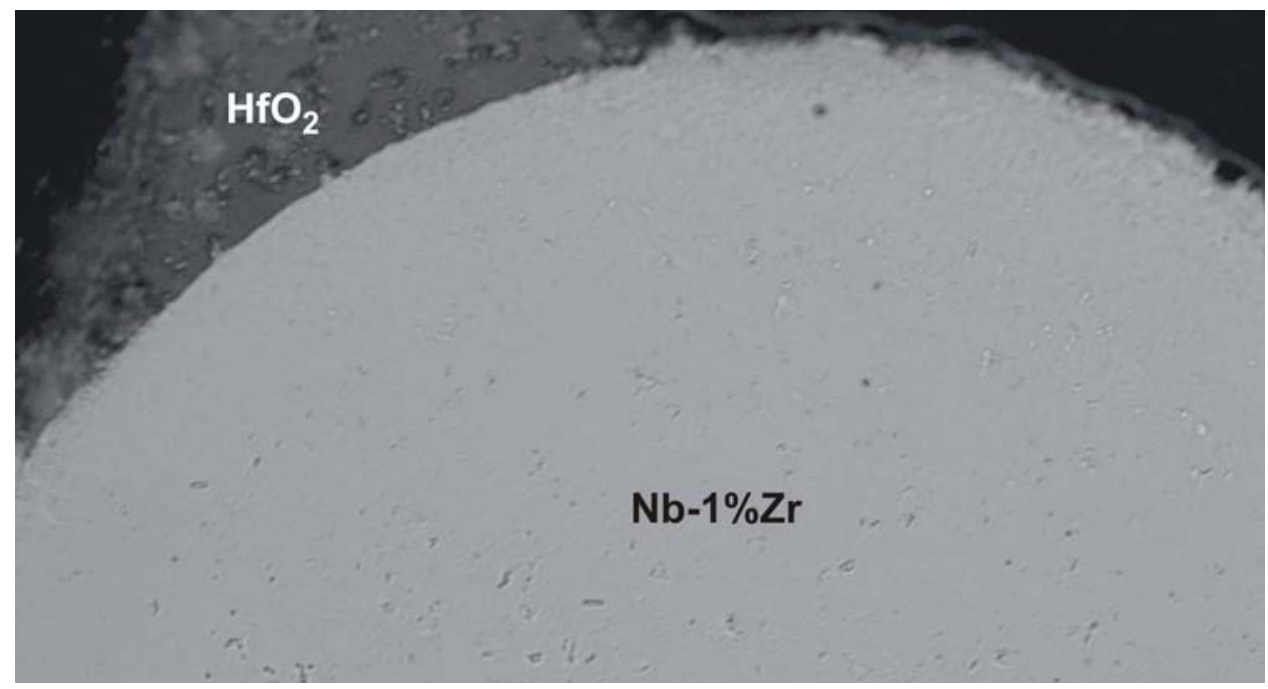

Figure 7-11. Thermocouple 15-1600-4 Nb1\%Zr thermoelement (500X) 
The endstate of the sheath and thermoelements of the 15-1600-8 thermocouple was similar to that of the 15-1600-4 thermocouple. However, the endstate of these components in the 15-1600-16 Nb1\%Zr thermoelement appeared different. As shown in Figures 7-12 and 7-13, an outer porous region has formed in the $\mathrm{Nb} 1 \% \mathrm{Zr}$ during its 16 hour heat treatment at $1600{ }^{\circ} \mathrm{C}$. Nevertheless, no materials interaction can be detected on the outer surface of either the KW-Mo or Nb1\%Zr thermoelement wire (see Figures 7-12 through 7-14).

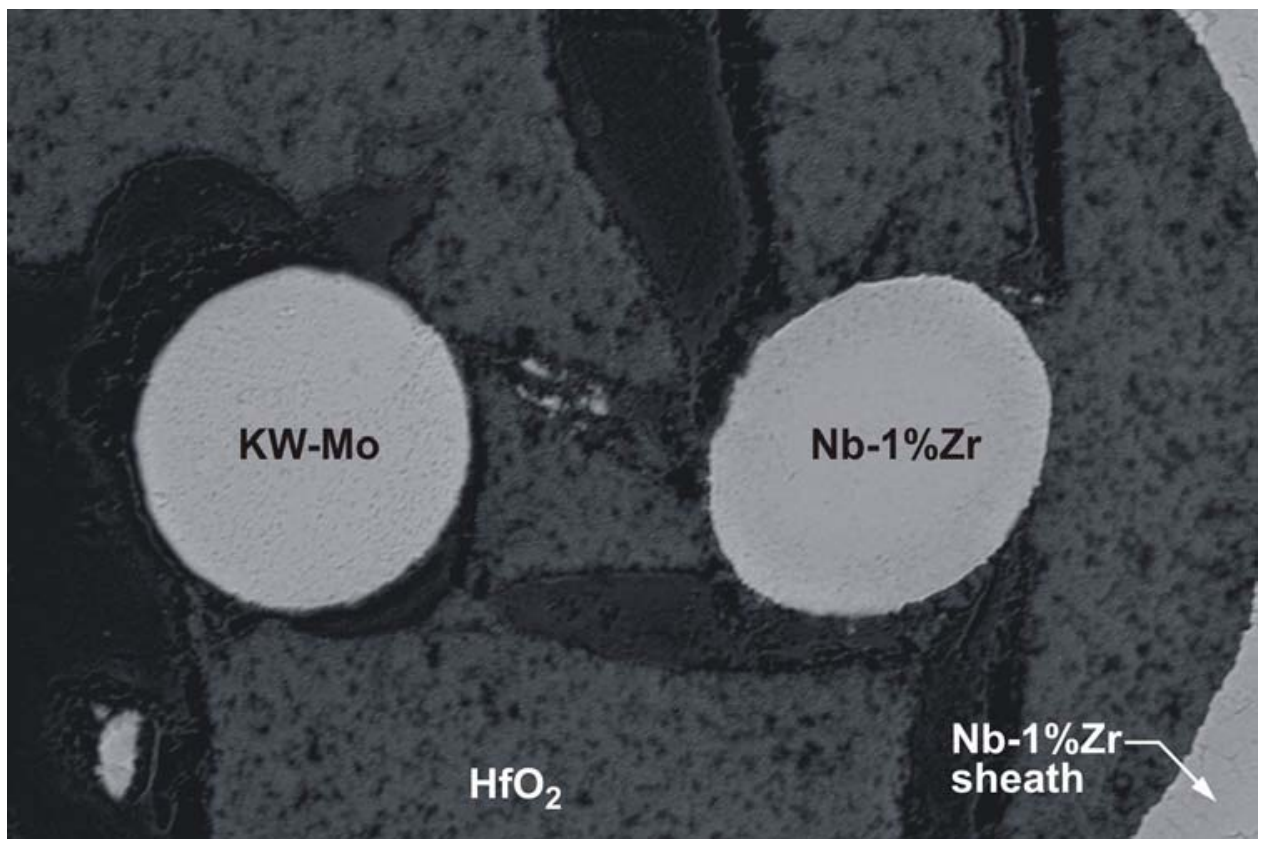

Figure 7-12. Cross-section of thermocouple 15-1600-16 (100X)

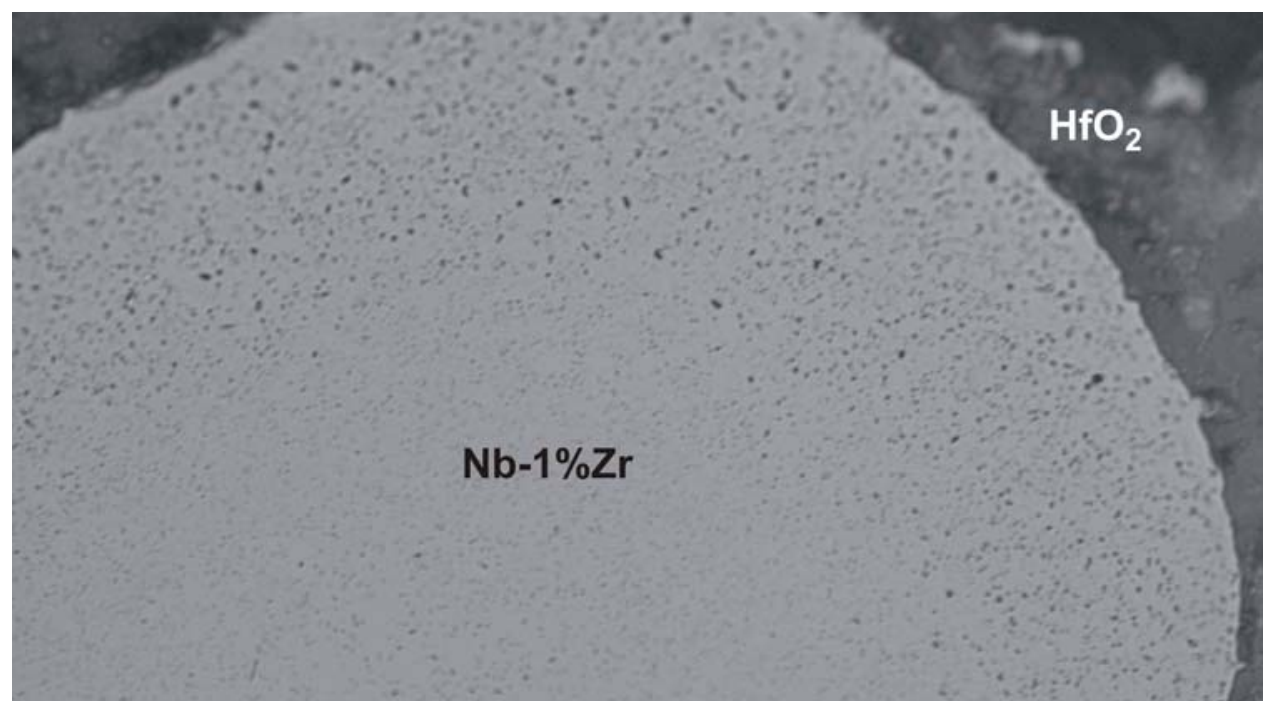

Figure 7-13. Thermocouple 15-1600-16 Nb1\%Zr thermoelement (500X). 


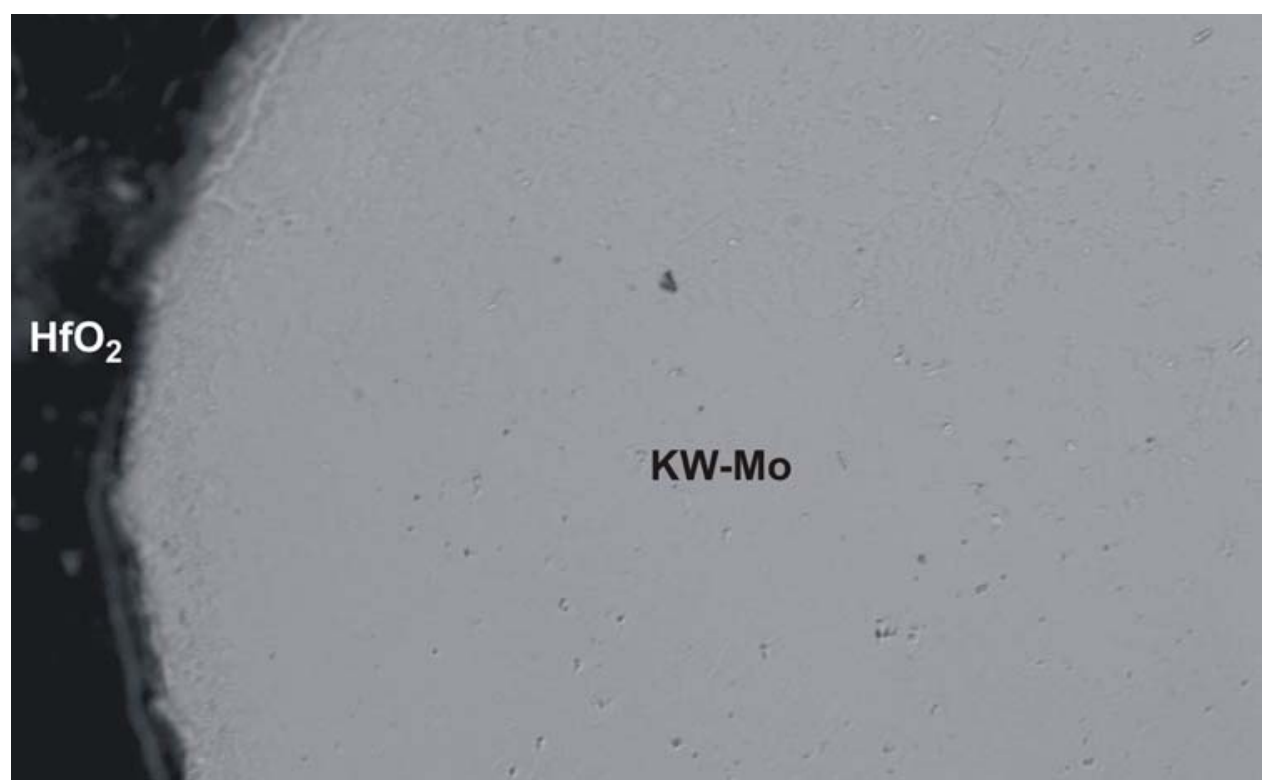

Figure 7-14. Thermocouple 15-1600-16 molybdenum thermoelement (500X)

\subsection{Summary}

HTIR-TC fabrication requires that grain growth in the thermoelement wires be stabilized by heat treating. However, limited data were available to select appropriate temperatures and durations for this heat treatment. As reported in this sections, tests were completed to evaluate the impact of heat treatment times, temperatures, and durations for HTIR-TCs operating at 1200 and $1500{ }^{\circ} \mathrm{C}$.

Results from calibration runs obtained for thermocouples heat treated at various temperatures (1300 to $1500{ }^{\circ} \mathrm{C}$ ) for 20 hours indicate that the peak emf is reduced as the heat treatment temperature increases, but that the decrease in emf is reduced at temperatures greater than $1400^{\circ} \mathrm{C}$. (see Figure $7-15$ )

Figure 7-16 compares the drift measured in thermocouples heat treated at $1300{ }^{\circ} \mathrm{C}$ for various durations. Results indicate that the thermocouple without any heat treatment drifted more than the other thermocouples. However, the observed drift was minimal in all of the heat treated thermocouples. Hence, investigations suggest that heat treatment times of 5 hours at $1300{ }^{\circ} \mathrm{C}$ will stabilize thermocouples for operating temperatures of $1200{ }^{\circ} \mathrm{C}$.

Results from a test to measure the drift in HTIR-TCs heat treated for operation at $1500{ }^{\circ} \mathrm{C}$ were inconclusive. Although the longer heat treatment durations and higher heat treatment temperatures decreased emf, all of these HTIR-TCs exhibited unacceptable drift. Post-test macroscopic evaluations revealed a porous region of the outer diameter in the Niobium$1 \%$ Zirconium wires that were heat treated for longer durations (greater than 4 hours) at $1600{ }^{\circ} \mathrm{C}$ 


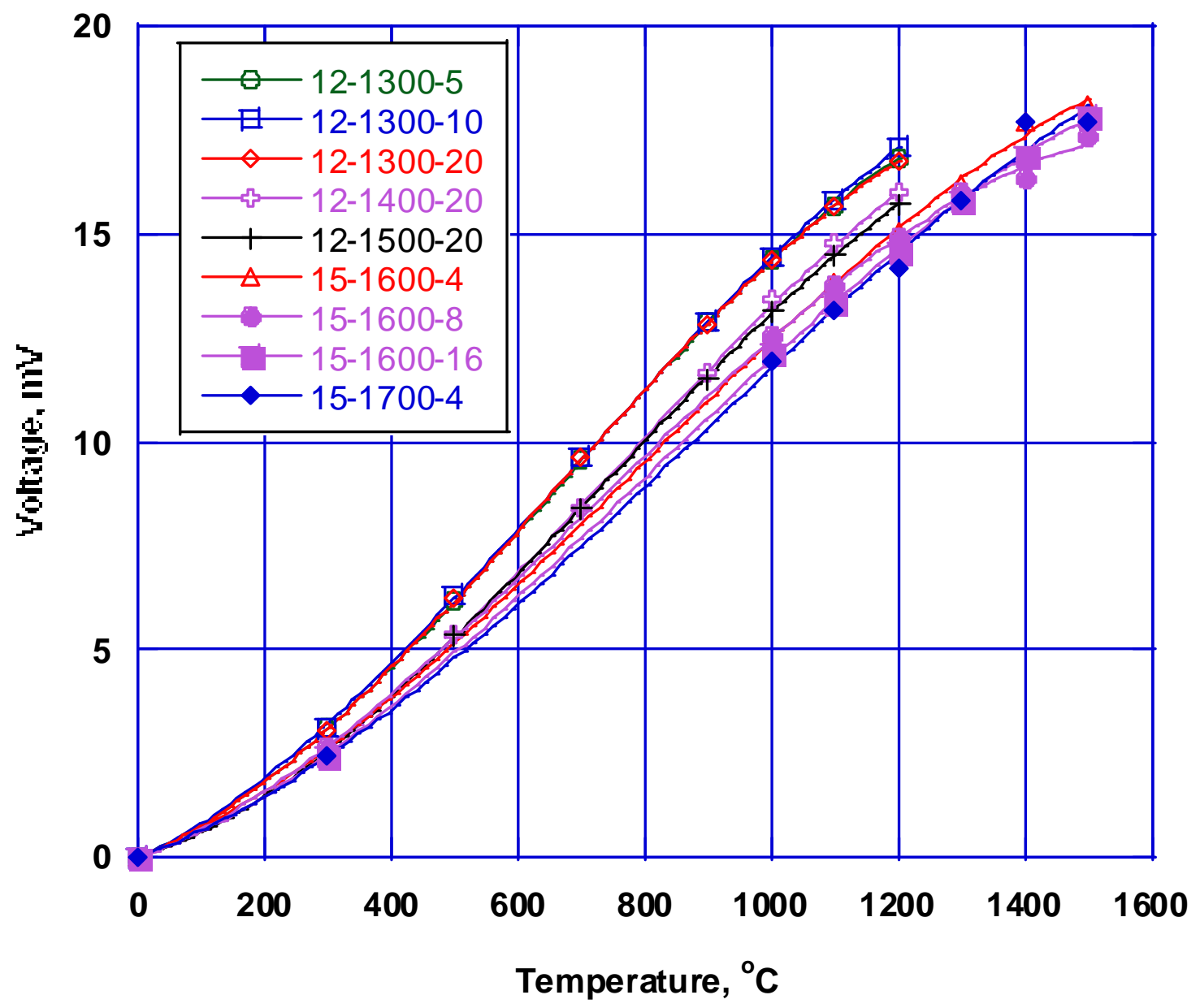

Figure 7-15. Calibration evaluations on HTIR-TCs heat treated at different temperatures and durations.

and at $1700{ }^{\circ} \mathrm{C}$. However, additional evaluations are needed before it can be concluded that this change in the $\mathrm{Nb}-1 \% \mathrm{Zr}$ wire affected thermocouple stability. 


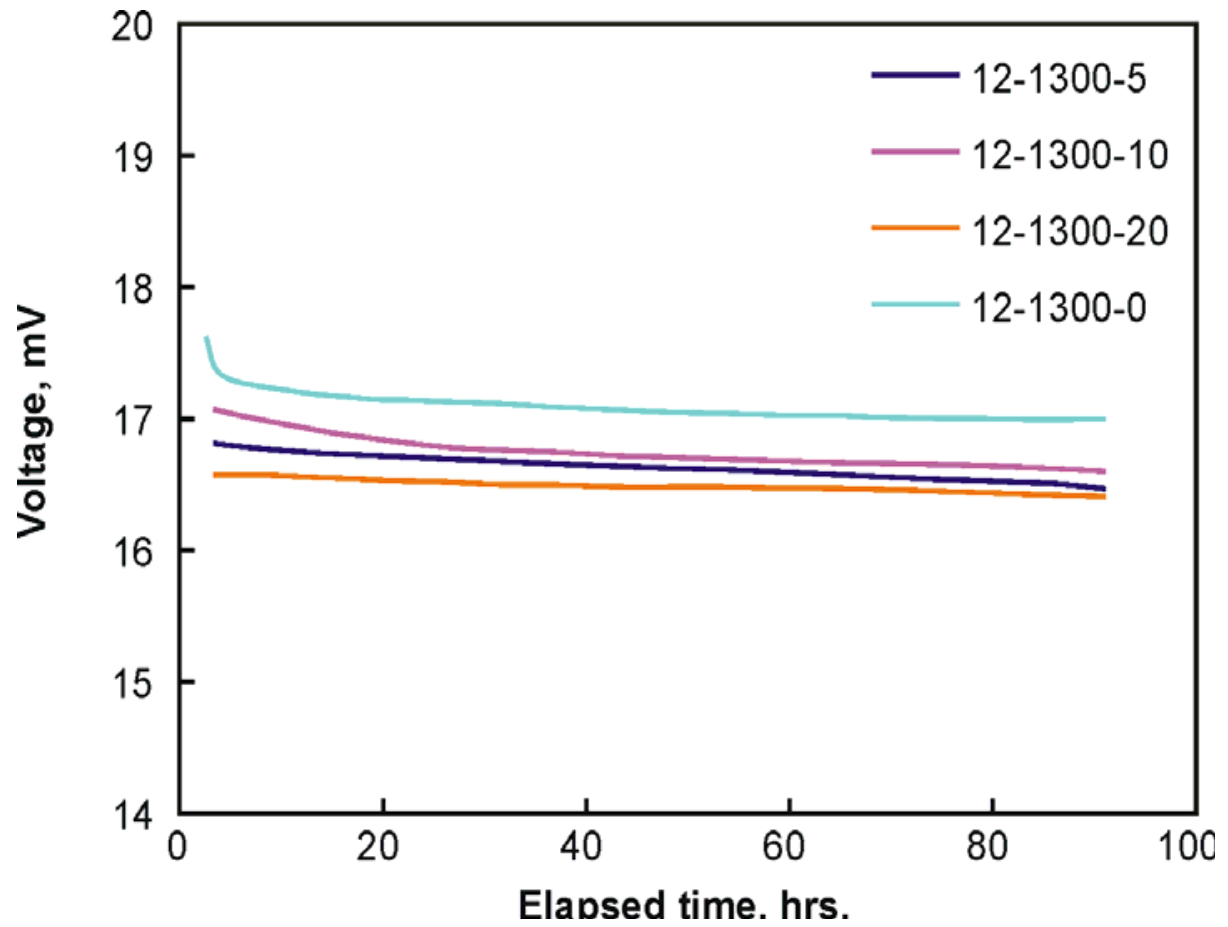

Figure 7-16. Measured drift of thermocouples heat treated at $1300^{\circ} \mathrm{C}$ at 0 (12-1300-0), 5 (12-1300-5), 10 (12-1300-10), and 20 (12-1300-20) hours in $1200^{\circ} \mathrm{C}$ constant temperature test. 
INL/EXT-08-14042 


\section{Alternate Fabrication Techniques - Loose Assembly Construction (Task 3.2)}

For many geometries and temperatures of interest, a "swaged" thermocouple design appears to be the simplest fabrication approach. As noted in Section 2, data indicate that recrystallization temperature is delayed somewhat if there is coldwork (or deformation) present in pure niobium. INL experience indicates that the presently used swaging process leads to about $30 \%$ elongation in thermoelement wires. This swaging process has the potential to increase wire ductility at higher temperatures because grain growth is delayed.

However, higher temperature applications may require alternate fabrication techniques, such as a "loose assembly" geometry. In a loose assembly configuration (see Figure 8-1), insulator beads are loaded onto the thermoelement wires and placed within the sheath. However, the sheath tubes are not swaged. Instead, the assembly is typically placed within an enclosure in which a vacuum is achieved (down to approximately $10^{-5}$ torr). The thermocouple assembly is then backfilled at room temperature with high purity helium and seal-welded.

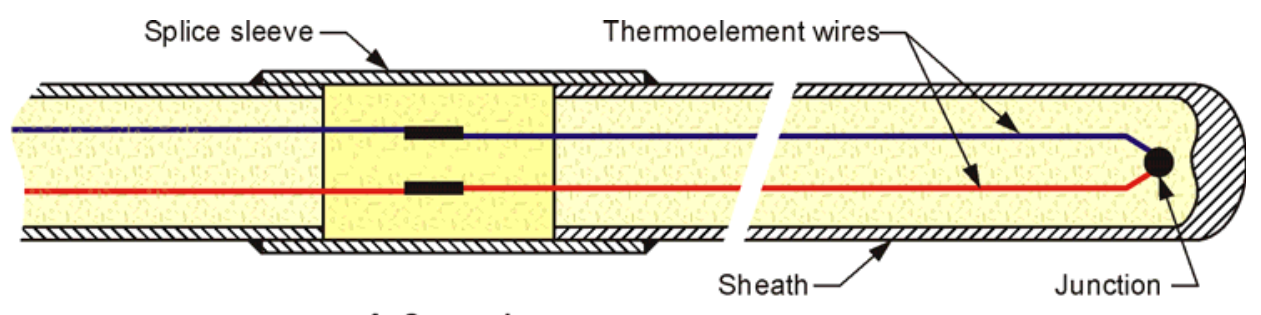

A. Swaged

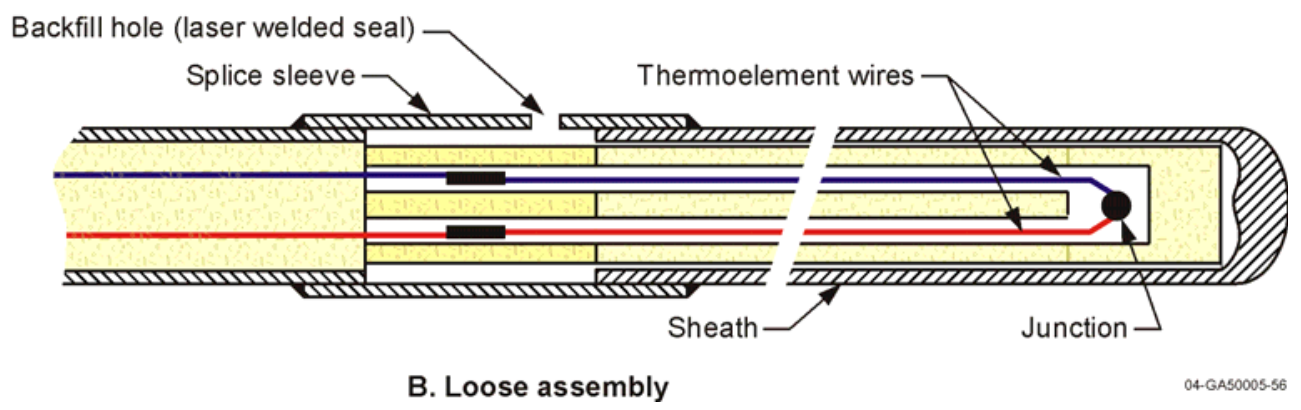

Figure 8-1. Comparison of “swaged” versus “loose assembly” thermocouple configurations.

An advantage of the loose assembly configuration is that it avoids irregular deformation and wire thinning that may occur during swaging. In addition, it is possible to use "hard-fired" insulation material that is in less intimate contact with the thermoelements. In high temperature applications, this may allow differential expansion of sheath, insulators, and wires without inducing stress on thermoelements. Although INL experience indicates that the swaged 
configuration is easier to fabricate, it is worthwhile exploring this alternate configuration because of its possible advantages.

Initial efforts to fabricate and evaluate the performance of loose assembly thermocouples were conducted using UNERI funds. After identifying appropriate materials for the thermocouple, extension cable, and splice sleeve, appropriate techniques for fabrication were developed. Where necessary, specialized fixturing was created to enable fabrication. Once thermocouples were fabricated, their performance was evaluated by comparing their performance with that of swaged thermocouples at high temperatures for long durations. Details about each of these steps are provided in this section.

\subsection{Components}

Initial loose assembly thermocouple investigations focused on using $0.51 \mathrm{~mm} / 0.020$ ” diameter thermoelement wires, which is twice the diameter of wires typically used in INL HTIR thermocouples. Materials for each thermocouple component are listed in Table 8-1.

Table 8-1. Loose assembly thermocouple sizes and materials investigated.

\begin{tabular}{|c|c|c|c|}
\hline Component & Material & \multicolumn{2}{|c|}{ Geometry } \\
\hline \multicolumn{4}{|l|}{ Thermocouple } \\
\hline + Wire & Doped Molybdenum (KW-Mo) & OD, inch & 0.020 \\
\hline - Wire & Niobium-1\%Zirconium & OD, inch & 0.020 \\
\hline Insulator & Hafnia & $\begin{array}{l}\text { OD, inch } \\
2 \text { hole, ID, inch }\end{array}$ & $\begin{array}{l}0.081 \\
0.023\end{array}$ \\
\hline Sheath & Molybdenum & $\begin{array}{l}\text { OD, inch } \\
\text { Wall Thickness, inch }\end{array}$ & $\begin{array}{l}0.125 \\
0.015\end{array}$ \\
\hline \multicolumn{4}{|l|}{ Swaged Extension Cable } \\
\hline + Wire & Doped Molybdenum (KW-Mo) & Initial OD, inch & 0.010 \\
\hline - Wire & Niobium-1\%Zirconium & Initial OD, inch & 0.010 \\
\hline Insulator & Alumina & $\begin{array}{l}O D \text {, inch } \\
2 \text { hole, ID, inch }\end{array}$ & $\begin{array}{c}0.057-0.059 \\
0.014\end{array}$ \\
\hline Sheath & Stainless Steel & Final OD, inch & 0.062 \\
\hline
\end{tabular}

Designs were developed for the specialized components need to fabricate loose assembly thermocouples. As shown in Figure 8-2, specialized splice sleeves were needed that connect the molybdenum-sheathed thermocouple to the stainless steel extension cable. In addition, hard fired transition insulators are needed to house the spliced thermocouple/extension cable wires. Appropriate parameters were defined for laser welding the splice sleeve to the thermocouple and extension cable sheaths and for splicing the thermoelement wires. 


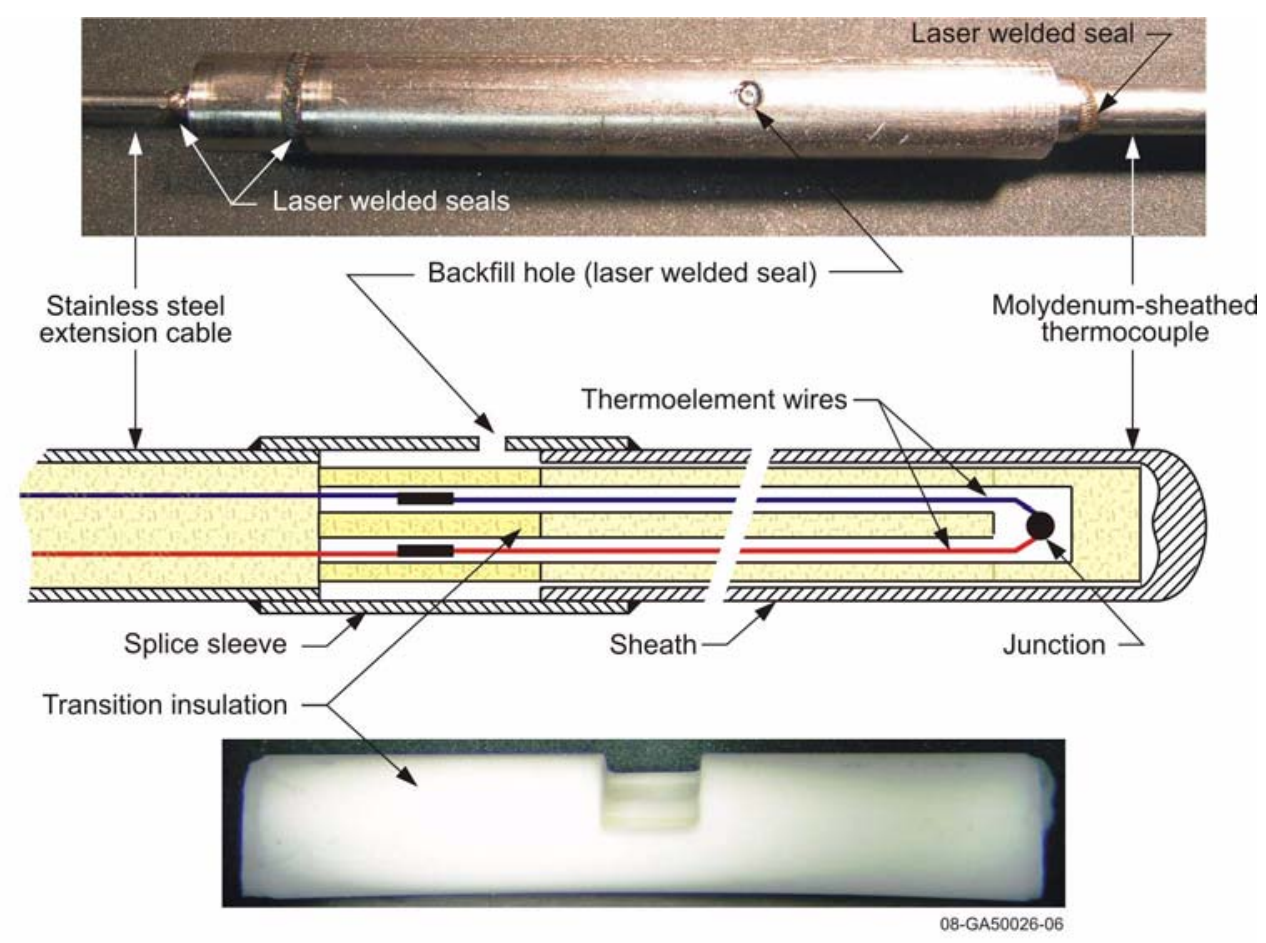

Figure 8-2. Specialized components for HTIR-TC loose assembly design.

\subsection{Fabrication}

With the exception of differences associated with swaging versus evacuating/inert gas backfilling, fabrication of loose assembly thermocouples is quite similar to the fabrication of swaged thermocouples. Specifically, thermoelement wires need to be selected, cut, cleaned, and a junction connecting the ends of the wires must be made. Insulators need to be strung along the length of the thermoelement wires before inserting into the selected sheath. At this point in loose assembly fabrication, extension cable needs to be laser welded to the thermoelement wires and the resulting splice needs to be insulated and protected by a splice sleeve (which provides the means to couple the TC sheath to the extension cable sheath via laser welding). Evacuating/backfilling of the loose assembly completes fabrication. That process and the required fixturing is described below.

\subsubsection{Fixturing}

A specialized vacuum chamber had to be designed and developed to evacuate loose assembly thermocouples and backfill them with an inert gas (To date, helium and argon gases have been used). As shown in Figure 8-3, a five-way cross is at the heart of this vacuum chamber. The $2.54 \mathrm{~cm} / 1$ in OD cross is stainless steel and fitted with quick connect vacuum flanges on all five legs. 


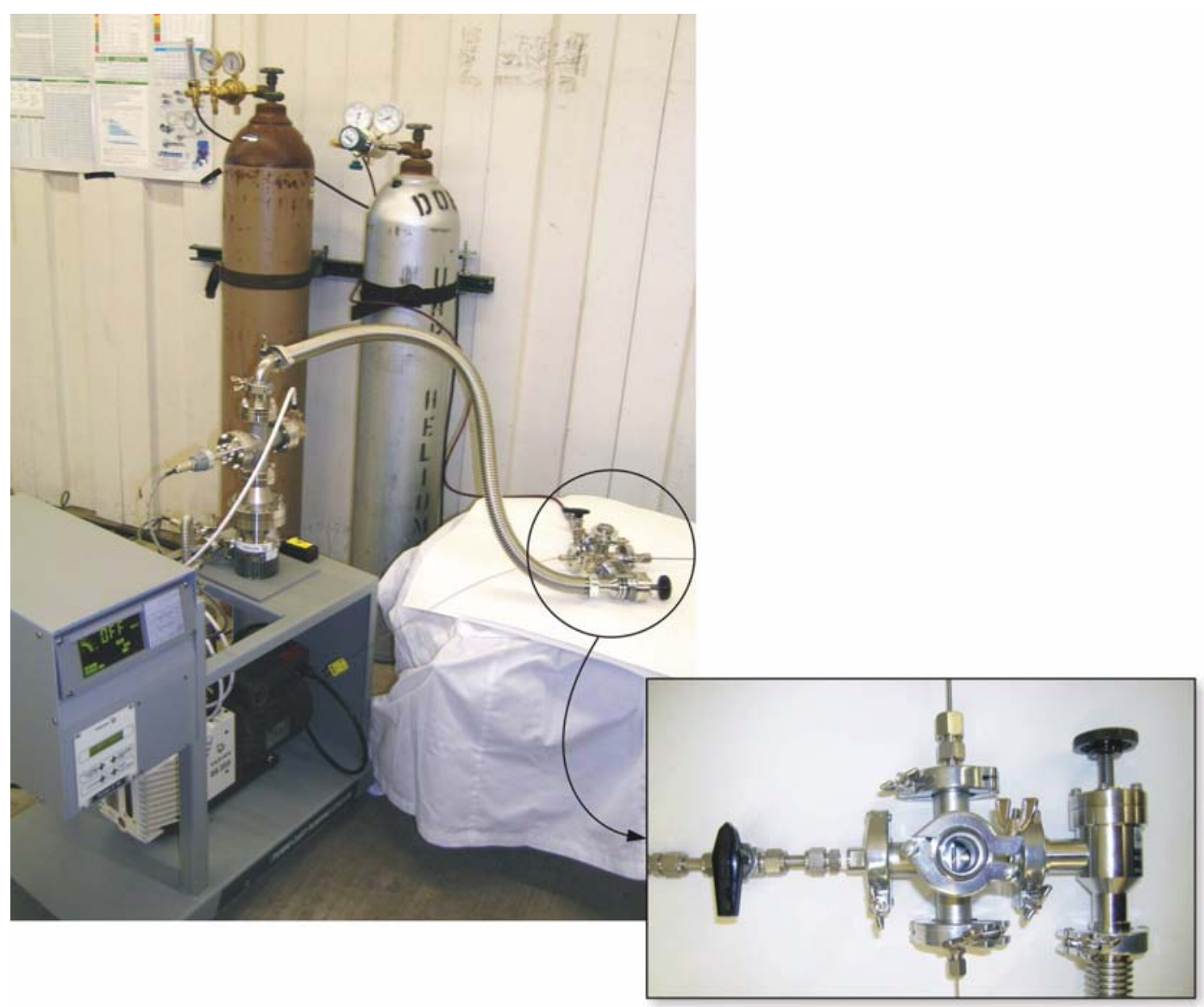

Figure 8-3. Vacuum chamber for loose assembly fabrication.

To complete the evacuation/backfill, the backfill hole in the splice sleeve is centered in the vacuum chamber by inserting the thermocouple straight through two legs of the cross. Quick connect vacuum flanges with integral SwageLock fittings are used to seal against the thermocouple and extension cable sheaths. One leg of the cross is connected to an inert gas supply through an isolation valve. The leg opposite the inert gas supply is connected to a vacuum pump through another isolation valve. The remaining leg of the five-way cross is fitted with a glass viewport. Vacuuming is completed with the valve on the inert gas supply closed and the valve on the vacuum pump open. After depressurizing to $\sim 10^{-5}$ torr, the vacuum isolation valve is closed (with the vacuum pump running) and the inert gas isolation valve is opened to pressurize the vacuum chamber and the loose assembly thermocouple (through its backfill hole) with an inert gas at $\sim 4$ psig. With the inert gas pressure applied, a weld is then made through the viewport with a laser welder to seal the backfill hole (See Figure 8-3).

\subsubsection{Lessons Learned}

Several insights have been gained through the process of designing and developing loose assembly thermocouples. 
A decision was made to use molybdenum sheaths for these thermocouples because cost is reasonable. However, molybdenum tube manufacturing typically involves generous use of lubricants. Although lubricants were removed from outer tube surfaces by the manufacturer, inner surfaces had to be cleaned at the HTTL. The cleaning effort involved indicates it would be best if future orders specify "thermocouple grade" tubing so that the manufacturer will be obligated to clean all surfaces.

A number of welds are required to fabricate a loose assembly thermocouple as indicated in Table 8-2. Parameters had to be developed for each of the listed welds to ensure the weld met the stated purpose. As indicated, sealing was the primary purpose of most of the welds. In those cases, a trial and error process using helium leak detection was necessary. (In other words, a weld was made with a given set of parameters and the joint was subjected to helium leak testing. If a leak was discovered, parameters were adjusted and the weld was redone. This process was repeated until the weld provided a complete seal.) To ensure optimum thermocouple performance, leak detection for all sealing welds was completed before and after the thermocouple was exposed to high temperatures. Electrical continuity was the basis for the trial and error development of parameters for the thermoelement/extension wire weld. Again, qualified welds required continuity before and after thermocouple heating.

Table 8-2. Loose assembly thermocouple welds.

\begin{tabular}{|c|c|c|}
\hline Weld & Purpose & Comment \\
\hline End of molybdenum sheath & $\begin{array}{l}\text { Seals junction end of thermocouple } \\
\text { sheath }\end{array}$ & TIG welded molybdenum plug \\
\hline Thermoelement/extension wires & $\begin{array}{l}\text { Thermoelement/extension wire } \\
\text { electrical continuity }\end{array}$ & $\begin{array}{l}\text { Laser welded; } \\
\text { Mo-KW to Mo-KW and Nb-1\%Zr to Nb-1\%Zr }\end{array}$ \\
\hline Molybdenum sheath/splice sleeve & Seals molybdenum sheath & Laser welded \\
\hline Splice sleeve slip joint & Seals two halves of the splice sleeve & Laser welded \\
\hline Extension sheath/splice sleeve & Seals splice sleeve & Laser welded \\
\hline Splice sleeve backfill hole & Seals splice sleeve & $\begin{array}{l}\text { Laser welded; } \\
\text { tack filler wire bank next to hole }\end{array}$ \\
\hline
\end{tabular}

The process of performing and verifying the performance of these welds was found to be particularly labor intensive. Specifically, labor is required to set up the welder and the work piece, labor is required to complete the (leak detection or electrical continuity) acceptance tests, and labor is required if the process is repeated because a given weld fails to meet its purpose. Labor costs are further increased if welds appear acceptable before heating but are found unacceptable after heating. Additional efforts are needed to improve the current process and reduce the labor costs associated with performing and verifying the performance of these welds.

Molybdenum tends to become brittle after heating. Although this was known when molybdenum was selected as the thermocouple sheath material, potential problems associated with the brittleness were not immediately realized. It is now known that the junction tip weld 
represents a potential failure of the sheath due to embrittlement after heating. Unlike swaged thermocouples, molybdenum sheathed thermocouples can never be bent to fit into a complicated geometry (as is often required for irradiation test capsules). It is now also clear that shipment of the molybdenum sheathed thermocouples could present a unique set of problems associated with protecting the sheath. Directions for customer handling of these thermocouples will also need attention beyond cautions associated with handling swaged assemblies.

Initial testing of loose assembly thermocouples indicated wire degradation sufficient to result in loss of electrical continuity. Degradation, as shown in Figure 8-4, appeared to be the result of oxidation, which was difficult to understand given efforts to seal, evacuate, and backfill these thermocouples with inert gas. Separate effects tests, as listed in Table 8-3, were completed to investigate possible causes for this degradation. As shown in this table, tests considered alternate inert gases, inert gas filling processes, and insulator materials. Results from these tests indicated there was some off-gassing from the hard-fired hafnia insulation used in the loose assembly thermocouples. However, degradation was essentially eliminated in those tests if insulators were baked in an inert atmosphere at high temperatures prior to assembly.

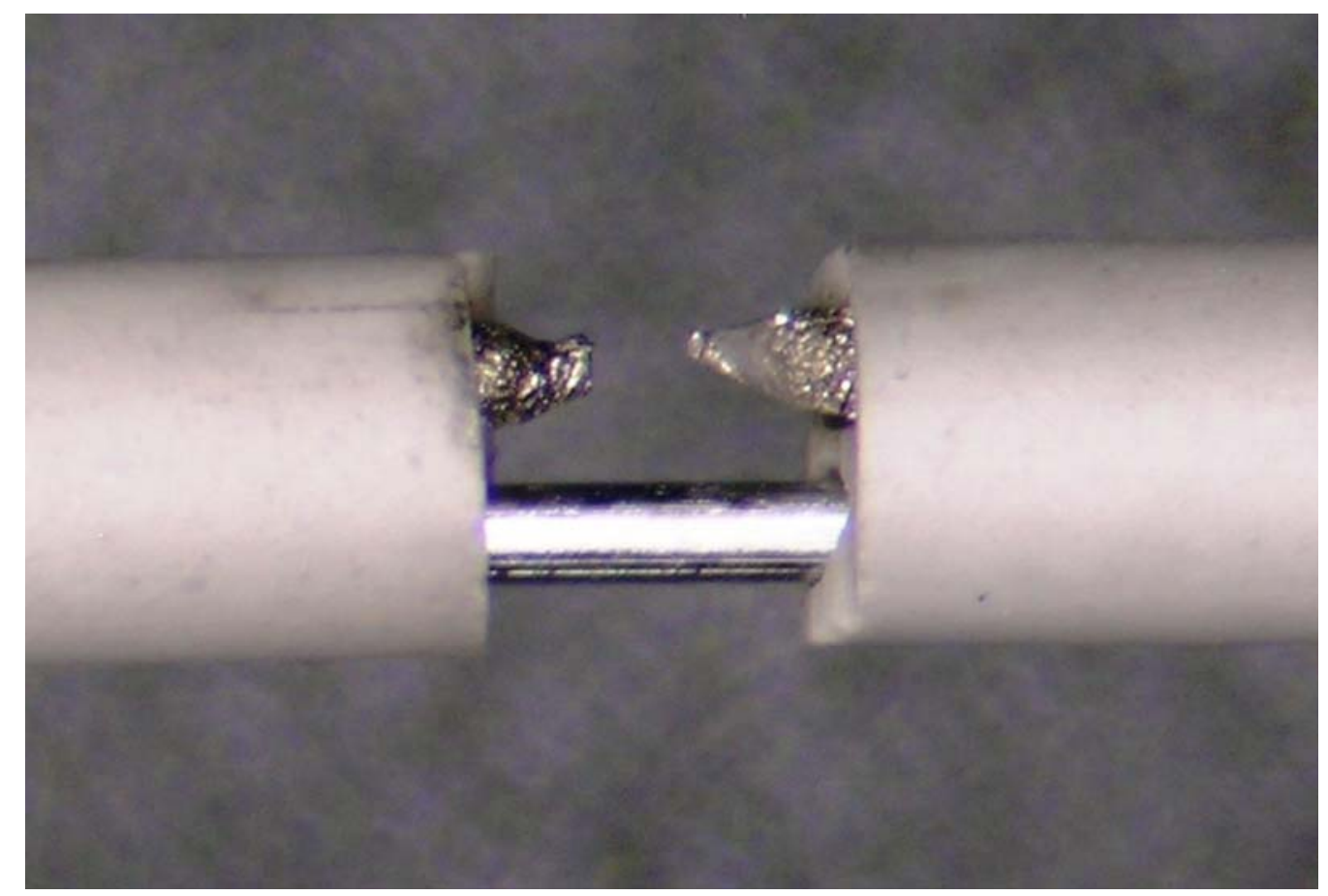

Figure 8-4. Thermoelement wire degradation following initial testing of loose assembly thermocouples. 
Table 8-3. Sensitivities to investigate wire degradation.

\begin{tabular}{|c|c|c|c|c|c|c|}
\hline ID & Insulator & Length & Bakeout & Gas & $\begin{array}{l}\text { Pumpdown } \\
\text { Cycle }\end{array}$ & Results \\
\hline LA-01 & $\mathrm{HfO}_{2}$ & $\begin{array}{l}\text { Full w. exten- } \\
\text { sion }\end{array}$ & None & Helium & $\begin{array}{l}\text { Lowest vac- } \\
\text { uum only } 1 \mathrm{x} \\
10^{-4}\end{array}$ & $\begin{array}{l}\mathrm{Nb} \text { wire eroded } \\
\text { between insula- } \\
\text { tors }\end{array}$ \\
\hline LA-02 & $\mathrm{HfO}_{2}$ & $\begin{array}{l}\text { Full w/o } \\
\text { extension } \\
\text { cable }\end{array}$ & None & Helium & $\begin{array}{l}\text { Lowest vac- } \\
\text { uum only } 1 \mathrm{x} \\
10^{-4}\end{array}$ & $\begin{array}{l}\text { Nb wire eroded } \\
\text { between insula- } \\
\text { tors }\end{array}$ \\
\hline LA-03 & $\mathrm{HfO}_{2}$ & $\begin{array}{l}12 \text { " piece } \\
\text { with Mo tube }\end{array}$ & None & Helium & $\begin{array}{l}\text { Pumpdown } \\
\text { much slower } \\
\text { than others; } \\
\text { Lowest vac- } \\
\text { uum only } 1 \mathrm{x} \\
10^{-4}\end{array}$ & $\begin{array}{l}\text { Nb wire oxidized } \\
\text { but not eroded } \\
\text { where exposed }\end{array}$ \\
\hline LA-04 & $\mathrm{HfO}_{2}$ & 3 2” pieces & None & Helium & $\begin{array}{l}\text { Lowest vac- } \\
\text { uum only } 8.5 \mathrm{x} \\
10^{-5}\end{array}$ & $\begin{array}{l}\text { Nb wire oxidized } \\
\text { but not eroded } \\
\text { where exposed }\end{array}$ \\
\hline LA-05 & $\mathrm{HfO}_{2}$ & 3 2” pieces & $\begin{array}{l}1600^{\circ} \mathrm{C} \text { for } 4 \\
\text { hours in argon }\end{array}$ & Helium & $\begin{array}{l}\text { Lowest vac- } \\
\text { uum only } 8.5 \mathrm{x} \\
10^{-5}\end{array}$ & $\begin{array}{l}\text { Nb wire oxidized } \\
\text { but not eroded } \\
\text { where exposed }\end{array}$ \\
\hline LA-06 & $\mathrm{HfO}_{2}$ & 3 2” pieces & $\begin{array}{l}1600^{\circ} \mathrm{C} \text { for } 4 \\
\text { hours in vac- } \\
\text { uum }\end{array}$ & Helium & $\begin{array}{l}\text { Lowest vac- } \\
\text { uum only } 4.3 \mathrm{x} \\
10^{-4}\end{array}$ & $\begin{array}{l}\text { Nb wire eroded } \\
\text { where exposed }\end{array}$ \\
\hline LA-07 & $\mathrm{HfO}_{2}$ & Full length & $\begin{array}{l}1600{ }^{\circ} \mathrm{CC} \text { for } \\
4 \text { hours in } \\
\text { argon }\end{array}$ & Helium & Horizontal & $\begin{array}{l}\text { Nb wire oxidized } \\
\text { but not eroded } \\
\text { where exposed }\end{array}$ \\
\hline LA-08 & $\mathrm{HfO}_{2}$ & Full length & $\begin{array}{l}1600^{\circ} \mathrm{C} \text { for } 4 \\
\text { hours in argon }\end{array}$ & Helium & $\begin{array}{l}\text { Vertical, } \\
\text { closed end up }\end{array}$ & $\begin{array}{l}\text { Nb wire oxidized } \\
\text { but not eroded } \\
\text { where exposed }\end{array}$ \\
\hline LA-09 & $\mathrm{HfO}_{2}$ & Full length & $\begin{array}{l}1600^{\circ} \mathrm{C} \text { for } 4 \\
\text { hours in argon }\end{array}$ & Argon & $\begin{array}{l}\text { Vertical, } \\
\text { closed end } \\
\text { down }\end{array}$ & $\begin{array}{l}\text { Nb wire oxidized } \\
\text { but not eroded } \\
\text { where exposed }\end{array}$ \\
\hline LA-10 & $\begin{array}{l}\mathrm{BeO} / \mathrm{HfO} \\
2\end{array}$ & $\begin{array}{l}\text { Full length } \\
\text { (BeO in hot } \\
\text { region) }\end{array}$ & None & Argon & $\begin{array}{l}\text { Vertical, } \\
\text { closed end } \\
\text { down }\end{array}$ & $\begin{array}{l}\text { Nb wire eroded } \\
\text { where exposed }\end{array}$ \\
\hline
\end{tabular}




\subsection{Long Term High Temperature Evaluations}

The long duration performance of the loose assembly thermocouples was compared to the performance of swaged designs by testing them for $1500^{\circ} \mathrm{C}$. Tests were conducted in a tube furnace using a configuration similar to that shown in Figure 5-1. However, to avoid the air ingress that occurred in the test described in Section 5.3, the tube furnace only contained four of the smaller alumina tubes. Table 8-4 lists the HTIR-TCs included in this test. The two $0.254 \mathrm{~mm}$ wire swaged HTIR-TCs were inserted into one alumina tube, the two $0.508 \mathrm{~mm}$ wire swaged HTIR-TCs were inserted into a second alumina tube, the two loose assembly HTIR-TCs were inserted into a third alumina tube, and a NIST-traceable Type S reference thermocouple was inserted into the fourth alumina tube. All of the HTIR-TCs were heat treated for 4 hours at $1600{ }^{\circ} \mathrm{C}$.

Table 8-4. HTIR-TCs designs tested at $1500{ }^{\circ} \mathrm{C}$.

\begin{tabular}{|c|c|c|c|c|c|}
\hline TC ID & Description & $\begin{array}{c}\text { KW Mo wire } \\
\text { Diameter, mm }\end{array}$ & $\begin{array}{c}\text { Nb1\%Zr wire } \\
\text { Diameter, mm }\end{array}$ & $\begin{array}{c}\text { HfO2 } \\
\text { insulation }\end{array}$ & $\begin{array}{c}\text { Sheath } \\
\text { Material }\end{array}$ \\
\hline $15-10-1$ & Swaged & 0.254 & 0.254 & crushable & $\mathrm{Nb1 \% Zr}$ \\
$15-10-2$ & Swaged & 0.254 & 0.254 & crushable & $\mathrm{Nb1 \% Zr}$ \\
$15-20-1$ & Swaged & 0.508 & 0.508 & crushable & $\mathrm{Nb1 \% Zr}$ \\
$15-20-2$ & Swaged & 0.508 & 0.508 & crushable & $\mathrm{Nb1 \% Zr}$ \\
$15-20-1 \mathrm{~L}$ & Loose assembly & 0.508 & 0.508 & hard-fired & Mo \\
15-20-2L & Loose assembly & 0.508 & 0.508 & hard-fired & Mo \\
\hline
\end{tabular}

This test was initiated on February 20, 2008. Initial results from this test are shown in Figure 8-5. After the first 100 hours of testing, all of the swaged thermocouples are showing a gradual decrease in emf over time. The swaged thermocouples are also following trends exhibited in previous tests (see Section 5.3) in that the larger diameter thermocouples display greater stability and higher emf. After 600 hours of testing, the stability of one of the loose assembly thermocouples (15-20-L2) appears slightly superior to that of the other HTIR-TC designs. It is planned to continue this test using other INL funding sources. At the conclusion of the test, thermocouples will be sectioned to gain additional insights about their performance.

\subsection{Summary}

Loose assembly thermocouples offer the potential for greater durability and signal stability in high temperature environments than swaged models. This is due to the lack of strains introduced into the wires during the swaging process as well as the use of hard fired insulator beads which are in less intimate contact with thermoelement wires. However, this potential benefit is partially offset by the difficulty in producing viable loose assembly thermocouples. 


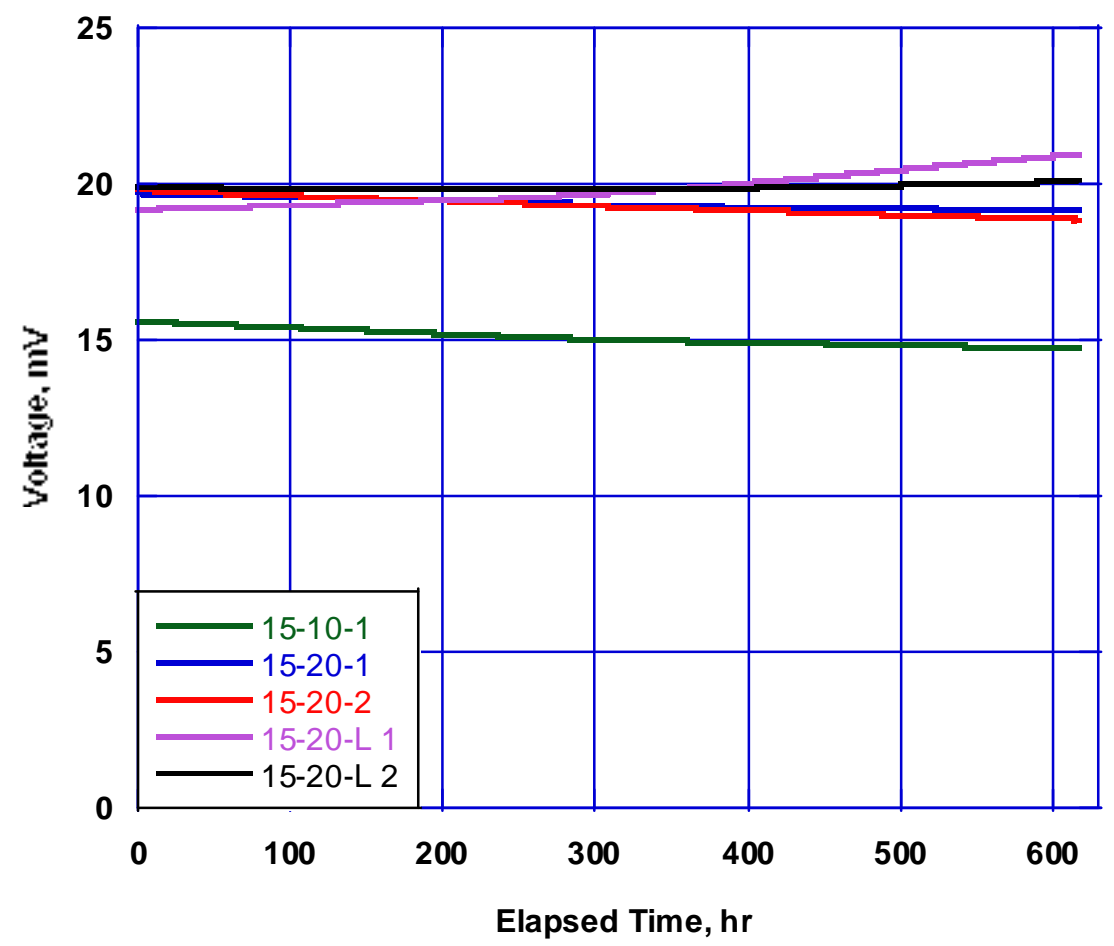

Figure 8-5. Initial results from long duration $1500{ }^{\circ} \mathrm{C}$ test with loose assembly and swaged HTIR-TCs.

Specialized sheath components must be used for splicing to extension cable and insulator beads must be baked out to prevent release of oxygen that can degrade thermoelements at service temperatures. Initial testing indicates that the stability and performance of the loose assembly and swaged HTIR-TCs designs are similar. 
INL/EXT-08-14042 


\section{Summary and Recommendations}

The overall objective of this joint University of Idaho (UI) and INL University Nuclear Research Initiative (UNERI) was to develop recommendations for an optimized thermocouple design for high temperature, long duration, in-pile testing by expanding upon results from initial INL efforts to develop doped molybdenum/niobium alloy High Temperature Irradiation Resistant Thermocouples (HTIR-TCs). Tasks were completed at INL's High Temperature Test Laboratory (HTTL), a state of the art facility equipped with specialized equipment and trained staff in the area of high temperature instrumentation development and evaluation. This section highlights results from tasks completed to quantify the impact of candidate enhancements, such as alternate alloys, alternate geometries, and alternate thermocouple fabrication techniques, on thermocouple performance.

\section{- Alternate Alloy Evaluations (Task 1)}

Table 9-1 lists alloys of molybdenum and niobium evaluated. Two types of doped molybdenum, two alloys of molybdenum with small amounts of niobium, three alloys of niobium with small amounts of molybdenum, and one alloy with a small amount of zirconium were investigated. Note that none of the developmental alloys contained doped molybdenum, which may improve their performance.

Table 9-1. Alloys investigated in this UNERI

\begin{tabular}{|c|c|}
\hline Designator & Description \\
\hline \multicolumn{2}{|l|}{ + WIre } \\
\hline KW-Mo & Molybdenum doped with Potassium, Silicon, and Tungsten \\
\hline ODS-Mo & Molybdenum doped with Lanthanum Oxide \\
\hline Mo-1.6\%Nb & Molybdenum 1.6\% Niobium alloy \\
\hline $\mathrm{Mo}-3 \% \mathrm{Nb}$ & Molybdenum 3\% Niobium alloy \\
\hline \multicolumn{2}{|l|}{ - Wire } \\
\hline $\mathrm{Nb}-1 \% \mathrm{Zr}$ & Niobium 1\% Zirconium alloy \\
\hline $\mathrm{Nb}-4 \% \mathrm{Mo}$ & Niobium 4\% Zirconium alloy \\
\hline $\mathrm{Nb}-6 \% \mathrm{Mo}$ & Niobium 6\% Zirconium alloy \\
\hline $\mathrm{Nb}-8 \% \mathrm{Mo}$ & Niobium 8\% Zirconium alloy \\
\hline
\end{tabular}

Ductility testing was completed at $1400{ }^{\circ} \mathrm{C}, 1600{ }^{\circ} \mathrm{C}$, and $1800{ }^{\circ} \mathrm{C}$. Results indicate that the ODS-Mo and KW-Mo samples retain suitable ductility (e.g., the wire samples could be wrapped around the mandrel several times without breaking) for all tested temperatures and heating durations. As shown in Figure 9-1, the Mo-1.6\% Nb and the Mo-3\%Nb samples became brittle after 12 hours at $1800{ }^{\circ} \mathrm{C}$, but the doped molybdenum samples remained ductile. 

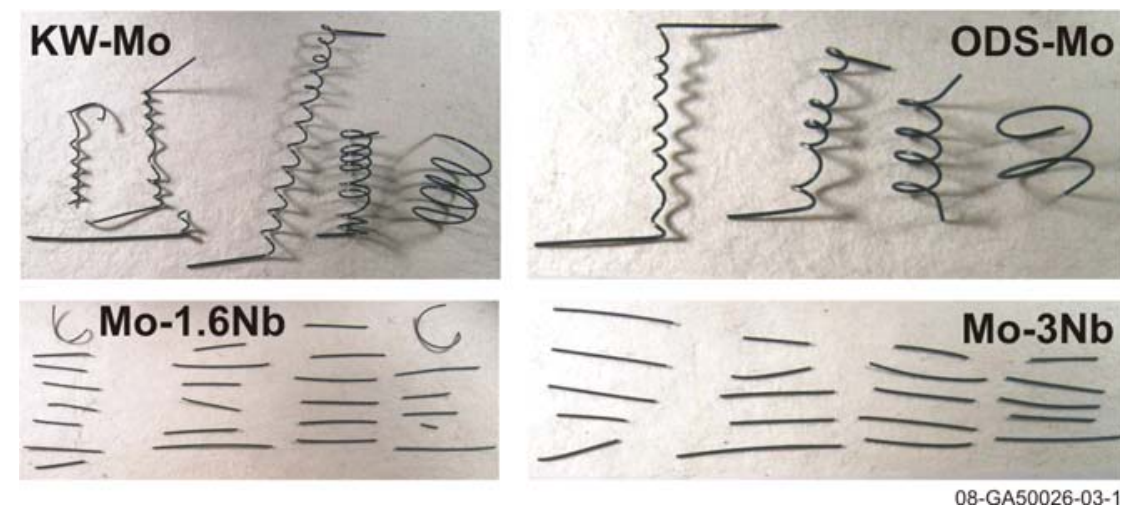

Figure 9-1. Candidate molybdenum doped and alloy samples heated for 12 hours at $1800{ }^{\circ} \mathrm{C}$.

Mandrel wrap tests indicate that the niobium wires were generally less ductile than the doped molybdenum samples tested. As shown in Figure 9-2, only the Nb-1\%Zr wires remained ductile after heating at $1600{ }^{\circ} \mathrm{C}$ for 2 hours.

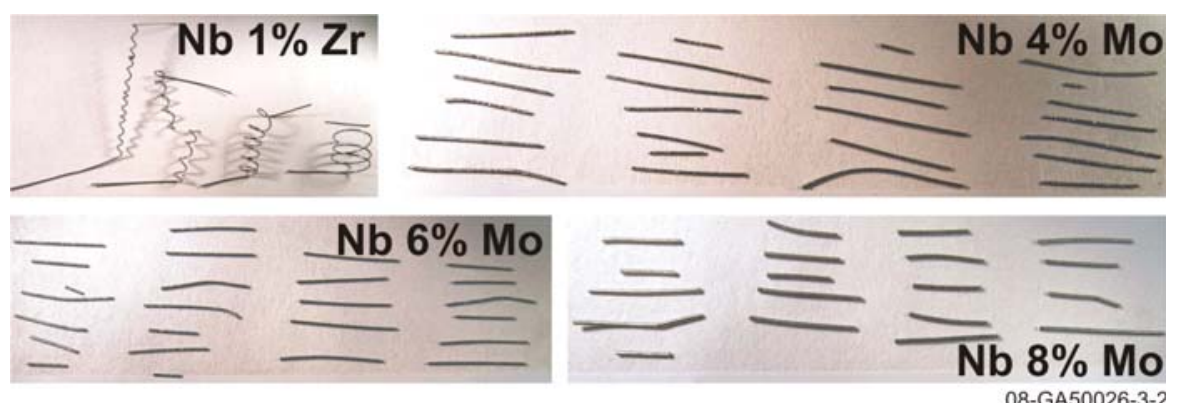

Figure 9-2. Candidate niobium alloy samples heated for 2 hours at $1600{ }^{\circ} \mathrm{C}$.

Figure 9-3 compares calibration evaluation data obtained from thermocouples containing various candidate materials. The thermocouples with $\mathrm{Nb}-1 \% \mathrm{Zr}$ negative thermoelements all show higher sensitivity than any thermocouples constructed other candidate negative thermoelements, with the ODS-Mo/Nb-1\%Zr thermocouple showing the best sensitivity by a significant margin. All thermocouples constructed with Nb-8\%Mo negative thermoelements show lower sensitivity than any others and show a flattening of the output signal over the high temperature range. The signals from thermocouples constructed with $\mathrm{Nb}-6 \% \mathrm{Mo}$ and $\mathrm{Nb}-8 \%$ Mo negative thermoelements all lie between the $\mathrm{Nb}-8 \% \mathrm{Mo}$ and $\mathrm{Nb}-1 \% \mathrm{Zr}$ thermocouple signals, with no definitive trends setting them apart from each other.. 


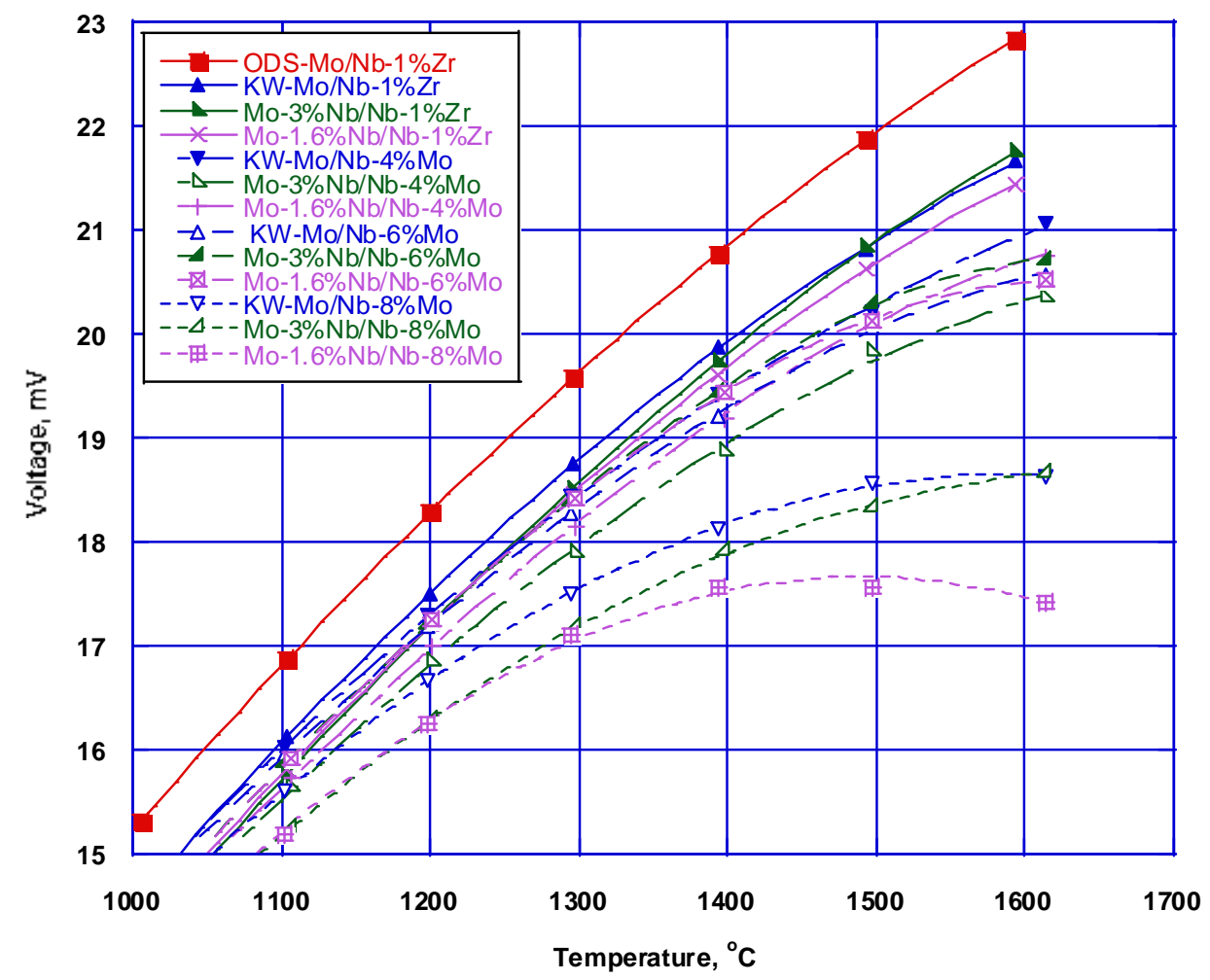

Figure 9-3. High temperature comparison of thermocouples containing candidate thermoelement wires.

In summary, evaluations indicate that doped molybdenum alloys, either ODS-Mo or KWMo, and the Nb-1\%Zr retain ductility better than the developmental molybdenum-low niobium alloys and the niobium-low molybdenum alloys evaluated. Although the resolution of the thermocouple containing ODS-Mo and Nb-1\%Zr is slightly superior, the lower cost of the commercially available KW-Mo makes a thermocouple containing KW-Mo and Nb1\%Zr the best option at this time.

\section{- Alternate Geometry Evaluations (Task 2)}

Initial INL efforts focused on swaged thermocouples fabricated from $0.254 \mathrm{~mm} / 0.010$ ” diameter thermoelement wires. However, it is anticipated that some applications will require larger or smaller diameter thermocouples. This task included activities to assess the impact of size on HTIR-TC performance and to develop designs for alternate diameter thermocouples and assess the impact of size on thermocouple performance.

To assess the impact of diameter on thermoelement ductility, mandrel wrap tests were completed on 0.254 to $0.508 \mathrm{~mm}$ (0.010 and 0.020 inch) samples of Nb-1\%Zr and KW-Mo wire. Tests were conducted at $1400{ }^{\circ} \mathrm{C}$ for 5 and 12 hours and at $1600{ }^{\circ} \mathrm{C}$ for 6 hours. Test results showed that for the shorter durations at $1400{ }^{\circ} \mathrm{C}$, the increased wire diameter remained more ductile (see Figure 9-4). However, for longer heating durations and higher temperatures, the effect of wire diameter was diminished. As shown in Figure 9-4, both sizes of KW-Mo wire remained 
ductile, whereas both sizes of $\mathrm{Nb}-1 \% \mathrm{Zr}$ were brittle. However, it should be noted that the larger wire size could still improve thermocouple durability by increasing the thermoelements' resistance to bending and fracture..
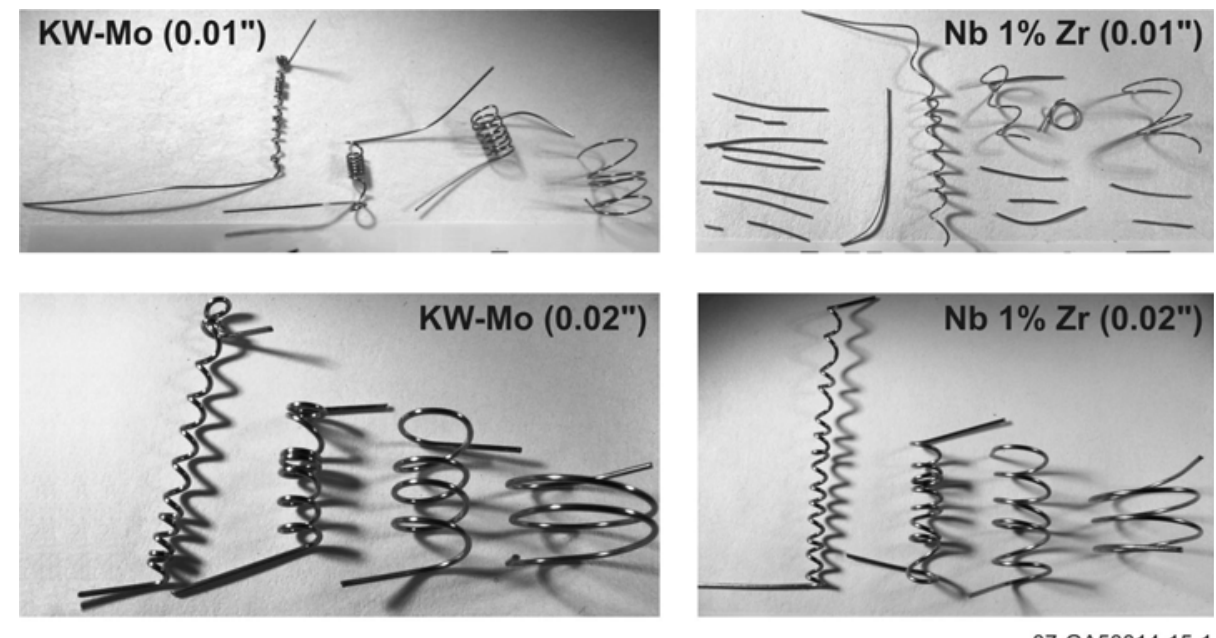

07-GA50014-15-1

Figure 9-4. Effect of wire diameter on samples heated at $1400^{\circ} \mathrm{C}$ for 5 hours

Prototype HTIR-TCs were fabricated with thermo-element wires of three different diameters (0.127, $0.254 \mathrm{~mm}$, and $0.508 \mathrm{~mm}$ wire). For each size of HTIR-TC, appropriate sizes of sheath tubing and insulator materials were obtained and a process was developed for swaging reductions. Two thermocouples of each size were prepared, but the thermocouples containing $0.127 \mathrm{~mm}$ wire failed during fabrication and heat treatment processes. Transient tests were performed on the remaining thermocouples made with larger diameter wires $(0.254$ and $0.508 \mathrm{~mm}$ wire). Changes in emf were minimal (less than 1\%) for the thermocouples made with $0.508 \mathrm{~mm}$ wire. Larger drifts (up to 4\%) were observed in the standard-sized thermocouples, which were fabricated with $0.254 \mathrm{~mm}$ wires. Long duration $1500{ }^{\circ} \mathrm{C}$ test were performed that included HTIRTC prototypes fabricated with $0.127,0.254$, and $0.508 \mathrm{~mm}$ wires. Figure $9-5$ compares the emf of representative thermocouples of each diameter tested. Clearly, the INL thermocouples with larger diameter wire exhibited less drift.

Initial geometry evaluations indicated that HTIR-TCs containing larger diameter thermoelement wires are even more stable and robust than thermocouples containing $0.254 \mathrm{~mm}$ diameter thermoelement wires. Several difficulties were experienced in initial efforts to develop thermocouples containing smaller diameter thermoelements $(0.127 \mathrm{~mm})$. Future efforts should focus on an improved fabrication process for these smaller diameter thermocouples so that they will be more robust.

\section{- Alternate Fabrication Techniques (Task 3)}

Task 3 considered two variations in HTIR-TC fabrication that could enhance the performance of these thermocouples. 


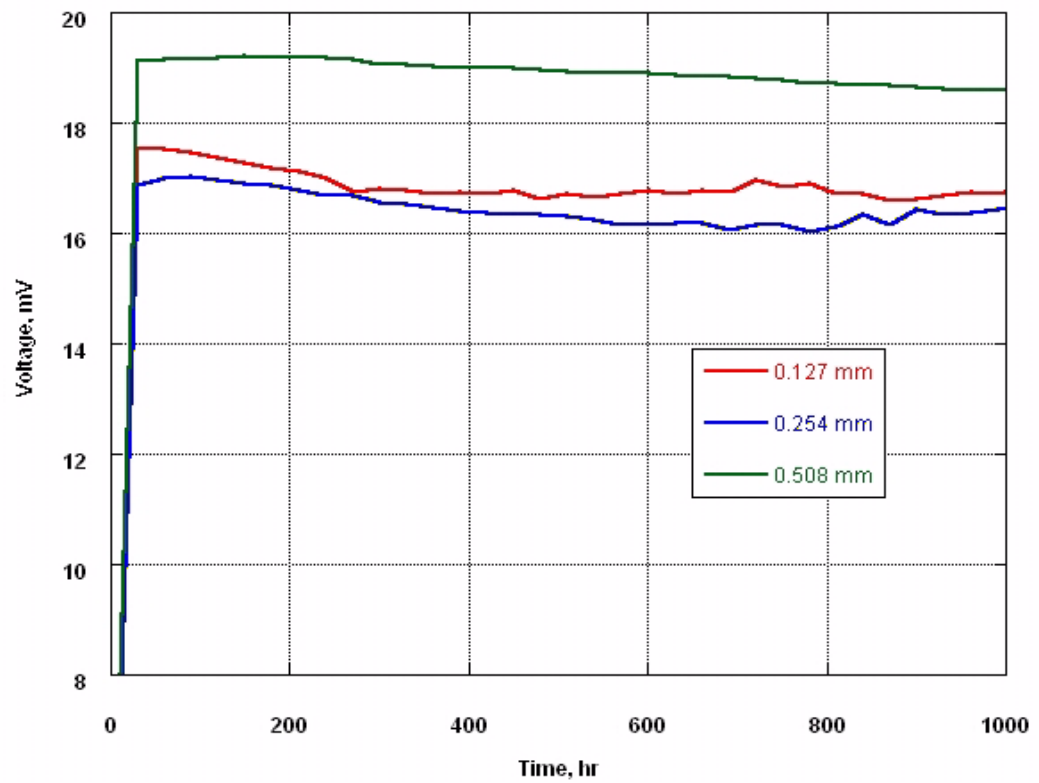

Figure 9-5. Measured emf for various HTIR-TC geometries in $1500{ }^{\circ} \mathrm{C}$ test.

- Alternate Heat Treatments. This task required assessing the impact of alternate heat treatments on HTIR-TC performance.

- Loose Assembly Construction This task required developing appropriate parameters for this process, such as acceptable wire, insulator, and sheath size combinations, and comparing the performance of loose assembly and swaged HTIR-TCs.

HTIR-TC fabrication requires that grain growth in the thermoelement wires be stabilized by heat treating. However, limited data were available to select appropriate temperatures and durations for this heat treatment. Table 9-2 lists the heat treatment times, temperatures, and durations for HTIR-TCs operating at 1200 and $1500{ }^{\circ} \mathrm{C}$ investigated in this project. For the thermocouples heat treated at $100{ }^{\circ} \mathrm{C}$ above their operating temperature $\left(1300{ }^{\circ} \mathrm{C}\right.$, and $\left.1600{ }^{\circ} \mathrm{C}\right)$, calibration cycles were completed on the thermocouples, followed by a 100 hour test at constant temperature to evaluate what drift occured. 
Table 9-2. Heat treatment options explored for $1200{ }^{\circ} \mathrm{C}$ and $1500{ }^{\circ} \mathrm{C}$ operation

\begin{tabular}{|c|c|c|c|c|}
\hline \multirow{2}{*}{$\begin{array}{c}\text { Operating } \\
\text { Temperature, } \\
{ }^{\circ} \mathrm{C}\end{array}$} & \multicolumn{2}{|c|}{ Heat Treatment } & \multirow{2}{*}{ Designator } & \multirow{2}{*}{ Evaluations } \\
\hline & Temperature, ${ }^{\circ} \mathrm{C}$ & Duration, Hours & & \\
\hline \multirow[t]{6}{*}{1200} & \multirow[t]{4}{*}{1300} & 0 & $12-1300-0$ & \multirow{4}{*}{$\begin{array}{l}\text { Calibration to } 1200^{\circ} \mathrm{C} \text {, } \\
100 \text { hours at } 1200^{\circ} \mathrm{C} .\end{array}$} \\
\hline & & 5 & $12-1300-5$ & \\
\hline & & 10 & $12-1300-10$ & \\
\hline & & 20 & $12-1300-20$ & \\
\hline & 1400 & 20 & $12-1400-20$ & Calibration to $1200^{\circ} \mathrm{C}$ \\
\hline & 1500 & 20 & $12-1500-20$ & Calibration to $1200^{\circ} \mathrm{C}$ \\
\hline \multirow[t]{5}{*}{1500} & \multirow[t]{4}{*}{1600} & 0 & $15-1600-0$ & \multirow{4}{*}{$\begin{array}{l}\text { Calibration to } 1500^{\circ} \mathrm{C} \text {, } \\
100 \text { hours at } 1500^{\circ} \mathrm{C} .\end{array}$} \\
\hline & & 4 & $15-1600-4$ & \\
\hline & & 8 & $15-1600-8$ & \\
\hline & & 16 & $15-1600-16$ & \\
\hline & 1700 & 4 & $15-1700-4$ & Calibration to $1500^{\circ} \mathrm{C}$ \\
\hline
\end{tabular}

Figure 9-6 compares results from calibration runs obtained for thermocouples heat treated at various temperatures (1300 to $1500{ }^{\circ} \mathrm{C}$ ) for 20 hours. Results indicate that the peak emf is reduced as the heat treatment temperature increases, but that the decrease in emf is reduced at temperatures greater than $1400^{\circ} \mathrm{C}$.

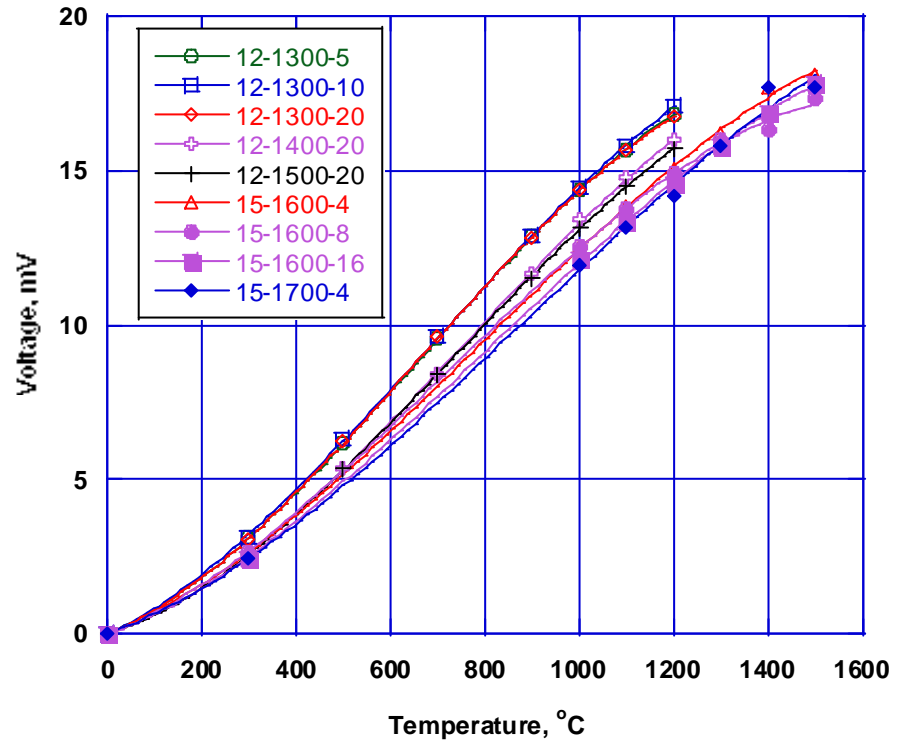

Figure 9-6. Calibration evaluations on HTIR-TCs heat treated at different temperatures and durations. 
Figure 9-7 compares the drift measured in thermocouples heat treated at $1300{ }^{\circ} \mathrm{C}$ for various durations. Results indicate that the thermocouple without any heat treatment drifted more than the other thermocouples. However, the observed drift was minimal in all of the heat treated thermocouples. Hence, investigations suggest that heat treatment times of 5 hours at $1300{ }^{\circ} \mathrm{C}$ will stabilize thermocouples for operating temperatures of $1200^{\circ} \mathrm{C}$.

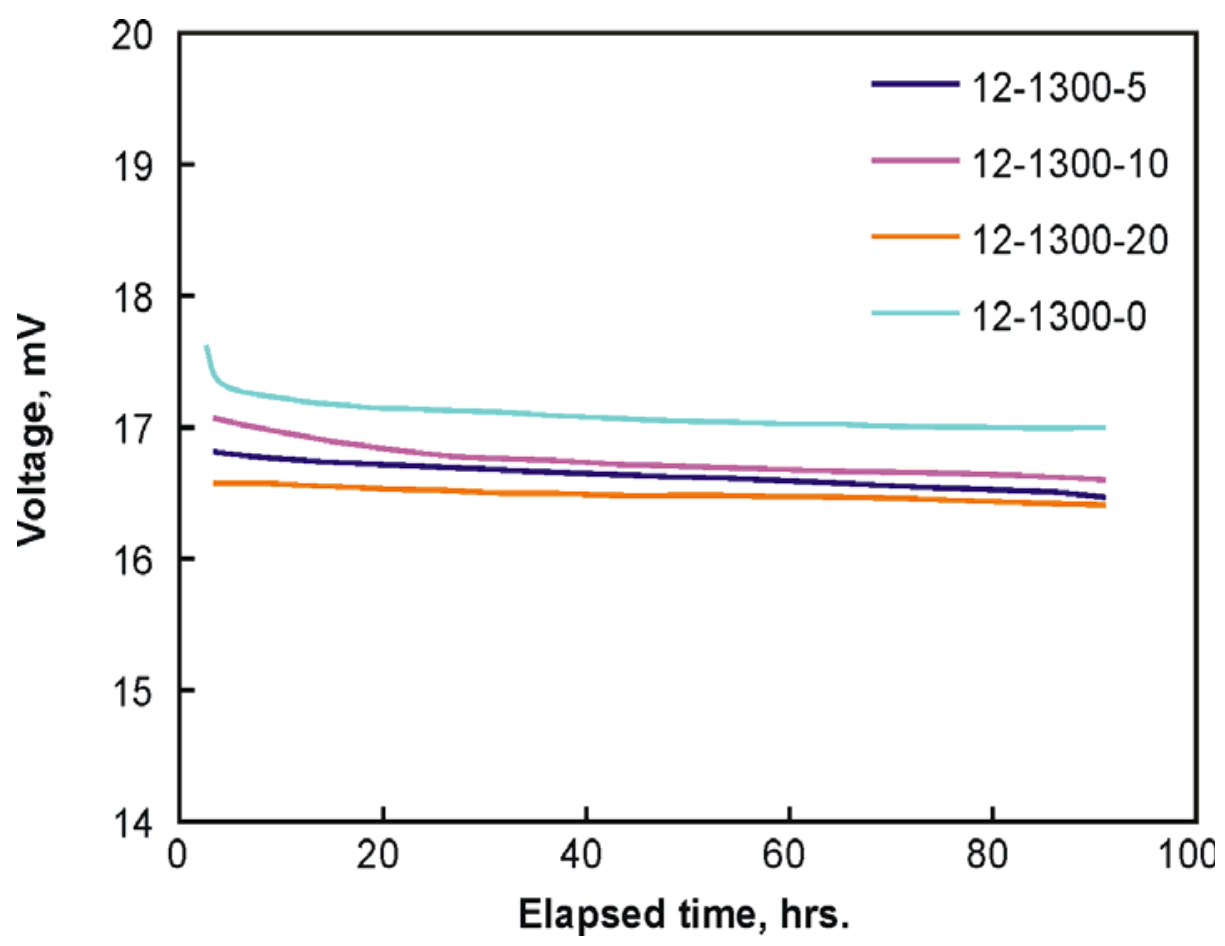

Figure 9-7. Measured drift of thermocouples heat treated at $1300^{\circ} \mathrm{C}$ at 0 (12-1300-0), 5 (12-1300-5), 10 (12-1300-10), and 20 (12-1300-20) hours in $1200^{\circ} \mathrm{C}$ constant temperature test.

Figure 9-8 compares measured drift for HTIR-TCs heat treated for operation at $1500{ }^{\circ} \mathrm{C}$. Results from this test were inconclusive. Although the longer heat treatment durations and higher heat treatment temperatures decreased emf, all of these HTIR-TCs exhibited unacceptable drift. Post-test macroscopic evaluations (see Figure 9-9) revealed a porous region of the outer diameter in the $\mathrm{Nb}-1 \% \mathrm{Zr}$ wires that were heat treated for longer durations (greater than 4 hours) at $1600{ }^{\circ} \mathrm{C}$ and at $1700^{\circ} \mathrm{C}$. However, additional evaluations are needed before it can be concluded that this change in the $\mathrm{Nb}-1 \% \mathrm{Zr}$ wire affected thermocouple stability. 


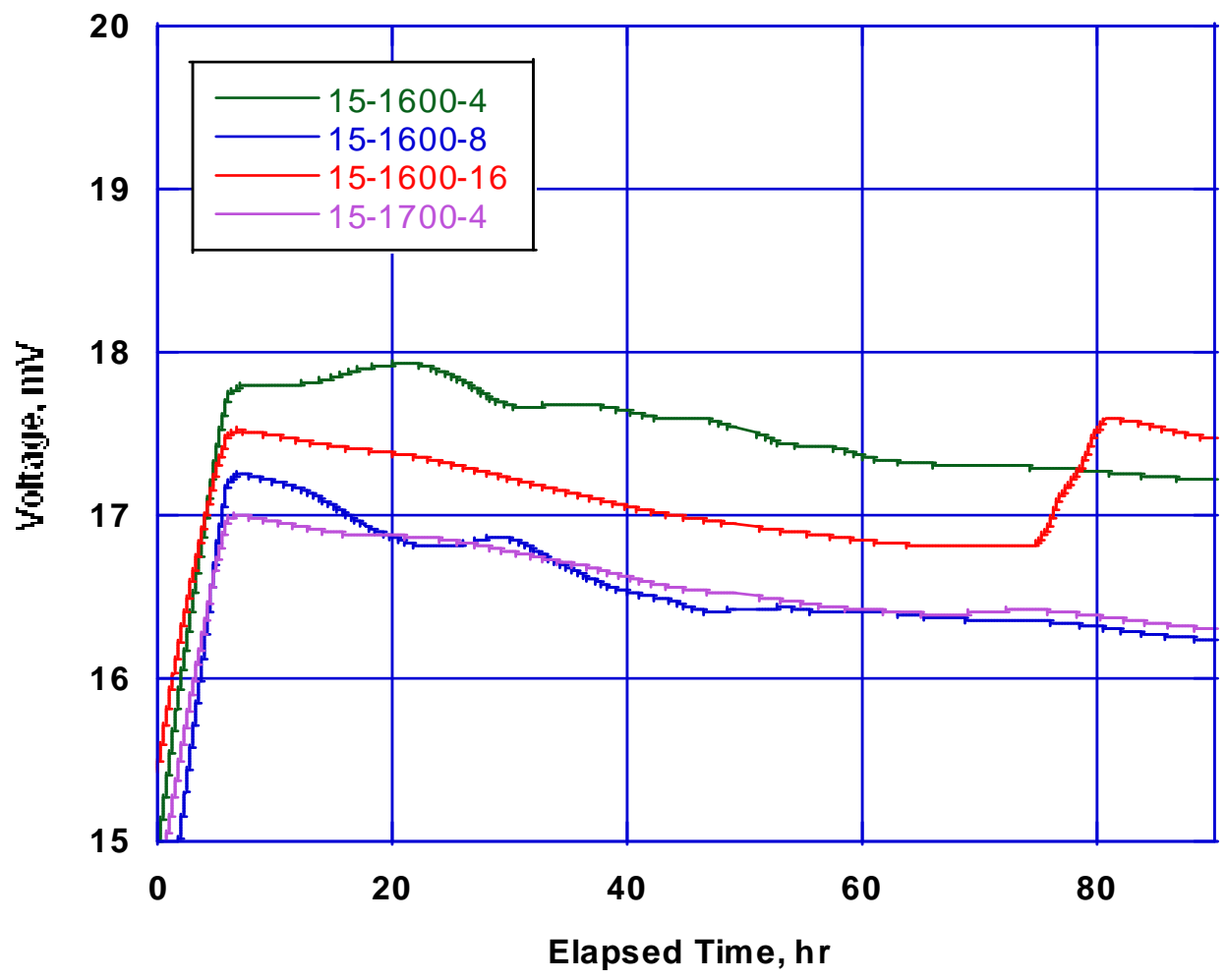

Figure 9-8. Drift exhibited in swaged thermocouples heat treated for service at $1500{ }^{\circ} \mathrm{C}$.

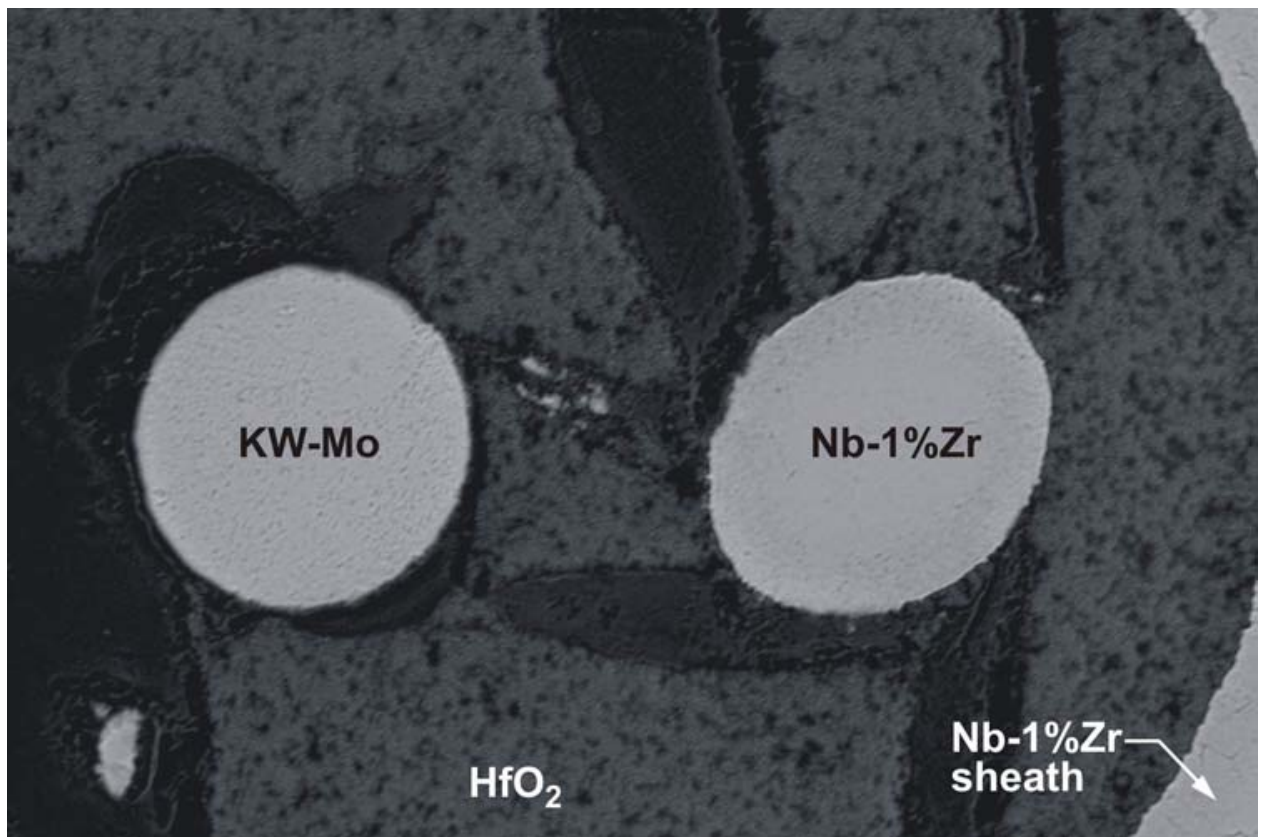

Figure 9-9. Cross-section of thermocouple 15-1600-16 (100X)

This project also explored the viability of a "loose assembly" HTIR-TC design. Loose assembly fabrication required that unique HTIR-TC thermocouple components and fixturing designs be developed. For example, Figure 9-10 shows the specialized splice sleeves and 
transition insulator components that were developed as part of this project. Fabrication process and parameters were developed using a "trial and error" approach. For example, a high temperature "off-gas" step was included to prevent degradation of thermocouple wires due to oxygen release from hard-fired insulators. The performance of prototype HTIR-TCs is currently being evaluated in a long duration test at $1500{ }^{\circ} \mathrm{C}$. Initial results, as shown in Figure 9-11, indicate that the loose assembly and swaged HTIR-TCs have similar stability. It is planned to continue this long duration test and perform post-test examinations on test thermocouples using an alternate source of INL funding.

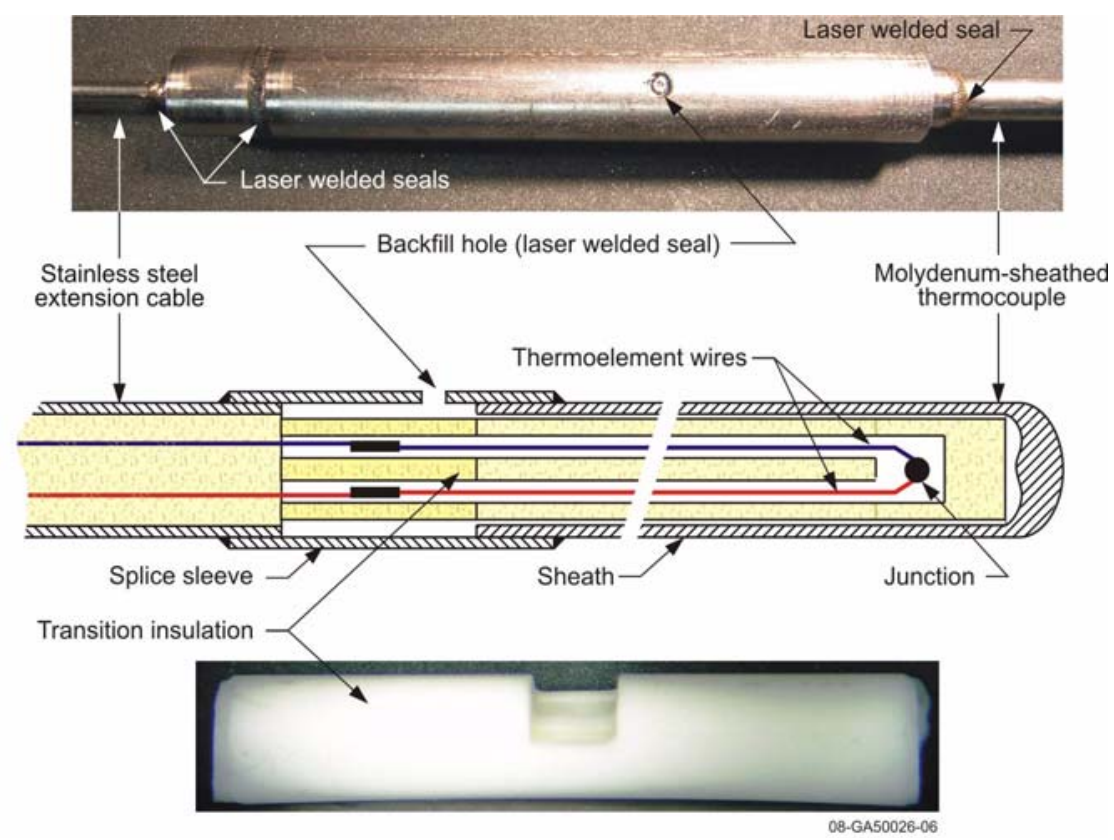

Figure 9-10. Specialized components for HTIR-TC loose assembly design.

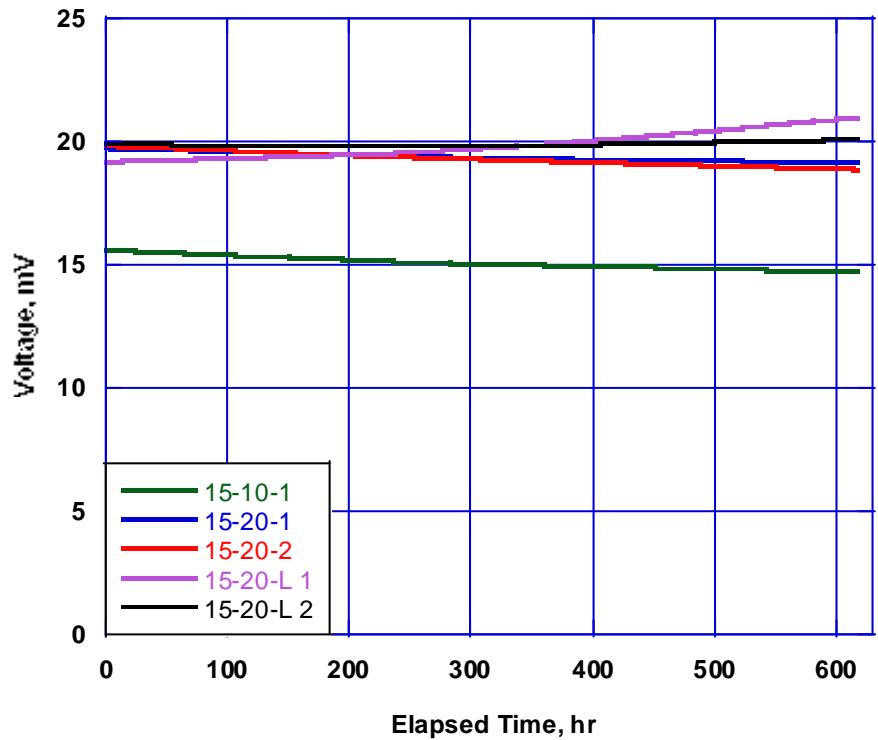

Figure 9-11. Initial results from $1500{ }^{\circ} \mathrm{C}$ long duration test containing loose assembly HTIR-TCs. 
Based on results from these evaluations, several recommendations for HTIR-TC have been developed.

- Doped molybdenum alloys, either ODS-Mo or KW-Mo, and the Nb-1\%Zr retain ductility better than the developmental molybdenum-low niobium alloys and the niobium-low molybdenum alloys evaluated.

- Although the resolution of the thermocouple containing ODS-Mo and $\mathrm{Nb}-1 \% \mathrm{Zr}$ is slightly superior, the lower cost of the commercially available KW-Mo makes a thermocouple containing KW-Mo and Nb-1\%Zr the best option at this time.

- HTIR-TCs containing larger diameter wires offer the potential to increase HTIR-TC stability and reliability at higher temperatures (e.g., greater than $1500^{\circ} \mathrm{C}$ ).

- HTIR-TC heat treatment temperatures and times should be limited to not more than $100{ }^{\circ} \mathrm{C}$ above the proposed operating temperatures and to durations of approximately 4 to 5 hours.

- Preliminary investigations suggest that the performance of swaged and loose assembly HTIR-TC designs is similar. However, the swaged designs are less expensive and easier to construct.

In addition to optimizing HTIR-TC performance, This project provided opportunities to several University of Idaho Students, allowing them to become familiar with the techniques and equipment used for specialized high temperature instrumentation fabrication and evaluation and to author/co-author several key conference papers and journal articles. Table 9-3 summarizes publications and presentations reporting results from this research project.

Table 9-3. Peer-reviewed publications summarizing research results

\begin{tabular}{|c|c|}
\hline & Publications \\
\hline & $\begin{array}{l}\text { J. Daw, J. Crepeau, J. Rempe, D. Knudson, K. Condie and C. Wilkins, “Initial Results from Investigations to } \\
\text { Enhance the Performance of High Temperature Irradiation-Resistant Thermocouples”, JSME Journal of Power } \\
\text { and Energy Systems, Vol. 2, No. } 2 \text { (2008), pp.854-863. }\end{array}$ \\
\hline & $\begin{array}{l}\text { J. E. Daw, J. C. Crepeau, J. L. Rempe, S. C. Wilkins, D. L. Knudson, and K. G. Condie, "Initial Results from } \\
\text { Investigations to Enhance the Performance of High Temperature Irradiation-Resistant Thermocouples," 15th } \\
\text { International Conference on Nuclear Engineering (ICONE15), Paper ICONE15-10842, Nagoya, Japan, April } \\
2007 .\end{array}$ \\
\hline & $\begin{array}{l}\text { J. L. Rempe, D. L. Knudson, K. G. Condie, S. C. Wilkins, J. C. Crepeau, and J. E. Daw, "Options Extending } \\
\text { the Applicability of High Temperature Irradiation Resistant Thermocouples," Invited paper for NURETH12 } \\
\text { Special Edition, Nuclear Technology, MS 08005, submitted January } 2008 .\end{array}$ \\
\hline & $\begin{array}{l}\text { J. L. Rempe, D. L. Knudson, K. G. Condie, S. C. Wilkins, J. C. Crepeau, and J. E. Daw, "Options to Increase } \\
\text { the Applicability of High Temperature Irradiation Resistant Thermocouples," Paper 218, Proceedings of the } \\
\text { 12th International Topical Meeting on Nuclear Reactor Thermal-Hydraulics (NURETH12), Pittsburgh, PA, } \\
\text { September 30-October 4, } 2007 .\end{array}$ \\
\hline & $\begin{array}{l}\text { D. L. Knudson, J. L. Rempe, K. G. Condie, S. C. Wilkins, J. E. Daw, and J. C. Crepeau, "High Temperature } \\
\text { Irradiation Resistant Thermocouples - A Low Cost Sensor for In-Pile Testing at High Temperatures," Paper } \\
\text { 8222, Proceeding of the } 2008 \text { International Congress on Advances in Nuclear Power Plants (ICAPP '08), } \\
\text { Anaheim, CA, June 8-12, } 2008 .\end{array}$ \\
\hline
\end{tabular}


In summary, this UNERI completed all of the research objectives within the proposed budget and schedule. In addition, it provided the opportunity for graduate students to complete nuclear engineering research in a state-of-the art facility. 
INL/EXT-08-14042 


\section{References}

1. J. L. Rempe, D. L. Knudson, K. G. Condie, and S. C. Wilkins, "Thermocouples for High-Temperature In-Pile Testing," Nuclear Technology, 156, No. 3, December 2006, pp 320-331.

2. J..L. Rempe, D. L. Knudson, K. G. Condie, and S. C. Wilkins, "Long Duration Performance of High Temperature Irradiation Resistant Thermocouples," Proceedings of the 2007 International Congress on Advances in Nuclear Power Plants (ICAPP'07), Nice, France, May 13-18, 2007.

3. J. L. Rempe, D. L. Knudson, K. G. Condie, and S. C. Wilkins, "Evaluation of Specialized Thermocouples for High-Temperature In-Pile Testing,” Proceedings of the 2006 International Congress on Advances in Nuclear Power Plants (ICAPP'06), Reno, NV, June 4-8, 2006.

4. $\quad$ J. L. Rempe and S. C. Wilkins, "High Temperature Thermocouples for In-Pile Applications," Paper 143, Proceedings of the 11th International Topical Meeting on Nuclear Reactor ThermalHydraulics (NURETH-11), Popes Palace Conference Center, Avignon, France, October 2-6, 2005.

5. R. R. Holmes, Development of High Temperature Sensors, July 1, 1959-April 30, 1961” Pratt \& Whitney Report PWAC-339, June 30, 1961.

6. P. Bliss and S. Fanciullo, "High Temperature Thermometry at Pratt \& Whitney Aircraft-CANEL," Pratt \& Whitney Report, PWAC-462, June 2, 1965.

7. D. E. Fornwalt, B. R. Gourley, and A. V. Manzione, “A Study of the Compatibility of Selected Refractory Metals with Various Ceramic Insulation Materials,” Pratt \& Whitney Aircraft Report CNLM-5942, November 30, 1964.

8. S. Fanciullo, Thermocouple Development Lithium-Cooled Reactor Experiment, Pratt \& Whitney Report PWAC-422, March 5, 1964.

9. S. C. Wilkins, "Characterization and Materials-Compatibility Tests of Molybdenum-Niobium Thermocouples," Seventh International Symposium on Temperature: Its Measurement and Control in Science and Industry, Toronto, Ontario, Canada, April 28-May 1, 1992.

10. R. C. Knight and D. L. Greenslade, "Irradiation Testing of a Niobium-Molybdenum Developmental Thermocouple,” Westinghouse Hanford Company Technical Report WHC-SA-1256-FP, October 1991 (also presented at the Ninth Symposium on Space Nuclear Power Systems, 13-16 January 1992, Albuquerque, NM).

11. S.C. Wilkins, et al., "Low Cross-Section Mo-Nb Thermocouples for Nuclear Applications: The State-of-the-Art,” Fifth Symposium on Space Nuclear Power Systems, pp 499-502, Albuquerque, New Mexico, January 11-14, 1988.

12. R. D. McCormick and S. C. Wilkins, "Thermocouples in a High-Temperature Oxidizing Environment," Seventh International Symposium on Temperature: Its Measurement and Control in Science and Industry, Toronto, Ontario, Canada, April 28-May 1, 1992. 
13. R. Schley and G. Metauer, "Thermocouples for Measurements under Conditions of High Temperature and Nuclear Radiation,” Temperature: Its Measurement and Control in Science and Industry, J. F. Schooley, Ed.-in-Chief (American Institute of Physics, New York, 1982, Vol. 5, Part 2, pp. 1109- 1113.

14. C. P. Cannon, " $2200^{\circ} \mathrm{C}$ Thermocouples for Nuclear Reactor Fuel Centerline Temperature Measurements,” Temperature: Its Measurement and Control in Science and Industry, J. F. Schooley, Ed.-in- Chief (American Institute of Physics, New York, 1982) Vol. 5, Part 2, pp 1061-1067.

15. Martinson, Z. R., et al., “Test NPR-1A Results Report,” EDF-NPR-MHTGR-0656, July 1993.

16. T. R. Billeter and C. P. Cannon, "Dual High Temperature Measurements using Johnson Noise Thermometry,” 1982 American Institute of Physics, p 1245-1248.

17. C. J. Borkowski and T. V. Blalock, “A New Method of Johnson Noise Thermometry,” Rev. Sci. Instrum., Vol. 45, No. 2, February 1974.

18. T. V. Blalock and R. L. Shepard, "A Decade of Progress in High-Temperature Johnson Noise Thermometry," Sixth Symposium on Temperature, Washington, DC, March 1982 (Publication Date December 1982).

19. R. Kisner, C.L. Britton, U. Jagadish, J.B. Wilgen, M. Roberts, T.V. Blalock, D. Holcomb, M. Bobrek, M.N. Ericson, “Johnson Noise Thermometry for Harsh Environments,” Proceedings of the 2004 IEEE Aerospace Conference, March 6-14, 2004, Big Sky, MT.

20. David E. Holcomb, Roger A. Kisner, Charles L. Britton, Jr., “Thermometry for Long-Term, Unattended Space Reactor Operation,” Proceedings of the 2005 Space Nuclear Conference, San Diego, CA, June 5-9, 2005 (paper 1170).

21. R. Kisner, C.L. Britton, U. Jagadish, J.B. Wilgen, M. Roberts, T.V. Blalock, D. Holcomb, M. Bobrek, M.N. Ericson, “Johnson Noise Thermometry for Harsh Environments,” Proceedings of the 2004 IEEE Aerospace Conference, March 6-14, 2004, Big Sky, MT.

22. F. D. Carpenter, et al., Temperature: Its Measurement and Control in Science and Industry, J. F. Schooley, Ed.-in-Chief (Instrument Society of America, Pittsburgh, PA1972), Vol. 4, Part 3, pp. 1927-1934.

23. S. C. Wilkins, “A Single-Crystal Tungsten Ultrasonic Thermometer," Seventh International Symposium on Temperature: Its Measurement and Control in Science and Industry, Toronto, Ontario, Canada, April 28-May 1, 1992.

24. S. C. Wilkins, "Ultrasonic Thermometer Development at the INEL," Specialists' Meeting on SP100 Space Nuclear Reactor Temperature Measurement, Albuquerque, New Mexico, January 1992.

25. J. K. Partin, "Fiber Optics in High Dose Radiation Fields,” Radiation Effects in Optical Materials, 541, 1985.

26. M. S. El-Genk and M. D. Hoover, Ed., Space Nuclear Power Systems, Chapter 33: "Radiation Effects Testing of Optical Fibers in a Nuclear Reactor," this needs help?. 
27. T. Shikama, "Development of Heat and Radiation Resistant Optical Fibers," Survey on Basic Studies in the Field of High Temperature Engineering, Paris, France, September 1999.

28. Verwimp, et al., "Irradiation and Post-irradiation Capabilities at SCK-CEN," Survey on Basic Studies in the Field of High Temperature Engineering, Paris, France, September 1999.

29. J.F. Villard, "Innovative In-Pile Instrumentation Developments for Irradiation Experiments in Material Testing Reactors,” Tenth International Group on Research Reactors (IGORR) Meeting, Gaithersburg, Maryland, September 13-16, 2005.

30. G. M. Ludtka, et al., "Performance of Chromel versus Alumel and Nicrosil versus Nisil Thermocouple Assemblies in Vacuum and Argon Between $1000^{\circ} \mathrm{C}$ and $1200{ }^{\circ} \mathrm{C}$," presented at the Industrial Temperature Measurement Conference, Hyatt Regency Hotel, September 10-12, 1984.

31. D. A. Prokoshkin and E. V. Vasil 'eva, Alloys of Niobium, S. Monson, Jerusalem, Israel, 1964.

32. T. E. Tietz and J. W. Wilson, Behavior and Properties of Refractory Metals, Stanford University Press, Stanford, CA, 1965.

33. L. E. Iorio, et al., "Dopant Particle Characterization and Bubble Evolution in Aluminum-Potassium-Silicon-Doped Molybdenum Wire,” Metallurgical and Materials Transactions A, Volume 33A, November 2002, pp3349-3356.

34. D.J. Jones and A. Leach, Powder Metallurgy, 22, No 3, 1979, p 125-132.

35. E. D. Zysk and A. R. Robertson, "Newer Thermocouple Materials," presented at Fifth Symposium on Temperature. Washington, D.C., June 1971, published in Temperature: Its Measurement and Control in Science and Industry, H. H. Plumb, Ed.-in-Chief (American Institute of Physics, New York, 1972, Vol. 4, Part 3, pp. 1697- 1734.

36. T.B Massalski, H. Okamoto, P. R. Subramanian, and L. Kacprzak, Binary Alloy Phase Diagrams, 2nd Edition, ASM International, 1996. 
INL/EXT-08-14042

$10-4$ 